\title{
Structural organozinc chemistry
}

\author{
JOHANN T. B. H. JASTRZEBSKI, JAAP BOERSMA \\ and GERARD VAN KOTEN
}

Debye Institute, Organic Chemistry and Catalysis, Utrecht University, Padualaan 8, $3584 \mathrm{CH}$ Utrecht, The Netherlands

Fax: +31 30252 3615; e-mail: g.vankoten@chem.uu.nl

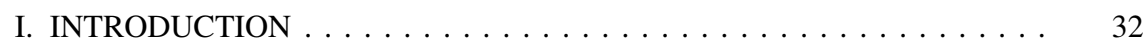

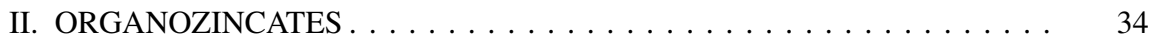

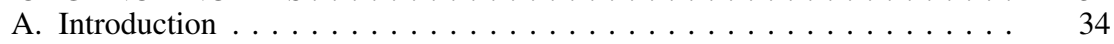

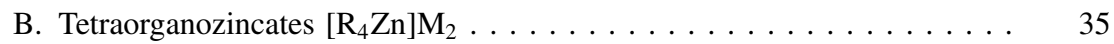

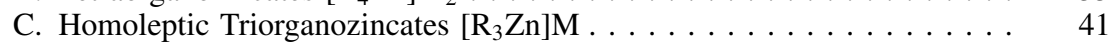

D. Heteroleptic Triorganozincates $\left[R_{2} R^{\prime} Z n\right] M \ldots \ldots \ldots \ldots \ldots \ldots \ldots \ldots \ldots$

III. DIALKYL- AND DIARYLZINC COMPOUNDS . . . . . . . . . . 53

A. Donor-base-free, $\sigma, \sigma$-Bonded Homoleptic $\mathrm{R}_{2} \mathrm{Zn}$ and Heteroleptic $\mathrm{RR}^{\prime} \mathrm{Zn}$

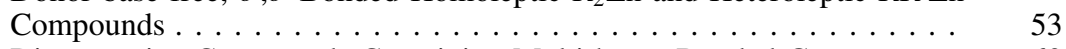

B. Diorganozinc Compounds Containing Multi-hapto Bonded Groups . . . . 60

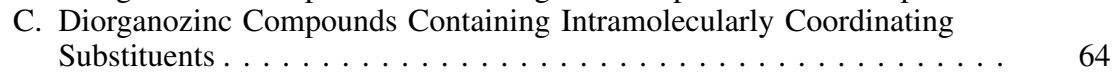

D. Donor-Acceptor Complexes of Diorganozinc Compounds . . . . . . . 70

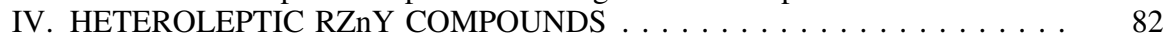

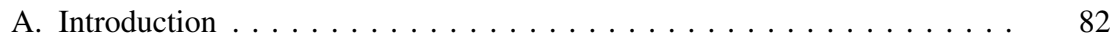

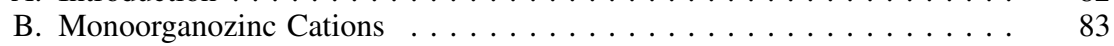

C. Monoorganozinc Compounds RZnY with $\mathrm{Y}=$ Halogen $\ldots \ldots \ldots \ldots . . \ldots 8$

D. Monoorganozinc Compounds RZnY with $Y=O R \ldots \ldots$. . . . . . . . 94

E. Monoorganozinc Compounds RZnY with $\mathrm{Y}=\mathrm{NR}_{2} \ldots \ldots \ldots \ldots$

F. Monoorganozinc Compounds RZnY with $\mathrm{Y}=$ Other Heteroatom Bonded

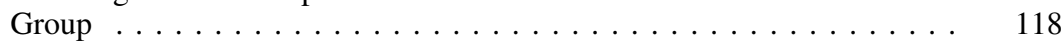

V. ORGANOZINC COMPOUNDS CONTAINING A ZINC-TRANSITION

METAL BOND . . . . . . . . . . . . . . . . . . . . . . . . 123

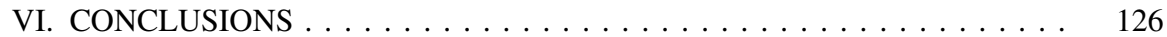

VII. REFERENCES . . . . . . . . . . . . . . . . . . . . . . . . . . 127

The chemistry of organozinc compounds

Edited by Z. Rappoport and I. Marek (c) 2006 John Wiley \& Sons, Ltd 


\section{INTRODUCTION}

Organozinc compounds are the first organometallic compounds ever made. Already in 1852, Edward Frankland prepared diethylzinc by heating ethyl iodide with zinc metal in a Carius tube ${ }^{1}$. Diethylzinc appeared to be a volatile colourless liquid that inflames spontaneously upon exposure to air. Until the invention of the Grignard reagents around 1900 organozinc compounds were used extensively as alkylating agents in organic synthesis.

Until fairly recently, little was known of the structures and properties of the organozinc compounds occurring as intermediates in various reactions. Interestingly, the complexforming ability of organozinc compounds had already been recognized very early. In 1858 , Wanklyn reported the formation of the ionic sodium triethylzinc complex ${ }^{2}$. One year later, Frankland observed that the formation of dimethylzinc from methyl iodide and zinc was accelerated by the addition of dimethyl ether or diethyl ether. It appeared that separation of the dimethylzinc from the ether was impossible, but it lasted until 1962 when it was established that dimethylzinc and dimethyl ether form a 1:1 complex in solution, which is appreciably dissociated in the vapour phase ${ }^{3}$.

Most of the structures of organozinc compounds have been determined by X-ray crystallography, but, in view of the fact that many of these compounds are liquids, also Gas-phase Electron Diffraction of some volatile organozinc compounds as well as solution studies have been used. The latter category involves molecular weight measurements, microwave titrations, dipole moment determinations and complexation reactions. ${ }^{57} \mathrm{Zn}$ NMR spectroscopy has not played an important role since only one naturally occurring isotope of zinc possesses a nuclear magnetic moment, i.e. ${ }^{67} \mathrm{Zn}$ with a natural abundance of $4.11 \%$ and a nuclear spin of $5 / 2$. Because of its low receptivity and its quadrupole moment, ${ }^{67} \mathrm{Zn}$ has received very little attention ${ }^{4}$ and in only a few cases have resonances of zinc ions in aqueous solutions been observed.

In the February 2005 version of the CSD database ${ }^{5}, 349$ structures containing one or more direct zinc-carbon interactions have been found (excluding structures containing the $\mathrm{Zn}-\mathrm{CN}$ structural motif). Together with the gas-phase data, this means that at that date a total of 354 molecular structures had been determined. Of these structures a large majority (225) deals with compounds in which 4-coordinate zinc is present.

With its electron configuration $3 \mathrm{~d}^{10} 4 \mathrm{~s}^{2}$, its normal valency is $2^{+}$and the symmetrical, full, low-lying $3 \mathrm{~d}$ shell of the $\mathrm{Zn}^{2+}$ ion does not cause ligand-field effects in coordination complexes. Its coordination behaviour is therefore relatively simple in that it basically forms trigonal planar or tetrahedral complexes with electron-donating ligands. Some examples of organozinc compounds containing formally $\mathrm{Zn}^{+}$(organozinc cations) and $\mathrm{Zn}^{-}$(organozincates) are known.

In a typical organozinc compound of the type $\mathrm{R}_{2} \mathrm{Zn}$, the zinc-carbon bonds occupy two equivalent sp-hybridized molecular orbitals, resulting in a linear coordination. The dipole moment of symmetric diorganozinc compounds in non-polar solvents is therefore zero, as indeed was observed for $\mathrm{Me}_{2} \mathrm{Zn}$ in cyclohexane solution ${ }^{6}$. In this situation, the valency shell of the zinc atom has only two pairs of bonding electrons, but four empty lowenergy orbitals available for bonding. As a consequence, two further coordinate bonds with ligands containing non-bonding electrons may form. Zinc is fairly electropositive with a Pauling electronegativity of 1.6 and diorganozinc compounds therefore contain covalent but rather polar zinc-carbon bonds. This bond polarity is responsible for the ease with which such compounds form coordination complexes. In the absence of electron donors, diorganozinc compounds containing saturated alkyl or aryl groups, with a few exceptions, occur as monomers. Apparently, the zinc in these compounds is unable to attain coordination saturation through the formation of aggregates via alkyl or aryl bridges by electron-deficient multi-centre bonds, which is the common structural motif in, 


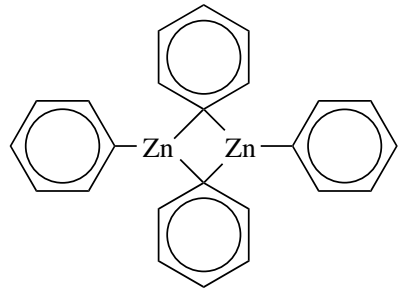

(1)

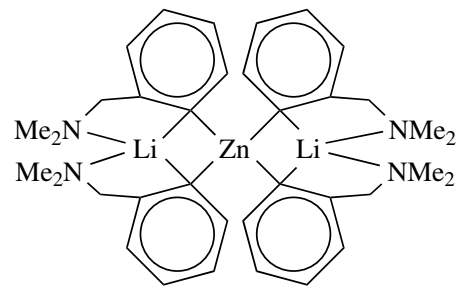

(2)

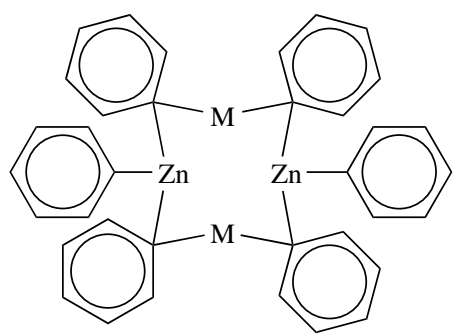

(3a) $\mathrm{M}=\mathrm{Cu}$

(3b) $\mathrm{M}=\mathrm{Au}$

FIGURE 1. Some examples of observed (1 and 2) and proposed (3) structures of organozinc compounds containing a bridging aryl group

e.g., structural organocopper ${ }^{7}$ and organolithium ${ }^{8}$ chemistry. The relatively small electron deficiency of zinc together with the relative large size of the zinc atom are thought to be responsible for this lack of additional coordination. In a few cases structures having bridging alkyl or aryl groups between two zinc atoms, e.g. $\mathbf{1}^{9}$, or zinc and a metal like lithium, e.g. $\mathbf{2}^{10}$, copper $\mathbf{3 a}$ or gold, e.g. $\mathbf{3} \mathbf{b}^{11}$, or aluminium have been observed, or have been proposed in a few cases (Figure 1). Moreover, the exchange of alkyl groups between various alkyl metal compounds and alkyl zinc compounds in solution has been attributed to the formation of transient species in which bridging alkyl groups are present ${ }^{12-14}$.

If one of the organic groups in a diorganozinc compound is replaced by an electronegative monoanionic grouping like a halogen atom or an alkoxy-, aryloxy- or organoamido group, but also by an alkynyl group, both the acceptor character of the zinc and the donor character of the zinc-bound electronegative group are enhanced. As a consequence, such compounds always form aggregates via multi-centre bonding of the electronegative substituent with various zinc centres.

The self-association and/or complex formation of organozinc compounds involves considerable rehybridization of the zinc valence orbitals. When only one coordinate bond is formed, the zinc atom becomes $\mathrm{sp}^{2}$-hybridized and the resulting complex is planar or nearly so with bond angles around the zinc of about $120^{\circ}$. The zinc centre then still has one unoccupied valence orbital and remains coordinatively unsaturated. Three-coordinate zinc, however, is relatively rare and only occurs when steric crowding around the zinc prevents the approach of a fourth ligand.

In general, both vacant valence orbitals of the zinc centre are used and consequently the bonding situation of zinc becomes close to $\mathrm{sp}^{3}$-hybridization reflected by a tetrahedral coordination geometry of the zinc centre. 
As the $3 \mathrm{~d}$ shell of zinc is completely filled it cannot function as a dative bond acceptor (Lewis acid). Also, the high ionization potential of the $3 \mathrm{~d}$ electrons makes it very unlikely that they can be used in dative $\pi$-bonding (Lewis base) with electron-accepting ligands. However, the latter possibility cannot be excluded completely in some complexes of diorganozinc compounds with planar $N$-heterocyclic ligands. Although coordination numbers five and six are well-known for both monoorganozinc and inorganic zinc compounds, in diorganozinc compounds this five- or six-coordination is seen only in a few special instances.

From a structural point of view, three classes of organozinc compounds can be distinguished according to the number of carbon atoms directly bound to zinc. These classes are: (i) ionic organozinc compounds in which the number of directly zinc-bound carbon atoms (three or four) exceeds the valence number of zinc, the so-called organozincates; (ii) the diorganozinc compounds and their coordination complexes, which can be divided into subclasses depending on various types of coordinating ligands; and (iii) heteroleptic $\mathrm{RZnX}$ compounds in which $\mathrm{X}$ is an electronegative substituent like a halogen atom or a monoanionic group bound to zinc via an electronegative atom like oxygen or nitrogen. Depending on the nature of $\mathrm{X}$, also the latter class of compounds may be further divided into subclasses. In the following sub-sections the structural aspects of these classes of compounds will be discussed.

\section{ORGANOZINCATES}

\section{A. Introduction}

Organometallic compounds that exhibit Lewis acidity on the metal centre are susceptible towards nucleophilic attack by alkali metal compounds, thus forming the socalled 'ate compounds' in which the Lewis acidic metal is often coordinatively saturated. Already in 1858 Wanklyn reported the formation of a crystalline compound formulated as $\left[\mathrm{Et}_{3} \mathrm{Zn}\right] \mathrm{Na}$ which he obtained from the reaction of diethylzinc with metallic sodium (equation 1$)^{2,15,16}$.

$$
3 \mathrm{Et}_{2} \mathrm{Zn}+2 \mathrm{Na} \longrightarrow \mathrm{Zn}+2\left[\mathrm{Et}_{3} \mathrm{Zn}\right] \mathrm{Na}
$$

Compounds of the types $\left[\mathrm{R}_{4} \mathrm{Zn}\right] \mathrm{M}_{2}$ and $\left[\mathrm{R}_{3} \mathrm{Zn}\right] \mathrm{M}$ can be prepared from the reaction of a strongly electropositive metal with the diorganozinc compound or directly from the reaction of the parent compounds $\mathrm{R}_{2} \mathrm{Zn}$ with $\mathrm{RM}^{10-22}$. In the first type of compounds the anionic zincate fragment has a formal negative charge of minus two and in the second type of compounds of minus one. In particular, conductivity measurements ${ }^{23,24}$ provided information on the products formed by dissolution of alkali metal alkyls in zinc alkyls.

In the early days the organozincates and organozinc compounds were regarded as academic curiosities whose structural characterization was particularly hampered by their extreme sensitivity towards oxygen and moisture. This phenomenon had already been recognized by Frankland and has plagued chemists ever since ${ }^{25}$.

When it was recognized that 'ate' compounds often have enhanced reactivity and selectivity profiles compared to their parent organometallic compounds ${ }^{26,27}$, systematic studies of synthetic applications and structural features of organozincates started. Nowadays, organozincates and other organozinc reagents are valuable synthetic tools in organic chemistry which have had comparable impact in organic synthesis as the corresponding organocopper and -cuprate reagents ${ }^{28}$. Recent developments in the synthetic and structural chemistry of zincates have been nicely reviewed ${ }^{29,30}$.

Some examples of the synthetic usefulness of zincate reagents in organic synthesis are: stereoselective alkylation reactions of cyclic ketones ${ }^{31}$, conjugate-addition reactions 
to $\alpha, \beta$-unsaturated carbonyl compounds ${ }^{32}$, ring-opening reactions of epoxides ${ }^{33}$ and the oxovanadium-induced ligand coupling of aryltrimethylzincates (equation 2 ) $^{34}$.

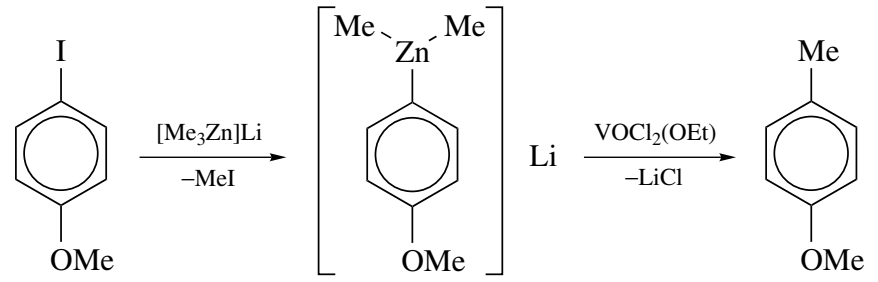

Computational studies have extensively contributed to the better understanding of the mechanistic aspects of reactions with organozincates ${ }^{35-37}$.

In early days structural investigations on organozincates were limited to physicochemical measurements. For example, the calcium, strontium and barium tetraethylzincates were studied by ${ }^{1} \mathrm{H}$ NMR and UV spectroscopy and by cryoscopic molecular-weight determinations ${ }^{38}$. These solution studies provided limited information, contrary to the more recently combined NMR and Raman spectroscopic and EXAFS studies on 'highly coordinated' heteroleptic organozincates $\left[\mathrm{Me}_{3} \mathrm{ZnR}\right] \mathrm{Li}_{2}(\mathrm{R}=\mathrm{CN}$ or $\mathrm{SCN})$. These suggested the presence of a $\mathrm{R}-\mathrm{Zn}$ bond and a $\mathrm{Zn}$-centred dianion ${ }^{35,39,40}$.

$\mathrm{X}$-ray structural investigations on organozincates provided very detailed information about the structure of these species in the solid state. It has now been well-established that two types of organozincates exist, i.e. 'highly coordinated' zincates containing a $\left[\mathrm{R}_{4} \mathrm{Zn}\right]^{2-}$ dianionic fragment in which the zinc atom is tetrahedrally coordinated, and zincates containing a $\left[\mathrm{R}_{3} \mathrm{Zn}\right]^{-}$monoanionic fragment in which the zinc atom has a trigonal coordination geometry. Depending on the particular zincate involved and or the presence of additional solvent donor molecules, the zincates may exist as real anionic and cationic fragments in the crystal lattice. Most probably they exist in (polar) solvents either as solvent separated ion pairs, or as contact ion pairs in which the anionic and cationic fragments are integral parts of a neutral aggregate.

\section{B. Tetraorganozincates $\left[\mathrm{R}_{4} \mathrm{Zn}\right] \mathrm{M}_{\mathbf{2}}$}

The zincates $\left[\mathrm{Me}_{4} \mathrm{Zn}\right] \mathrm{Li}_{2}(\mathbf{4})$ and $\left[(\mathrm{HC} \equiv \mathrm{C})_{4} \mathrm{Zn}\right] \mathrm{K}_{2}(\mathbf{5})$ are the first examples of which the structures in the solid state were unambiguously established by X-ray crystallographic techniques. Compound 4 was prepared by mixing $\mathrm{Me}_{2} \mathrm{Zn}$ and $\mathrm{MeLi}$ in a one-to-two molar ratio in diethyl ether. After removal of the solvent 4 was obtained as a white pyrophoric microcrystalline powder. Its structure was determined from the X-ray powder data $^{41}$. At first sight the structure seems to consist of $\left[\mathrm{Me}_{4} \mathrm{Zn}\right]^{2-}$ dianionic units located at the special position $0,0,0$ and two lithium cations at $0,0,0.5$ and $0,0.5,0.25$ in space group $\mathrm{I} \overline{4}$ (Figure 2). The four methyl groups of the $\mathrm{Me}_{4} \mathrm{Zn}$ unit are arranged in an almost perfect tetrahedral arrangement $\left[\mathrm{C}-\mathrm{Zn}-\mathrm{C}\right.$ bond angles $105(2)$ and $\left.111(2)^{\circ}\right]$. The observed $\mathrm{Zn}-\mathrm{C}$ bond distance of $2.07(15) \AA$ is slightly elongated, compared to that in linear $\mathrm{Me}_{2} \mathrm{Zn}\left(1.930(2) \AA\right.$ in the gas phase (from gas-phase electron diffraction studies) ${ }^{42}$. Each of the methyl groups also has interactions with the two lithium atoms, $\mathrm{C}-\mathrm{Li}$ (1) 2.52 and $\mathrm{C}-\mathrm{Li}(2)$ 2.84(4) $\AA$, rendering each lithium atom pseudo-tetrahedrally surrounded by four carbon atoms. Such secondary interactions are not uncommon for lithium, and have also been observed in the solid state structures of unsolvated $\mathrm{Me}_{4} \mathrm{Li}_{4}{ }^{43}$ and $\mathrm{Et}_{4} \mathrm{Li}_{4}{ }^{44}$.

$\left[(\mathrm{HC} \equiv \mathrm{C})_{4} \mathrm{Zn}\right] \mathrm{K}_{2}(5)$ was prepared from potassium acetylide and $\mathrm{Zn}\left(\mathrm{NH}_{3}\right)_{2}(\mathrm{SCN})_{2}$ in liquid ammonia. Its structure in the solid state was obtained from X-ray powder data ${ }^{45}$. 


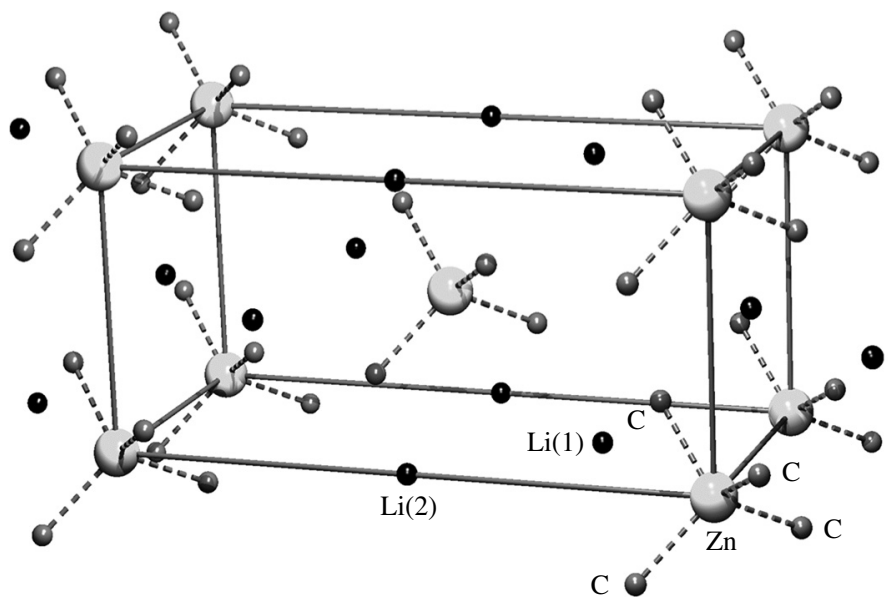

FIGURE 2. Unit cell contents of $\mathbf{4}$ in the space group I $\overline{4}$

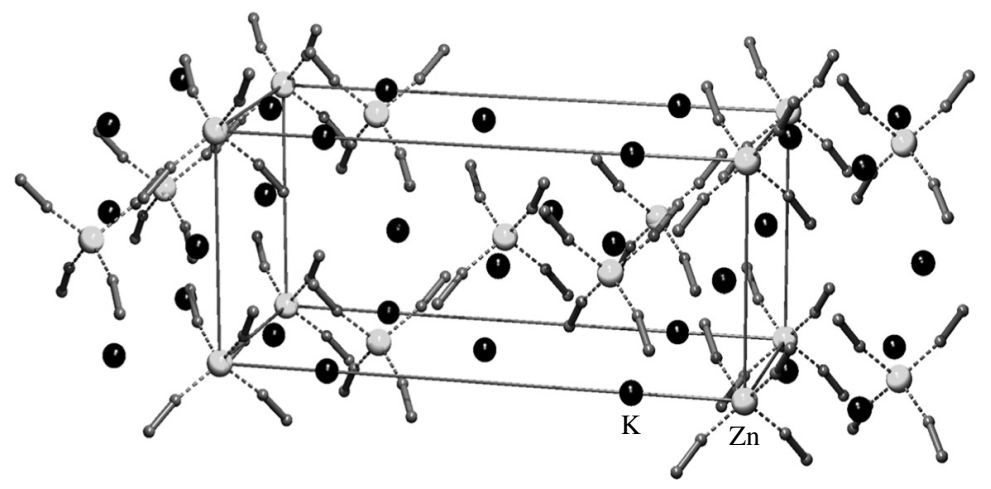

FIGURE 3. Unit cell contents of 5 in the space group $\mathrm{I}_{1} / a$

The zinc atoms are located at the special position $0,0,0$ and the potassium atoms at 0,0 , $z$ in the tetragonal space group I $4_{1} / a$ (Figure 3 ). The four acetylide groups are arranged in a tetrahedral fashion around the zinc atom, with a $\mathrm{Zn}-\mathrm{C}$ bonding distance of 2.0(1) $\AA$ and bond angles of $\mathrm{C}-\mathrm{Zn}-\mathrm{C}$ of $105(5)$ and $112(5)^{\circ}$. The $\mathrm{Zn}-\mathrm{C}(1)-\mathrm{C}(2)$ bond angle of $175(5)^{\circ}$ is close to the ideal value of $180^{\circ}$. The $\mathrm{C}(1)-\mathrm{C}(2)$ bond length of 1.4 (2) $\AA$ of the acetylenic moiety is elongated compared to the $\mathrm{C}-\mathrm{C}$ bond length in normal organic acetylene compounds. This elongation has been explained by back donation from zinc to the acetylene substituent via a $d_{\pi}-p_{\pi}$ interaction. The relatively close proximity of the potassium cations to three neighbouring acetylenic moieties ( 3.1 to $3.5 \AA$ ) points to an electrostatic interaction of these cations with the $\pi$-system of the acetylene.

Single crystals of the bis-ammonia adduct of $\mathbf{5},\left[(\mathrm{HC} \equiv \mathrm{C})_{4} \mathrm{Zn}\right] \mathrm{K}_{2}\left(\mathrm{NH}_{3}\right)_{2}$ (6), were obtained by crystallization from liquid ammonia at $195 \mathrm{~K}$ and special equipment was used to isolate the crystals at low temperature. ${ }^{46}$ The solid state structure of $\mathbf{6}$ was determined by single-crystal X-ray crystallography (Figure 4$)^{47}$. Its solid state structure, a 


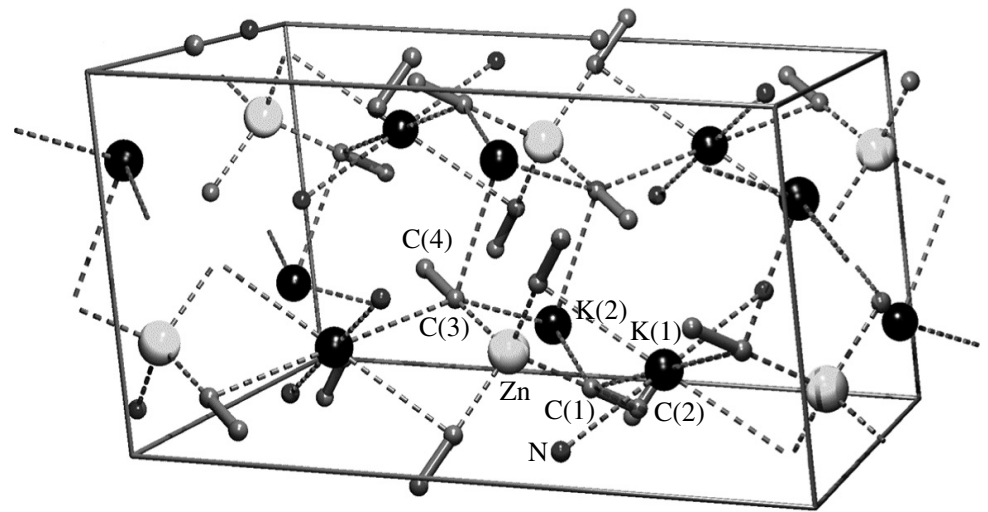

FIGURE 4. Unit cell contents of $\mathbf{6}$; atoms outside the cell are omitted for clarity

coordination polymer, shows similarities with that of $\mathbf{5}$. Also in this case, the zinc atom is tetrahedrally coordinated by four $\sigma$-bonded acetylene groups. The $\mathrm{C}-\mathrm{Zn}-\mathrm{C}$ bond angles are in the range of $105.8(1)$ to $116.9(2)^{\circ}$, indicating that the tetrahedral coordination geometry at zinc is more distorted than that observed in $\mathbf{5}$, which is explained by the presence of ammonia molecules in the second coordination sphere of zinc. $K(1)$ is octahedrally coordinated by four $\mathrm{HC} \equiv \mathrm{C}$ units in a side-on bonding mode [bonding distances range from 2.997(3) to 3.276(3) $\AA$ ], and two ammonia molecules in trans-position with bond distances $\mathrm{K}(1)-\mathrm{N}$ of $2.952(4) \AA . \mathrm{K}(2)$ is octahedrally coordinated by six $\mathrm{HC} \equiv \mathrm{C}$ units in a side-on bonding mode with similar bonding distances as observed for $\mathrm{K}(1)$.

The tetraorganozincate $\left[(\mathrm{PhC} \equiv \mathrm{C})_{4} \mathrm{Zn}\right] \mathrm{Li}_{2}(\mathrm{TMEDA})_{2}$ (7) was prepared according to equation 3.

$$
\left\{\left[\left(\mathrm{Me}_{3} \mathrm{Si}\right)_{2}\right]_{2} \mathrm{~N}\right\}_{2} \mathrm{Zn}+4 \mathrm{PhC} \equiv \mathrm{CLi} \underset{\mathrm{TMEDA}}{\stackrel{\text { toluene/THF }}{\longrightarrow}}\left[(\mathrm{PhC} \equiv \mathrm{C})_{4} \mathrm{Zn}\right] \mathrm{Li}_{2}(\mathrm{TMEDA})_{2}
$$

$$
+2\left[\left(\mathrm{Me}_{3} \mathrm{Si}\right)_{2}\right]_{2} \mathrm{NLi}
$$

The structure of $\mathbf{7}$ in the solid state was determined from a single-crystal X-ray crystallographic study ${ }^{48}$. The overall structural geometry comprises a pseudo-tetrahedral $\left[(\mathrm{PhC} \equiv \mathrm{C})_{4} \mathrm{Zn}\right]^{2-}$ dianion with average $\mathrm{Zn}-\mathrm{C}$ bond distances of $2.05 \AA$ and two Li(TMEDA) cations each bonded via $\pi$-acetylide interactions to two acetylide groups (Figure 5). The pairwise symmetrical bonding of the acetylide groups with each of the Li(TMEDA) cations induces a considerable distortion from an ideal tetrahedral geometry at zinc. The $\mathrm{C}-\mathrm{Zn}-\mathrm{C}$ bond angles vary from $102.9(5)$ to $115.4(10)^{\circ}$. However, these interactions do not induce a major distortion in the linearity of the $\sigma$-bonding of the acetylenic groups to zinc (average $\mathrm{Zn}-\mathrm{C} \equiv \mathrm{C}$ bond angle $175^{\circ}$ ).

The synthesis and structural characterization of a series of spirocyclic organozincates containing two five- or six-membered metallacycles in which zinc is the central spiro atom, is shown in Scheme 1. Compound 8a was prepared via an elegant one-pot synthesis, starting from 1,5-dichloropentane, $\mathrm{ZnCl}_{2}$ and a lithium/sodium alloy (1\% sodium) in diethyl ether as a solvent (equation 4 in Scheme 1). ${ }^{49}$ Subsequent treatment of a solution of 8a with TMEDA afforded the corresponding TMEDA complex $\mathbf{8 b}$ of which the structure in the solid state was unambiguously established by an X-ray crystal structure determination. 


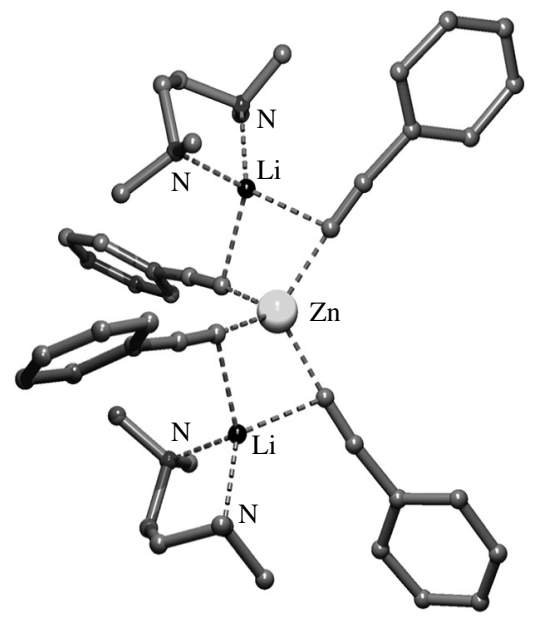

FIGURE 5. Molecular geometry of $\mathbf{7}$ in the solid state

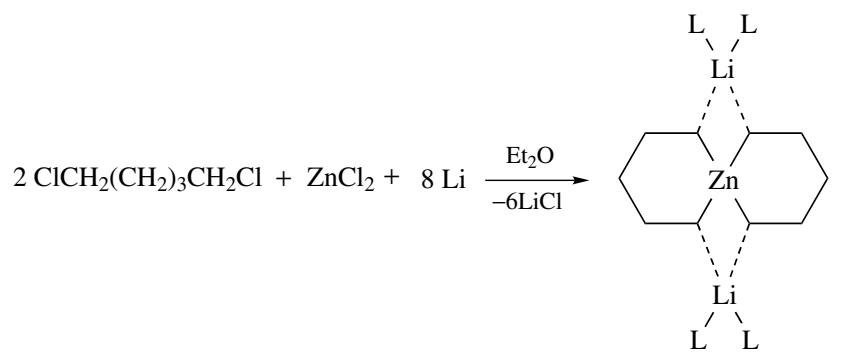

(8a) $\mathrm{L}=\mathrm{Et}_{2} \mathrm{O}$

(8b) $\mathrm{L}_{2}=$ TMEDA

$2 \mathrm{LiCH}\left(\mathrm{R}^{1}\right) \mathrm{CH}\left(\mathrm{R}^{2}\right) \mathrm{CH}\left(\mathrm{R}^{3}\right) \mathrm{CH}\left(\mathrm{R}^{4}\right) \mathrm{Li}+\mathrm{ZnCl}_{2} \underset{-2 \mathrm{LiCl}}{\stackrel{\mathrm{Et}_{2} \mathrm{O}}{\longrightarrow}}$

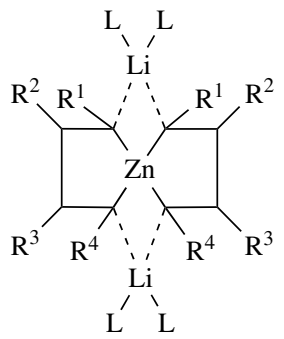
(9a) $\mathrm{R}^{1}=\mathrm{R}^{2}=\mathrm{R}^{3}=\mathrm{R}^{4}=\mathrm{H} ; \mathrm{L}=\mathrm{Et}_{2} \mathrm{O}$
(9b) $\mathrm{R}^{1}=\mathrm{R}^{2}=\mathrm{R}^{3}=\mathrm{R}^{4}=\mathrm{H} ; \mathrm{L}_{2}=$ TMEDA
(9c) $\mathrm{R}^{1}=\mathrm{Me} ; \mathrm{R}^{2}=\mathrm{R}^{3}=\mathrm{R}^{4}=\mathrm{H} ; \mathrm{L}_{2}=$ TMEDA
(9d) $\mathrm{R}^{1}=\mathrm{R}^{4}=\mathrm{Me} ; \mathrm{R}^{2}=\mathrm{R}^{3}=\mathrm{H} ; \mathrm{L}_{2}=$ TMEDA
(9e) $\mathrm{R}^{2}=\mathrm{Me} ; \mathrm{R}^{1}=\mathrm{R}^{3}=\mathrm{R}^{4}=\mathrm{H} ; \mathrm{L}_{2}=$ TMEDA
(9f) $\mathrm{R}^{2}=\mathrm{R}^{3}=\mathrm{Me} ; \mathrm{R}^{1}=\mathrm{R}^{4}=\mathrm{H} ; \mathrm{L}_{2}=$ TMEDA 
$2 \mathrm{ClCH}_{2} \mathrm{SiMe}_{2} \mathrm{SiMe}_{2} \mathrm{CH}_{2} \mathrm{Cl}+\mathrm{ZnCl}_{2}+8 \mathrm{Li} \stackrel{\mathrm{Et} \mathrm{T}_{2}-6 \mathrm{LiCl}}{\mathrm{TMEDA}}$

(10)

\section{SCHEME 1. (continued)}

These spirocyclic zincates, each containing two five-membered metallacycles having methyl substituents at the various positions of the five-membered ring, were prepared from the corresponding 1,4-dilithio compounds and $\mathrm{ZnCl}_{2}$ in diethyl ether. Some examples are shown in equation 5 in Scheme $1^{50}$. Similar compounds with other donor molecules at lithium, like DME, $\operatorname{Pr}_{2} \mathrm{O}$ and dioxane, were reported in the same paper. The structural features of the zincates in solution were studied by ${ }^{1} \mathrm{H},{ }^{13} \mathrm{C}$ and DEPT NMR spectroscopic techniques. It was concluded that they most likely exist in apolar solvents like benzene as discrete aggregated species having a $\mathrm{ZnLi}_{2}$-core stoichiometry, but that they occur in polar solvents like THF as solvent separated ion pairs. Furthermore, it was shown that the compounds having chiral centres in the five-membered ring, i.e. 9c-f, exist in solution as complicated mixtures of stereoisomers. The spirocyclic zincate (10) was prepared via a similar one-pot reaction as 8a in the presence of TMEDA (equation 6 in Scheme 1$)^{51}$.

The structures in the solid state of zincates $\mathbf{8 b}, \mathbf{9 b}$ and $\mathbf{1 0}$ which have many similarities were unambiguously established by X-ray crystallography (Figure 6). Relevant structural features, bond distances and angles are given in Table 1.

The spirocyclic structures of $\mathbf{8 b}, \mathbf{9 b}$ and $\mathbf{1 0}$ consist of two zincacyclopentane $(\mathbf{8 b}$ and 10) or two zincacyclohexane (9b) rings, having the zinc atom in common. Each of the lithium atoms is bonded to the $\alpha$-carbon atoms of the two metallacycles, while a tetrahedral coordination geometry at lithium is reached by bidentate $\mathrm{N}-\mathrm{Li}$ coordination

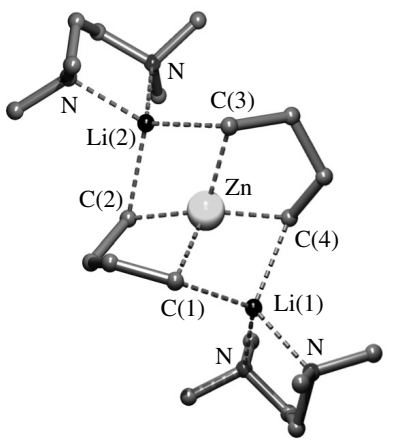

(8b)

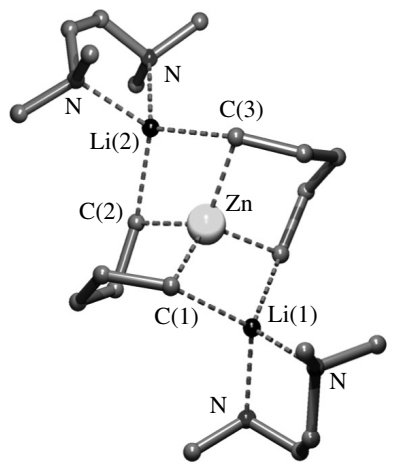

(9b)

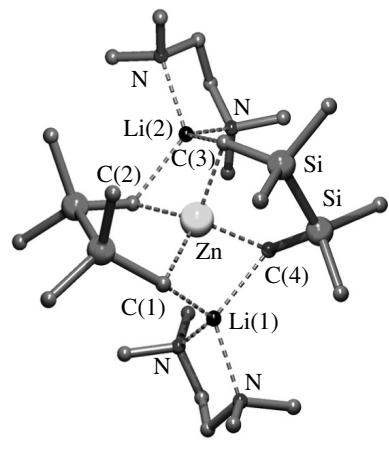

(10)

FIGURE 6. Molecular geometries of $\mathbf{8 b}, \mathbf{9 b}$ and $\mathbf{1 0}$ in the solid state 
TABLE 1. Relevant bond distances and angles in $\mathbf{8 b}, \mathbf{9 b}$ and $\mathbf{1 0}$

\begin{tabular}{lccc}
\hline Bond distances $(\AA)$ & $\mathbf{8 b}$ & $\mathbf{9 b}$ & $\mathbf{1 0}$ \\
\hline $\mathrm{Zn}-\mathrm{C}(1)$ & $2.133(4)$ & $2.115(4)$ & $2.139(2)$ \\
$\mathrm{Zn}-\mathrm{C}(2)$ & $2.122(5)$ & $2.109(4)$ & $2.205(2)$ \\
$\mathrm{Zn}-\mathrm{C}(3)$ & $2.127(5)$ & $2.119(4)$ & $2.139(2)$ \\
$\mathrm{Zn}-\mathrm{C}(4)$ & $2.127(4)$ & $2.129(4)$ & $2.205(2)$ \\
$\mathrm{C}(1)-\mathrm{Li}(1)$ & $2.282(7)$ & $2.312(8)$ & $2.347(5)$ \\
$\mathrm{C}(2)-\mathrm{Li}(2)$ & $2.257(8)$ & $2.279(8)$ & $2.255(4)$ \\
$\mathrm{C}(3)-\mathrm{Li}(2)$ & $2.299(8)$ & $2.302(8)$ & $2.347(5)$ \\
$\mathrm{C}(4)-\mathrm{Li}(1)$ & $2.232(9)$ & $2.316(8)$ & $2.225(4)$ \\
$\mathrm{N}-\mathrm{Li}(\mathrm{average})$ & $2.130(8)$ & $2.124(8)$ & $2.170(5)$ \\
\hline $\mathrm{Bond}$ angles $\left(^{\circ}\right)$ & & & \\
\hline $\mathrm{C}(1)-\mathrm{Zn}-\mathrm{C}(2)$ & $101.1(2)$ & $90.5(2)$ & $98.90(9)$ \\
$\mathrm{C}(1)-\mathrm{Zn}-\mathrm{C}(3)$ & $106.4(2)$ & $122.8(2)$ & $123.96(13)$ \\
$\mathrm{C}(1)-\mathrm{Zn}-\mathrm{C}(4)$ & $119.2(2)$ & $119.5(2)$ & $108.18(9)$ \\
$\mathrm{C}(2)-\mathrm{Zn}-\mathrm{C}(3)$ & $118.6(2)$ & $119.1(2)$ & $108.18(9)$ \\
$\mathrm{C}(2)-\mathrm{Zn}-\mathrm{C}(4)$ & $110.1(2)$ & $117.9(2)$ & $120.43(12)$ \\
$\mathrm{C}(3)-\mathrm{Zn}-\mathrm{C}(4)$ & $102.4(2)$ & $90.0(2)$ & $98.90(9)$ \\
\hline
\end{tabular}

of the TMEDA molecule. The bridge bonding of the $\alpha$-carbon atoms to zinc and lithium represents an example of electron-deficient two-electron three-centre type of bonding. These bridged bonds between lithium and zinc are slightly asymmetric, as is indicated by the different bonding distances between zinc and carbon, and lithium and carbon, respectively (Table 1). As expected, the bond distances between zinc and the four $\alpha$ carbon atoms in these zincates are slightly elongated compared to the zinc-carbon bond distance in linear neutral dialkylzinc compounds. The observed $\alpha$-carbon-lithium bond distances (Table 1) are in the same range as those found in alkyllithium compounds ${ }^{43,44}$. The observed $\mathrm{C}-\mathrm{Zn}-\mathrm{C}$ bond angles deviate considerably from the ideal tetrahedral value (Table 1) as a result of the acute angles in the five-membered metallacycles. However, in $9 \mathrm{~b}$ the angle between the planes defined by $\mathrm{C}(1), \mathrm{C}(2)$ and $\mathrm{Zn}$ and $\mathrm{C}(3), \mathrm{C}(4)$ and $\mathrm{Zn}$ amounts to $89.2(1)^{\circ}$, a value close to the ideal value of $90^{\circ}$ for tetrahedra. In $\mathbf{8 b}$ this value is $81.8^{\circ}$, indicating a more distorted situation at zinc compared to that in $\mathbf{9 b}$.

The tetraorganozincate 11, obtained from the 2:1 reaction of $2-\{[($ dimethylamino $)$ methyl]phenyl $\}$ lithium $^{52}$ with bis $\{2-[($ dimethylamino)methyl $]$ phenyl $]\}$ zinc $^{53}$ (equation 7 ), represents the only example of a highly coordinated tetraorganozincate in which an aryl organic group is bound to zinc.

The structure of $\mathbf{1 1}$ in the solid state (Figure 7) was established by an X-ray crystal structure determination ${ }^{10}$. The four aryl groups are $\eta^{1}$-bonded to the central zinc atom with bonding distances ranging from 2.124(4) to $2.152(3) \AA$. The $\mathrm{C}_{i p s o}-\mathrm{Zn}-\mathrm{C}_{\text {ipso }}$ bond angles range from $106.51(15)$ to $111.26(15)^{\circ}$, indicating a slightly distorted tetrahedral coordination geometry at zinc. The aryl groups are pairwise bridge-bonded between zinc and lithium atoms in an asymmetric manner, as is indicated by the difference in bonding distance between $\mathrm{C}_{i p s o}$ and zinc and $\mathrm{C}_{i p s o}$ and lithium (C-Li $2.234 \AA$ mean value). The rather acute angles [mean value $120.4(3)^{\circ}$ ] between the $\mathrm{C}_{\text {para }}-\mathrm{C}_{i p s o}$ and the $\mathrm{C}_{i p s o}-\mathrm{Li}$ vectors compared to the angle of the corresponding vectors with the $\mathrm{C}_{i p s o}-\mathrm{Zn}$ bond [mean value $167.3(3)^{\circ}$ ] suggest that there is considerable $\pi$-interaction of $C_{i p s o}$ with lithium. Such an asymmetric bonding mode of an aryl group between lithium and other metals has been observed before in cuprates ${ }^{7,54}$ and aurates ${ }^{55}$. Finally, each lithium atom 


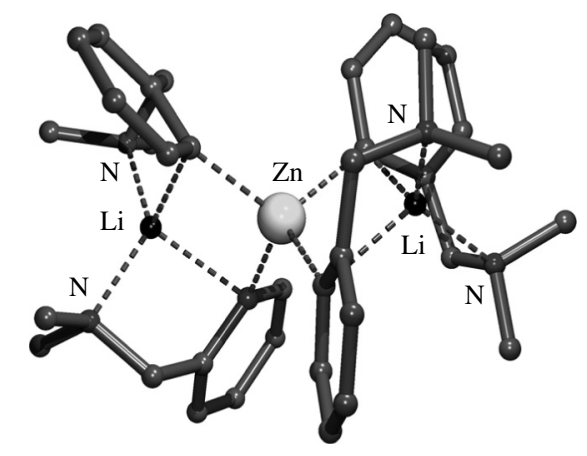

FIGURE 7. Molecular geometry of $\mathbf{1 1}$ in the solid state

is tetrahedrally coordinated by intramolecular $\mathrm{N}-\mathrm{Li}$ coordination with the two orthodimethylaminomethyl substituents.

$1 / 2\left[2-\mathrm{Me}_{2} \mathrm{NCH}_{2} \mathrm{C}_{6} \mathrm{H}_{4} \mathrm{Li}\right]_{4}+\left(2-\mathrm{Me}_{2} \mathrm{NCH}_{2} \mathrm{C}_{6} \mathrm{H}_{4}\right)_{2} \mathrm{Zn}$

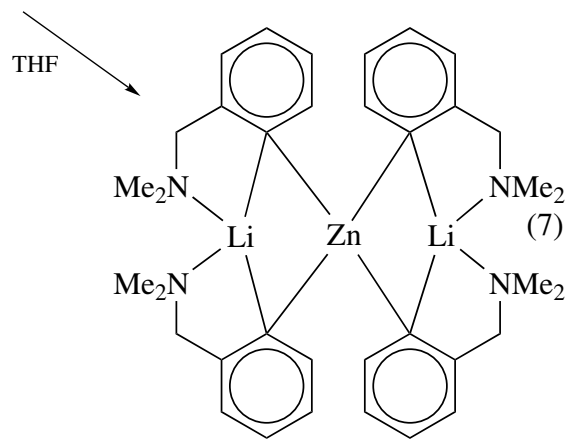

(11)

\section{Homoleptic Triorganozincates $\left[\mathbf{R}_{3} \mathrm{Zn}\right] \mathrm{M}$}

Reaction of $\left(\mathrm{Me}_{3} \mathrm{SiCH}_{2}\right)_{2} \mathrm{Zn}$ with an alkali $(\mathrm{K})$ or alkali earth metal $(\mathrm{Ba}, \mathrm{Sr}$ or $\mathrm{Ca})$ in a suitable solvent affords the corresponding triorganozincates 12-16 (Scheme 2).

The structures in the solid state of these compounds, $\mathbf{1 2}^{56}, \mathbf{1 3 - 1 5}^{57}$ and $\mathbf{1 6}^{58}$, have been established by X-ray crystal structure determinations. In all cases the anionic part, i.e. the $\left[\left(\mathrm{Me}_{3} \mathrm{SiCH}_{2}\right)_{3} \mathrm{Zn}\right]^{-}$anion, has comparable structural features (Table 2). The anionic part of $\mathbf{1 2}$ is shown as a representative example (Figure 8).

As expected, the observed $\mathrm{Zn}-\mathrm{C}$ bond distances (Table 1 ) are slightly elongated compared to the bond length found in linear dialkylzinc compounds [e.g. the $\mathrm{Zn}-\mathrm{C}$ bond distances in $\left(\mathrm{Me}_{3} \mathrm{Si}\right)_{2} \mathrm{CH}-\mathrm{Zn}-\mathrm{C}\left(\mathrm{SiMe}_{3}\right)_{3}$ are 1.946(4) and 1.971(3) $\AA$, respectively $]^{59}$. Although the various $\mathrm{C}-\mathrm{Zn}-\mathrm{C}$ bond angles differ from the ideal value of $120^{\circ}$ for a perfect trigonal geometry, the sum of these bond angles (Table 2) for all compounds is $360^{\circ}$ within experimental error, indicating a perfectly planar arrangement at the zinc 
Johann T. B. H. Jastrzebski, Jaap Boersma and Gerard van Koten

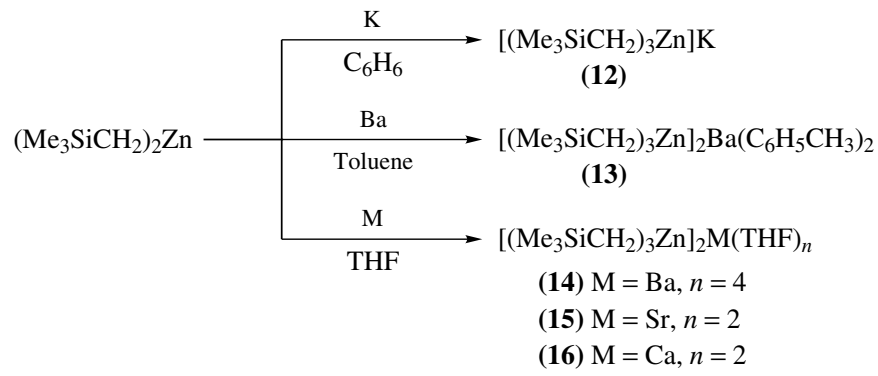

SCHEME 2

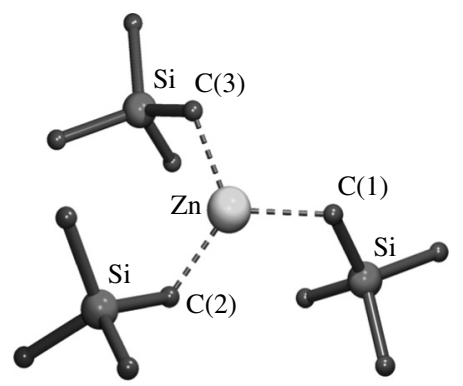

FIGURE 8. Molecular geometry of the $\left[\left(\mathrm{Me}_{3} \mathrm{SiCH}_{2}\right)_{3} \mathrm{Zn}\right]$ anion in $\mathbf{1 2}$

TABLE 2. Structural features of the $\left[\left(\mathrm{Me}_{3} \mathrm{SiCH}_{2}\right)_{3} \mathrm{Zn}\right]^{-}$anion in compounds 12-16

\begin{tabular}{lcrrrr}
\hline Bond distances $(\AA)$ & \multicolumn{1}{c}{$\mathbf{1 2}$} & \multicolumn{1}{c}{$\mathbf{1 3}$} & \multicolumn{1}{c}{$\mathbf{1 4}$} & \multicolumn{1}{c}{$\mathbf{1 5}$} & \multicolumn{1}{c}{$\mathbf{1 6}$} \\
\hline $\mathrm{Zn}-\mathrm{C}(1)$ & $2.043(3)$ & $2.080(5)$ & $2.125(2)$ & $2.076(7)$ & $1.996(2)$ \\
$\mathrm{Zn}-\mathrm{C}(2)$ & $2.026(3)$ & $2.012(5)$ & $2.013(8)$ & $2.019(6)$ & $2.081(2)$ \\
$\mathrm{Zn}-\mathrm{C}(3)$ & $2.086(4)$ & $2.072(4)$ & $2.066(7)$ & $2.095(7)$ & $2.080(2)$ \\
$\mathrm{C} \cdots \cdots \mathrm{X}^{a}$ & $3.15-3.27$ & $3.03-3.06$ & $3.06-3.23$ & $2.81-2.86$ & $2.66-2.72$ \\
\hline Bond angles $\left(^{\circ}\right)$ & & & & \\
\hline $\mathrm{C}(1)-\mathrm{Zn}-\mathrm{C}(2)$ & $123.0(1)$ & $119.6(2)$ & $120.5(3)$ & $120.1(3)$ & $119.6(1)$ \\
$\mathrm{C}(1)-\mathrm{Zn}-\mathrm{C}(3)$ & $113.0(1)$ & $119.8(2)$ & $116.1(3)$ & $114.4(3)$ & $114.79(9)$ \\
$\mathrm{C}(2)-\mathrm{Zn}-\mathrm{C}(3)$ & $123.7(1)$ & $120.6(2)$ & $123.3(3)$ & $125.4(3)$ & $125.6(1)$ \\
$\Sigma^{b}$ & 359.7 & 360.0 & 359.9 & 359.9 & 360.0 \\
\hline
\end{tabular}

${ }^{a}$ Closest contacts between $\mathrm{C}(1)$ and $\mathrm{C}(3)$ and the alkali or alkali earth metal cation $\mathrm{X}$.

${ }^{b}$ Sum of the $\mathrm{C}-\mathrm{Zn}-\mathrm{C}$ bond angles.

atom. That the $\mathrm{C}(1)-\mathrm{Zn}-\mathrm{C}(3)$ bond angles are significantly smaller than $120^{\circ}$ is not unexpected because these carbon atoms have (long-range) interactions with the cations in the crystal lattice.

Although the structural features of the anionic part of all compounds 12-16 are comparable, these structures are entirely different with respect to the cationic parts and relative positions of cations and anions within the unit cell. In the crystal lattice of 12 each potassium atom has long-range interactions with seven carbon atoms. In $\mathbf{1 3}$ and $\mathbf{1 4}$ each barium atom has an interaction with two carbon atoms $[\mathrm{C}(1)$ and $\mathrm{C}(3)]$ of two adjacent 
$\left[\left(\mathrm{Me}_{3} \mathrm{SiCH}_{2}\right)_{3} \mathrm{Zn}\right]^{-}$anions, in $\mathbf{1 3}$ two additional toluene molecules and in $\mathbf{1 4}$ four additional THF molecules have interactions with barium, rendering this atom eight-coordinate. Similarly, in the crystal lattice of $\mathbf{1 5}$ and $\mathbf{1 6}$ the strontium and calcium atoms interact with two $\left[\left(\mathrm{Me}_{3} \mathrm{SiCH}_{2}\right)_{3} \mathrm{Zn}\right]^{-}$anions, while a pseudo-octahedral coordination geometry at these atoms is reached by coordination of two THF molecules which are in cis-position.

In an approach similar to the synthesis of 12, the neopentyl derivatives $\left[\left(\mathrm{Me}_{3} \mathrm{CCH}_{2}\right)_{3} \mathrm{Zn}\right.$ ] $\mathrm{K}\left(\mathrm{C}_{6} \mathrm{H}_{6}\right)(17)$ and $\left[\left(\mathrm{Me}_{3} \mathrm{CCH}_{2}\right)_{3} \mathrm{Zn}\right] \mathrm{Na}(18)$ have been prepared from the reaction of $\left(\mathrm{Me}_{3} \mathrm{CCH}_{2}\right)_{2} \mathrm{Zn}$ and potassium and sodium, respectively. Also, the structures of these compounds were crystallographically determined and are closely related to the structures of the (trimethylsilyl)methyl zincates described above ${ }^{56}$.

Mixing a diorganozinc compound with an organometallic reagent in an appropriate solvent is another approach to the synthesis of triorganozincates (Scheme 3).

$$
\begin{gathered}
{\left[\left(\mathrm{Me}_{3} \mathrm{Si}\right)_{2} \mathrm{CH}\right]_{2} \mathrm{Zn}+\left(\mathrm{Me}_{3} \mathrm{Si}\right)_{2} \mathrm{CHLi} \frac{\mathrm{Et}_{2} \mathrm{O}}{1 \text { eq. TMEDA }}\left\{\begin{array}{c}
\left.\left\{\left[\left(\mathrm{Me}_{3} \mathrm{Si}\right)_{2} \mathrm{CH}\right]_{3} \mathrm{Zn}\right\} \mathrm{Li}_{(\mathrm{Et}} \mathrm{O}\right)_{2} \mathrm{TMEDA} \\
(\mathbf{( 1 9 )}
\end{array}\right.} \\
2\left(\mathrm{PhCH}_{2}\right)_{2} \mathrm{Zn}+\left(\mathrm{PhCH}_{2}\right)_{2} \mathrm{Mg}(\mathrm{THF})_{2} \stackrel{\mathrm{THF}}{\longrightarrow} 2\left[\left(\mathrm{PhCH}_{2}\right)_{3} \mathrm{Zn}\right]_{2} \mathrm{Mg}(\mathrm{THF})_{6}
\end{gathered}
$$

\section{SCHEME 3}

Reaction of $\left[\left(\mathrm{Me}_{3} \mathrm{Si}\right)_{2} \mathrm{CH}\right]_{2} \mathrm{Zn}$ with $\left(\mathrm{Me}_{3} \mathrm{Si}\right)_{2} \mathrm{CHLi}$ in a $1: 1$ molar ratio in the presence of one equivalent of TMEDA in diethyl ether as a solvent affords zincate $\mathbf{1 9}$ as the only product $^{60}$ (equation $8 \mathrm{a}$ in Scheme 3 ). It should be noted that when this reaction is carried out in the absence of TMEDA the zincate $\left[\left(\mathrm{Me}_{3} \mathrm{Si}\right)_{2} \mathrm{CH}\right]_{3} \mathrm{ZnLi}\left(\mathrm{Et}_{2} \mathrm{O}\right)_{4}$ is obtained, while the presence of excess TMEDA results in the formation of $\left[\left(\mathrm{Me}_{3} \mathrm{Si}\right)_{2} \mathrm{CH}\right]_{3} \mathrm{ZnLi}(\mathrm{TMEDA})_{2}$.

When dibenzylzinc and dibenzylmagnesium are mixed in a 2:1 molar ratio in THF as a solvent, a rapid disproportionation reaction occurs (equation $8 \mathrm{~b}$ ) resulting in the formation of tris(benzylzincate) $(\mathbf{2 0})^{61}$. It is notable that the reversed reaction is also possible, i.e. addition of excess TMEDA to a THF solution of $\mathbf{2 0}$ results in the immediate formation of $\left(\mathrm{PhCH}_{2}\right)_{2} \mathrm{Zn}$ (TMEDA) and $\left(\mathrm{PhCH}_{2}\right)_{2} \mathrm{Mg}(\mathrm{TMEDA})$ in quantitative yield. This observation indicates that the actual structures of zincates present in solution are influenced by the type of solvent and by the presence and nature of additional donor molecules.

The structures in the solid state of both $\mathbf{1 9}$ and $\mathbf{2 0}$ have been established by X-ray crystal structure determinations. For both compounds the unit cell contains well distinguishable triorganozinc anions and corresponding cations, $\left[\mathrm{Li}\left(\mathrm{OEt}_{2}\right)_{2}(\mathrm{TMEDA})\right]^{+}$for 19 and $\left[\mathrm{Mg}(\mathrm{THF})_{6}\right]^{2+}$ for 20. The molecular geometries of the triorganozinc anions, $\left[\left\{\left(\mathrm{Me}_{3} \mathrm{Si}\right)_{2} \mathrm{CH}\right\}_{3} \mathrm{Zn}\right]^{-}$for 19 and $\left[\left(\mathrm{PhCH}_{2}\right)_{3} \mathrm{Zn}\right]^{-}$for 20, are shown (Figure 9).

The solid state structure of 19 comprises the packing of eight discrete $\left[\left\{\left(\mathrm{Me}_{3} \mathrm{Si}\right)_{2} \mathrm{CH}\right\}_{3}\right.$ $\mathrm{Zn}]^{-}$anionic units and eight $\left[\mathrm{Li}^{-}\left(\mathrm{OEt}_{2}\right)_{2}(\mathrm{TMEDA})\right]^{+}$cationic units in an orthorhombic unit cell. The coordination geometry of zinc in the anions is almost perfectly trigonal planar; within experimental error the $\mathrm{Zn}-\mathrm{C}$ bonding distances are equal [2.089(9) $\AA$ mean value]. Also, the $\mathrm{C}-\mathrm{Zn}-\mathrm{C}$ bond angles are all close to the ideal value of $120^{\circ}[120.4(4), 119.6(4)$ and $118.7(4)^{\circ}$, respectively]. The lithium cations are each bidentate coordinated by one TMEDA molecule and two additional monodentate coordinated diethyl ether molecules.

An X-ray crystal structure determination of the $\left[t-\mathrm{Bu}_{3} \mathrm{Zn}\right]^{-}$anion present in $\mathbf{2 1}^{62}$ has an almost perfect trigonal planar arrangement $[\mathrm{Zn}-\mathrm{C}$ bond distances 2.080(7), 2.059(7) and 2.057(8) $\AA ; \mathrm{C}-\mathrm{Zn}-\mathrm{C}$ angles 118.1(2), 120.7(3) and 120.6(3) $)^{\circ}$. Compound 21 was prepared by reacting 1,3,4,6,7,8-hexahydro- $2 \mathrm{H}$-pyrimido[1,2]pyrimidine, $\mathrm{Me}_{2} \mathrm{Zn}$ and $t$ BuLi (equation 9). It is notable that the methyl groups initially bound to zinc all become 


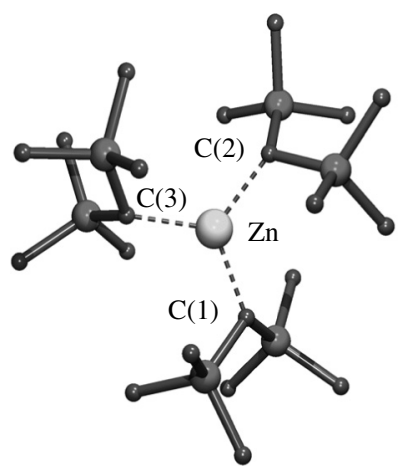

(19)

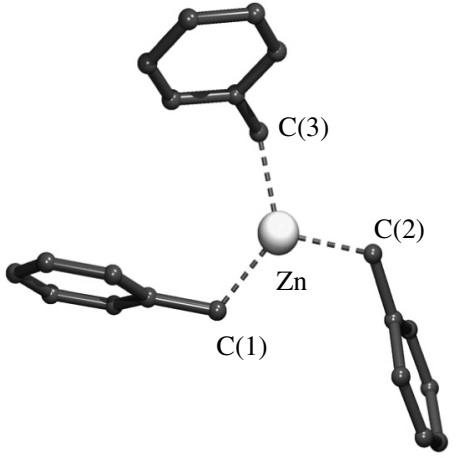

(20)

FIGURE 9. Molecular geometries of the triorganozincate anions of $\mathbf{1 9}$ and $\mathbf{2 0}$

replaced by $t$-butyl groups during the reaction. Also, the cationic part, i.e. $\mathrm{Li}_{8}(\mathrm{H})(\mathrm{hpp})_{6}$, has interesting structural features, but it is beyond the scope of this chapter to discuss this aspect in detail.

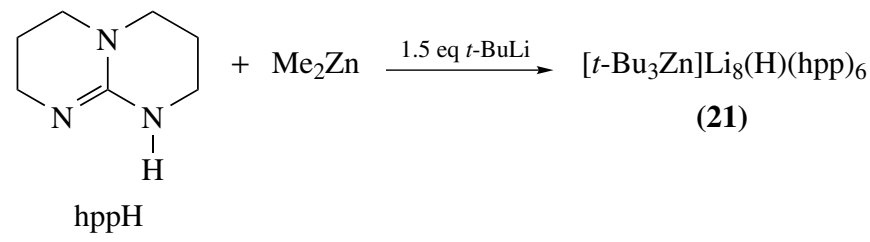

Reaction of zincate $\left[\left(\mathrm{Me}_{3} \mathrm{Si}\right)_{2} \mathrm{~N}\right]_{3} \mathrm{ZnNa}(12 \text {-crown-4) })_{2}$, which exists in solution as solvent-separated ion pairs, with phenylacetylene results in the quantitative substitution of the anionic $\left[\left(\mathrm{Me}_{3} \mathrm{Si}\right)_{2} \mathrm{~N}\right]^{-}$groups by $[\mathrm{PhC} \equiv \mathrm{C}]^{-}$groups to give zincate 22 (equation 10) ${ }^{63}$.

$$
\begin{gathered}
{\left[\left\{\left(\mathrm{Me}_{3} \mathrm{Si}\right)_{2} \mathrm{~N}\right\}_{3} \mathrm{Zn}\right] \mathrm{Na}(12 \text {-crown-4 })_{2}+3 \mathrm{PhC} \equiv \mathrm{CH}} \\
\underset{-3\left(\mathrm{Me}_{3} \mathrm{Si}\right)_{2} \mathrm{NH}}{\longrightarrow}\left[(\mathrm{PhC} \equiv \mathrm{C})_{3} \mathrm{Zn}\right] \mathrm{Na}(12 \text {-crown-4) }
\end{gathered}
$$

Recrystallization of $\mathbf{2 2}$ from THF afforded a crystalline material, suitable for an X-ray crystal structure determination. Surprisingly, the asymmetric unit contains two different zincate anions, one having a planar trigonal geometry with almost equal $\mathrm{Zn}(2)-\mathrm{C}$ bond distances (1.967 $\AA$, mean value), the sum of the bond angles at $\operatorname{Zn}(2)$ being $360.0^{\circ}$. The other $(\mathrm{PhC} \equiv \mathrm{C})_{3} \mathrm{Zn}$ anion is associated with one THF molecule, rendering the zinc atom four-coordinate (Figure 10). In this latter anion the $\mathrm{Zn}-\mathrm{C}$ distances are slightly elongated $[\mathrm{Zn}(1)-\mathrm{C} 2.003 \AA$, mean value] compared to the first one. The relatively long $\mathrm{Zn}-\mathrm{O}$ coordination bond $[2.244(5) \AA]$ and the sum of the $\mathrm{C}-\mathrm{Zn}(1)-\mathrm{C}$ bond angles of $356.1^{\circ}$ indicate that $\mathrm{Zn}(1)$ has rather a tetrahedral than a planar trigonal pyramidal geometry, with the coordinating oxygen atom residing at the apical position.

As described in the previous section, reaction of two equivalents of 2-[(dimethylamino) methyl]phenyllithium with bis(2-[(dimethylamino)methyl]phenyl)zinc affords the highly 


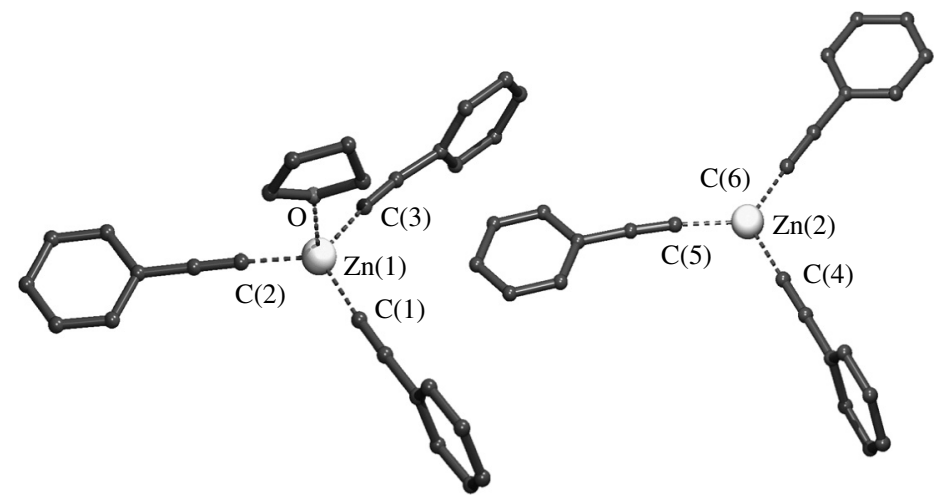

FIGURE 10. Molecular geometries of the $\left[(\mathrm{PhC} \equiv \mathrm{C})_{3} \mathrm{Zn}(\mathrm{THF})\right]^{-}$and $\left[(\mathrm{PhC} \equiv \mathrm{C})_{3} \mathrm{Zn}\right]^{-}$anions as present in the asymmetric unit of $\mathbf{2 2}$

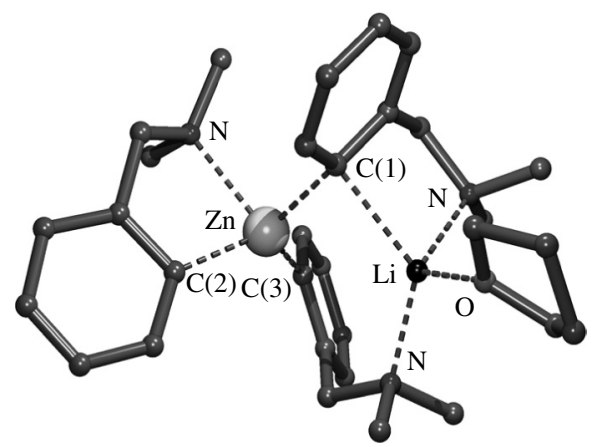

FIGURE 11. Molecular geometry of $\mathbf{2 3}$ in the solid state

coordinated tetraorganozincate $\left[\left(2-\mathrm{Me}_{2} \mathrm{NCH}_{2} \mathrm{C}_{6} \mathrm{H}_{4}\right)_{4} \mathrm{Zn}\right] \mathrm{Li}_{2}$. When the same reaction is carried out with 1:1 zinc-to-lithium stoichiometry, triorganozincate [ $\left(2-\mathrm{Me}_{2} \mathrm{NCH}_{2} \mathrm{C}_{6} \mathrm{H}_{4}\right)_{3}$ $\mathrm{Zn}$ ]Li(THF) (23) was obtained, whose structure in the solid state was established by an Xray crystal structure determination ${ }^{10}$. Compound $\mathbf{2 3}$ does not comprise (solvent) separated ions, but both in the solid state and in solution this compound exists as a neutral species. The molecular geometry of $\mathbf{2 3}$ in the solid state (Figure 11) reveals a distorted tetrahedral coordination geometry at zinc as a result of the bonding of three $\mathrm{C}_{i p s o}$ atoms of the three aryl groups [Zn-C(1) 2.082(2), Zn-C(2) 2.038(2) and $\mathrm{Zn}-\mathrm{C}(3) 2.026(2) \AA]$ and one intramolecularly coordinating $\mathrm{Me}_{2} \mathrm{~N}$ group. One of the aryl groups is $\eta^{1}, \mu^{2}$-bridgebonded via $\mathrm{C}_{i p s o}$ between zinc and lithium in a rather asymmetric way, which is reflected in the different bond distances between zinc and $\mathrm{C}_{i p s o}(2.082 \AA)$ and lithium and $\mathrm{C}_{\text {ipso }}$ $(2.414 \AA)$ as well as the different $\mathrm{C}(4) \cdots \mathrm{C}(1)-\mathrm{Zn}$ and $\mathrm{C}(4) \cdots \mathrm{C}(1)-\mathrm{Li}$ bond angles of 159.66 and $117.96^{\circ}$. A distorted tetrahedral coordination geometry at lithium is reached by additional intramolecular coordination of two $\mathrm{Me}_{2} \mathrm{~N}$ substituents and a THF molecule. Molecular weight determinations (by cryoscopy in benzene) and ${ }^{1} \mathrm{H}$ and ${ }^{13} \mathrm{C}$ NMR studies revealed that this structure in the solid state is most likely retained in solution.

Preliminary ${ }^{1} \mathrm{H}$ and ${ }^{13} \mathrm{C}$ NMR studies pointed to the existence of heterozincates $\left[\left(\mathrm{Me}_{2} \mathrm{NCH}_{2} \mathrm{C}_{6} \mathrm{H}_{4}\right)_{2}(n-\mathrm{Bu}) \mathrm{Zn}\right] \mathrm{Li}$ or $\left[\left(\mathrm{Me}_{2} \mathrm{NCH}_{2} \mathrm{C}_{6} \mathrm{H}_{4}\right)(n-\mathrm{Bu})_{2} \mathrm{Zn}\right] \mathrm{Li}$ in equilibrium with 23 
in solutions containing $\left(\mathrm{Me}_{2} \mathrm{NCH}_{2} \mathrm{C}_{6} \mathrm{H}_{4}\right)_{2} \mathrm{Zn}$ and $n$ - $\mathrm{BuLi}$ in 1:1 molar ratio. The presence of such heterozincates was furthermore corroborated by the observation of the exclusive formation of an 1,4-addition product, obtained from reaction of these heterozincates with 2-cyclohexenone (equation 11). The additional formation of the 1,2-aryl-addition product is not unexpected, because in a separate experiment it was demonstrated that reaction of 23 with 2-cyclohexenone affords this 1,2-adduct exclusively.

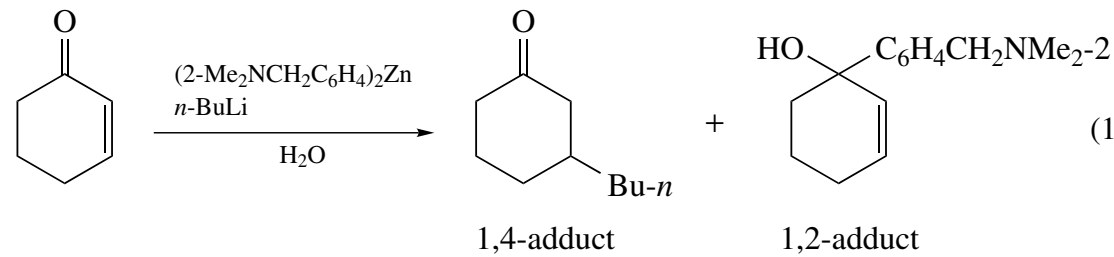

The structures of three triarylzincates, $\left[\left(\mathrm{Ph}_{3} \mathrm{Zn}\right)_{2}\right] \mathrm{Mg}_{2} \mathrm{Br}_{3}(\mathrm{THF})_{6}(\mathbf{2 4})$, [ $\left.\mathrm{Mes}_{3} \mathrm{Zn}\right] \mathrm{MgBr}$ $(\mathrm{THF})_{5}(\mathbf{2 5})$ and $\left[\left(2,4,6-i-\mathrm{Pr}_{3} \mathrm{C}_{6} \mathrm{H}_{2}\right)_{3} \mathrm{Zn}\right] \mathrm{Li}(\mathrm{TMEDA})_{2}(\mathbf{2 6})$, have been established in the solid state by X-ray crystal structure determinations. The first two compounds were prepared from the reaction of $\left[\mathrm{ZnBr}\left(\mathrm{NPMe}_{3}\right)\right]_{4}$ with excess of the corresponding Grignard reagent ${ }^{64}$, while the latter compound was isolated as a side product from the reaction of zinc halide containing $\mathrm{VCl}_{2}$ (TMEDA) 2 with 2,4,6-i- $\operatorname{Pr}_{3} \mathrm{C}_{6} \mathrm{H}_{2} \mathrm{Li}^{65}$. The molecular geometry of the respective triarylzincate anions are shown in Figure 12. All three compounds have in common that in the solid state they exist as solvent separated ion pairs. The coordination geometry at zinc in all three anions is almost perfectly planar trigonal. To release steric interference between the ortho-substituents in $\mathbf{2 5}$ and 26, the aryl groups in these compounds are tilted with respect to the trigonal plane in a propeller-like conformation. The presence of a complex counter cation $\left[\mathrm{Mg}_{2} \mathrm{Br}_{3}(\mathrm{THF})_{6}\right]^{+}$in the solid state of $\mathbf{2 4}$, in which the three bromine atoms bridge between two magnesium atoms while in $\mathbf{2 5}$ the counter cation is a simple $\left\{\mathrm{MgBr}(\mathrm{THF})_{5}\right]^{+}$cation, is notable. In the solid state structure of 26 the asymmetric unit contains, in addition to the $\left[\operatorname{Li}(\mathrm{TMEDA})_{2}\right]^{+}$cation, an additional neutral $\mathrm{Li}_{2} \mathrm{Cl}_{2}$ (TMEDA) $)_{2}$ molecule.

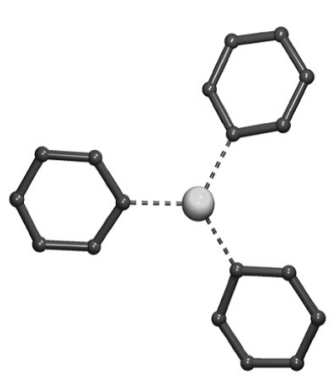

(24)

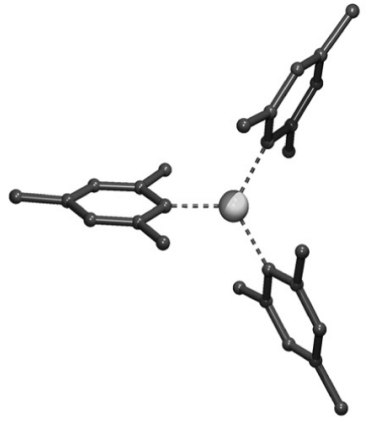

(25)

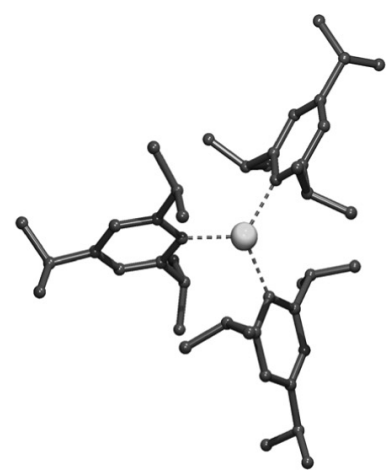

(26)

FIGURE 12. Molecular geometry of the triarylzincate anions as present in 24, 25 and 26 


\section{Heteroleptic Triorganozincates $\left[\mathbf{R}_{\mathbf{2}} \mathbf{R}^{\prime} \mathbf{Z n}\right] \mathbf{M}$}

So far, only organozincates have been considered in which the three or four organic groups bound to zinc are identical (homoleptic zincates). It is well established that heteroleptic organozinc compounds undergo the so-called Schlenk equilibrium (equation 12). This is also true for heteroleptic zincates (equation 13). In this case, the equilibria are even more complicated, due to the possible formation of a variety of homo- and heteroleptic species.

$$
\begin{aligned}
& \mathrm{R}_{2} \mathrm{Zn}+\mathrm{R}_{2}^{\prime} \mathrm{Zn} \rightleftarrows 2 \mathrm{RR}^{\prime} \mathrm{Zn} \\
& {\left[\mathrm{R}_{3} \mathrm{Zn}\right]^{-}+\left[\mathrm{R}_{3}^{\prime} \mathrm{Zn}\right]^{-} \rightleftarrows\left[\mathrm{RR}_{2}^{\prime} \mathrm{Zn}\right]^{-}+\left[\mathrm{R}_{2} \mathrm{R}^{\prime} \mathrm{Zn}\right]^{-} }
\end{aligned}
$$

Such equilibria are driven by thermodynamics and therefore a selective synthetic route towards one of these species and isolation of such heteroleptic zincates in pure form is often very difficult or impossible. Only if one of the species has a sufficiently enhanced thermodynamic stability compared to the others in the equilibrium is its isolation as a pure compound possible. This is often the case when the various groups bound to zinc have a sufficiently different electronegativity, for example when one of the groups is bound to zinc via a heteroatom, or when the steric requirements of the groups bound to zinc are rather different. Sometimes it is possible to isolate one of the species present in the Schlenk equilibrium as a solid material, for example when one of the species preferentially crystallizes from solution.

The heteroleptic zincate $\left[\left(\mathrm{Me}_{3} \mathrm{SiCH}_{2}\right)_{2} \mathrm{PhZn}\right] \mathrm{K}(\mathbf{2 7})$ was isolated as a side product from a benzene solution of the homoleptic zincate $\left[\left(\mathrm{Me}_{3} \mathrm{SiCH}_{2}\right)_{3} \mathrm{Zn}\right] \mathrm{K}$ due to reaction of this zincate with the benzene solvent (equation 14) ${ }^{56}$.

$$
\left[\left(\mathrm{Me}_{3} \mathrm{SiCH}_{2}\right)_{3} \mathrm{Zn}\right] \mathrm{K} \underset{-\mathrm{Me}_{4} \mathrm{Si}}{\stackrel{\mathrm{C}_{6} \mathrm{H}_{6}}{\longrightarrow}}\left[\left(\mathrm{Me}_{3} \mathrm{SiCH}_{2}\right)_{2} \mathrm{PhZn}\right] \mathrm{K}
$$

The asymmetric unit of $\mathbf{2 7}$ is located near a crystallographic inversion centre, resulting in a dimeric molecular geometry (Figure 13), involving asymmetric bridging of the $\mathrm{Me}_{3} \mathrm{SiCH}_{2}$ group between zinc and potassium [Zn-C(1) 2.06(1), K-C(1) 3.10(1) $\AA$ ]. The potassium atom is $\eta^{6}$-bonded with the symmetry-related $\sigma$-zinc-aryl group [C-K distances range from $3.10(1)$ to $3.65(1) \AA]$. It should be noted that the potassium also has (long-range) interactions with an aryl group of a neighbour dimeric unit. The sum of the $\mathrm{C}-\mathrm{Zn}-\mathrm{C}$ bond angles around zinc is $360^{\circ}$, which is in line with a planar trigonal coordination geometry at zinc.

According to the procedures shown in Scheme 4, three triorganozincates (28-30) containing the benzylic $\mathrm{Ph}\left(\mathrm{Me}_{3} \mathrm{Si}\right) \mathrm{CH}$ group have been prepared ${ }^{66}$. Both in the solid state and in solution these compounds exist as solvent-separated ion pairs, the counter cation being $\mathrm{Li}(\mathrm{TMEDA})_{2}$. Two of these, the heteroleptic ones $\left[\left\{\mathrm{Ph}\left(\mathrm{Me}_{3} \mathrm{Si}\right) \mathrm{CH}\right\} \mathrm{Me}_{2} \mathrm{Zn}\right] \mathrm{Li}(\mathrm{TMEDA})_{2}$ (28) and $\left[\left\{\mathrm{Ph}\left(\mathrm{Me}_{3} \mathrm{Si}\right) \mathrm{CH}\right\}_{2} \mathrm{MeZn}\right] \mathrm{Li}(\mathrm{TMEDA})_{2}(\mathbf{2 9})$, have been structurally characterized by X-ray crystallography.

The molecular geometries of the triorganozincate anions as present in $\mathbf{2 8}$ and $\mathbf{2 9}$ are shown in Figure 14. The sum of the $\mathrm{Zn}-\mathrm{C}$ bond angles around zinc in $\mathbf{2 8}$ and $\mathbf{2 9}$ is close to $360^{\circ}$ (359.9 and $359.6^{\circ}$, respectively), indicating a slightly distorted trigonal planar coordination geometry at zinc. The differences in $\mathrm{Zn}-\mathrm{C}$ bond distances between the benzylic carbon atom [2.113(4) $\AA]$ and the two methyl carbon atoms [2.005(5) and $2.011(5) \AA]$ is notable. The elongation of the benzyl carbon-to-zinc distance indicates that a major part of the negative charge is located on the benzylic carbon atom. In a 


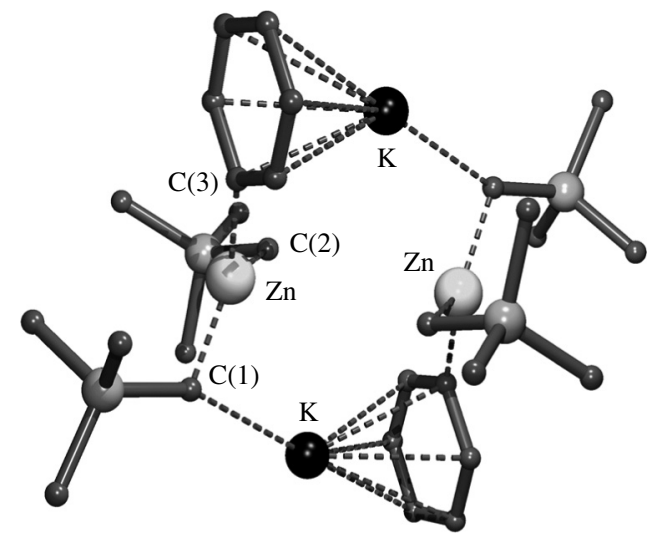

FIGURE 13. Molecular geometry of the dimeric units as present in the solid state structure of 27

$\left[\mathrm{Ph}\left(\mathrm{Me}_{3} \mathrm{Si}\right) \mathrm{CHZn}\right] \mathrm{Cl}(\mathrm{TMEDA}) \stackrel{\text { TMEDA }}{\stackrel{\text { TMeLi }}{\longrightarrow}}\left[\stackrel{\mathrm{LiCl}}{\longrightarrow}\left[\mathrm{Ph}\left(\mathrm{Me}_{3} \mathrm{Si}\right) \mathrm{CH}\right\} \mathrm{Me}_{2} \mathrm{Zn}\right] \mathrm{Li}(\mathrm{TMEDA})_{2}$

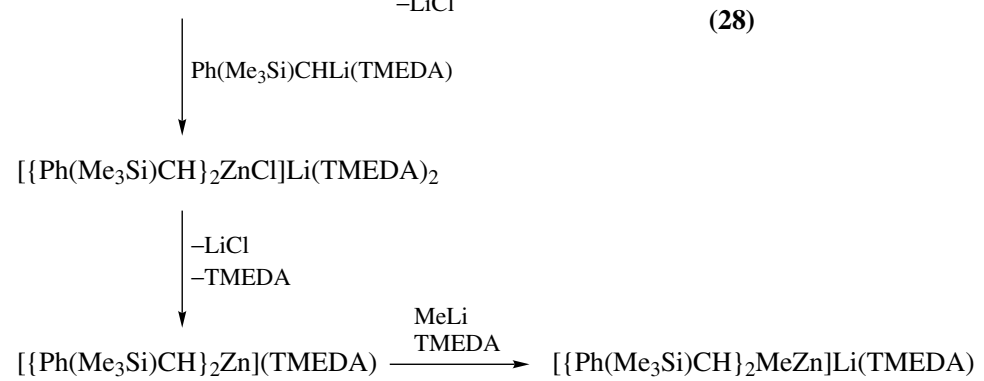

(29)

$\mathrm{Ph}\left(\mathrm{Me}_{3} \mathrm{Si}\right) \mathrm{CHLi}(\mathrm{TMEDA})$

$\left[\left\{\mathrm{Ph}\left(\mathrm{Me}_{3} \mathrm{Si}\right) \mathrm{CH}\right\}_{3} \mathrm{Zn}\right] \operatorname{Li}(\mathrm{TMEDA})_{2}$

(30)

SCHEME 4

highly simplified view, the bonding of the benzylic group to zinc can be regarded as the coordination of a benzyl anion to a molecule of dimethylzinc. Also in $\mathbf{2 9}$ the bond distances between the benzylic carbon atoms and zinc compared to that of the methyl carbon atom are elongated [Zn-C(1) 2.089(6), Zn-C(3) 2.084(5) vs. $\mathrm{Zn}-\mathrm{C}(2)$ 1.989(8) $\AA$ ]. It is remarkable that the bond angle between the two bulky benzylic groups in $\mathbf{2 9}$ is the smallest one $\left[\mathrm{C}(1)-\mathrm{Zn}-\mathrm{C}(3) 115.2^{\circ}\right]$ of the bond angles around zinc $[\mathrm{C}(1)-\mathrm{Zn}-\mathrm{C}(2)$ 125.1(3) and $\left.\mathrm{C}(2)-\mathrm{Zn}-\mathrm{C}(3) 119.7(3)^{\circ}\right]$. However, these bulky groups are oriented in such a way that the steric repulsion between them is minimal (Figure 14).

Due to the presence of two chiral benzylic centres in 29 the possible formation of two diastereoisomers must be expected. The ${ }^{1} \mathrm{H}$ and ${ }^{13} \mathrm{C}$ NMR spectra of 29 indeed 


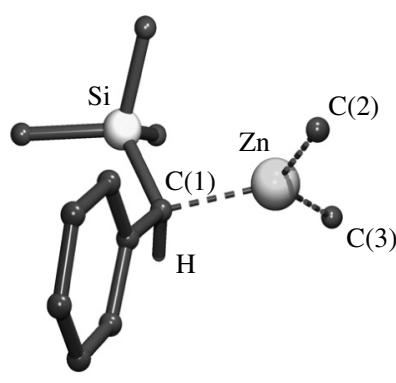

(28)

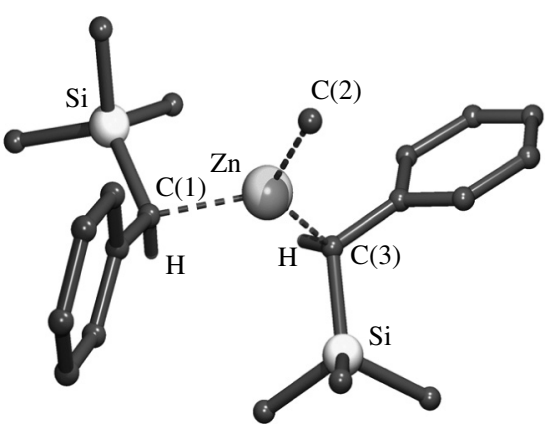

(29)

FIGURE 14. Molecular geometries of the heteroleptic triorganozincate anions present in $\mathbf{2 8}$ and $\mathbf{2 9}$

show two resonance patterns indicating the presence of two diastereoisomers in solution. One diastereoisomer crystallizes preferentially, i.e. the one in which the two chiral benzylic centres have an identical configuration. In Figure 14, the diastereoisomer in which both chiral centres have $(S)$-configuration is shown, but as a requirement of space-group symmetry (Pbca) both enantiomers are present in the crystal lattice.

The heteroleptic triorganozincate (31) in which the zincate anion contains one methyl group and two bulky 2,2,4,4,6,6-hexamethyl-2,4,6-trisilacyclohexyl groups (Figure 15) involves solvent-separated ion pairs of which the lithium cation is coordinated by two 1,3,5-trimethyl-1,3,5-triazine molecules ${ }^{67}$. All three nitrogen atoms of each triazine molecule are coordinated to lithium to give a six-coordinated lithium cation. Like in 28 and 29, the $\mathrm{Zn}-\mathrm{C}$ bond distances to the silicon-containing substituent are somewhat elongated [ $\mathrm{Zn}-\mathrm{C}(1)$ 2.083(6) and $\mathrm{Zn}-\mathrm{C}(3)$ 2.063(6) $\AA$ ] as compared to the $\mathrm{Zn}-\mathrm{C}$ methyl distance of 2.017(6) $\AA$. In this anion the bond angle between the bulky substituents is again relatively small $\left[\mathrm{C}(1)-\mathrm{Zn}-\mathrm{C}(3) 114.7(2)^{\circ}\right]$ as was also observed in 29 and was attributed to enhanced delocalization of electron density in silicon-containing anion. The coordination geometry of zinc in $\mathbf{3 1}$ is close to trigonal planar as indicated by the sum of the bond angles at zinc $\left(360^{\circ}\right)$.

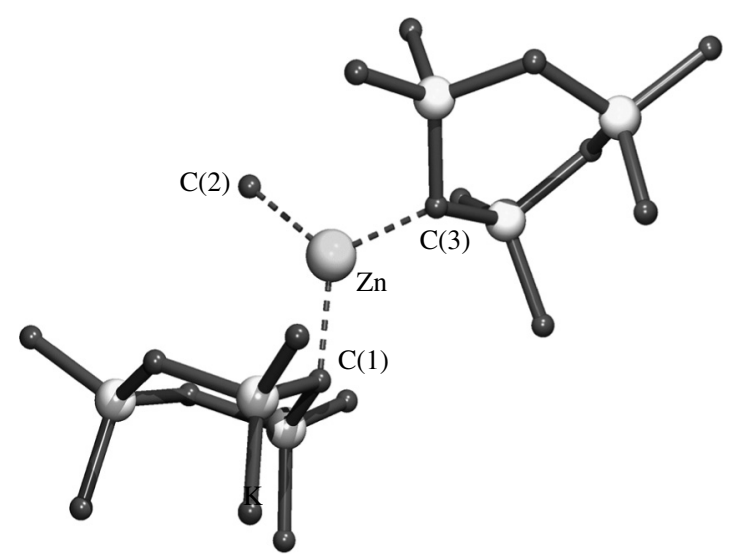

FIGURE 15. Molecular geometry of the heteroleptic triorganozincate anion $\mathbf{3 1}$ 


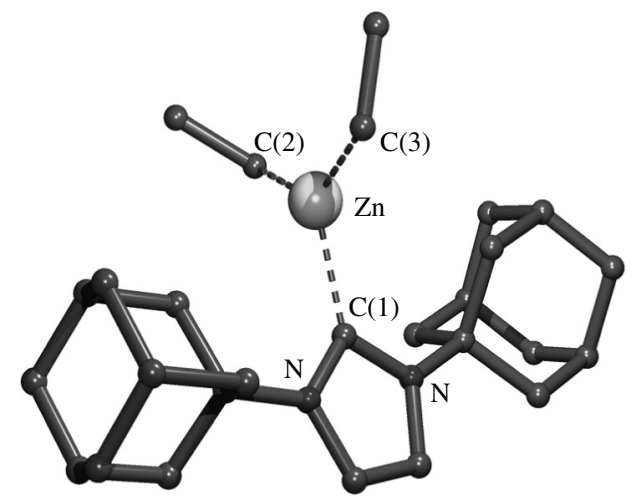

FIGURE 16. Molecular geometry of the neutral compound $\mathbf{3 2}$

The product (32) obtained from the reaction of the carbene 1,3-di(1-adamantyl)imidazol2 -ylidene with diethylzinc has been structurally characterized (Figure 16$)^{68}$. This neutral compound should be regarded as containing a (neutral) carbene complexed to diethylzinc. Although the individual bond angles around zinc vary considerably $[\mathrm{C}(1)-\mathrm{Zn}-\mathrm{C}(2)$ 109.8(1), C(1) $-\mathrm{Zn}-\mathrm{C}(3)$ 118.1(1) and $\left.\mathrm{C}(2)-\mathrm{Zn}-\mathrm{C}(3) 132.1^{\circ}\right]$ the sum of these bond angles is $360^{\circ}$, indicating a trigonal planar coordination geometry at zinc. The $\mathrm{Zn}-\mathrm{C}(1)$ bond distance of 2.096(3) $\AA$ is somewhat longer than the $\mathrm{Zn}-\mathrm{C}($ ethyl) bonds $[\mathrm{Zn}-\mathrm{C}(2)$ 1.994(4) and $\mathrm{Zn}-\mathrm{C}(3) 2.009(4) \AA]$.

It has been shown that dialkyl- and diarylmagnesium compounds interact with strongly coordinating agents like cryptands, crown ethers or aza-crown ethers in a disproportionation reaction yielding an ionic structure comprising an alkyl- or arylmagnesium cation and a triorgano-magnesiate anion ${ }^{69-71}$. A similar reaction with dialkylzinc compounds failed ${ }^{72}$. However, according to NMR studies the reaction of a mixture of $\mathrm{Et}_{2} \mathrm{Zn}$ and $\mathrm{Ph}_{2} \mathrm{Zn}$ with aza-crown ether $14 \mathrm{~N} 4$ afforded a mixture consisting of the heteroleptic $\left[\mathrm{Ph}_{2} \mathrm{EtZn}\right]^{-}$anion and the homoleptic $\left[\mathrm{Ph}_{3} \mathrm{Zn}\right]^{-}$anion $^{72}$ (equation 15).

$$
\mathrm{Et}_{2} \mathrm{Zn}+\mathrm{Ph}_{2} \mathrm{Zn} \underset{\mathrm{C}_{6} \mathrm{H}_{6}}{\stackrel{14 \mathrm{~N} 4}{\longrightarrow}}[\mathrm{EtZn}(14 \mathrm{~N} 4)]^{+}+\left[\mathrm{Ph}_{2} \mathrm{EtZn}\right]^{-}+\left[\mathrm{Ph}_{3} \mathrm{Zn}\right]^{-}
$$

So far, only zincates have been considered in which the organic groups are bonded to zinc via a carbon atom. However, also organozincates are known in which one of the groups is bound to zinc via an electronegative heteroatom. The heteroleptic organozinc compounds [EtZnX] containing an electronegative $\mathrm{X}$ group $(\mathrm{X}=\mathrm{Cl}, \mathrm{Br}$, I or $\mathrm{OR})$ undergo a similar disproportionation reaction as described above, resulting in the formation of $\left[\mathrm{Et}_{2} \mathrm{ZnX}\right]^{-}$anions $^{73}$.

Furthermore, reaction of $\left(\mathrm{Me}_{3} \mathrm{SiCH}_{2}\right)_{2} \mathrm{Zn}$ with $\left(\mathrm{Me}_{3} \mathrm{Si}\right)_{2} \mathrm{NLi}$ in the presence of 1,3,5trimethyl-1,3,5-triazine (TMTA) afforded compound (33) (equation 16) ${ }^{67}$.

$$
\left(\mathrm{Me}_{3} \mathrm{SiCH}_{2}\right)_{2} \mathrm{Zn}+\left(\mathrm{Me}_{3} \mathrm{Si}\right)_{2} \mathrm{NLi} \underset{\mathrm{THF}}{\stackrel{\mathrm{TMTA}}{\longrightarrow}}\left[\left(\mathrm{Me}_{3} \mathrm{SiCH}_{2}\right)_{2}\left(\mathrm{Me}_{3} \mathrm{Si}\right)_{2} \mathrm{NZn}\right] \mathrm{Li}(\mathrm{TMTA})
$$

An X-ray crystallographic study of $\mathbf{3 3}$ shows this compound to be neutral with two $\mathrm{Me}_{3} \mathrm{SiCH}_{2}$ groups $\eta^{1}$-bonded to zinc while the amide group is $\mu^{2}$-bonded via its nitrogen 


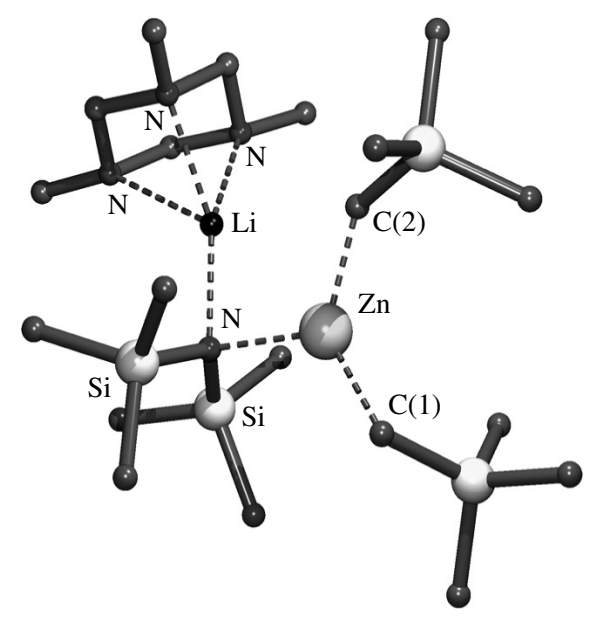

FIGURE 17. Molecular geometry of $\mathbf{3 3}$

atom between zinc and lithium (Figure 17). The TMTA molecule is tridentate coordinated to lithium. The $\mathrm{Zn}-\mathrm{C}$ bond distances $[\mathrm{Zn}-\mathrm{C}(1)$ 2.025(14) and $\mathrm{Zn}-\mathrm{C}(2) 2.030(13) \AA]$ are in the expected range for organozincates. The $\left(\mathrm{Me}_{3} \mathrm{Si}\right)_{2} \mathrm{~N}$ group is symmetrically bonded between lithium and zinc [ $\mathrm{Zn}-\mathrm{N} 2.131(9)$ and $\mathrm{Li}-\mathrm{N}$ 2.083(23) $\AA$ ]. The $\mathrm{Zn}-\mathrm{N}$ bond distance in 33 is rather elongated compared to that in linear $\left[\left(\mathrm{Ph}_{2} \mathrm{MeSi}\right)_{2} \mathrm{~N}\right]_{2} \mathrm{Zn}^{74}$, which is 1.850 (3) $\AA$, most likely as a consequence of the bridging nature of the $\left(\mathrm{Me}_{3} \mathrm{Si}\right)_{2} \mathrm{~N}$ anion. In this respect it should be noted that the $\mathrm{N}-\mathrm{Li}$ distances found in trimeric $\left[\left(\mathrm{Me}_{3} \mathrm{Si}\right)_{2} \mathrm{NLi}\right]_{3}$ range from 1.994(13) to 2.022(13) $\AA^{75}$. The $\mathrm{Zn}-\mathrm{N}-\mathrm{Li}$ bond angle of $89.5(7)^{\circ}$ is rather acute, probably as a result of a secondary interaction of the $\alpha$-carbon atom of one of the $\mathrm{Me}_{3} \mathrm{SiCH}_{2}$ groups with lithium [Li …C(2) $\left.2.74 \AA\right]$. The sum of the bond angles around zinc is $259.9^{\circ}$, indicating a trigonal planar coordination geometry, while the lithium atom has a slightly distorted tetrahedral geometry as a result of the additional tridentate coordination of the TMTA molecule.

Also, alkali metal alkoxides interact with diorganozinc compounds to give heteroleptic zincates containing alkoxide moieties, as indicated by NMR spectroscopic studies ${ }^{76,77}$. The structure in the solid state of the product $\left[\mathrm{Et}_{2} \mathrm{ZnOBu}-t\right] \mathrm{K}, \mathbf{3 4}$, obtained from the reaction of $\mathrm{Et}_{2} \mathrm{Zn}$ with $t$-BuOK, was established by X-ray crystallography ${ }^{76}$. In the solid state, compound 34 consists of dimers of which the two dimeric halves are symmetry related via an inversion centre. Two $t$-butoxy groups bridge in a symmetric way [ $\mathrm{Zn}-\mathrm{O}$ bond distances 2.091(4) and 2.097(4) $\AA$ ] between two $\mathrm{Et}_{2} \mathrm{Zn}$ units, forming a flat $\mathrm{O}-\mathrm{Zn}-\mathrm{O}-\mathrm{Zn}$ arrangement (Figure 18). One of the potassium atoms is located below, and the other one above this plane. Each potassium atom has interactions with both oxygen atoms, one relatively short $[2.626(5) \AA]$ and one relatively long [3.734(5) $\AA$. The acute $\mathrm{O}-\mathrm{Zn}-\mathrm{O}$ bond angle of $79.56(2)^{\circ}$ is compensated by a $\mathrm{Zn}-\mathrm{O}-\mathrm{Zn}$ angle of $100.4(3)^{\circ}$. Moreover, this acute angle causes the $\mathrm{C}-\mathrm{Zn}-\mathrm{C}$ angle to open up to $116.2(3)^{\circ}$. Each potassium atom has interactions with the $\alpha-\mathrm{C}$ atoms of one of the ethyl groups of both halves of the dimer (both $3.065 \AA$ ). Each potassium atom also has an interaction, although much longer $(3.331 \AA$ ), with an $\alpha-\mathrm{C}$ atom of an ethyl group in a neighbouring dimeric unit.

The interesting compound $\mathbf{3 5}$ was prepared according to the sequence shown in Scheme $5^{78}$. It is notable that the last step involves ortho-metallation of one of 


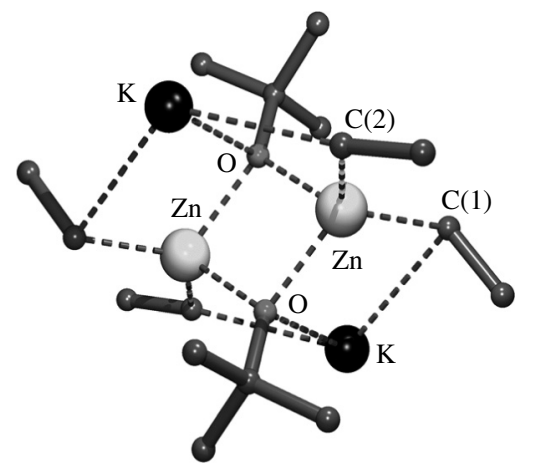

FIGURE 18. The dimeric heteroleptic zincate unit as present in the solid state of $\mathbf{3 4}$

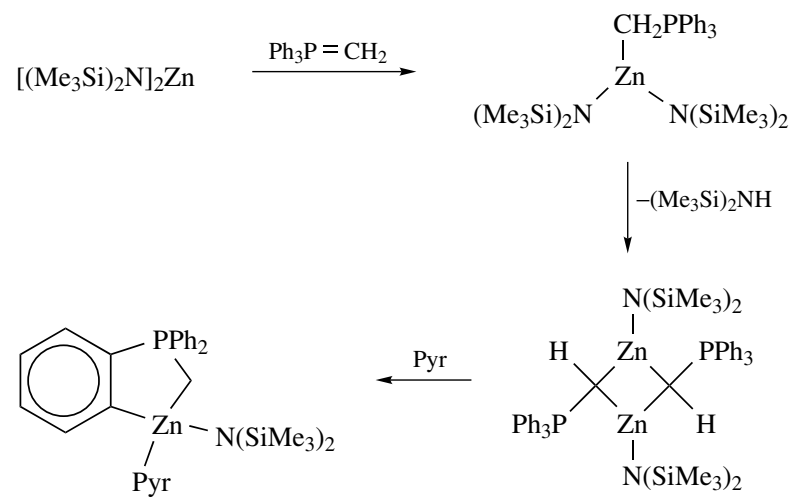

(35)

\section{SCHEME 5}

the phenyl phosphorus groups. This compound can be regarded as a $C, C^{\prime}$-orthochelated heterozincate with two $\mathrm{Zn}-\mathrm{C}$ bonds, one $\mathrm{Zn}-\mathrm{N}$ amido bond and an additional coordinating pyridine molecule. Formally, the negative charge is located at zinc and the positive charge at the phosphorus atom.

The molecular geometry of $\mathbf{3 5}$ was established by an X-ray crystallographic study (Figure 19). The zinc centre has a distorted tetrahedral coordination geometry with unlike $\mathrm{C}-\mathrm{Zn}$ distances of which the $\mathrm{Zn}-\mathrm{C}(2)$ distance [2.137(4) $\AA$ ] is quite long. The acute $\mathrm{C}(1)-\mathrm{Zn}-\mathrm{C}(2)$ bond angle of $92.9(1)^{\circ}$ is a consequence of the bite angle of the fivemembered $\mathrm{C}-\mathrm{P}-\mathrm{C}-\mathrm{C}$ chelate ring.

According to ${ }^{13} \mathrm{C}$ NMR data, reaction of lithium tetramethylpiperidine (TMP) and $t$ $\mathrm{Bu}_{2} \mathrm{Zn}$, in a 1:1 molar ratio (Scheme 6) affords the heteroleptic zincate $\left[t-\mathrm{Bu}_{2} \mathrm{Zn}(\mathrm{TMP})\right] \mathrm{Li}$ $(36)^{79}$. An interesting feature of this compound is that it is capable of metalate arenes that contain a directing metalating group (DMG) in ortho-position and thus allow further derivatization by reaction of the zincate intermediate with electrophiles $\left(\mathrm{E}^{+}\right)$.

The in situ formation of dialkylhydrido zincates $\left[\mathrm{R}_{2} \mathrm{HZn}\right] \mathrm{M}(\mathrm{M}=\mathrm{Li}$ or $\mathrm{Na})$, which have been used as highly selective and mild reducing agents, is notable ${ }^{80}$. Unfortunately, no structural data for this type of zincates are available yet. 


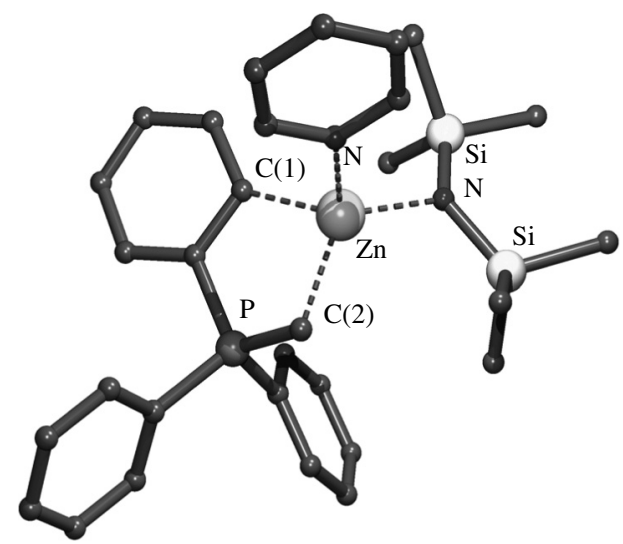

FIGURE 19. Molecular geometry of $\mathbf{3 5}$ in the solid state<smiles>CC1(C)CCCC(C)(C)N1[Tl]</smiles>

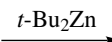<smiles>C</smiles><smiles>CC1(C)CCCC(C)(C)N1[Ga]Br</smiles>

(36)

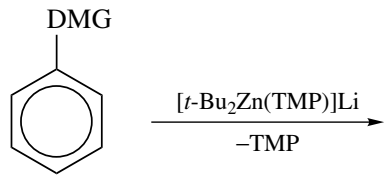<smiles>Cc1ccccc1[14C](C)(C)[O]</smiles>
$\mathrm{Zn}(\mathrm{Bu}-t)_{2} \mathrm{Li}$

\section{electrophile \\ e.g., electrophile $=\mathrm{I}_{2}$}<smiles>Cc1ccccc1P(C)(C)(F)F</smiles>

SCHEME 6

\section{DIALKYL- AND DIARYLZINC COMPOUNDS}

\section{A. Donor-base-free, $\sigma, \sigma$-Bonded Homoleptic $\mathbf{R}_{2} \mathbf{Z n}$ and Heteroleptic $\mathbf{R} \mathbf{R}^{\prime} \mathbf{Z n}$ Compounds}

Although dialkylzinc compounds have been known for more than 150 years, the actual structural characterization of these compounds in the solid state by X-ray diffraction studies started only 15 years ago. Such investigations were hampered particularly by the physical properties of these compounds; many of them are low-boiling liquids which, moreover, are extremely sensitive towards oxygen and moisture. It was suggested, based on molar heats of evaporation and molecular weight determinations in solvents like benzene, heptane and dioxane, that dialkylzinc compounds exist as monomers ${ }^{81,82}$. The electronic configuration of zinc in the ground state, observed IR frequencies for $\mathrm{Me}_{2} \mathrm{Zn}^{83}$ and the observed polarization of Raman frequencies ${ }^{84}$ indicated that dialkylzinc compounds adopt a linear $\mathrm{C}-\mathrm{Zn}-\mathrm{C}$ arrangement in which the zinc atom is sp-hybridized.

The first quantitative structural parameters $\left(\mathrm{C}-\mathrm{Zn}\right.$ bond distances) in $\mathrm{Me}_{2} \mathrm{Zn}$ [1.930(2) $\AA], \mathrm{Et}_{2} \mathrm{Zn}[1.950(2) \AA]$ and $n$ - $\operatorname{Pr}_{2} \mathrm{Zn}$ [1.952(2) $\AA$ ] became available from gasphase electron diffraction studies ${ }^{42}$. Later, the same authors extended these studies, in 


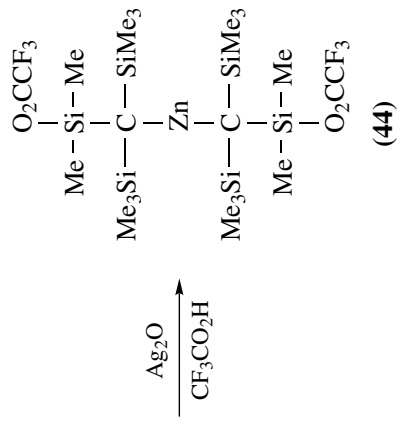

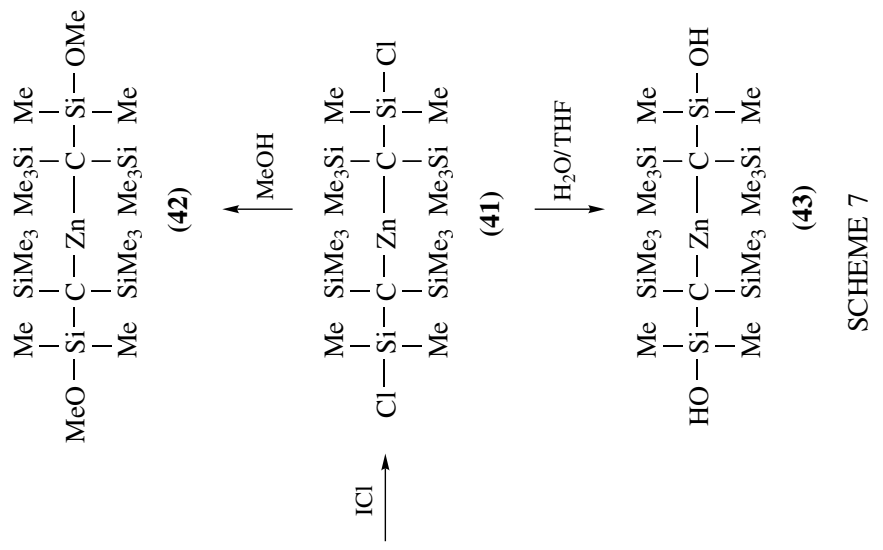

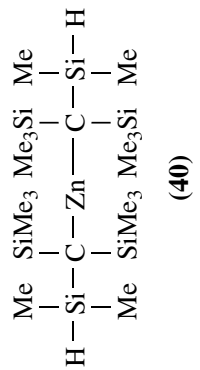


combination with DFT computational studies, to $i-\mathrm{Pr}_{2} \mathrm{Zn}, t-\mathrm{Bu}_{2} \mathrm{Zn}$, neo-Pent ${ }_{2} \mathrm{Zn}$ and $\left(\mathrm{Me}_{3} \mathrm{SiCH}_{2}\right)_{2} \mathrm{Zn}^{85}$.

The trimethylsilylmethyl-substituted diorganozinc compounds $\left(\mathrm{Me}_{3} \mathrm{SiCH}_{2}\right)_{2} \mathrm{Zn}(37)^{86}$, $\left.\left.\left[\left(\mathrm{Me}_{3} \mathrm{Si}\right)_{2} \mathrm{CH}\right)\right]_{2} \mathrm{Zn} \mathrm{(38}\right)^{87}$ and $\left[\left(\mathrm{Me}_{3} \mathrm{Si}\right)_{3} \mathrm{C}\right]_{2} \mathrm{Zn}(\mathbf{3 9})^{88}$ were prepared from the corresponding Grignard or organolithium reagents. Whereas $\mathbf{3 7}$ and $\mathbf{3 8}$ are pyrophoric liquids and extremely sensitive towards hydrolysis, compound $\mathbf{3 9}$ is a crystalline material having a melting point of about $300^{\circ} \mathrm{C}$. Moreover, this compound is air-stable and its resistance towards hydrolysis was demonstrated by the fact that it could be purified by steam distillation techniques ${ }^{88}$. The inertness of the $\mathrm{Zn}-\mathrm{C}$ carbon bonds in tris(silyl-substituted) methylzinc derivatives was further demonstrated by reaction of $\left[\left(\mathrm{HMe}_{2} \mathrm{Si}\right)\left(\mathrm{Me}_{3} \mathrm{Si}\right)_{2} \mathrm{C}\right]_{2} \mathrm{Zn}$ (40) with various electrophiles like $\mathrm{ICl}, \mathrm{Br}_{2}$ and $\mathrm{I}_{2}$ and subsequent substitution reactions resulting in compounds of general type $\left[\left(\mathrm{XMe}_{2} \mathrm{Si}\right)\left(\mathrm{Me}_{3} \mathrm{Si}\right)_{2} \mathrm{C}\right]_{2} \mathrm{Zn}$ with $\mathrm{X}=\mathrm{Cl}, \mathrm{Br}, \mathrm{I}, \mathrm{F}$, $\mathrm{OH}, \mathrm{OMe}, \mathrm{O}_{2} \mathrm{CCF}_{3}, \mathrm{O}_{2} \mathrm{CH}$ or $\mathrm{NCS}^{89}$. As representative examples, the synthetic pathways towards $\left[\left(\mathrm{ClMe}_{2} \mathrm{Si}\right)\left(\mathrm{Me}_{3} \mathrm{Si}\right)_{2} \mathrm{C}\right]_{2} \mathrm{Zn}(\mathbf{4 1}),\left[\left(\mathrm{MeOMe}_{2} \mathrm{Si}\right)\left(\mathrm{Me}_{3} \mathrm{Si}\right)_{2} \mathrm{C}\right]_{2} \mathrm{Zn}(\mathbf{4 2}),\left[\left(\mathrm{HOMe}_{2} \mathrm{Si}\right)\right.$ $\left.\left(\mathrm{Me}_{3} \mathrm{Si}\right)_{2} \mathrm{C}\right]_{2} \mathrm{Zn}(43)$ and $\left.\left[\mathrm{F}_{3} \mathrm{CCO}_{2} \mathrm{Me}_{2} \mathrm{Si}\right)\left(\mathrm{Me}_{3} \mathrm{Si}\right)_{2} \mathrm{C}\right]_{2} \mathrm{Zn}(\mathbf{4 4})$ are shown in Scheme 7.

The structures of $\mathbf{3 9}^{87}, \mathbf{4 2}^{90}, \mathbf{4 3}^{90}$ and $\mathbf{4 4}^{89}$ in the solid state were determined by X-ray crystal structure determinations. The $\mathrm{Zn}-\mathrm{C}$ bond distances and angles in these compounds are comparable (Table 3). As a representative example the structure of $\mathbf{3 9}$ is shown in Figure 20.

Compounds 39, 42 and $\mathbf{4 4}$ exist as discrete monomeric molecules. The $\mathrm{Zn}-\mathrm{C}$ bond distances are close to the values of simple dialkylzinc compounds obtained from gasphase electron diffraction studies and are also close to the values predicted by DFT computational studies ${ }^{85}$. Because the zinc atoms in 39, $\mathbf{4 2}$ and $\mathbf{4 4}$ are located at special positions in the crystallographic unit cell (at $0.25,0.25,0.5$ in $\mathbf{3 9}$, and at $0,0,0$ in both $\mathbf{4 2}$ and 44) the $\mathrm{C}-\mathrm{Zn}-\mathrm{C}$ bond angles are by definition $180^{\circ}$ as a consequence of space-group symmetry. Compound $\mathbf{4 3}$ forms dimers in the solid state via hydrogen bridges between

TABLE 3. Structural features of the $\left[\mathrm{XSiMe}_{2}\left(\mathrm{Me}_{3} \mathrm{Si}\right)_{2} \mathrm{C}\right]_{2} \mathrm{Zn}$ compounds $\mathbf{3 9}, \mathbf{4 2 - 4 4}$

\begin{tabular}{lcccc}
\hline Bond distances $(\AA)$ & $\mathbf{3 9}$ & $\mathbf{4 2}$ & $\mathbf{4 3}$ & $\mathbf{4 4}$ \\
\hline $\mathrm{Zn}-\mathrm{C}(1)$ & $1.982(2)$ & $1.980(4)$ & $1.965(2)$ & $1.974(3)$ \\
$\mathrm{Zn}-\mathrm{C}(2)$ & $1.982(2)$ & $1.980(4)$ & $1.970(2)$ & $1.974(3)$ \\
\hline Bond angles $\left(^{\circ}\right)$ & & & & \\
\hline $\mathrm{C}(1)-\mathrm{Zn}-\mathrm{C}(2)$ & 180 & 180 & $175.9(1)$ & 180 \\
\hline
\end{tabular}

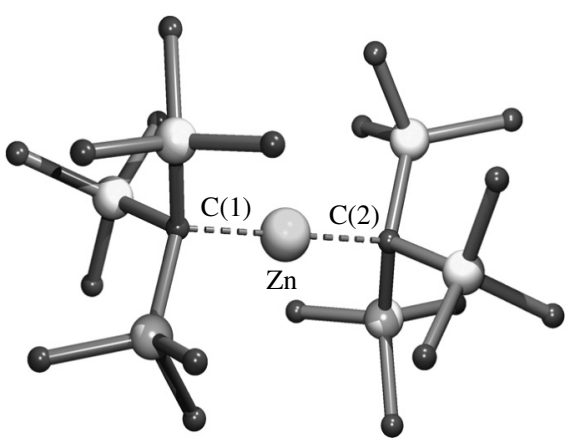

FIGURE 20. Molecular geometry of $\mathbf{3 9}$ in the solid state 
the two terminal $\mathrm{SiOH}$ groups and the two oxygen atoms of an adjacent molecule. The two halves of the dimer are symmetry related via an inversion centre. The two $\mathrm{OH}$ groups in each molecule are inequivalent, one oxygen atom, $\mathrm{O}(1)$, donating its hydrogen atom intramolecularly and accepting a hydrogen atom intermolecularly, while the other oxygen atom, $\mathrm{O}(2)$, shows the complementary behaviour (Figure 21).

The X-ray crystal structure determination of bis[2,2,4,4,6,6-hexamethyl-2,4,6-trisilacyclohexyl]zinc (45) shows that this compound exists as a monomer in the solid state ${ }^{91}$ (Figure 22). The observed $\mathrm{Zn}-\mathrm{C}$ bond distance of 1.937(2) $\AA$ is remarkably short. The zinc atom is located at a crystallographic inversion centre and consequently enforces a perfectly linear $\mathrm{C}-\mathrm{Zn}-\mathrm{C}$ arrangement. The $\mathrm{Zn}-\mathrm{C}(1)-\mathrm{Si}$ and $\mathrm{Si}-\mathrm{C}-\mathrm{Si}$ bond angles of 110 and $117^{\circ}$, respectively, indicate that a considerable planarization of $\mathrm{C}(1)$ has occurred. That such a planarization of the carbon atoms bound to zinc is most likely also present in the structure of $\mathbf{4 5}$ in solution was concluded from their exceptional low field shift of $13 \mathrm{ppm}$ and the small ${ }^{1} J\left({ }^{13} \mathrm{C}-{ }^{1} \mathrm{H}\right)$ and ${ }^{1} J\left({ }^{13} \mathrm{C}-{ }^{29} \mathrm{Si}\right)$ coupling constants observed in its ${ }^{13} \mathrm{C}$ NMR spectrum.

Dialkylzinc compound 46 contains two 2,4-di-tert-butyl-2,4-dienyl anions (Figure 23). In the solid state the two organic groups are $\eta^{1}$-bonded to zinc via $\mathrm{C}(1)$ with a $\mathrm{Zn}-\mathrm{C}$

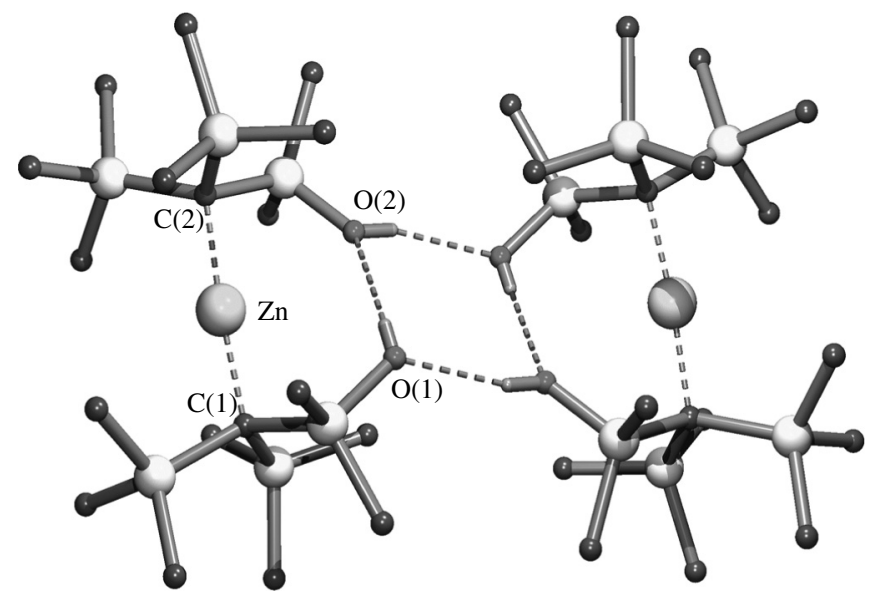

FIGURE 21. Molecular geometry of dimeric $\mathbf{4 3}$

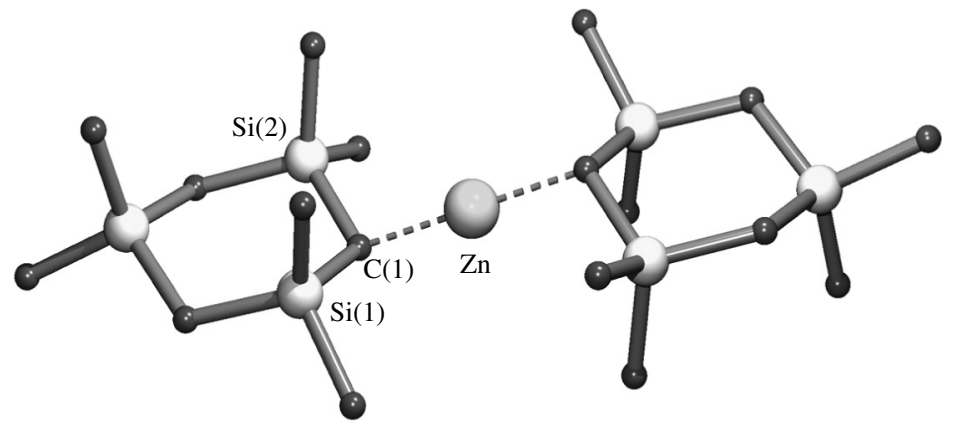

FIGURE 22. Structure in the solid state of $\mathbf{4 5}$ 


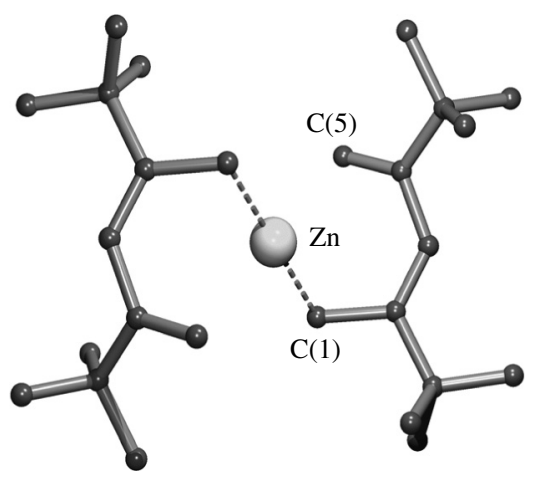

FIGURE 23. Molecular geometry of $\mathbf{4 6}$ in the solid state

distance of $1.969(8) \AA^{92}$. Also in this case the molecule is located on a crystallographic inversion centre and consequently the $\mathrm{C}-\mathrm{Zn}-\mathrm{C}$ bond angle is by definition $180^{\circ}$. The alternating long-short-long-short bond distances in the carbon backbone are indicative for a localized diene system. Both dienyl ligands are present in the $\mathrm{U}$ conformation and orientated in such a way that they bring $C(5)$ in relatively close proximity $(2.850 \AA)$ to the zinc atom (Figure 23). In solution, a ${ }^{1} \mathrm{H}$ NMR spectroscopic study of $\mathbf{4 6}$ shows a perfectly symmetric resonance pattern for the dienyl ligand, indicating equivalence of the two sides of the ligand. This pattern remains unchanged down to temperatures below $-100^{\circ} \mathrm{C}$, pointing to a process involving a 1,5-metal shift with a low activation barrier.

Reaction of cyclic lithiate (47) with $\mathrm{ZnCl}_{2}$ affords a unique 1-zinca-3,6-disilacycloheptane (48) (equation 17) ${ }^{93}$. Like its acyclic analogs 39-44 (vide supra), compound 48 is air-stable and no hydrolysis was observed after treatment with aqueous THF during a period of $5 \mathrm{~h}$ at $80^{\circ} \mathrm{C}$.

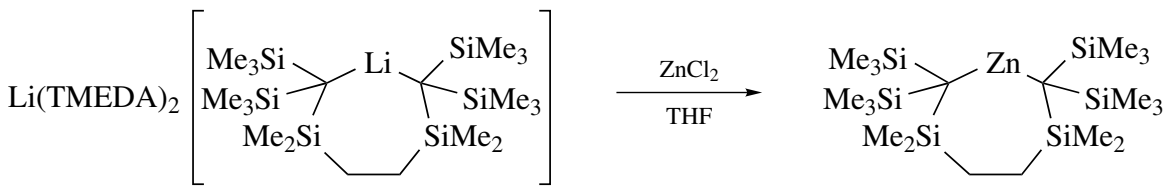

(48)

The cyclic nature of $\mathbf{4 8}$ was confirmed by an X-ray crystal structure determination (Figure 24). The observed $\mathrm{Zn}-\mathrm{C}$ bond distances of 1.963(7) and 1.962(7) $\AA$ are in the range expected for dialkylzinc compounds. The $\mathrm{C}(1)-\mathrm{Zn}-\mathrm{C}(2)$ bond angle of $169.7(3)^{\circ}$ slightly deviates from linear, but the other bond angles in the seven-membered ring are close to the ideal tetrahedral value, indicating minimal ring strain.

$\left(\mathrm{Me}_{3} \mathrm{Si}\right)_{3} \mathrm{CZnCH}\left(\mathrm{SiMe}_{3}\right)_{2}(49)$ and $\left(\mathrm{Me}_{3} \mathrm{Si}\right)_{3} \mathrm{CZnPh}(\mathbf{5 0})$ are the only examples of heteroleptic diorganozinc compounds the structures of which were determined by X-ray crystal structure determinations (Figure 25) ${ }^{59}$. These compounds have been prepared from the reaction of $\left(\mathrm{Me}_{3} \mathrm{Si}\right)_{3} \mathrm{CZnCl}$ with one equivalent of $\left(\mathrm{Me}_{3} \mathrm{Si}\right)_{2} \mathrm{CHLi}$ or $\mathrm{PhLi}$, respectively. It should be noted that $\mathbf{4 9}$ and $\mathbf{5 0}$ are not accessible via a redistribution reaction of the corresponding symmetric diorganozinc compounds, i.e. 49 from $\left[\left(\mathrm{Me}_{3} \mathrm{Si}\right)_{3} \mathrm{C}_{2} \mathrm{Zn}\right.$ and $\left[\left(\mathrm{Me}_{3} \mathrm{Si}\right)_{2} \mathrm{CH}\right]_{2} \mathrm{Zn}$, and $\mathbf{5 0}$ from $\left[\left(\mathrm{Me}_{3} \mathrm{Si}\right)_{3} \mathrm{C}\right]_{2} \mathrm{Zn}$ and $\mathrm{Ph}_{2} \mathrm{Zn}$, respectively, due to the inertness of $\left[\left(\mathrm{Me}_{3} \mathrm{Si}\right)_{3} \mathrm{C}\right]_{2} \mathrm{Zn}$ towards any reaction ${ }^{87}$. The $\mathrm{Zn}-\mathrm{C}$ bond distances in 49 differ only slightly, $\mathrm{Zn}-\mathrm{C}(1) \mathrm{1.971(3)}$ and $\mathrm{Zn}-\mathrm{C}(2) 1.946(4) \AA$, while the $\mathrm{C}(1)-\mathrm{Zn}-\mathrm{C}(2)$ 


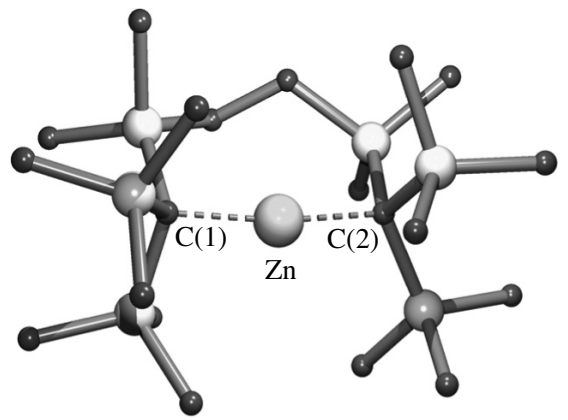

FIGURE 24. Solid state structure of $\mathbf{4 8}$

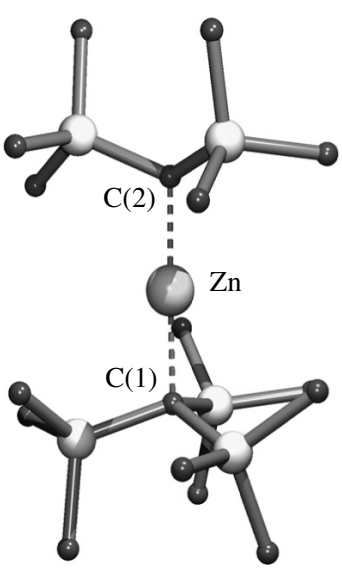

(49)

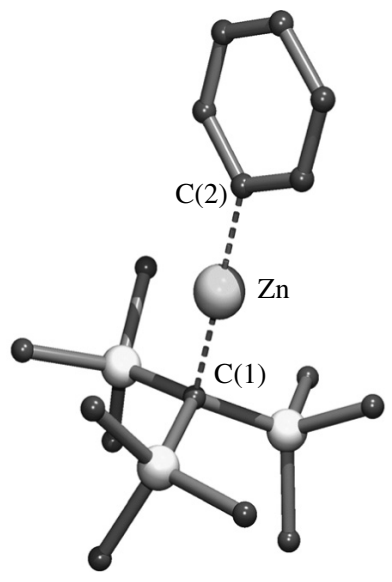

(50)

FIGURE 25. Molecular geometry of the heteroleptic diorganozinc compounds $\mathbf{4 9}$ and $\mathbf{5 0}$ in the solid state

bond angle is close to linear. In $\mathbf{5 0}$ the bond distance between the aryl carbon atom and zinc $[1.1917(10) \AA]$ is slightly shorter than the $\mathrm{Zn}-\mathrm{C}(1)$ (alkyl) distance [1.956(10) $\AA$ ], but this is to be expected because the two carbon atoms involved have different hybridization states. The $\mathrm{C}(1)-\mathrm{Zn}-\mathrm{C}(2)$ bond angle of $177.6(4)^{\circ}$ in $\mathbf{5 0}$ is very close to the ideal value of $180^{\circ}$ for a linear arrangement.

A rather exotic diorganozinc compound $\mathbf{5 2}$ is obtained from the reaction of geminal dilithium compound $\mathbf{5 1}$ with 3 equivalents of $\mathbf{Z n C l}_{2}$. The structure is shown schematically in equation $18^{94}$. The short $\mathrm{Zn}-\mathrm{C}$ bond distances of $1.908(3)$ and $1.911(3) \AA$ are as expected for $\mathrm{sp}^{2}$-hybridized carbon atoms bound to zinc. Also, the almost linear $\mathrm{C}-\mathrm{Zn}-\mathrm{C}$ bond angle of $178.6^{\circ}$ is in agreement with this type of compounds. At each of the terminal parts of the ligands a $\mathrm{Zn}-\mathrm{Cl}$ cation is bonded to two nitrogen atoms of each of the $\mathrm{PN}$ functionalities. The $\mathrm{N}-\mathrm{Zn}-\mathrm{Cl}$ and $\mathrm{N}-\mathrm{Zn}-\mathrm{N}$ bond angles around these zinc atoms are $120^{\circ}$ within experimental error, indicating a perfectly trigonal planar coordination geometry for these zinc atoms. The fact that in the six-membered $\mathrm{Zn}-\mathrm{N}-\mathrm{P}-\mathrm{C}-\mathrm{P}-\mathrm{N}$ 
ring the $\mathrm{Zn}-\mathrm{N}$ bond distances as well as the $\mathrm{C}-\mathrm{P}$ distances and the $\mathrm{P}-\mathrm{N}$ distances are almost equal, indicates a considerable conjugation in this ring.

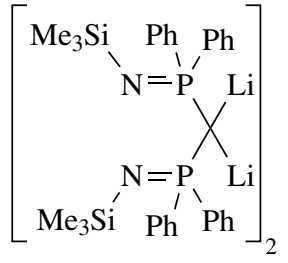

(51)<smiles>C[SiH3]N1[14CH](Cl)N([SiH3])[Te](c2ccccc2)(c2ccccc2)P(c2ccccc2)(c2ccccc2)=P1(c1ccccc1)c1ccccc1</smiles>

(52)

The X-ray crystal structure determination of diphenylzinc (53) reveals a unique structure ${ }^{9}$. It was known already that in apolar solvents like benzene and hexane $\mathrm{Ph}_{2} \mathrm{Zn}$ exists as discrete monomeric species ${ }^{9,95}$. Therefore, it was to be expected that also in the solid $\mathrm{Ph}_{2} \mathrm{Zn}$ would have a linear monomeric structure like dialkylzincs and other diarylzinc compounds. It appeared, however, that in the solid state $\mathrm{Ph}_{2} \mathrm{Zn}$ exists as a dimer comprising two PhZn units linked by two $\mu$-bridging phenyl groups (Figure 26). Such a structural motif, i.e. electron-deficient multi-centre bonding of alkyl or aryl groups is quite common for other metals like $\mathrm{Li}, \mathrm{Mg}, \mathrm{Cu}, \mathrm{Ag}, \mathrm{Au}, \mathrm{Al}$, etc. but unprecedented, at the time of its discovery, for dialkyl or diarylzinc compounds. The zinc atoms in $\mathbf{5 3}$ are threecoordinate as a result of bonding to one terminal and two bridging phenyl groups. Although the individual bond angles around zinc $[\mathrm{C}(1)-\mathrm{Zn}(1)-\mathrm{C}(2) 141.5(2), \mathrm{C}(1)-\mathrm{Zn}(1)-\mathrm{C}(4)$ 115.1(2), $\left.C(2)-Z n(1)-C(4) 102.6(2)^{\circ}\right]$ deviate considerably from the ideal value of $120^{\circ}$, the sum of these bond angles $\left(359.4^{\circ}\right)$ is close to $360^{\circ}$, pointing to a trigonalplanar coordination geometry. The $\mathrm{Zn}(1)-\mathrm{C}(1)$ bond distance of 1.951(5) $\AA$ between zinc and the terminal phenyl group is in the expected range. The asymmetric bonding of the bridging aryl groups to the two zinc atoms, with one relatively short $[\mathrm{Zn}(1)-\mathrm{C}(2)$ 2.016(3) $\AA]$ and one relatively long $[\mathrm{Zn}(1)-\mathrm{C}(4) 2.364(5) \AA]$ bond, is remarkable. This dimeric structure may be regarded as consisting of two associated monomeric molecules, i.e. $[\mathrm{C}(1) \mathrm{Zn}(1)(\mathrm{C} 2)]$ and $[\mathrm{C}(3) \mathrm{Zn}(2) \mathrm{C}(4)]$. The two monomers are linked by interactions of the aryl $\pi$-system in one of the monomeric units via its ipso-carbon atom with the zinc atom of the other monomeric unit, i.e. $\mathrm{C}(2)$ with $\mathrm{Zn}(2)$ and $\mathrm{C}(4)$ with $\mathrm{Zn}(1)$.

The structures of dimesitylzinc $(\mathbf{5 4})^{96}$, bis[2,4,6-tris(trifluoromethyl)phenyl]zinc (55) ${ }^{97}$ and bis(pentafluorophenyl)zinc $(\mathbf{5 6})^{98}$ have comparable structural features. They are discrete monomeric molecules with a linear $\mathrm{C}-\mathrm{Zn}-\mathrm{C}$ arrangement at zinc (Figure 27). The

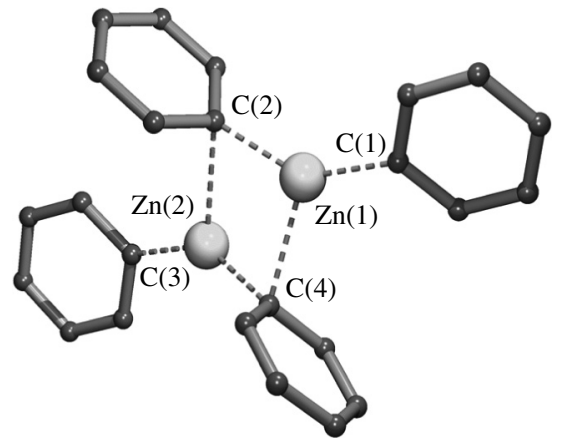

FIGURE 26. Dimeric structure of $\mathrm{Ph}_{2} \mathrm{Zn}(\mathbf{5 3})$ in the solid state 


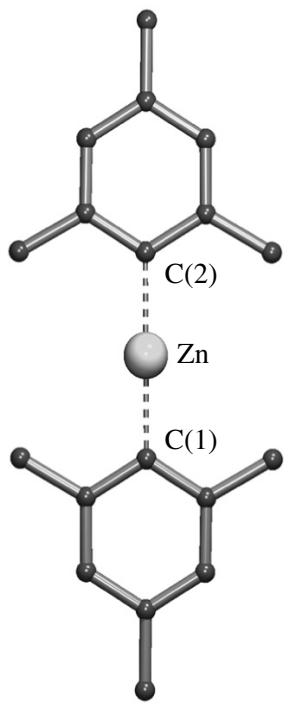

(54)

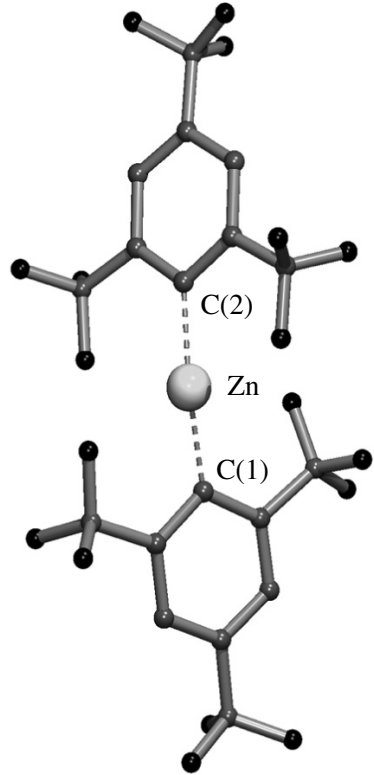

(55)

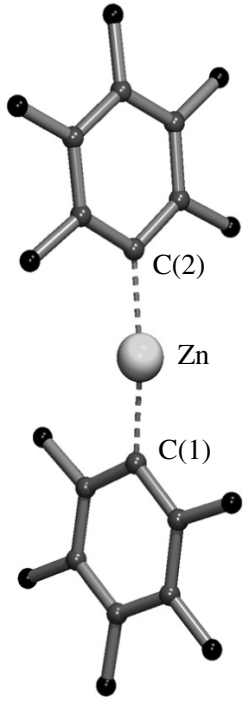

(56)

FIGURE 27. Structures of the arylzinc compounds $\mathbf{5 4 , 5 5}$ and $\mathbf{5 6}$ in the solid state

observed $\mathrm{Zn}-\mathrm{C}$ bond distances [1.9422(19) $\AA$ in 54, 1.949(3) and 1.950(3) $\AA$ in $\mathbf{5 5}$ and $1.930(4)$ and 1.926(4) $\AA$ in 56] are as expected for $\mathrm{sp}^{2}$-carbon atoms bound to zinc. In 54, the zinc atom is located on a crystallographic inversion centre and therefore the $\mathrm{C}-\mathrm{Zn}-\mathrm{C}$ bond angle is strictly $180^{\circ}$ while the two aryl groups are coplanar with respect to each other. In 55 and $\mathbf{5 6}$ such a symmetry is not present, but the observed $\mathrm{C}-\mathrm{Zn}-\mathrm{C}$ bond angles $\left[170.0(1)^{\circ}\right.$ in $\mathbf{5 5}$ and $172.6(2)^{\circ}$ in 56] are close to linear. In $\mathbf{5 5}$ the aryl rings are twisted by 67.1 and in $\mathbf{5 6}$ by $76.7^{\circ}$. In the former compound this twist has been explained by minimization of the steric congestion and electrostatic repulsion of the ortho- $\mathrm{CF}_{3}$ groups ${ }^{97}$. In the latter compound the twist seems to be dictated by intermolecular stacking interactions between adjacent molecules ${ }^{98}$. In $\mathbf{5 5}$, the zinc atom has additional interactions with one fluorine atom of each of the ortho- $\mathrm{CF}_{3}$ groups (average $\mathrm{Zn}-\mathrm{F}$ distance $2.60 \AA$ ) which are shorter than the sum of the Van der Waals radii of the constituent atoms.

\section{B. Diorganozinc Compounds Containing Multi-hapto Bonded Groups}

With the discovery of ferrocene by two independent groups at the end of 1951 ${ }^{99-101}$ and its structural elucidation and the subsequent development of metal-cyclopentadienyl chemistry, a new era started in organometallic chemistry. It has been well-established that dicyclopentadienyl compounds of the transition metals have a ferrocene-like structure. On the other hand, cyclopentadienides of the main-group metals tend to form polymers with bridging cyclopentadienyl groups, although exceptions are known ${ }^{102,103}$. Zinc occupies a borderline position between the transition metals and the main-group metals and the question arises whether the structure of dicyclopentadienylzinc is intermediate between both categories of cyclopentadienyl metal compounds. 
Dicyclopentadienylzinc, $\mathrm{Cp}_{2} \mathrm{Zn}$, was first prepared by Fischer and coworkers in 1969 and, based on the similarities of the IR spectra between $\mathrm{Cp}_{2} \mathrm{Zn}$ and $\mathrm{Cp}_{2} \mathrm{Mg}$, a ferrocenelike sandwich structure with predominantly ionic cyclopentadienyl-metal interactions was proposed ${ }^{104}$. A similar structure, but with centrally $\sigma$-bonded cyclopentadienyl rings, was also suggested because in the ${ }^{1} \mathrm{H}$ NMR spectrum of $\mathrm{Cp}_{2} \mathrm{Zn}$ all protons are equivalent ${ }^{105}$. Other authors formulated dicyclopentadienylzinc as $\left(\eta^{1}-\mathrm{Cp}\right)_{2} \mathrm{Zn}$, probably by analogy with the monohapto structure, suggested ${ }^{105}$ and later established by X-ray crystallography for $\mathrm{Cp}_{2} \mathrm{Hg}^{106}$.

The first cyclopentadienylzinc compound that was structurally characterized by an $\mathrm{X}$-ray crystallographic study is cyclopentadienyl(methyl)zinc, $\mathrm{Cp}(\mathrm{Me}) \mathrm{Zn}(\mathbf{5 7})^{107}$. The structure of $\mathbf{5 7}$ in the solid state consists of puckered chains of methylzinc fragments, linked by bridging cyclopentadienyl groups (Figure 28).

Due to disorder in the cyclopentadienyl groups the exact bonding of the cyclopentadienyl group to zinc remained uncertain, but it has been suggested that the cyclopentadienyl group is $\eta^{3}$-bonded to one zinc atom and $\eta^{2}$-bonded to the other one. In solution, however, cryoscopic measurements in benzene pointed to the existence of discrete monomeric species. IR and ${ }^{1} \mathrm{H}$ NMR studies of solutions of $\mathbf{5 7}$ are consistent with $\eta^{5}$-binding of the cyclopentadienyl group to zinc in a symmetric $C_{5 \mathrm{v}}$ structure.

Sixteen years after its first synthesis had been reported ${ }^{104}$, dicyclopentadienylzinc, $\mathrm{Cp}_{2} \mathrm{Zn}(\mathbf{5 8})$, was structurally characterized in the solid state by an X-ray crystal structure determination $^{108}$. Like in $\mathbf{5 6}$, the structure of $\mathbf{5 7}$ in the solid state consists of infinite chains of zinc atoms with bridging cyclopentadienyl groups, while a terminal $\mathrm{Cp}$ group is bonded to each zinc atom. The chain contains two crystallographically independent zinc atoms, $\mathrm{Zn}(1)$ and $\mathrm{Zn}(2)$. The $\mathrm{Cp}$ groups bridging zinc atoms of the same type are located at inversion centres, and these $\mathrm{Cp}$ groups therefore are disordered (Figure 29). That the terminal $\mathrm{Cp}$ groups are not purely $\eta^{1}$-bonded is clearly indicated by the fact that

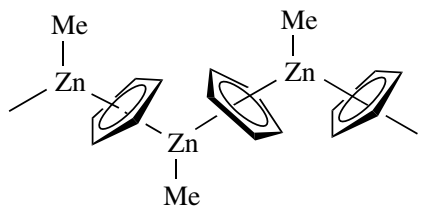

FIGURE 28. Schematic structure of $\mathbf{5 7}$ in the solid state

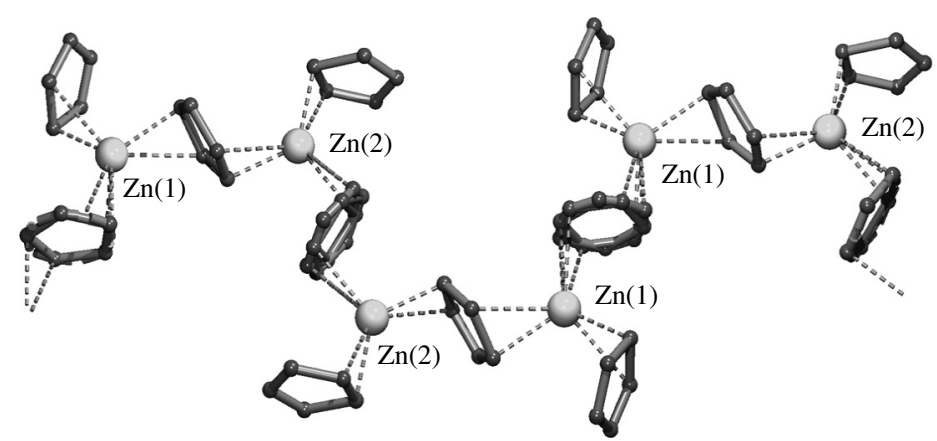

FIGURE 29. Part of the polymeric chain of $\mathbf{5 8}$ in the solid state. Note the disordered cyclopentadienyl groups bridging between zinc atoms of the same type 
in addition to one short $\mathrm{Zn}-\mathrm{C}$ interaction [Zn-C 2.04(6) $\AA$, suggesting $\sigma$-bonding] a second, relatively short interaction $[\mathrm{Zn}-\mathrm{C} 2.48(6) \AA]$ is present. The Cp group bridging two different types of zinc atoms is asymmetrically bonded with two carbon atoms to one zinc atom [ $\mathrm{Zn}-\mathrm{C} 2.04(3)$ and 2.41(3) $\AA]$ and two other carbon atoms to the other zinc atom [Zn-C 2.19(3) and 2.46(2) $\AA$ ]. Due to disorder in the Cp groups bridging the same type of zinc atoms, their $\mathrm{Zn}-\mathrm{C}$ bond distances are less certain, but the bonding mode, i.e. two carbon-to-zinc interactions to each zinc atom, is similar.

Structural investigations of monomeric $\mathrm{Cp}_{2} \mathrm{Zn}$ in the gas phase by gas-phase electron diffraction studies indicate a structure in which one of the $\mathrm{Cp}$ groups is $\eta^{5}$-bonded to zinc while the other $\mathrm{Cp}$ group is mainly $\eta^{1}$-bonded ${ }^{109}$. These data were corroborated by DFT calculations. The $\mathrm{Zn}-\mathrm{C}$ bond distance $(2.10 \AA)$ to the $\eta^{1}$-bonded $\mathrm{Cp}$ group is considerably longer than expected for a pure $\sigma-\mathrm{Zn}-\mathrm{C}$ bond and the angle $\left(95^{\circ}\right.$ ) between the centre of $\eta^{5}$-bonded $\mathrm{Cp}$ group, $\mathrm{Zn}$ and $\mathrm{C}(1)$, is significantly smaller than expected for a $\mathrm{sp}^{3}$ carbon atom. This structure is best described as a slip sandwich.

Bis(pentamethylcyclopentadienyl)zinc $\mathrm{Cp}^{*}{ }_{2} \mathrm{Zn}(\mathbf{5 9})^{110}$ is a crystalline solid, readily soluble in apolar solvents. Its ${ }^{1} \mathrm{H}$ and ${ }^{13} \mathrm{C}$ NMR spectra (only one resonance is observed in the ${ }^{1} \mathrm{H}$ NMR spectrum and two resonances in the ${ }^{13} \mathrm{C}$ NMR spectrum at temperatures down to $-100{ }^{\circ} \mathrm{C}$ ) suggest a highly symmetric structure, most likely similar to that of ferrocene. Although single crystals of $\mathbf{5 9}$ suitable for an X-ray structure determination were easily obtained, the structural refinement ${ }^{111}$ resulted in a crystallographic 'disaster' (Figure 30). In the solid state $\mathbf{5 9}$ exists as discrete monomeric molecules; however, due to the fact that the molecule is located at a crystallographic inversion centre, the zinc atom is disordered over two positions between the cyclopentadienyl rings. Moreover, it appeared that rotational disorder is present in the cyclopentadienyl rings. The data are consistent with a model in which one of the $\mathrm{Cp}^{*}$ groups is $\eta^{5}$-bonded and the other one $\eta^{1}$-bonded to zinc, a similar slip sandwich structure as was found in the gas phase for $\mathrm{Cp}_{2} \mathrm{Zn}$. It is obvious that no reliable data with respect to individual bond distances and angles could be obtained. Gas-phase electron diffraction studies of $\mathbf{5 9}$ pointed to a slip sandwich structure also in the gas phase ${ }^{110}$.

To overcome the problem of crystallographic disorder during the structural characterization by $\mathrm{X}$-ray crystallography, various substituted cyclopentadienyl compounds, i.e. $\left[t-\mathrm{Bu}(\mathrm{Me})_{4} \mathrm{C}_{5}\right]_{2} \mathrm{Zn}(\mathbf{6 0})^{112},\left[\mathrm{Ph}(\mathrm{Me})_{4} \mathrm{C}_{5}\right]_{2} \mathrm{Zn}(\mathbf{6 1})^{111},\left[(i-\mathrm{Pr})_{4} \mathrm{C}_{5} \mathrm{H}\right]_{2} \mathrm{Zn}(\mathbf{6 2})^{113}$ and $\left[\left(\mathrm{Me}_{3} \mathrm{Si}\right)\right.$

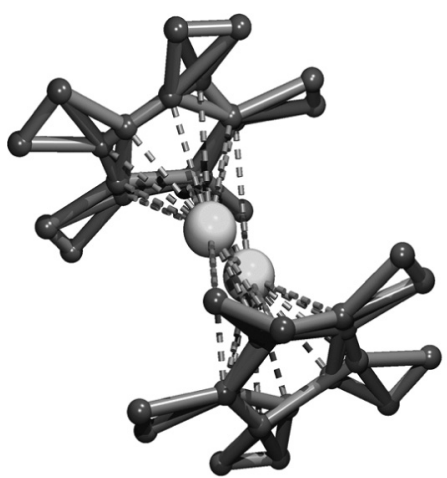

(59)

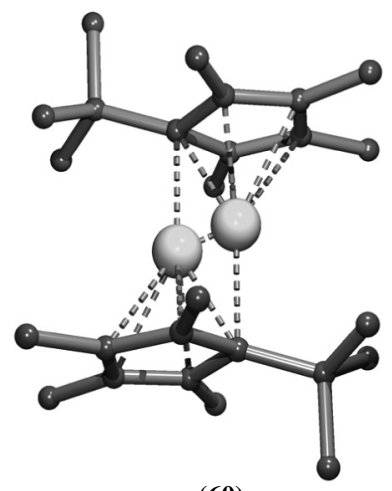

(60)

FIGURE 30. Left, the crystallographic 'disaster' of 59. Right, disordered structure of $\mathbf{6 0}$ in the solid state 


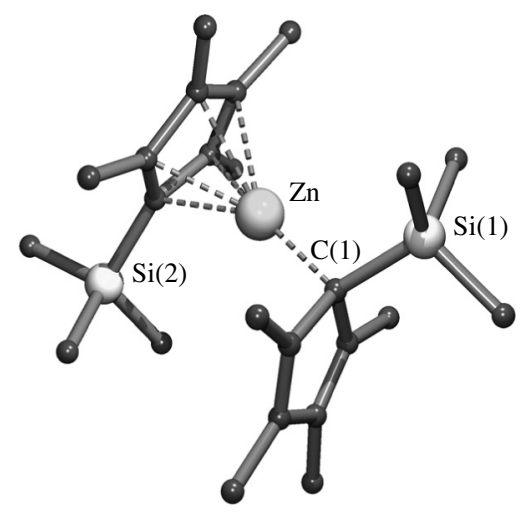

FIGURE 31. Molecular geometry of $\mathbf{6 3}$ in the solid state

$\left.\mathrm{Me}_{4} \mathrm{C}_{5}\right]_{2} \mathrm{Zn}(\mathbf{6 3})^{112}$, were prepared and structurally characterized. Unfortunately, in the solid state structures of compounds 60-62, which are all discrete monomers, the molecules are, as in 59, located at a crystallographic inversion centre. As a representative example the disordered structure of $\mathbf{6 0}$ is shown (Figure 30). The structural features of 60-62 are closely related, i.e. they have a slip sandwich structure in which one of the substituted cyclopentadienyl groups is $\eta^{5}$-bonded to zinc and the other one $\eta^{1}$-bonded to zinc. In the solid state structure of 63, the disorder as found for 59-62 is not present and therefore this structure could be analysed more in detail (Figure 31$)^{112}$. Although there is a slight difference in $\mathrm{Zn}-\mathrm{C}$ bond distances [2.154(3) to 2.323(3) $\AA$ ], indicating a ring slippage of $0.18 \AA$, such a situation can be regarded as quite normal. Most notable is the way in which the $\eta^{1}$-bonded cyclopentadienyl group (the same carbon atom to which $\mathrm{Si}$ is bonded) in 63 is bonded to zinc. The bond angles around C(1) are close to the ideal values of $109.5^{\circ}$ and the $\mathrm{Zn}-\mathrm{C}(1)$ bond distance of 1.953(3) $\AA$ is as expected for a $\mathrm{Zn} \sigma$-bonded to a sp $\mathrm{sp}^{3}$ carbon atom. The structure of $\mathbf{6 3}$ is not a slip sandwich, as is indicated by the angle of $18^{\circ}$ between the two cyclopentadienyl rings, which are perfectly co-planar in 59-62.

Reaction of $\mathrm{Cp}^{*}{ }_{2} \mathrm{Zn}$ with $\mathrm{Et}_{2} \mathrm{Zn}$ afforded, instead of the anticipated $\mathrm{Cp} * \mathrm{ZnEt}$, a mixture of $\mathrm{Cp} * \mathrm{ZnEt}$ and a product, formulated as $\mathrm{Cp}^{*}{ }_{2} \mathrm{Zn}_{2}(\mathbf{6 4})^{114}$. An X-ray crystallographic structure determination of $\mathbf{6 4}$ revealed the unique structural features of this compound (Figure 32). The solid state structure of $\mathbf{6 4}$ comprises two metal-metal bonded $\mathrm{Cp} * \mathrm{Zn}$ moieties in each of which the pentamethylcyclopentadienyl group is $\eta^{5}$-bonded to zinc with almost equal $\mathrm{Zn}-\mathrm{C}$ distances $(2.27-2.30 \AA)$. The linearity of the molecule is shown in the bond angle of $177.4^{\circ}$ between $\mathrm{Zn}(1)$, the centre of the cyclopentadienyl group, and $\mathrm{Zn}(2)$. The most striking feature of $\mathbf{6 4}$ is the short $[2.305(3) \AA] \mathrm{Zn}(1)-\mathrm{Zn}(2)$ distance, which is substantially shorter than twice the Pauling single-bond metallic radius $(2.50 \AA)$ and therefore indicative for a bonding $\mathrm{Zn}-\mathrm{Zn}$ interaction. Compound 64 may be regarded as containing a hypothetical $\mathrm{Zn}_{2}{ }^{2+}$ dication, in which formally the oxidation state of zinc is +1 . Such a structural motif, i.e. $\mathrm{M}_{2}{ }^{2+}$, is common for mercury, rare for cadmium but unprecedented for zinc.

${ }^{!} \mathrm{H}$ and ${ }^{13} \mathrm{C}$ NMR spectroscopic studies of $\mathbf{6 4}$ showed that the structure present in the solid state is retained in solution. That the reactivity of $\mathbf{6 4}$ is different compared to that of 'normal' organozinc compounds became evident from a hydrolysis reaction of $\mathbf{6 4}$ with a carboxylic acid affording the corresponding zinc salt of the carboxylic acid and metallic zinc in a 1:1 ratio and pentamethylcyclopentadiene. This product formation suggests the 


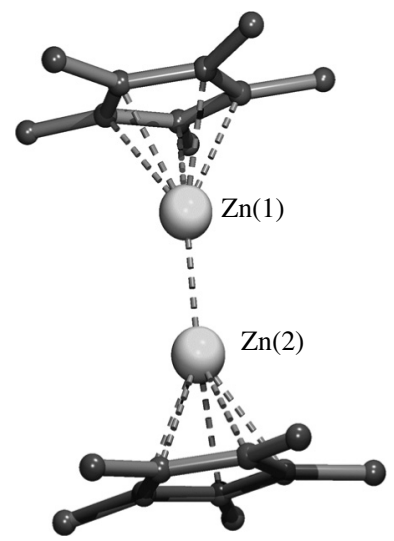

FIGURE 32. Molecular geometry of $\mathbf{6 4}$ in the solid state

occurrence of a valence disproportionation of the initially present $\mathrm{Zn}^{1+}$ into $\mathrm{Zn}^{2+}$ and metallic zinc during or after the hydrolysis of the cyclopentadienyl monoanionic groups.

\section{Diorganozinc Compounds Containing Intramolecularly Coordinating Substituents}

In the early days of organometallic chemistry it was thought that in many cases the metal-carbon bond would be intrinsically unstable, especially in transition-metalorganic compounds. The two most important pathways by which decomposition of such organometallic compounds may occur are $\beta$-hydrogen elimination and thermally induced homolytic cleavage of the metal-carbon bond. To suppress such decomposition pathways several approaches have been put forward, e.g. the use of organic groups lacking $\beta$-hydrogen atoms, the introduction of bulky (often trimethylsilyl containing) substituents and the use of organic groups containing a functionalized substituent capable of coordinating to the metal. The isolation and structural characterization of $\left(\mathrm{Me}_{3} \mathrm{SiCH}_{2}\right)_{4} \mathrm{Cu}_{4}{ }^{115}$ and $\left(2-\mathrm{Me}_{2} \mathrm{NCH}_{2} \mathrm{C}_{6} \mathrm{H}_{4}\right)_{4} \mathrm{Cu}_{4}{ }^{116}$ are clear examples of these two approaches and represent the first examples of organocopper compounds sufficiently stable to allow their structural characterization by X-ray crystallography. In $\left(2-\mathrm{Me}_{2} \mathrm{NCH}_{2} \mathrm{C}_{6} \mathrm{H}_{4}\right)_{4} \mathrm{Cu}_{4}$ the monoanionic, potentially bidentate $2-\mathrm{Me}_{2} \mathrm{NCH}_{2} \mathrm{C}_{6} \mathrm{H}_{4}$ ligand stabilizes the organocopper compound via intramolecular coordination of the nitrogen to copper. In particular, this ligand was used in the early days to stabilize certain organometallic compounds. Nowadays, about 275 organometallic compounds containing this particular ligand, covering almost the whole periodic system of the elements, have been structurally characterized by X-ray crystallography ${ }^{5}$. When other ligand skeletons and also other heteroatom-functionalized substituents capable of intramolecular coordination are included, several thousands of organometallic derivatives are known ${ }^{5}$.

In this respect it is rather surprising that only a few diorganozinc compounds have been reported in which intramolecular coordination of a heteroatom-containing substituent is present. Although the synthesis of $\left(2-\mathrm{Me}_{2} \mathrm{NCH}_{2} \mathrm{C}_{6} \mathrm{H}_{4}\right)_{2} \mathrm{Zn}(\mathbf{6 5})$ was reported already in $1984^{117}$ and it was suggested that, based on the observed ${ }^{1} \mathrm{H}$ NMR spectra, both nitrogen substituents are involved in nitrogen-zinc coordination, its structure in the solid state has not been established by X-ray crystallography. 
A series of dialkylzinc compounds, functionalized with a heteroatom-containing substituent (Scheme 8), has been prepared and was structurally characterized by X-ray crystallographic studies $\left(\mathbf{6 6}^{118}\right.$ and $\left.\mathbf{6 9}^{119}\right)$ or gas-phase electron diffraction $\left(66,67^{118}, \mathbf{6 8}^{120}\right.$ and $\mathbf{7 0}^{120}$ ). The relevant structural data are summarized in Table 4 and, as a representative example, the molecular geometry of $\mathbf{6 6}$ is shown in Figure 33.

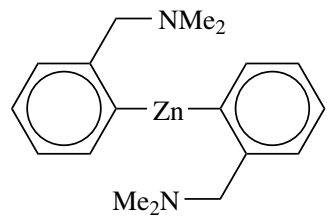

(65)

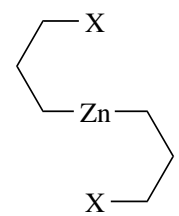

(66) $\mathrm{X}=\mathrm{NMe}_{2}$

(67) $\mathrm{X}=\mathrm{SMe}$

(68) $\mathrm{X}=\mathrm{OMe}$

(69) $\mathrm{X}=\mathrm{N}$

(70) $\mathrm{X}=\mathrm{CH}_{2} \mathrm{OMe}$

SCHEME 8

All compounds have comparable structural features, the hydrocarbon chains being coiled back to allow the donor atom to coordinate to zinc. The $\mathrm{Zn}-\mathrm{C}$ bond distances

TABLE 4. Structural data of compounds $\mathbf{6 6 - 7 0}$

\begin{tabular}{lcrcccc}
\hline & $\begin{array}{c}\mathrm{X}=\mathrm{N}\left(\mathrm{CH}_{2}\right)_{5} \\
\mathrm{X} \text {-ray }{ }^{a}\end{array}$ & $\begin{array}{c}\mathrm{X}=\mathrm{NMe}_{2} \\
\mathrm{X} \text {-ray }\end{array}$ & $\begin{array}{c}\mathrm{X}=\mathrm{NMe}_{2} \\
\mathrm{GED}^{b}\end{array}$ & $\begin{array}{c}\mathrm{X}=\mathrm{SMe} \\
\mathrm{GED}^{b}\end{array}$ & $\begin{array}{c}\mathrm{X}=\mathrm{OMe} \\
\mathrm{GED}^{b}\end{array}$ & $\begin{array}{c}\mathrm{X}=\mathrm{CH}_{2} \mathrm{OMe} \\
\mathrm{GED}^{b}\end{array}$ \\
\hline \multicolumn{7}{c}{ Bond distances (A) } \\
$\mathrm{Zn}-\mathrm{C}(1)$ & $1.992(3)$ & $1.984(5)$ & $1.991(6)$ & $1.966(6)$ & $1.974(4)$ & $1.984(6)$ \\
$\mathrm{Zn}-\mathrm{C}(2)$ & $1.992(3)$ & $1.984(5)$ & $1.991(6)$ & $1.966(6)$ & $1.974(4)$ & $1.984(6)$ \\
$\mathrm{Zn}-\mathrm{X}(1)$ & $2.404(2)$ & $2.307(4)$ & $2.392(15)$ & $2.732(12)$ & $2.37(3)$ & $2.38(5)$ \\
$\mathrm{Zn}-\mathrm{X}(2)$ & $2.404(2)$ & $2.307(4)$ & $2.392(15)$ & $2.732(12)$ & $2.37(3)$ & $2.38(5)$ \\
\hline \multicolumn{7}{c}{ Bond angles (deg) } \\
\hline $\mathrm{C}(1)-\mathrm{Zn}-\mathrm{C}(2)$ & $155.5(2)$ & $156.4(2)$ & $152(8)$ & $163(15)$ & $175(20)$ & $158(13)$ \\
$\mathrm{C}(1)-\mathrm{Zn}-\mathrm{X}(1)$ & $84.75(11)$ & $85.6(1)$ & $82(2)$ & $85(2)$ & $77(3)$ & $102(3)$ \\
$\mathrm{C}(1)-\mathrm{Zn}-\mathrm{X}(2)$ & $110.4(11)$ & $108.2(1)$ & $113(4)$ & $96(2)$ & $106(3)$ & $93(7)$ \\
$\mathrm{C}(2)-\mathrm{Zn}-\mathrm{X}(1)$ & $110.4(11)$ & $108.2(1)$ & $113(4)$ & $96(2)$ & $106(3)$ & $93(7)$ \\
$\mathrm{C}(2)-\mathrm{Zn}-\mathrm{X}(2)$ & $84.75(11)$ & $85.6(1)$ & $82(2)$ & $85(2)$ & $77(3)$ & $102(3)$ \\
$\mathrm{X}(1)-\mathrm{Zn}-\mathrm{X}(2)$ & $107.47(12)$ & $109.7(1)$ & $117(4)$ & $173(12)$ & $111(20)$ & $92(10)$ \\
\hline
\end{tabular}

${ }^{a}$ Data obtained from single-crystal X-ray diffraction.

${ }^{b}$ Data obtained from gas-phase electron diffraction.

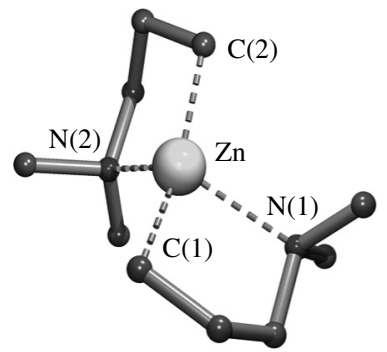

FIGURE 33. Molecular geometry of $\mathbf{6 6}$ in the solid state 
are as expected, but the coordination bonds of the heteroatoms to zinc are extremely long. A considerable distortion of the tetrahedral coordination geometry at zinc appears from the various bond angles around zinc. The $\mathrm{C}(1)-\mathrm{Zn}-\mathrm{C}(2)$ bond angles are all considerably larger $\left(147.1^{\circ}\right.$ in 69 to almost $180^{\circ}$ in 67$)$ than the ideal tetrahedral value of $107^{\circ}$. The $\mathrm{C}-\mathrm{Zn}-\mathrm{X}$ bond angles in the chelate rings of 67-69 are exceptionally small (Table 4), but this is most likely a consequence of the bite angle of the bidentate ligand in combination with the long $\mathrm{Zn}-\mathrm{X}$ bond length. It should be noted that in $\mathbf{7 0}$ this bond angle has a more normal value of $102^{\circ}$, but in this compound more flexible six-membered chelate rings are present. Especially in $\mathbf{6 8}$ all bond angles are rather extreme, and point rather to a distorted square planar (with the carbon atoms in trans-position) than a tetrahedral coordination geometry at zinc. Also, the diphenylphosphino analog $\left[\mathrm{Ph}_{2} \mathrm{P}\left(\mathrm{CH}_{2}\right)_{3}\right]_{2} \mathrm{Zn}$ (71) has been prepared and structurally characterized by X-ray crystallography ${ }^{121}$. Its structural features are closely related to those of 66-70.

Reaction of $\mathrm{MeN}\left(\mathrm{CH}_{2} \mathrm{CH}_{2} \mathrm{CH}_{2} \mathrm{Li}\right)_{2}$ with $\mathrm{ZnCl}_{2}$ afforded a macrocyclic product (67) containing two zinc atoms, which was structurally characterized by X-ray crystallography (Figure 34$)^{119}$. Each of the propyl groups of one ligand are bonded to a different zinc atom, while the nitrogen atoms are intramolecularly coordinated to the zinc atoms rendering them three-coordinate. The two halves of the macrocycle are symmetry related via an inversion centre. The $\mathrm{Zn}-\mathrm{C}$ bond distances [ $\mathrm{Zn}-\mathrm{C}(1)$ 1.979(3), $\mathrm{Zn}-\mathrm{C}(2)$ 1.983(3) $\AA$ ] are in the range as expected for dialkylzinc compounds but the $\mathrm{Zn}-\mathrm{N}$ coordination bond $[2.216(2) \AA]$ is rather long. Consequently, the $\mathrm{N}-\mathrm{Zn}-\mathrm{C}(1)$ bond angle in the chelate ring is acute $\left(87.38^{\circ}\right)$. The fact that the sum of the bond angles around zinc is close to $360^{\circ}$ implies that the $\mathrm{C}(1), \mathrm{C}(2), \mathrm{Zn}$ and $\mathrm{N}$ atoms essentially lie in the same plane. This together with the large $\mathrm{C}(1)-\mathrm{Zn}-\mathrm{C}(2)$ bond angle $\left[156.38(13)^{\circ}\right]$ suggest that the coordination geometry at zinc is T-shaped rather than trigonal planar.

Reaction of two equivalents of 2-[(dimethylamino)methyl]ferrocenyllithium with $\mathrm{ZnCl}_{2}$ affords the corresponding diorganozinc compound (68) in which two 2-[(dimethylamino) methyl]ferrocenyl ligands are $C, N$-chelate bonded to zinc ${ }^{122}$. Due to the chirality of the bidentate ligands 68 exists in two diastereoisomeric forms. Indeed, in solution a meso one and an $(S, S) /(R, R)$ enantiomeric pair in a $1: 4$ ratio were observed by ${ }^{1} \mathrm{H}$ and ${ }^{13} \mathrm{C}$ NMR spectroscopy. However, it is only the $(S, S) /(R, R)$ enantiomeric pair that preferentially crystallizes from solution. An X-ray crystallographic study of such crystals afforded the structure of $(R, R) /(S, S)-\mathbf{6 8}$ in the solid state (Figure 35$)$.

The $\mathrm{Zn}-\mathrm{C}$ bond lengths $[\mathrm{Zn}-\mathrm{C}(1) 1.948(2), \mathrm{Zn}-\mathrm{C}(2) 1.945(2) \AA]$ are in the range expected for $\mathrm{sp}^{2}$-hybridized carbon atoms bound to zinc. Also in this case the $\mathrm{Zn}-\mathrm{N}$ coordinate bonds [Zn-N(1) 2.3091(16), $\mathrm{Zn}-\mathrm{N}(2) 2.3622(16) \AA]$ are rather long. The zinc atom has an extremely distorted tetrahedral coordination geometry, which is expressed by the large $\mathrm{C}(1)-\mathrm{Zn}-\mathrm{C}(2)$ and $\mathrm{N}(1)-\mathrm{Zn}-\mathrm{N}(2)$ bond angles of $155.54(8)^{\circ}$ and $115.25(6)^{\circ}$, respectively. The bite angles $\left[\mathrm{C}(1)-\mathrm{Zn}-\mathrm{N}(1) 82.02(7)^{\circ}\right.$ and $\left.\mathrm{C}(2)-\mathrm{Zn}-\mathrm{C}(2) 83.06(8)^{\circ}\right]$

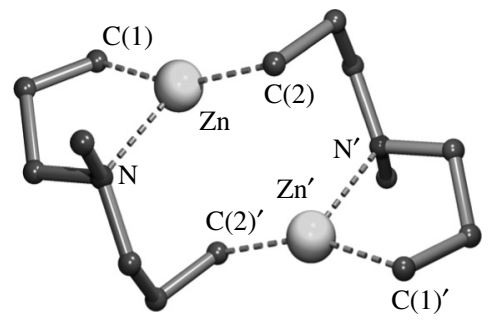

FIGURE 34. Structure of macrocycle $\mathbf{6 7}$ in the solid state 


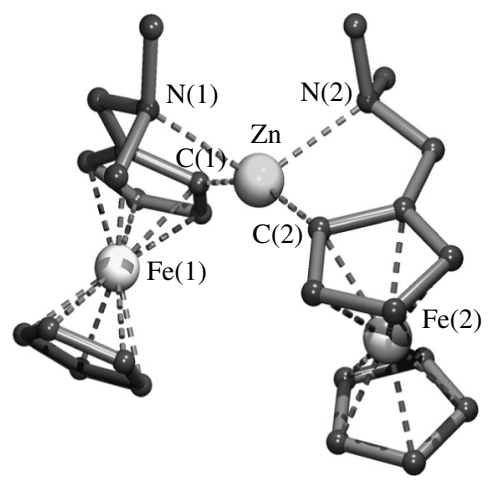

FIGURE 35. Molecular geometry of the $(R, R)$-diastereoisomer of $\mathbf{6 8}$ in the solid state

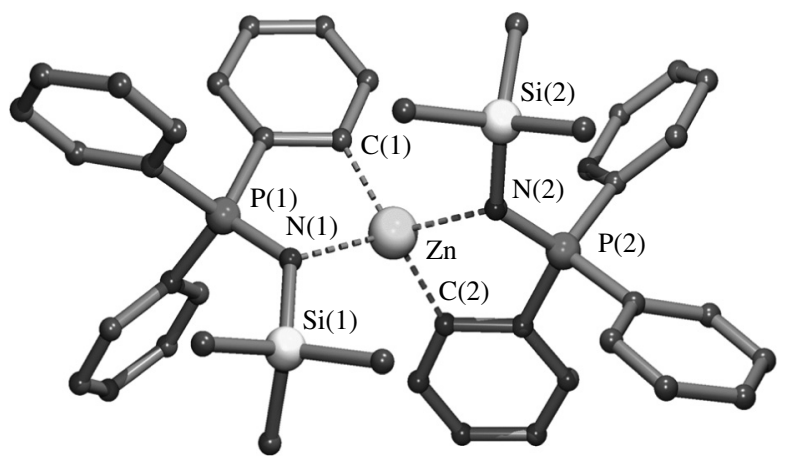

FIGURE 36. Molecular geometry of the bis-iminophosphorane zinc compound 69

of the $C, N$-chelating ligands are small, but typical for this ligand system, and are mainly determined by the radius of the bonded metal.

Compound $69^{123}$ contains two $C, N$-chelate-bonded iminophosphorane ligands and was obtained from the reaction of $\mathrm{ZnCl}_{2}$ with two equivalents of the corresponding ortholithiated derivative ${ }^{124}$. An X-ray structure determination of 69 revealed a molecular geometry as shown in Figure 36. Because the zinc atom is located on a crystallographic inversion centre, the two $C, N$-chelate-bonded ligands are symmetry-related.

The $\mathrm{Zn}-\mathrm{C}$ bond lengths $[2.008(5) \AA]$ are as expected for diarylzinc compounds, but the $\mathrm{Zn}-\mathrm{N}$ coordinate bonds [2.158(4) $\AA$ ] are considerably shorter than those in the diorganozinc compounds described above containing an intramolecular coordinating nitrogen atom (e.g. 68). The zinc atom in 69 has a distorted tetrahedral coordination geometry. The $\mathrm{C}-\mathrm{Zn}-\mathrm{C}$ and $\mathrm{N}-\mathrm{Zn}-\mathrm{N}$ bond angles, $129.28(21)^{\circ}$ and $116.07(13)^{\circ}$ respectively, are larger than the ideal tetrahedral value. The $\mathrm{C}-\mathrm{Zn}-\mathrm{N}$ bond angles $\left[89.33(18)^{\circ}\right]$ in the fivemembered chelate rings are acute, but not as acute as in $\mathbf{6 8}$. This is a consequence of the shorter $\mathrm{Zn}-\mathrm{N}$ bond lengths in 69 compared to those in 68 .

The structural features of a series of organometallic compounds $\left[\mathrm{NC}_{5} \mathrm{H}_{4} \mathrm{C}\left(\mathrm{SiMe}_{3}\right)_{2}-\right.$ $2]_{2} \mathrm{M}(\mathrm{M}=\mathrm{Mg}, \mathrm{Zn}, \mathrm{Cd}, \mathrm{Hg})$ containing the monoanionic, potentially $C, N$-bidentate coordinating $\left[\mathrm{NC}_{5} \mathrm{H}_{4} \mathrm{C}\left(\mathrm{SiMe}_{3}\right)_{2}-2\right]$ anion have been studied ${ }^{125}$. It appeared that the $\mathrm{Mg}$, 


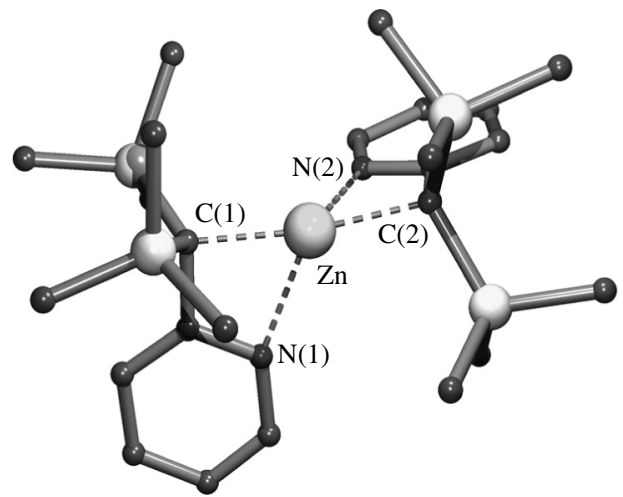

FIGURE 37. Structure of $\left[\mathrm{NC}_{5} \mathrm{H}_{4} \mathrm{C}\left(\mathrm{SiMe}_{3}\right)_{2}-2\right]_{2} \mathrm{Zn}(\mathbf{7 0})$

$\mathrm{Zn}$ and $\mathrm{Cd}$ compounds are isostructural, having two ligands that are $C, N$-chelate bonded to the metal. This is in contrast with the mercury compound in which only the carbon atoms are bonded to the metal in an almost ideal linear $\mathrm{C}-\mathrm{Hg}-\mathrm{C}\left[179.5(3)^{\circ}\right]$ arrangement. In the zinc compound (70) both the $\mathrm{Zn}-\mathrm{C}$ bonds $(2.07 \AA)$ and the $\mathrm{Zn}-\mathrm{N}$ bonds $(2.29 \AA)$ are rather long. The coordination geometry around zinc is extremely distorted from tetrahedral (Figure 37). In fact, the $\mathrm{C}-\mathrm{Zn}-\mathrm{C}$ bond angle of $164^{\circ}$ suggests a linear rather than a tetrahedral arrangement. On the other hand, the $\mathrm{C}-\mathrm{Zn}-\mathrm{N}$ bond angles in the four-membered chelate ring are extremely acute $\left(67.0^{\circ}\right)$, a consequence of the combination of a four-membered chelate ring with a rather long $\mathrm{Zn}-\mathrm{N}$ bond.

The bis(benzoyloxymethyl)zinc (71) was prepared either from zinc benzoate and diazomethane or from benzoyloxymethyl iodide and $\mathrm{Et}_{2} \mathrm{Zn}$ under photolysis conditions (Scheme 9) ${ }^{126}$. Such an acyloxymethylzinc compound appeared to be a reactive carbenoid capable of reacting with a variety of non-functionalized alkenes to afford cyclopropanes in excellent yields (Scheme 9).

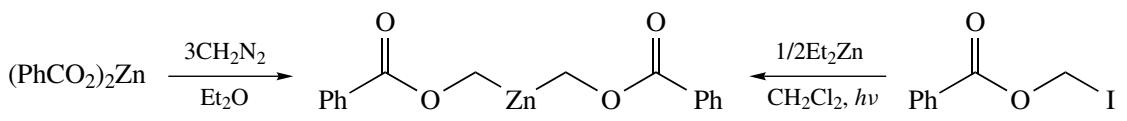<smiles>[101In]</smiles><smiles>[R]C([R])=C([Y7])C</smiles>

During these studies, $\mathbf{7 1}$ was obtained as a crystalline material and its structure in the solid state was established by an X-ray crystal structure determination ${ }^{126}$. In 71 the two benzoyloxymethyl groups are symmetry-related via an inversion centre at the zinc position 


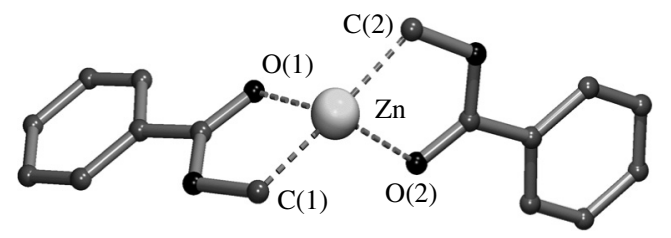

FIGURE 38. Molecular geometry of bis(benzoyloxymethyl)zinc (71) in the solid state

and $C, O$-chelate-bonded to zinc, rendering the zinc atom four-coordinate (Figure 38). The $\mathrm{Zn}-\mathrm{C}$ bond length [1.978(2) $\AA$ ] is in the range expected for an alkylzinc compound. The bond angles around zinc $\left[\mathrm{C}(1)-\mathrm{Zn}-\mathrm{C}(2) 159.35(13)^{\circ}, \mathrm{O}(1)-\mathrm{Zn}-\mathrm{O}(2) 124.01(18)^{\circ}\right.$, $\mathrm{C}(1)-\mathrm{Zn}-\mathrm{O}(1) 80.66(7)^{\circ}$ and $\left.\mathrm{C}(1)-\mathrm{Zn}-\mathrm{O}(2) 113.53(8)^{\circ}\right]$ point to a distorted squarebipyramidal environment at zinc.

Reaction of $\alpha, \alpha^{\prime}$-bis(2-pyridyl)methyllithium with $\mathrm{Me}_{2} \mathrm{Zn}$ afforded the unexpected transmetalation product $\left[\mathrm{MeZnCH}(\mathrm{Py})_{2}\right]_{2}$ (72) instead of the anticipated triorganozincate ${ }^{127}$. An X-ray crystal structure determination of $\mathbf{7 2}$ revealed a dimeric molecule (Figure 39) in which the monomeric parts are arranged in a head-to-tail fashion. In each monomeric part a methylzinc unit is chelate-bonded between the two nitrogen atoms [Zn-N(1) 2.044(2), Zn-N(2) 2.035(2) Å] of one dipyridylmethane unit and bonded to the $\mathrm{C}_{\alpha}$ atom of the other dipyridylmethane unit. The (methyl) $-\mathrm{C}-\mathrm{Zn}$ bond distance [1.974(3) $\AA]$ is quite normal, but the $\mathrm{C}_{\alpha}-\mathrm{Zn}$ bond distance [2.269(3) $\AA$ ] is considerably elongated. This is most likely a consequence of considerable steric strain as the result of two almost eclipsed pyridyl rings (Figure 39).

A rather exotic organozinc compound was obtained starting from 2-pyridylbis(trimethylsilyl)methane, which essentially is the same ligand as is present in deprotonated form in 70 (vide supra). Its monolithio derivative was treated with $\mathrm{SbCl}_{3}$ and subsequently with $\mathrm{Et}_{2} \mathrm{Zn}$ affording, along with other products, tetrameric $\left\{\left[(2 \text {-pyridyl })\left(\mathrm{Me}_{3} \mathrm{Si}\right) \mathrm{C}\right] \mathrm{Zn}\right\}_{4}(\mathbf{7 3})$ as a crystalline material ${ }^{128}$. An X-ray crystal structure determination revealed a cage-like structure in which four bis-anionic $\left[(2 \text {-pyridyl })\left(\mathrm{Me}_{3} \mathrm{Si}\right) \mathrm{C}\right]^{2-}$ ligands are bonded to four zinc atoms (Figure 40). As a requirement of the space-group symmetry the tetrameric aggregate has $S_{4}$ crystallographic symmetry. The structure consists of a tetrahedron of zinc atoms, while each $\left[(2-\text { pyridyl })\left(\mathrm{Me}_{3} \mathrm{Si}\right) \mathrm{C}\right]^{2-}$ ligand spans the face of the tetrahedron with the $\mathrm{C}_{\alpha}$ atom bridge-bonded between two zinc atoms and the pyridyl nitrogen

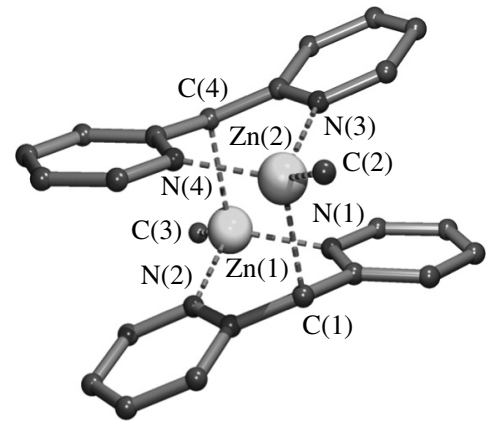

FIGURE 39. Solid state structure of dimeric $\mathbf{7 2}$ 


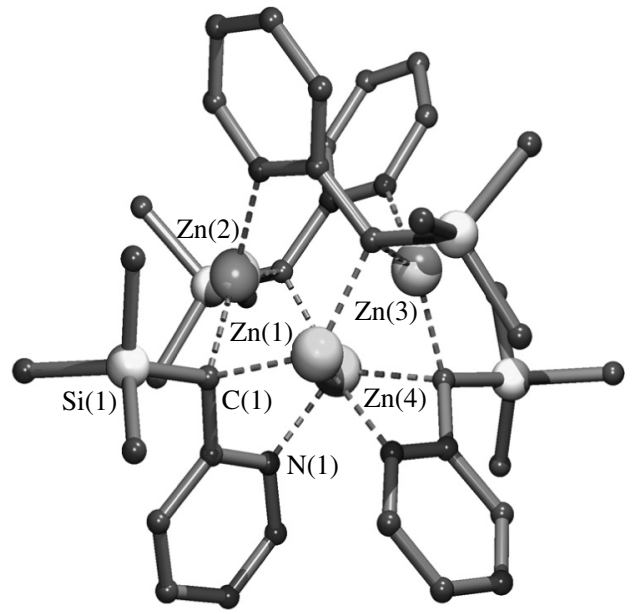

FIGURE 40. Cage-like structure of tetrameric $\mathbf{7 3}$ in the solid state

atom coordinating to the third zinc atom. Consequently, the zinc atoms in $\mathbf{7 3}$ are threecoordinate. The bridging carbon atom is bonded slightly asymmetric between the two zinc atoms, as is reflected in a small difference in bonding distances $[\mathrm{Zn}(1)-\mathrm{C}(1) 2.040(7)$, $\mathrm{Zn}(1)-\mathrm{C}(2) 2.024(7) \AA]$. The $\mathrm{Zn}-\mathrm{N}$ coordinate bond [2.031(5) $\AA]$ is rather short, and most likely is a consequence of its $\mathrm{sp}^{2}$ character and of the fact that this nitrogen atom is bonding to a three-coordinate zinc centre.

\section{Donor-Acceptor Complexes of Diorganozinc Compounds}

That diorganozinc compounds are capable of forming donor-acceptor complexes was discovered around 1960. The discovery that ethers like dioxane and DME form welldefined complexes with $\mathrm{Me}_{2} \mathrm{Zn}^{129}$ and that nitrogen-, phosphorus- and arsenic-containing donor molecules interact with a variety of dialkyl and diaryl zinc compounds to form isolable adducts ${ }^{130}$ started a renaissance in the chemistry of organozinc coordination compounds. Before that time it was generally accepted that diorganozinc compounds are unable to form such adducts. Nowadays, it is well-established that diorganozinc compounds readily form complexes with donor molecules ${ }^{81,82}$. Generally, in such complexes two donor atoms interact with the diorganozinc moiety leading to a (distorted) tetrahedral coordination geometry at zinc. More rare are complexes in which only one donor atom is coordinated to zinc, to give trigonal planar coordination at zinc. With one exception, all diorganozinc coordination complexes of which the structure has been determined by $\mathrm{X}$-ray crystallography contain either $\mathrm{Zn}-\mathrm{N}$ or $\mathrm{Zn}-\mathrm{O}$ coordination bonds.

Although compounds like $\mathrm{Me}_{2} \mathrm{Zn}\left(\mathrm{OMe}_{2}\right)^{131}$ and $\mathrm{Me}_{2} \mathrm{Zn}\left(\mathrm{NMe}_{3}\right)^{132}$, which were presumed to contain three-coordinate zinc, have been known for a long time, only very few structures of compounds containing such a structural motif have been established by X-ray crystallography, and these are relatively recent.

Bis[(dimethylisopropoxysilyl)methyl]zinc (74) has proven to be a valuable reagent in the nickel-catalysed cross-coupling reactions with alkenylsulfoximines, giving allylic silanes with complete retention of configuration ${ }^{133}$. An X-ray crystal structure determination of $\mathbf{7 4}$ showed this compound to exist in the solid state as a coordination polymer (Figure 41$)^{134}$. In 74, in addition to the two covalent $\mathrm{Zn}-\mathrm{C}$ bonds $[\mathrm{Zn}-\mathrm{C}(1)$ 1.953(7) 


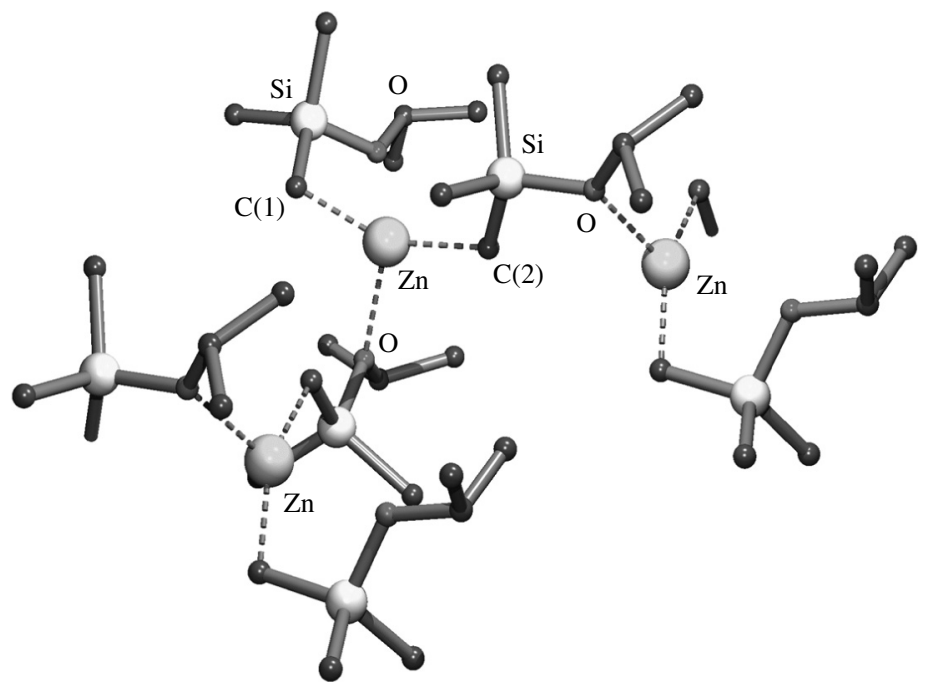

FIGURE 41. Part of the polymeric structure of $\mathbf{7 4}$ in the solid state

and $\mathrm{Zn}-\mathrm{C}(2) 1.988(6) \AA$ ], the oxygen atom of an isopropoxy group of a neighbouring molecule is coordinated to the zinc atom $[\mathrm{Zn}-\mathrm{O} 2.252(4) \AA]$. The bond angles around zinc $\left[\mathrm{O}-\mathrm{Zn}-\mathrm{C}(1) 104.2(2)^{\circ}, \mathrm{O}-\mathrm{Zn}-\mathrm{C}(2) 103.5(2)^{\circ}\right.$ and $\left.\mathrm{C}(1)-\mathrm{Zn}-\mathrm{C}(2) 152.3(3)^{\circ}\right]$ point to a trigonal planar coordination geometry at zinc. As a result of intermolecular coordination, the molecules are arranged in helices which are perpendicular to the $b c$ plane of the unit cell.

A surprising compound (75) was obtained as a by-product in low yield from the synthesis of a barium zincate starting from $\left(\mathrm{Me}_{3} \mathrm{SiCH}_{2}\right)_{2} \mathrm{Zn}$ and metallic barium in heptane $/ \mathrm{THF}^{57}$. The X-ray crystal structure determination of this compound revealed a central $\mathrm{Ba}_{2} \mathrm{O}_{2}$ core arranged in a four-membered ring with three THF molecules coordinated to each barium atom. Each of the oxygen atoms of the central ring is coordinated to the two zinc atoms of a $\mathrm{Me}_{3} \mathrm{SiCH}_{2} \mathrm{ZnCH}_{2} \mathrm{SiMe}_{2} \mathrm{CH}_{2} \mathrm{ZnCH}_{2} \mathrm{SiMe}_{3}$ molecule with bond distances of $\mathrm{Zn}(1)-\mathrm{O}(1)$ 1.964(3) and $\mathrm{Zn}(2)-\mathrm{O}(1)$ 1.972(3) $\AA$, respectively (Figure 42). The $\mathrm{Zn}-\mathrm{C}$ bond distances $[\mathrm{Zn}(1)-\mathrm{C}(1) 2.025(4), \mathrm{Zn}(1)-\mathrm{C}(2)$ 1.995(4), $\mathrm{Zn}(2)-\mathrm{C}(3) 2.006(4)$ and $\mathrm{Zn}(2)-\mathrm{C}(4) 2.043(4) \AA]$ are in the range as expected for $\mathrm{sp}^{3}$-hybridized carbon atoms bound to zinc. Each of the terminal $\mathrm{Me}_{3} \mathrm{SiCH}_{2}$ to $\mathrm{Zn}$ bonds is slightly elongated due to additional interactions with the respective barium atoms $(\mathrm{C}-\mathrm{Ba} 3.22 \AA$, average $)$. The zinc atoms have a trigonal planar coordination geometry, as is indicated by the respective bond angles around zinc $\left[\mathrm{O}(1)-\mathrm{Zn}(1)-\mathrm{C}(1) 110.0(2)^{\circ}, \mathrm{O}(1)-\mathrm{Zn}(1)-\mathrm{C}(2) 116.5(2)^{\circ}, \mathrm{C}(1)-\mathrm{Zn}(1)-\mathrm{C}(2) 132.6(2)^{\circ}\right.$ and $\mathrm{O}(1)-\mathrm{Zn}(2)-\mathrm{C}(3) \quad 120.1(2)^{\circ}, \quad \mathrm{O}(1)-\mathrm{Zn}(2)-\mathrm{C}(4) \quad 110.9(1)^{\circ}, \mathrm{C}(3)-\mathrm{Zn}(2)-\mathrm{C}(4)$ $\left.129.0(2)^{\circ}\right]$.

From the reaction of bis[bis(trimethylsilyl)methyl]zinc with 1,3,5-trimethyl-1,3,5triazine (TMTA) the mono-adduct $\left[\left(\mathrm{Me}_{3} \mathrm{Si}\right)_{2} \mathrm{CH}\right]_{2} \mathrm{Zn}$ (TMTA) (76) was isolated as a crystalline material ${ }^{60}$. The X-ray crystal structure determination of $\mathbf{7 6}$ revealed a structure in which the zinc atom is three-coordinate as a result of two binding two $\eta^{1}-\left(\mathrm{Me}_{3} \mathrm{Si}\right)_{2} \mathrm{CH}$ groups $[\mathrm{Zn}-\mathrm{C}(1)$ 1.985(3) and $\mathrm{Zn}-\mathrm{C}(2) 2.002(3) \AA]$ and one of the nitrogen atoms of the TMTA molecule (Figure 43). The latter $\mathrm{Zn}-\mathrm{N}$ coordinate bond is relatively long $[2.387(2) \AA]$. Whereas the $\mathrm{C}(1)-\mathrm{Zn}-\mathrm{C}(2)$ bond angle $\left[157.4(1)^{\circ}\right]$ deviates considerably 


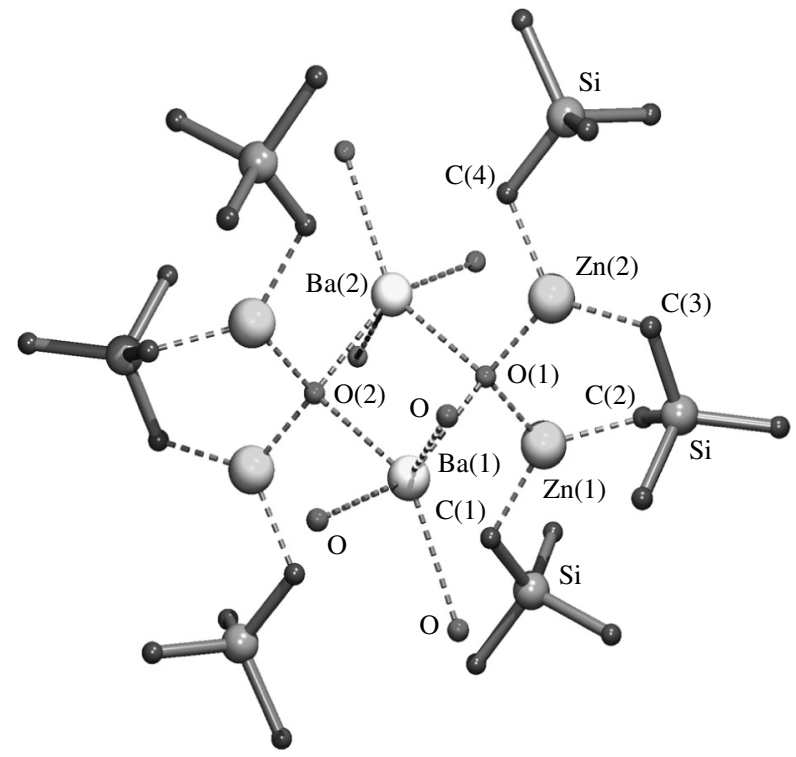

FIGURE 42. Molecular geometry of $\mathbf{7 5}$ in the solid state. Note that the $\mathrm{CH}_{2}$ groups of the coordinated THF molecules are omitted for clarity

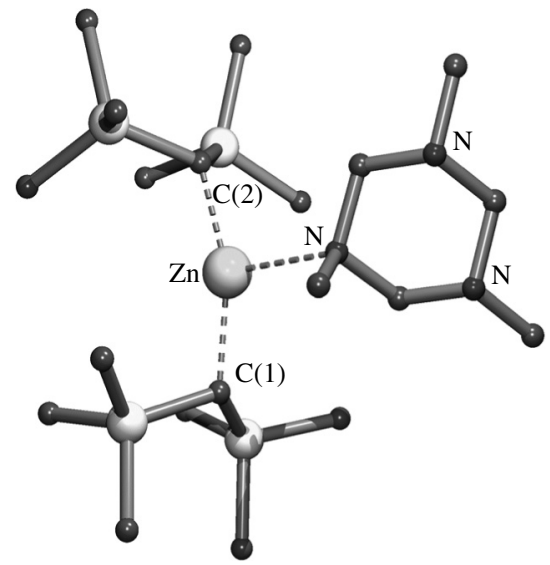

FIGURE 43. Solid state structure of coordination complex $\mathbf{7 6}$

from the ideal value of $120^{\circ}$, the sum of the bond angles around zinc of $360^{\circ}$ indicates a perfectly planar arrangement at zinc. That the $\mathrm{Zn}-\mathrm{N}$ coordination bond is relatively weak indeed is indicated by the fact that $\mathbf{7 6}$ is dissociated to a large extent into $\left[\left(\mathrm{Me}_{3} \mathrm{Si}\right)_{2} \mathrm{CH}\right]_{2} \mathrm{Zn}$ and free TMTA when dissolved in apolar solvents like benzene.

Reaction of tri(tert-butyl)sulfurtriimide with one equivalent of MeLi followed by an in situ reaction with one equivalent of $\mathrm{Me}_{2} \mathrm{Zn}$ afforded the bimetallic compound $\mathbf{7 7}$ (equation 19) ${ }^{135}$. The molecular geometry of $\mathbf{7 7}$ was unambiguously established by an 
$\mathrm{X}$-ray crystal structure determination. The lithium atom is $N, N$-chelate bonded to the monoanionic ligand while a tetrahedral coordination geometry at lithium is reached by the coordination of two additional THF molecules. The presence of considerable conjugation in this part of the molecule is reflected by the almost equal N-Li distances [2.014(4) and 2.000(4) $\AA$ ] and almost equal S-N distances [1.5607(17) and 1.5622(17) $\AA$ ]. The third nitrogen atom acts as a neutral donor to the dimethylzinc molecule [Zn-N 2.1374(17) $\AA$ ] rendering the zinc atom trigonal planar.

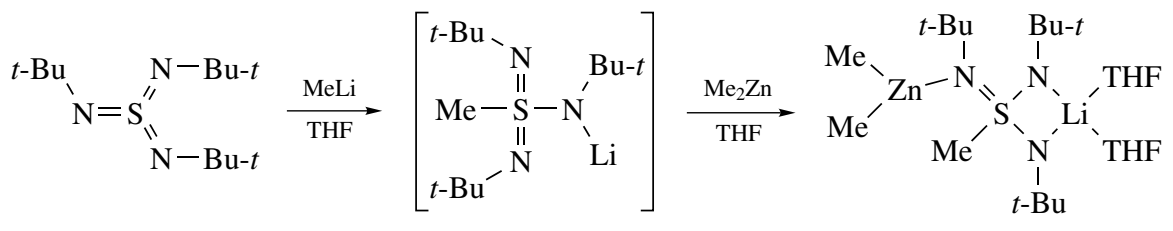

For a long time it has been known that dialkylzinc compounds can deprotonate secondary carboxylic amides affording heteroleptic alkylzinc carboxylic amides which, according to molecular weight determinations in solution, are highly aggregated species ${ }^{136}$. The actual structural elucidation of these compounds by X-ray crystallography is from a more recent date and will be discussed elsewhere in this chapter. These alkylzinc carboxylic amides react with $t$-BuLi to afford the novel species $\mathbf{7 8}$ and $\mathbf{7 9}$ (Scheme 10). The author describes $\mathbf{7 8}$ and $\mathbf{7 9}$ as organozincates, but in fact they are lithium enolates in which the terminal imino-nitrogen atoms are coordinated to a $t-\mathrm{Bu}_{2} \mathrm{Zn}$ moiety ${ }^{137}$.

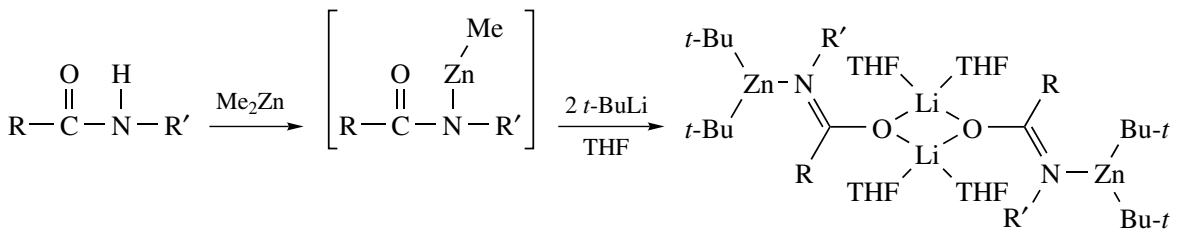

(78) $\mathrm{R}=\mathrm{Ph}, \mathrm{R}^{\prime}=i$-Pr

(79) $\mathrm{R}=\mathrm{Ph}, \mathrm{R}^{\prime}=\mathrm{Me}$

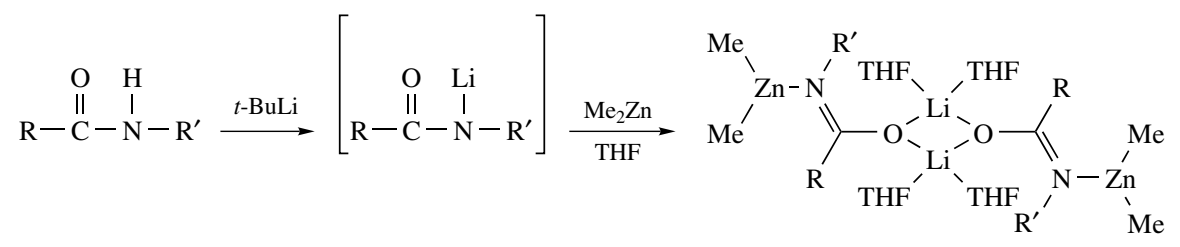

(80) $\mathrm{R}=\mathrm{Ph}, \mathrm{R}^{\prime}=\mathrm{Ph}$

SCHEME 10

Another synthetic approach towards the synthesis of compound $\mathbf{8 0}$ involves prior deprotonation of the carboxylic amide with $t-\mathrm{BuLi}$, which is then followed by reaction with dimethylzinc (Scheme 10). All three compounds have similar structural features, i.e. they are dimers as a result of two $O$-bridging enolate anions between two lithium atoms. The 


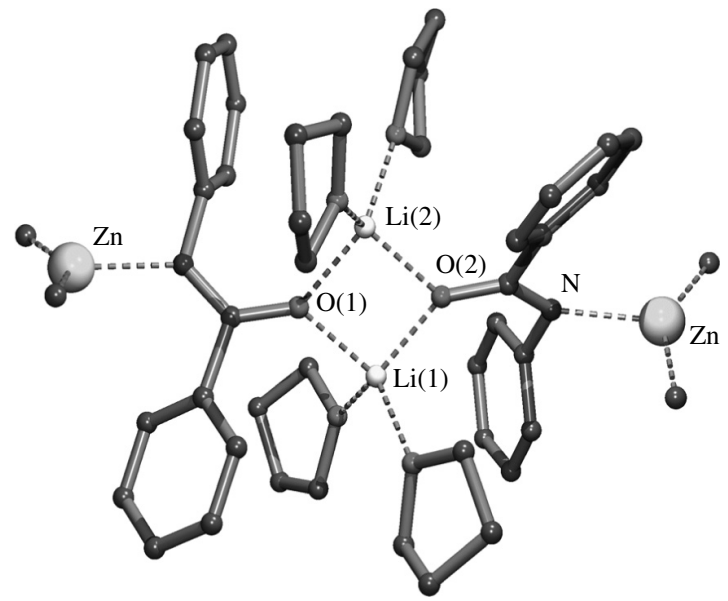

FIGURE 44. Molecular geometry of $\mathbf{8 0}$ in the solid state

terminal imino-nitrogen atoms are coordinated to the dialkylzinc units. The solid state structure of $\mathbf{8 0}$ is shown in Figure 44 as a representative example.

That a particular combination of substituents, i.e. $\mathrm{R}$ and $\mathrm{R}^{\prime}$ and the diorganozinc compound, may influence the overall structure of this type of compounds was shown by the $\mathrm{X}$-ray crystal structure determination of the $t-\mathrm{Bu}_{2} \mathrm{Zn}$ derivative of $\mathbf{8 0}$. The latter structure consists of a tetrameric aggregate in which the four enolate oxygen atoms and the four lithium atoms are arranged in a 'ladder'-type arrangement while two of the imino-nitrogen atoms are involved in nitrogen-lithium coordination and the other two imino-nitrogens are coordinated to $t$ - $\mathrm{Bu}_{2} \mathrm{Zn}$ units.

The structural features of the dialkylzinc units in these compounds are closely related, i.e. the zinc atoms are trigonal-planar coordinated, with $\mathrm{C}-\mathrm{Zn}$ distances as expected. The $\mathrm{Zn}-\mathrm{N}$ coordination bonds range from 2.078 to $2.184 \AA$ and the $\mathrm{C}-\mathrm{Zn}-\mathrm{C}$ bond angles range from $132^{\circ}$ to $145^{\circ}$.

So far, only coordination complexes of diorganozinc compounds were considered in which one additional ligand is coordinated via its heteroatom to zinc, thus affording a trigonal planar coordination geometry at zinc. This is a rather rare situation for zinc, and complexes containing either two monodentate or one bidentate chelating ligand, thus affording a (distorted) tetrahedral coordination geometry, are far more common for zinc. With one exception the heteroatoms involved in coordination to zinc are always either oxygen or nitrogen atoms (at least for compounds of which the structure was established by an X-ray crystal structure determination). Due to the rather soft character of zinc in diorganozinc compounds, the $\mathrm{Zn}-\mathrm{N}$ coordination bonds in these complexes are generally stronger than corresponding $\mathrm{Zn}-\mathrm{O}$ coordination bonds.

It should be noted that most diorganozinc coordination complexes having a tetrahedral coordination geometry are discrete monomers in which the $\mathrm{Zn}-\mathrm{C}$ bond distances in the diorganozinc moieties are as expected for $\mathrm{sp}^{3}$ (in alkylzinc) or $\mathrm{sp}^{2}$ (in arylzinc) carbon atoms. However, $\mathrm{C}-\mathrm{Zn}-\mathrm{C}$ bond angles may vary and seem to be dependent on the nature of the particular heteroatom that is involved in coordination to zinc. Also, the $\mathrm{Y}-\mathrm{Zn}-\mathrm{Y}$ ( $\mathrm{Y}=$ coordinating heteroatom) bond angle may vary, depending on the particular ligand.

In Table 5, relevant structural features of diorganozinc complexes containing two coordinating oxygen atoms are compiled; only those compounds that have special structural features will be discussed in more detail. 
TABLE 5. Relevant structural features of $\mathrm{R}_{2} \mathrm{ZnL}_{2}$ complexes ( $\mathrm{L}=\mathrm{O}$-coordinating ligand)

\begin{tabular}{lccclcc}
\hline Compound & $\mathrm{R}$ & $\mathrm{L}$ & $\mathrm{Zn}-\mathrm{O}$ & $\mathrm{C}-\mathrm{Zn}-\mathrm{C}$ & $\mathrm{O}-\mathrm{Zn}-\mathrm{O}$ & Reference \\
\hline $\mathbf{8 1}$ & $\mathrm{C}_{6} \mathrm{~F}_{5}$ & $\mathrm{THF}$ & $2.093(2), 2.113(3)$ & $132.1(2)$ & $92.4(1)$ & 138 \\
$\mathbf{8 2}$ & 1-fluorenyl & $\mathrm{THF}$ & $2.095(4), 2.114(5)$ & $117.6(2)$ & $89.3(2)$ & 139 \\
$\mathbf{8 3}$ & $a$ & $\mathrm{THF}$ & $2.209(1), 2.272(1)$ & $130.3(6)$ & $85.7(5)$ & 140 \\
$\mathbf{8 4}$ & $\mathrm{C}_{6} \mathrm{H}_{5}$ & $\mathrm{DME}$ & $2.287(4), 2.259(4)$ & $146.6(2)$ & $72.16(14)$ & 141 \\
$\mathbf{8 5}$ & $\mathrm{CH}_{2} \mathrm{I}$ & $b$ & $2.10(1), 2.20(1)$ & $138.4(7)$ & $72.7(4)$ & 142 \\
$\mathbf{8 6}$ & $\mathrm{C}_{2} \mathrm{H}_{5}$ & $\mathrm{Ni}[$ Salen $]$ & $2.321(6), 2.321(6)$ & $147.9(4)$ & $63.1(2)$ & 143 \\
$\mathbf{8 7}$ & $\mathrm{C}_{6} \mathrm{H}_{5}$ & $c$ & $2.274(6), 2.264(6)$ & $139.6(3)$ & $71.6(2)$ & 144 \\
$\mathbf{8 8}$ & $\mathrm{C}_{6} \mathrm{H}_{5}$ & $d$ & $2.239(3), 2.328(3)$ & $146.7(2)$ & $72.4(1)$ & 144 \\
$\mathbf{8 9}$ & $\mathrm{C}_{6} \mathrm{H}_{5}$ & $e$ & $2.300(3), 2.310(3)$ & $145.5(2)$ & $72.68(9)$ & 144 \\
\hline
\end{tabular}

a $1,2-\mathrm{C}_{6} \mathrm{H}_{4}$.

${ }^{b}$ (R)-2,3-Dimethoxy-4,7,7-trimethylbicyclo[2.2.1]heptane.

c 2-Bromo-1,3-xylyl 15-crown-4.

d 2-Bromo-1,3-xylyl 18-crown-5.

e 1,3-Xylyl 18-crown-5.

A common structural feature of compounds 81-89 is their distorted tetrahedral coordination geometry at zinc. A trend that can be observed in Table 5 is that with increasing $\mathrm{Zn}-\mathrm{O}$ distances, the $\mathrm{C}-\mathrm{Zn}-\mathrm{C}$ angle also increases and consequently the $\mathrm{O}-\mathrm{Zn}-\mathrm{O}$ angle decreases. From a structural point of view $\mathbf{8 3}$ has interesting structural features. In this complex two 1,2-phenylene dianionic units are $C, C$-bridge bonded between two zinc atoms (Figure 45) and it represents one of the few examples of polymetallated compounds for which the structure has been established by an X-ray crystal structure determination ${ }^{140}$.

It is interesting to compare the structure of $\mathbf{8 4}$ and of the diglyme complex of $\mathrm{Ph}_{2} \mathrm{Zn}$ (90) (Figure 46) $)^{141}$. In the latter compound all three oxygen atoms of the diglyme ligand are involved in coordination to zinc, resulting in the formation of an unprecedented and still unique example of pentacoordination in diarylzinc chemistry. It is remarkable that the $\mathrm{Ph}_{2} \mathrm{Zn}$ units in both complexes are almost identical, which is obvious from the comparable $\mathrm{C}(1)-\mathrm{Zn}-\mathrm{C}(2)$ bond angles $\left[146.6(2)^{\circ}\right.$ in $\mathbf{8 4}$ and $149.7(3)^{\circ}$ in 90]. However, in 90 all $\mathrm{O}-\mathrm{Zn}$ bond distances are longer than those in 84, i.e. 2.483(5), 2.330(5) and 2.509(6) $\AA$ in 90 vs. 2.287(4) and 2.259(4) $\AA$ in $\mathbf{8 4}$. The coordination geometry at zinc in 90 is neither a trigonal bipyramid nor a square planar pyramid and its configuration does not lie on the Berry pseudo-rotation path between the two.

It is remarkable that in the diphenylzinc crown-ether complexes 87-89 the $\mathrm{Ph}_{2} \mathrm{Zn}$ unit is placed outside the crown, in contrast to the $\mathrm{Ph}_{2} \mathrm{Mg}$ analog of $\mathbf{8 9}$ which exists in the

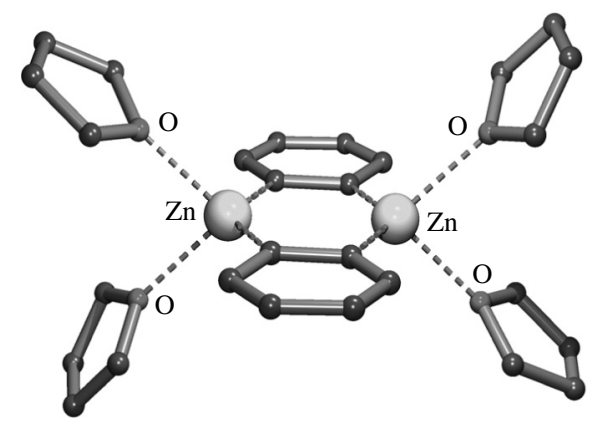

FIGURE 45. Structure of $\mathbf{8 3}$ in the solid state 


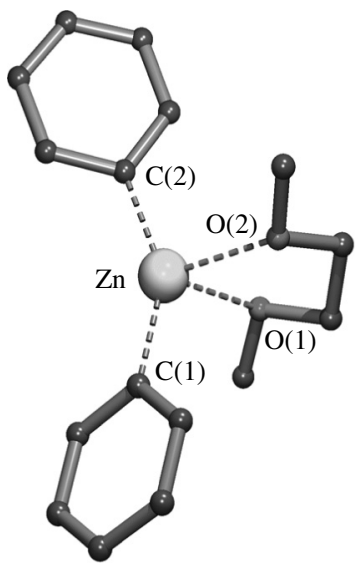

(84)

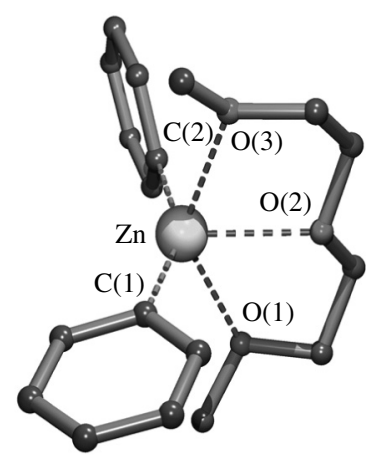

(90)

FIGURE 46. Solid state structures of $\mathbf{8 4}$ and $\mathbf{9 0}$

solid state as an organometallic rotaxane ${ }^{145}$. In 87-89 the crown ether acts as a bidentate chelating ligand. In fact, in these compounds the structure around zinc is identical to that in the DME complex of $\mathrm{Ph}_{2} \mathrm{Zn}$ (Table 5).

Both $\mathrm{Et}_{2} \mathrm{Zn}$ and $\mathrm{Ph}_{2} \mathrm{Zn}$ form rotaxane structures with 18-crown-6, 91 and 92, respectively (Figure 47) ${ }^{146,147}$. In 91, the zinc atom is located on a crystallographic inversion centre and consequently the $\mathrm{C}(1)-\mathrm{Zn}-\mathrm{C}(2)$ bond angle is $180^{\circ}$. The $\mathrm{Zn}-\mathrm{O}$ bond distances are extremely long [2.837(3), 2.890(3) and 2.873(3) $\AA$ ]. Compound 92 has a less symmetric structure but the $\mathrm{C}-\mathrm{Zn}-\mathrm{C}$ bond angle of $174.5(1)^{\circ}$ is close to linear. Also, in this compound the $\mathrm{Zn}-\mathrm{O}$ distances are extremely long [2.634(3) to 3.024(3) ̊]. In fact, these compounds may be regarded as clathrates containing a diorganozinc encapsulated within

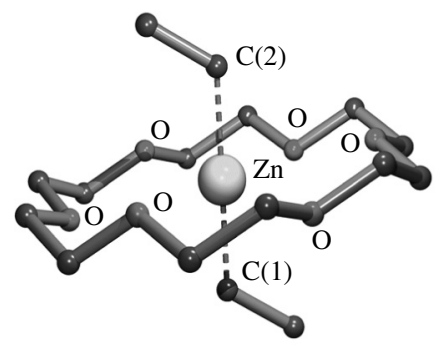

(91)

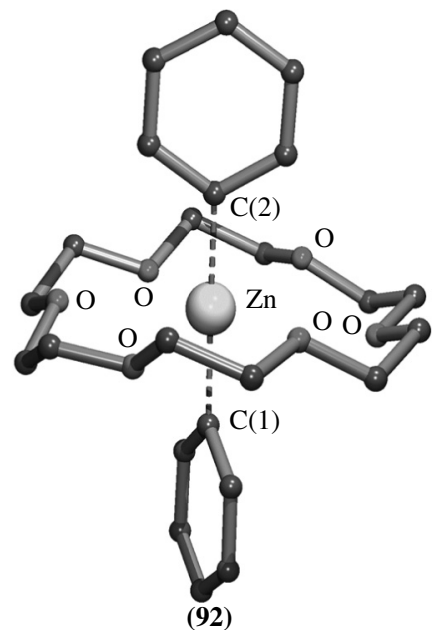

(92)

FIGURE 47. Solid state structures of the organometallic rotaxanes 91 and 92 
a crown ether but with very weak $\mathrm{Zn}-\mathrm{O}$ bonds. The formation of these organometallic rotaxanes has been explained by a mechanism involving a 'peripherally'-crown-ethercoordinated diorganozinc that subsequently disproportionates to triorganozincates and monoorganozinc cations encapsulated in the crown ether ${ }^{148}$.

The structure of the diphenylzinc tetrahydrothiophene complex (93) is the only example of a diorganozinc compound in which $\mathrm{Zn}-\mathrm{S}$ coordination bonds are present ${ }^{149}$. Like in diphenylzinc itself ${ }^{9}$ the solid state structure of $\mathbf{9 3}$ consists of dimeric molecules in which two of the phenyl groups are bridging between two zinc atoms and each of the zinc atoms contains a terminal phenyl group. In addition, one tetrahydrothiophene molecule is coordinated to each zinc atom via its sulfur atom (Figure 48). The bridging aryl group in $\mathbf{9 3}$ is less asymmetrically bonded $[\mathrm{Zn}(1)-\mathrm{C}(1) 2.114(2)$ and $\mathrm{Zn}(2)-\mathrm{C}(1) 2.261(2) \AA]$ compared with these bridges in the diphenylzinc dimer. The $\mathrm{Zn}-\mathrm{S}$ bond distance is $2.5025(5) \AA$, which is slightly longer than the sum of the covalent radii $(2.35 \AA)$, indicating a relatively weak coordination of the ligand. The bond angles around zinc are close to the ideal tetrahedral value, indicating a slightly distorted tetrahedral geometry at zinc.

The complex of dimethylzinc with 2-(1-methoxypropyl)ferrocenylaldimine, in which the 2-(1-methoxypropyl)ferrocenylaldimine ligand is $N, O$-chelate-bonded to zinc [ $\mathrm{Zn}-\mathrm{N}$ 2.213(2), $\mathrm{Zn}-\mathrm{O} 2.381(2) \AA]$, is the only example of a diorganozinc coordination complex in which in one complex both $\mathrm{Zn}-\mathrm{N}$ and $\mathrm{Zn}-\mathrm{O}$ coordination occurs ${ }^{149}$. The coordination geometry at zinc is distorted tetrahedral with a larger $\mathrm{C}-\mathrm{Zn}-\mathrm{C}\left(141.6^{\circ}\right)$ and a smaller $\mathrm{N}-\mathrm{Zn}-\mathrm{O}\left(74.9^{\circ}\right)$ bond angle.

The only two structurally characterized complexes of diorganozinc compounds, in which two monodentate $\mathrm{N}$-coordinating ligands are present, are $\mathrm{Me}_{2} \mathrm{Zn}\left[\left(\mathrm{CH}_{2} \mathrm{NMe}\right)_{3}\right]_{2}$ $\left[\left(\mathrm{CH}_{2} \mathrm{NMe}\right)_{3}=\right.$ hexahydro-1,3,5-trimethyl-1,3,5-triazine $]$ and $\left(\mathrm{CF}_{3}\right)_{2} \mathrm{Zn}(\mathrm{Pyr})_{2}$. In both complexes the zinc atoms have a distorted tetrahedral coordination geometry. In $\mathrm{Me}_{2} \mathrm{Zn}\left[\left(\mathrm{CH}_{2} \mathrm{NMe}\right)_{3}\right]_{2}$, the $\mathrm{Zn}-\mathrm{N}$ bond distance is relatively long [2.410(4) $\AA$ ] combined with a $\mathrm{N}-\mathrm{Zn}-\mathrm{N}$ bond angle of $105.6(2)^{\circ}$ and a $\mathrm{C}-\mathrm{Zn}-\mathrm{C}$ bond angle of $145.1(2)^{\circ} 150$. The structural features of $\left(\mathrm{CF}_{3}\right)_{2} \mathrm{Zn}(\mathrm{Pyr})_{2}$ are similar ${ }^{151}$, although the $\mathrm{Zn}-\mathrm{N}$ coordination bonds are relatively short $[2.075(2)$ and 2.082(2) $\AA]$. However, the $\mathrm{Zn}-\mathrm{C}$ bond lengths [2.056(3) and 2.069(4) $\AA$ ] are slightly elongated compared to those found in other $\mathrm{sp}^{3}$ $\mathrm{C}-\mathrm{N}$ bonding motifs.

Diethylzinc forms a 1:1 complex with DABCO, $\mathrm{Et}_{2} \mathrm{Zn}(\mathrm{DABCO})$ (94). An X-ray crystal structure determination revealed that $\mathrm{Et}_{2} \mathrm{Zn}(\mathrm{DABCO})$ exists in the solid state as a coordination polymer in which $\mathrm{Et}_{2} \mathrm{Zn}$ units are linked by the two coordinating nitrogen atoms

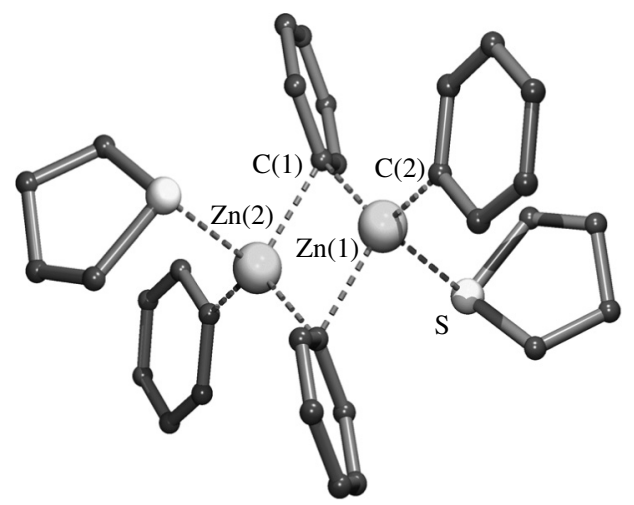

FIGURE 48. Solid state structure of dimeric $\mathbf{9 3}$ 


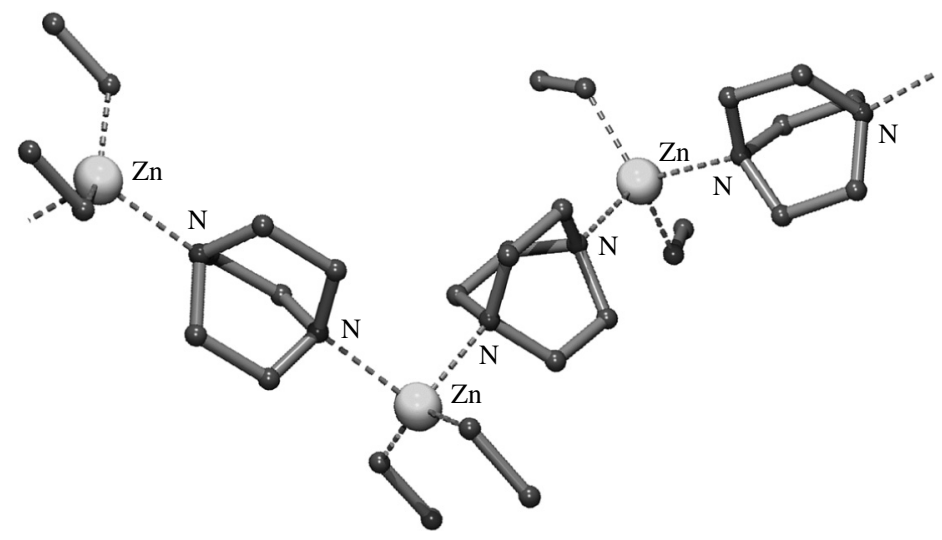

FIGURE 49. Polymeric structure of $\mathbf{9 4}$ in the solid state

of DABCO molecules (Figure 49) ${ }^{152}$. Also in this case, the zinc atoms have a distorted tetrahedral coordination geometry.

Ethylzinc-enamine (95) undergoes a condensation reaction with aldehydes, affording ethylzinc-aldolates (equation 20$)^{153}$. Such ethylzinc-aldolates are dimers, due to bridging of the aldolate-oxygen atoms between two zinc atoms. The structural features of this type of compounds will be discussed elsewhere in this chapter.<smiles>CCCCN1N(C(C)C)C=C[Te]1CC</smiles>

(95)

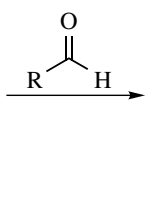

When 95 is reacted with 4-pyridinecarboxaldehyde, ethylzinc aldolate (96) is obtained (equation 20). When a solution of 96 is treated with excess diethylzinc, a crystalline material (97) is obtained which appears to be a coordination polymer. This polymer consists of dimeric ethylzinc-aldolate units, linked to a polymeric chain via coordination of the peripheral pyridyl groups to diethylzinc units (Figure 50) ${ }^{154}$. The diethylzinc units in 97 are distorted tetrahedral with $\mathrm{C}-\mathrm{Zn}-\mathrm{C}$ and $\mathrm{N}-\mathrm{Zn}-\mathrm{N}$ angles of $145.7(6)^{\circ}$ and $89.4(4)^{\circ}$, respectively.

The large majority of diorganozinc complexes of which the structure in the solid state has been elucidated are those in which a $N, N$-chelating ligand is coordinated to the zinc atom. The relevant structural features of all these compounds are summarized in Table 6.

The geometry at zinc in all compounds is comparable, i.e. the zinc atoms have a distorted tetrahedral coordination geometry. The $\mathrm{Zn}-\mathrm{C}$ bond lengths are as expected for $\mathrm{sp}^{3}$-bonded carbon atoms to zinc. A larger variation is seen in the $\mathrm{C}-\mathrm{Zn}-\mathrm{C}$ bond angles and the $\mathrm{Zn}-\mathrm{N}$ coordinate bond lengths. The $\mathrm{N}-\mathrm{Zn}-\mathrm{N}$ angles seem to be governed by the bite angle of the particular chelate ligand involved. When TMEDA complexes 98-103 


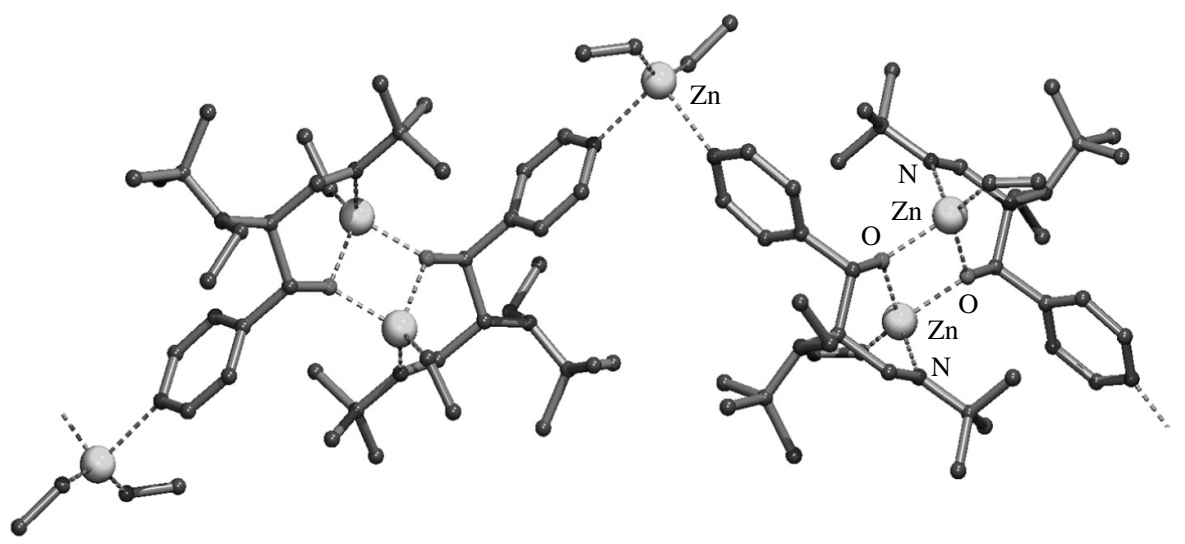

FIGURE 50. Part of the polymeric chain of coordination polymer $\mathbf{9 7}$

TABLE 6. Relevant structural features of $\mathrm{R}_{2} \mathrm{ZnN}_{2}$ complexes $\left(\mathrm{N}_{2}=N, N\right.$-chelating ligand)

\begin{tabular}{|c|c|c|c|c|c|c|}
\hline Compound & $\mathrm{R}$ & $\mathrm{N}_{2}$ & $\mathrm{Zn}-\mathrm{N}(\AA)$ & $\mathrm{C}-\mathrm{Zn}-\mathrm{C}\left({ }^{\circ}\right)$ & $\mathrm{N}-\mathrm{Zn}-\mathrm{N}\left({ }^{\circ}\right)$ & Reference \\
\hline 98 & $\mathrm{Me}$ & TMEDA & $2.260(8), 2.278(8)$ & $135.8(3)$ & $79.8(3)$ & 155 \\
\hline 99 & $\mathrm{Me}_{3} \mathrm{CCH}_{2}$ & TMEDA & $2.411(4), 2.411(4)$ & $148.3(1)$ & $77.3(2)$ & 155 \\
\hline 100 & Et & TMEDA & $2.293(5), 2.293(5)$ & 118 & $80.7(2)$ & 128 \\
\hline 101 & $\mathrm{Bn}$ & TMEDA & $2.202(3), 2.209(3)$ & $122.2(2)$ & $82.7(1)$ & 156 \\
\hline 102 & $\mathrm{Ph}\left(\mathrm{Me}_{3} \mathrm{Si}\right) \mathrm{CH}$ & TMEDA & $2.329(4), 2.314(4)$ & $141.6(2)$ & $79.6(1)$ & 156 \\
\hline 103 & $\begin{array}{c}\mathrm{Ph}\left(\mathrm{Me}_{3} \mathrm{Si}\right) \mathrm{CH}, \\
\mathrm{Me}^{a}\end{array}$ & TMEDA & $2.207(2), 2.260(2)$ & 131.1(1) & $81.57(7)$ & 157 \\
\hline 104 & $\mathrm{Me}$ & Sparteine & $2.222(5), 2.256(6)$ & $128.2(4)$ & $80.4(2)$ & 158 \\
\hline 105 & $\mathrm{Me}$ & $\mathrm{N}_{4}$-aza crown ${ }^{b}$ & $2.282(3), 2.282(3)$ & $125.5(2)$ & $87.21(9)$ & 159 \\
\hline 106 & $\mathrm{Me}$ & $\mathrm{N}_{6}$-aza crown ${ }^{c}$ & $2.331(2), 2.257(2)$ & 138.1(1) & $80.35(7)$ & 159 \\
\hline 107 & $\mathrm{Me}$ & $(S, S)$-ebpe ${ }^{d}$ & $2.230(3), 2.230(3)$ & $134.8(2)$ & $80.3(2)$ & 160 \\
\hline 108 & $\mathrm{Me}$ & $2,2^{\prime}$-bipy ${ }^{e}$ & $2.116(9), 2.116(9)$ & $127.9(1)$ & $74.3(6)$ & 161 \\
\hline 109 & $\left(\mathrm{Me}_{3} \mathrm{Si}\right)_{2} \mathrm{CH}$ & $2,2^{\prime}$-bipy ${ }^{e}$ & $2.179(4), 2.196(5)$ & $126.4(2)$ & $74.1(3)$ & 162 \\
\hline 110 & $\mathrm{ICH}_{2}$ & $2,2^{\prime}$-biqui ${ }^{f}$ & $2.135(7), 2.141(6)$ & $125.5(3)$ & $76.8(2)$ & 163 \\
\hline 111 & $\mathrm{ClCH}_{2}$ & $2,2^{\prime}$-biqui ${ }^{f}$ & $2.117(4), 2.137(4)$ & $127.7(3)$ & $77.0(2)$ & 163 \\
\hline 112 & $\mathrm{Me}$ & $t$-BuDAB ${ }^{g}$ & $2.207(7), 2.225(7)$ & $137.3(3)$ & $75.0(2)$ & 164 \\
\hline
\end{tabular}

${ }^{a}$ The $\mathrm{R}_{2} \mathrm{Zn}$ moiety contains two different $\mathrm{R}$ groups.

${ }^{b}$ 1,4,8,11-Tetramethyl-1,4,8,11-tetraazacyclotetradecane.

${ }^{c} 1,4,7,10,13,16$-Hexamethyl-1,4,7,10,13,16-hexaazacyclooctadecane.

${ }^{d}(S, S)-N, N^{\prime}$-Ethylenebis(1-phenylethylamine).

e $2,2^{\prime}$-Bipyridine.

$f 2,2^{\prime}$-Biquinoline

${ }^{g}$ 1,4-Di-tert-butyl-1,4-diaza-1,3-butadiene.

are compared, the general trend is that the $\mathrm{C}-\mathrm{Zn}-\mathrm{C}$ bond angle increases with increasing steric bulk of the organic groups bound to zinc. $\mathrm{Me}_{2} \mathrm{Zn}$ (TMEDA) (98) is an exception in that it has a relatively large $\mathrm{C}-\mathrm{Zn}-\mathrm{C}$ bond angle $\left[135.8(3)^{\circ}\right]$ while this compound has the least sterically demanding groups bound to zinc.

It is interesting to note that the $\mathrm{Me}_{2} \mathrm{Zn}$ complexes of the macrocyclic amines $\mathrm{N}_{4}$ aza crown and $\mathrm{N}_{6}$-aza crown (Table 6) ${ }^{159}, \mathbf{1 0 5}$ and 106, respectively, display a different coordination behaviour. Both macrocyclic amines coordinate to two $\mathrm{Me}_{2} \mathrm{Zn}$ units each, using two nitrogen atoms. In 105, the two $\mathrm{Me}_{2} \mathrm{Zn}$ units are coordinated in such a way that two six-membered chelate rings are formed. In 106, the only possibility is the formation of five-membered chelate rings. 


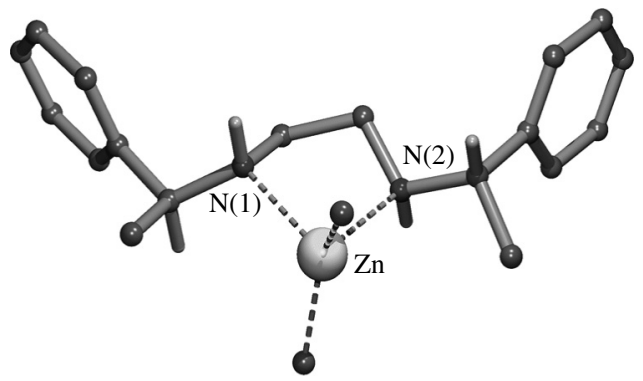

FIGURE 51. Solid state structure of $\mathrm{Me}_{2} \mathrm{Zn}[(S, S)$-ebpe $]$ (107)

The complex of $\mathrm{Me}_{2} \mathrm{Zn}$ with $(S, S)$-ebpe, 107, has been applied successfully as catalyst in the enantioselective reduction of ketones by polymethylhydrosiloxane and combines excellent product yields with high ee values ${ }^{160}$. Its structure comprises the $N, N$-chelate coordination of the ebpe ligand to the $\mathrm{Me}_{2} \mathrm{Zn}$ unit (Figure 51). It is remarkable that in this case the two secondary amine functionalities are coordinated to zinc and leave the $\mathrm{Zn}-\mathrm{C}$ bonds unaffected. Indeed, usually secondary amines undergo a fast deprotonation reaction with dialkylzinc compounds.

It has already been known for a long time that haloalkylzinc compounds are excellent reagents in cyclopropanation reactions ${ }^{165}$. Such compounds, however, are rather unstable and are usually prepared in situ. It appears that 2,2'-bipyridine and 2,2'-biquinoline stabilize these haloalkylzinc compounds to a large extent ${ }^{163}$. Compounds $\mathbf{1 1 0}$ and $\mathbf{1 1 1}$ (Table 6) are examples of stabilized cyclopropanating reagents that can be stored as solid materials over a longer period of time.

The diorganozinc coordination complexes considered so far are all colourless materials. However, the bipyridine complexes 108 and 109, the biquinoline complexes 110 and 111 and the $t$-BuDAB complex 112 (Table 6) are intensely coloured. This feature has been studied for a series of $\mathrm{R}_{2} \mathrm{Zn}\left(t\right.$-BuDAB) complexes $(\mathrm{R}=\mathrm{Me} \text {, Et, } i \text {-Pr, } t \text {-Bu })^{166,167}$. It appeared that the absorption maximum is dependent on the nature of the $\mathrm{R}$ group bound to zinc and shifts to longer wavelengths in the order $\mathrm{R}=\mathrm{Me}$, primary-alkyl, secondary-alkyl, tertiary-alkyl (Table 7). It has been suggested that the intense colour of these complexes is caused by a $S_{0} \rightarrow S_{1}$ LLCT transition $\sigma(\mathrm{Zn}-\mathrm{C}) \rightarrow \pi^{*}(t \text {-BuDAB })^{164,167}$. Furthermore, it appeared that in contrast to, e.g., $\mathrm{R}_{2} \mathrm{Zn}$ (bipy) complexes, which are stable compounds, the $\mathrm{R}_{2} \mathrm{Zn}(t$-BuDAB) complexes are intrinsically unstable and undergo an intramolecular reaction. This was a serendipitous observation when $\mathrm{Et}_{2} \mathrm{Zn}$ was reacted with $t$-BuDAB. An $N$-alkylated product was obtained instead of the anticipated $\mathrm{Et}_{2} \mathrm{Zn}(t-\mathrm{BuDAB})$ complex $^{167}$. The temperature at which the intramolecular reaction starts in the initially formed $\mathrm{R}_{2} \mathrm{Zn}(t$ BuDAB) complexes depends on the nature of the $\mathrm{R}$ group bound to zinc (Table 7). Computational studies on $\mathrm{R}_{2} \mathrm{Zn}(t-\mathrm{BuDAB})$ complexes, $\mathrm{R}=\mathrm{Me}$, Et, $i$-Pr, $t$-Bu, showed that the LUMOs of these complexes, which are localized within the chelated ligand, have comparable energy levels. However, the HOMO energies increase in the series $\mathrm{R}=\mathrm{Me}<\mathrm{Et}<i-\mathrm{Pr}<t$-Bu. This is also reflected in the stabilities of the corresponding complexes with $\mathrm{R}_{2} \mathrm{Zn}$ of which $t-\mathrm{Bu}_{2} \mathrm{Zn}(t$-BuDAB $)$ is only stable below $-90^{\circ} \mathrm{C}$ and $\mathrm{Me}_{2} \mathrm{Zn}(t-\mathrm{BuDAB})$ is stable at room temperature (Table 7).

The initial reaction step when the temperature of the $\mathrm{R}_{2} \mathrm{Zn}(t$-BuDAB) complex reaches its conversion temperature (Table 7) is an intramolecular SET leading to the $[\operatorname{RZn}(t$ $\mathrm{BuDAB}$ ) $]^{\bullet} / \mathrm{R}^{\bullet}$ radical pair (Scheme 11$)^{164,168}$. The further reaction path depends on the nature of the $\mathrm{R}$ group. When $\mathrm{R}=\mathrm{Me}$, a mixture of products $\mathbf{B}, \mathbf{C}$ and $\mathbf{D}$ (Scheme 11) 
TABLE 7. Characteristic features of $\mathrm{R}_{2} \mathrm{Zn}(t$-BuDAB) complexes

\begin{tabular}{lccc}
\hline $\mathrm{R}$ & Colour & $\lambda_{\max }(\mathrm{nm})$ & Conversion temp $\left({ }^{\circ} \mathrm{C}\right)$ \\
\hline $\mathrm{Me}$ & orange & 390 & 25 \\
$\mathrm{Et}$ & red & 490 & -50 \\
$i-\mathrm{Pr}$ & blue & 590 & -70 \\
$t-\mathrm{Bu}$ & purple & 650 & -90 \\
\hline
\end{tabular}

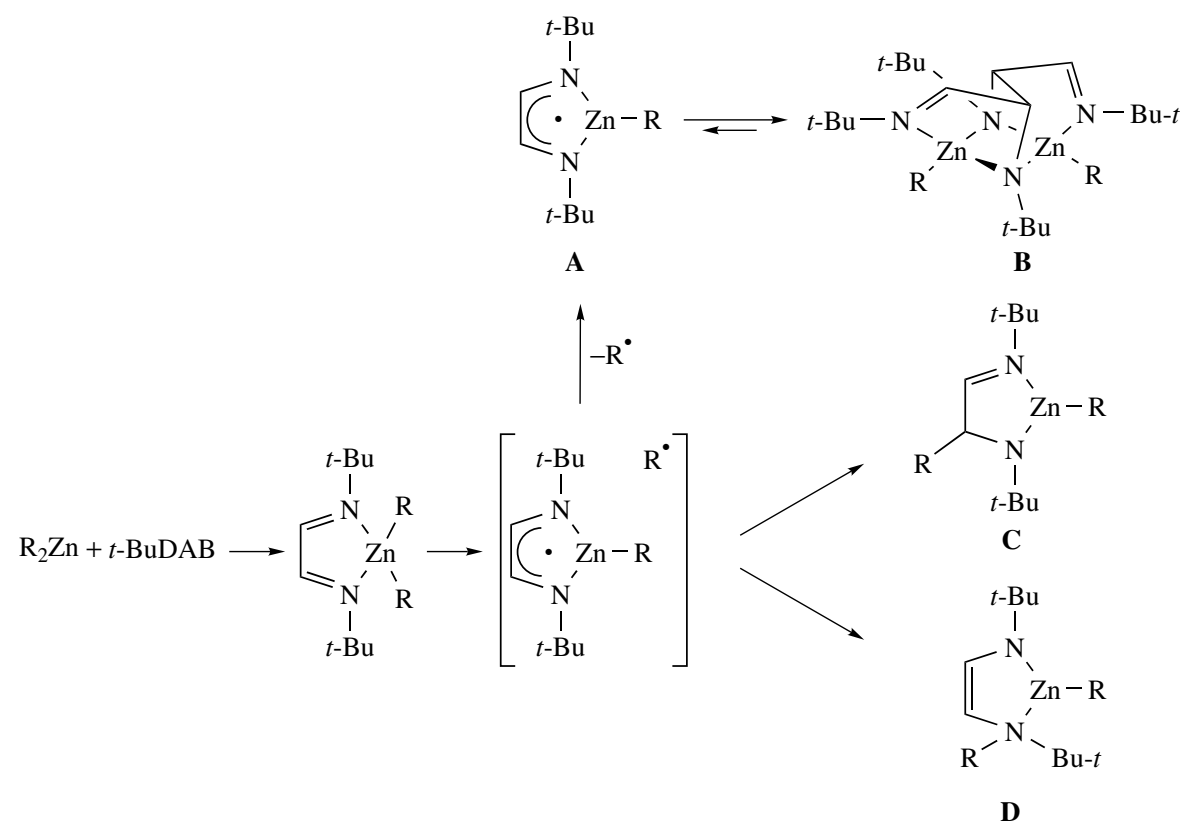

SCHEME 11

in 2:1:1 ratio is obtained. The formation of $\mathbf{B}$ involves a pathway in which the $\mathrm{R}$ radical escapes from the solvent cage followed by dimerization of the organometallic $\mathrm{RZn}(t$ BuDAB) radical $\mathbf{A}$. The formation of products $\mathbf{C}$ and $\mathbf{D}$ is the result of transfer of the $\mathrm{R}$ radical to the imine carbon atom and the imine nitrogen atom, respectively. When $\mathrm{R}$ is any primary alkyl group, the predominant product is $\mathbf{D}$ and traces of $\mathbf{B}$ are observed. When $\mathrm{R}$ is a secondary alkyl group, a mixture of $\mathbf{C}$ and $\mathbf{D}$ (2:1 ratio) and traces of $\mathbf{B}$ are obtained. When $\mathrm{R}=t$ - $\mathrm{Bu}$, almost exclusively $\mathbf{C}$ in addition to traces of $\mathbf{B}$ are obtained.

The formation of the $\mathrm{RZn}(t-\mathrm{BuDAB})$ radicals is notable and it appeared that these radicals are examples of persistent organometallic radicals in equilibrium with their $\mathrm{C}-\mathrm{C}$ coupled dimer. These dimers could be independently synthesized in high yield from the reaction of $(t-\mathrm{BuDAB}) \mathrm{K}$ and the corresponding $\mathrm{RZnCl}$ compound. The rate constant of the equilibrium between the persistent radical and its $\mathrm{C}-\mathrm{C}$ coupled dimer is sufficiently small to study the dimers by NMR spectroscopy and the radicals by ESR spectroscopy ${ }^{164,169}$. The obtained ESR data are in agreement with a structure for the radical in which the zinc atom adopts a trigonal planar geometry. In this respect it should be noted that the in situ 


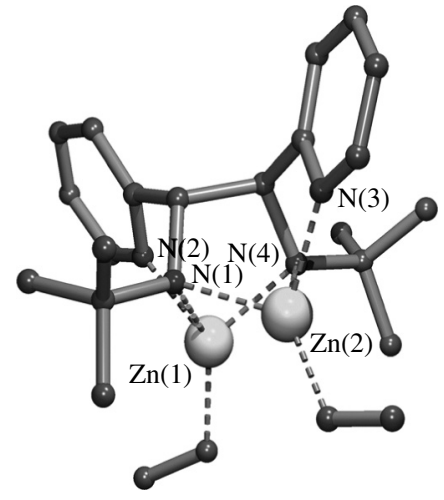

FIGURE 52. Solid state structure of $\mathbf{1 1 3}$

formation of $\mathrm{EtZn}$ (bipy) radicals from the reaction of (bipy)K and $\mathrm{EtZnCl}$ has also been reported ${ }^{170}$.

For one of the $\mathrm{C}-\mathrm{C}$ coupled dimers, i.e. the one with $\mathrm{R}=\mathrm{Me}_{3} \mathrm{SiCH}_{2}$ (113), the structure in the solid state was unambiguously established by an X-ray crystal structure determination ${ }^{169}$. The structure comprises a $\mathrm{C}-\mathrm{C}$ coupled dimer of the $t$-BuDAB ligand in which the length of the formed $\mathrm{C}-\mathrm{C}$ bond $(1.62 \AA)$ is notable and it is considerably longer than expected for a normal $\mathrm{sp}^{3}-\mathrm{C}-\mathrm{sp}^{3}-\mathrm{C}$ bond. Each of the two imido nitrogen atoms bridges between two EtZn units while each of the terminal imino nitrogen atoms coordinates to a zinc atom, thus rendering each zinc atom a distorted tetrahedral coordination geometry. A similar structure was observed for the $\mathrm{C}-\mathrm{C}$ coupled dimer (113) (Figure 52), obtained from dimerization of the corresponding radical EtZn(pyca) from the thermolysis reaction of $\mathrm{Et}_{2} \mathrm{Zn}$ (pyca) (pyca $=N$-tert-butyl-2-pyridinecarbaldimine) ${ }^{168,171}$. These $\mathrm{R}_{2} \mathrm{Zn}$ (pyca) complexes show a similar intramolecular reactivity to that observed for the $\mathrm{R}_{2} \mathrm{Zn}(t-\mathrm{BuDAB})$ complexes, but more forcing conditions are required (boiling toluene). Moreover, the pathway resulting in $N$-alkylated products (Scheme 11) is blocked, because this would require de-aromatization of the pyridyl group, which is an energetically highly unfavourable process.

\section{HETEROLEPTIC RZnY COMPOUNDS}

\section{A. Introduction}

In heteroleptic monoorganozinc compounds one organic group is $\sigma$-bonded via a carbon atom to the zinc atom. The other group, $\mathrm{Y}$, is bound to zinc via an electronegative heteroatom. Examples of such groups are halogen atoms, oxygen-containing groups like alkoxides, enolates and carboxylates, nitrogen-containing groups like primary and secondary amides, and other groups functionalized with heteroatoms like sulfur, phosphorus, arsenic and selenium. These monoorganozinc-hetero compounds are among the first organozinc compounds discovered; cf. EtZnI by Frankland in $1849^{1}$.

Three major synthetic pathways towards heteroleptic monoorganozinc compounds are available (Scheme 12). The first one involves the reaction of an organic halide with activated metallic zinc as applied in the original synthesis of EtZnI from EtI and $\mathrm{Zn}^{1}$. Other examples are the formation of the Reformatsky reagent from $\alpha$-bromoesters and metallic zinc ${ }^{172,173}$, the formation of the Simmons-Smith reagent, $\mathrm{ICH}_{2} \mathrm{ZnI}$, from $\mathrm{CH}_{2} \mathrm{I}_{2}$ and metallic zinc ${ }^{174}$ and the formation of polyfunctional organozinc reagents ${ }^{175}$. 


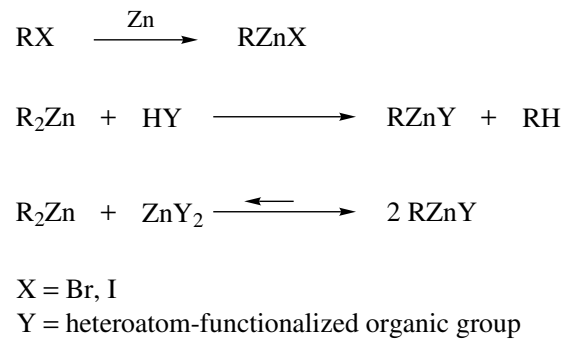

SCHEME 12

The second important route involves the protonolysis of one of the alkyl or aryl groups of dialkyl- or diarylzinc compounds by an organic molecule containing an acidic proton bound to a heteroatom, e.g. alcohols ${ }^{176,177}$ and primary ${ }^{178}$ and secondary amines ${ }^{176,179}$. It is remarkable that one of the alkyl or aryl groups can be removed selectively. When one of the organic groups is protolysed, the reactivity of the remaining zinc-carbon bond is much diminished ${ }^{82}$. It is possible to remove this second organic group, but that in general requires forcing conditions.

The third reaction pathway involves the redistribution reaction of a dialkyl- or diarylzinc compound with a zinc salt. An example of this route is the formation of the unsolvated organozinc halides $\mathrm{EtZnCl}, \mathrm{EtZnBr}$ and $\mathrm{EtZnI}$ from the reaction of pure $\mathrm{Et}_{2} \mathrm{Zn}$ with the corresponding zinc halide in a $1: 1$ ratio $^{180}$.

Due to the presence of an electronegative group directly bound to zinc, the Lewis acidity of the zinc atom in the heteroleptic monoorganozinc compounds is enhanced and they readily form complexes with donor molecules, in which the zinc atom has a tetrahedral coordination geometry. A typical feature of such heteroleptic monoorganozinc compounds is their tendency to form aggregates ${ }^{181}$. With only a very few exceptions often very complicated, aggregated structures occur as a result of the presence of heteroatoms, that are bridging and act as multi-electron donors, between zinc atoms.

A factor that always should be taken into account in case of heteroleptic monoorganozinc compounds, especially in solution, is the existence of Schlenk equilibria (equation 21).

$$
2 \mathrm{RZnY} \rightleftarrows \mathrm{R}_{2} \mathrm{Zn}+\mathrm{ZnY}_{2}
$$

The equilibrium position is dependent on several factors: (i) the nature of the groups bound to zinc, (ii) the nature and polarity of the solvent and (iii) the presence of additional donor molecules. It is therefore dangerous to draw conclusions from structural information about materials that crystallize from these equilibrium mixtures. Such solid materials are not necessarily representative for the 'bulk' material.

Based on the heteroatom directly bound to zinc, the structures of heteroleptic monoorganozinc compounds can be divided into several subclasses that will be discussed separately below. These subclasses are (i) monoorganozinc cations (i.e. compounds consisting of ion pairs), (ii) monoorganozinc halides, (iii) monoorganozinc compounds with one oxygen atom $\sigma$-bonded to zinc, (iv) monoorganozinc compounds with one nitrogen atom $\sigma$-bonded to zinc and (v) monoorganozinc compounds containing anions $\sigma$-bonded to zinc via other heteroatoms.

\section{B. Monoorganozinc Cations}

In the presence of crown ethers, aza-crowns or cryptands, the formation of monoorganozinc cations has been observed in solution when diorganozinc compounds 
are treated with Lewis acids that are capable of accepting an alkyl anion, e.g. $\mathrm{Et}_{3} \mathrm{Al}^{73}$. Similarly, a 1:1 mixture of $\mathrm{Et}_{2} \mathrm{Zn}$ and $\mathrm{Ph}_{2} \mathrm{Zn}$ in the presence of 14N4 (1,4,8,11-tetramethyl1,4,8,11-tetraazacyclotetradecane) undergoes a disproportionation reaction leading to a $[\operatorname{EtZn}(14 \mathrm{~N})]^{+}$cation and a $\left[\mathrm{MePh}_{2} \mathrm{Zn}\right]^{-}$anion ${ }^{72}$. Furthermore, it has been suggested that crown ether-complexed monoorganozinc cations play an important role in the formation of diorganozinc-crown ether rotaxanes ${ }^{148}$.

The reaction of $\mathrm{Et}_{2} \mathrm{Zn}$ with Jutzi's acid $\left[\left(\mathrm{Et}_{2} \mathrm{O}\right) \mathrm{H}\right]\left[\mathrm{B}\left(\mathrm{C}_{6} \mathrm{~F}_{5}\right)_{4}\right]$ in a 1:1 molar ratio in diethyl ether as a solvent proceeds quantitatively under the formation of [ $\mathrm{EtZn}\left(\mathrm{OEt}_{2}\right)_{3}$ ] $\left[\mathrm{B}\left(\mathrm{C}_{6} \mathrm{~F}_{5}\right)_{4}\right](\mathbf{1 1 4})$ and one equivalent of ethane ${ }^{182}$. The structure of 114 in the solid was established by an $\mathrm{X}$-ray crystal structure determination. The monoclinic unit cell contains four $\left[\mathrm{EtZn}\left(\mathrm{OEt}_{2}\right)_{3}\right]^{+}$cations (Figure 53) and four $\left[\mathrm{B}\left(\mathrm{C}_{6} \mathrm{~F}_{5}\right)_{4}\right]^{-}$anions that have no further interactions. The $\left[\mathrm{EtZn}\left(\mathrm{OEt}_{2}\right)_{3}\right]^{+}$cation has a slightly distorted tetrahedral geometry as a result of the coordination of three additional diethyl ether molecules. The $\mathrm{C}-\mathrm{Zn}-\mathrm{O}$ bond angles range from $115.37(10)^{\circ}$ to $123.60(9)^{\circ}$. The $\mathrm{Zn}-\mathrm{C}(1)$ bond distance of $1.964(3) \AA$ is of the same order as in neutral dialkylzinc compounds. The $\mathrm{Zn}-\mathrm{O}$ distances of 2.1096(17), 2.0313(18) and 2.073(18) $\AA$ are considerably shorter than the $\mathrm{Zn}-\mathrm{O}$ coordination bonds in neutral diorganozinc- $O$-coordination complexes, most likely as a consequence of the enhanced Lewis acidity of monoorganozinc cations.

A series of EtZn cationic complexes, stabilized by coordination of $N$-alkylated 1,3,5-triazacyclohexanes with weakly coordinating counter anions like $\mathrm{ClO}_{4}{ }^{-}, \mathrm{BF}_{4}{ }^{-}$or $\mathrm{B}\left(\mathrm{C}_{6} \mathrm{~F}_{5}\right)_{4}{ }^{-}$, has been reported. These complexes are readily available via protonolysis of $\mathrm{Et}_{2} \mathrm{Zn}$ with an acidic tertiary ammonium salt in the presence of the corresponding triazacyclohexane ${ }^{183}$. The structure in the solid state of one of these complexes, i.e. the one containing a 1,3,5-tribenzyl-1,3,5-triazacyclohexane ligand complexed to a EtZn cation and $\mathrm{PF}_{6}$ counter-anion (115), has been determined by X-ray crystallography ${ }^{184}$. As a result of the coordination of all three nitrogen atoms of the ligand to the EtZn cation the zinc atom has a distorted tetrahedral geometry (Figure 54). As a consequence of the rather rigid configuration of the ligand the $\mathrm{N}-\mathrm{Zn}-\mathrm{N}$ angles are acute $\left[62.37(6)^{\circ}, 63.20(7)^{\circ}\right.$ and $\left.62.37(6)^{\circ}\right]$, but the $\mathrm{C}-\mathrm{Zn}-\mathrm{N}$ angles $\left[137.31(9)^{\circ}, 153.33(13)^{\circ}\right.$ and $\left.137.31(9)^{\circ}\right]$ are larger than expected for a tetrahedral geometry. In the crystal lattice two trans-orientated fluorine atoms of the $\mathrm{PF}_{6}$ anion have interactions $(2.85 \AA)$ with the zinc atoms of two neighbouring EtZn cations, leading to a one-dimensional chain structure.

The synthesis and structural characterization of a compound containing $p$-tolylzinc cations complexed to a $N, N, N, N$-tetradentate ligand with a tetraphenylcyclopentadienyl anion as the counterpart has been reported ${ }^{185}$. It seems that all four nitrogen atoms are involved in coordination to zinc, thus giving a penta-coordinate EtZn cation. However,

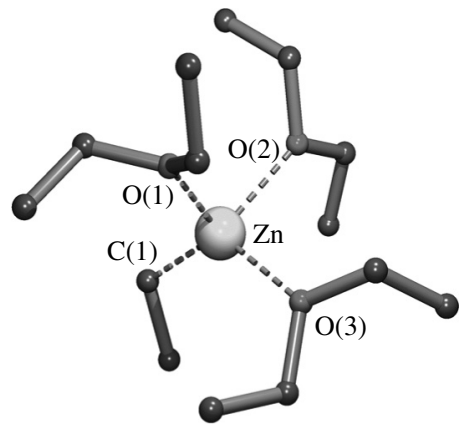

FIGURE 53. The $\left[\operatorname{EtZn}\left(\mathrm{OEt}_{2}\right)_{3}\right]^{+}$cationic part of the structure in the solid state of $\mathbf{1 1 4}$ 


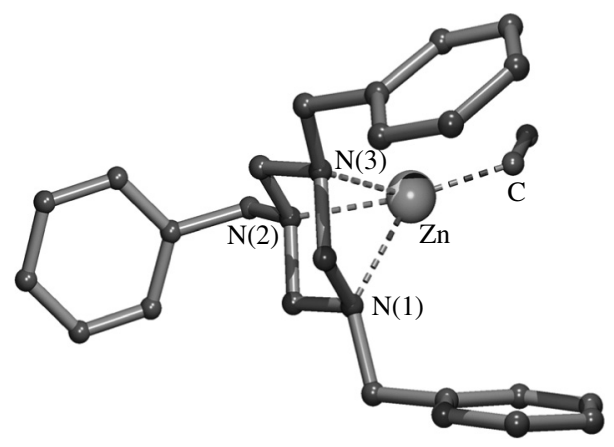

FIGURE 54. Cationic part of the solid state structure of $\mathbf{1 1 5}$

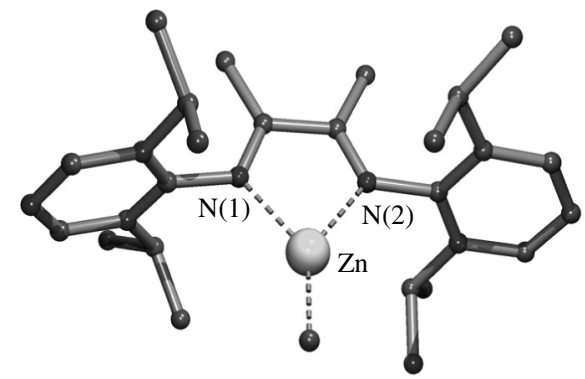

FIGURE 55. Solid state structure of the cationic part of $\mathbf{1 1 6}$

due to the poor quality of the X-ray data and crystallographic disorder in the ligand part, no reliable data with respect to bond distances and angles can be given.

When $\mathrm{Me}_{2} \mathrm{Zn}(\mathrm{DAD})\left[\mathrm{DAD}=\left(\mathrm{C}(\mathrm{Me}) \mathrm{NC}_{6} \mathrm{H}_{3} \mathrm{Pr}_{2}-i-2,6\right)_{2}\right]$ is treated with the strong Lewis acid $\left(\mathrm{C}_{6} \mathrm{~F}_{5}\right)_{3} \mathrm{~B}$, one of the methyl groups is transferred from zinc to boron, giving the ionic complex $[\mathrm{MeZn}(\mathrm{DAD})]\left[\mathrm{MeB}\left(\mathrm{C}_{6} \mathrm{~F}_{5}\right)_{3}\right]^{186}$. Likewise, the selective protonolysis of one of the methyl groups of $\mathrm{Me}_{2} \mathrm{Zn}$ with [DADH] $\left[\mathrm{B}\left(\mathrm{C}_{6} \mathrm{~F}_{5}\right)_{4}\right]$, which contains an acidic proton, gives $[\mathrm{MeZn}(\mathrm{DAD})]\left[\mathrm{B}\left(\mathrm{C}_{6} \mathrm{~F}_{5}\right)_{4}\right](\mathbf{1 1 6})$ and methane in quantitative yield. The solid state structure of $\mathbf{1 1 6}$ comprises the packing of isolated [MeZn(DAD)] ${ }^{+}$cations (Figure 55) and $\left[\mathrm{B}\left(\mathrm{C}_{6} \mathrm{~F}_{5}\right)_{4}\right]^{-}$anions in the crystal lattice. In the methylzinc cation both nitrogen atoms of the DAD ligand are bound to zinc [ $\mathrm{Zn}-\mathrm{N} 2.035(2)$ and 2.045(2) $\AA$ ]. Within experimental error the sum of the bond angles around zinc is $360^{\circ}$, indicating a perfectly planar trigonal coordination geometry around zinc. It has been demonstrated that compound $\mathbf{1 1 6}$ is active as an initiator in the ring-opening polymerization of epoxides.

\section{Monoorganozinc Compounds $\mathbf{R Z n Y}$ with $\mathbf{Y}=$ Halogen}

Although the simple alkylzinc halides $\mathrm{RZnX}(\mathrm{R}=\mathrm{Me}$ or $\mathrm{Et}, \mathrm{X}=\mathrm{Cl}, \mathrm{Br}$, I) were among the first known organozinc compounds ${ }^{1}$, for a long time nothing was known about the actual structures of such compounds in solution or in the solid state. The constitution of these compounds in solution seemed to depend on the particular solvent employed ${ }^{187-190}$. It should be noted that in ethereal solutions, the possibility of the presence of a Schlenk equilibrium should always be considered. In these solvents the organozinc halides most 


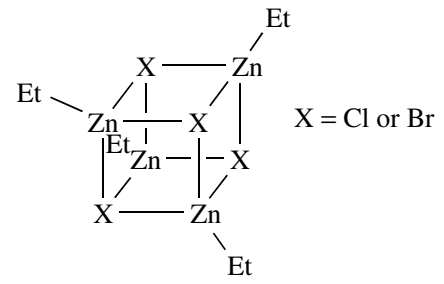

FIGURE 56. Proposed hetero-cubane structures for EtZnCl and EtZnBr

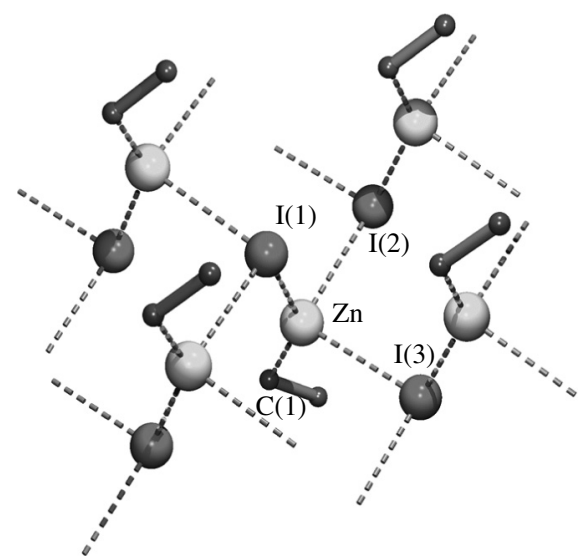

FIGURE 57. Part of the polymeric structure of $\mathbf{1 1 7}$ in the solid state

likely exist as equilibrium mixtures of the parent diorganozinc compound, a solvated zinc dihalide and the organozinc halide itself. However, in apolar solvents like benzene, molecular weight determinations by cryoscopy indicated that $\mathrm{EtZnCl}$ and $\mathrm{EtZnBr}$ exist as discrete tetrameric aggregates ${ }^{189}$. Based on these observations a hetero-cubane-like structure was proposed for these compounds (Figure 56).

EtZnI (117) behaves differently because no clear solutions of this compound could be obtained in apolar solvents. Crystals of $\mathbf{1 1 7}$ suitable for an X-ray crystal determination could be obtained by crystallization of crude $\mathbf{1 1 7}$ from EtI as a solvent ${ }^{189}$. The solid state structure of 117 involves the packing of four EtZnI units in an orthorhombic unit cell in such a way that each of the zinc atoms has additional bonding interactions with two iodine atoms of neighbouring EtZnI units, thus forming a coordination polymer (Figure 57) ${ }^{191}$.

In the structure of $\mathbf{1 1 7}$ the $\mathrm{Zn}-\mathrm{C}$ bond distance of $1.95 \AA$ is as expected for a $\mathrm{sp}^{3}$ hybridized carbon atom bound to zinc. Each of the zinc atoms has one relatively short $(2.64 \AA)$ and two longer $(2.91 \AA) \mathrm{Zn}-\mathrm{I}$ bonds. The zinc atom has a distorted tetrahedral coordination geometry $\left[\mathrm{C}(1)-\mathrm{Zn}-\mathrm{I}(1) 106^{\circ}, \mathrm{C}(1)-\mathrm{Zn}-\mathrm{I}(2) 144^{\circ}, \mathrm{C}(1)-\mathrm{Zn}-\mathrm{I}(3) 106^{\circ}\right.$ and $\left.\mathrm{I}(1)-\mathrm{Zn}-\mathrm{I}(3) 144^{\circ}\right]$ and the geometry of the iodine atoms is close to pyramidal.

It has been well-established that monoorganozinc halides readily form coordination complexes with bidentate ligands like 2.2'-bipyridine and TMEDA ${ }^{82}$. Invariably, such complexes are monomolecular species. The structures of four TMEDA complexes of $\mathrm{RZnCl}$ compounds have been established by X-ray crystal structure determinations. These 


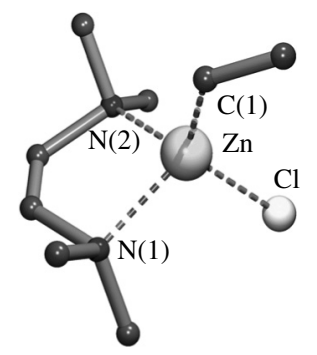

FIGURE 58. Solid state structure of EtZnCl(TMEDA) (118)

complexes are EtZnCl(TMEDA) ${ }^{128}, \mathrm{Ph}\left(\mathrm{Me}_{3} \mathrm{Si}\right) \mathrm{CHZnCl}(\mathrm{TMEDA})^{157}$, the TMEDA complex of 2,2,4,4-tetramethyl-2,4-disilacyclobutylzinc chloride ${ }^{192}$ and the TMEDA complex of 2,4-pentadienylzinc chloride ${ }^{193}$. The structures of these compounds are very closely related with respect to bond distances and bond angles at the zinc centre. As a representative example the details of the structure of $\mathrm{EtZnCl(TMEDA)} \mathrm{(118)} \mathrm{are} \mathrm{given} \mathrm{in}$ Figure 58.

In compound 118 the TMEDA ligand is $N, N$-chelate-bonded to zinc [Zn-N $2.138(7) \AA]$, resulting in a distorted tetrahedral coordination geometry at zinc. This is reflected in the bond angles around zinc $\left[\mathrm{C}(1)-\mathrm{Zn}-\mathrm{Cl} 124.9(4)^{\circ}, \mathrm{C}(1)-\mathrm{Zn}-\mathrm{N}\right.$ both $116.1(3)^{\circ}, \mathrm{Cl}-\mathrm{Zn}-\mathrm{N}$ both $103.8(2)^{\circ}$ and $\left.\mathrm{N}(1)-\mathrm{Zn}-\mathrm{N}(2) 84.4(3)^{\circ}\right]$. The $\mathrm{Zn}-\mathrm{C}(1)$ distance of 1.94(1) $\AA$ is as expected for a $\mathrm{Zn}-\mathrm{C}$ bond. The $\mathrm{Zn}-\mathrm{Cl}$ bond is 2.269(3) $\AA$, which is shorter than the sum of the van der Waals radii.

$\mathrm{CF}_{3} \mathrm{CCl}_{2} \mathrm{ZnCl}(\mathrm{DMF})_{2}$, which is a key intermediate in the one-pot synthesis of $\mathrm{CF}_{3} \mathrm{CCl}_{2}$ substituted alcohols ${ }^{194}$, can be prepared directly from $\mathrm{CF}_{3} \mathrm{CCl}_{3}$ and metallic zinc in the presence of DMF. An X-ray crystal structure determination of this compound revealed a monomolecular molecule, with the $\mathrm{CF}_{3} \mathrm{CCl}_{2}$ group and the chloride atom $\sigma$-bonded to zinc and two DMF molecules coordinated to zinc via their oxygen atoms ${ }^{195}$. The $\mathrm{Zn}-\mathrm{C}$ bond length of 2.021(7) is slightly elongated compared to the value observed in other alkylzinc compounds. With the exception of the $\mathrm{C}-\mathrm{Zn}-\mathrm{Cl}$ bond angle of $122.2(3)^{\circ}$, all other bond angles around zinc are close to the ideal tetrahedral value.

When 2-cyanoethylzinc iodide is recrystallized from THF, a crystalline material is obtained. This material appeared to be the mono-THF adduct of 2-cyanoethylzinc iodide which exists in the solid state as a coordination polymer via coordination of the cyanide functionality to an adjacent zinc atom. Coordination saturation at zinc is reached by the coordination of an additional THF molecule. No further structural data have been given for this compound ${ }^{196}$.

The reaction of (2-iodo-1,3-xylene)-15-crown-4 with $\mathrm{Ph}_{2} \mathrm{Zn}$ for several weeks afforded a remarkable zinc-iodide exchange reaction, resulting in the formation of arylzinc iodide (119) (Figure 59) ${ }^{197}$. In 119 the zinc atom is $\sigma$-bonded to the $\mathrm{C}(1)$-aryl carbon atom, while two of the oxygen atoms, $\mathrm{O}(2)$ and $\mathrm{O}(3)$, of the crown ether moiety are intramolecularly coordinated to zinc, resulting in a slightly distorted tetrahedral coordination geometry. This compound is the only example of an arylzinc halide of which the structure was established by an X-ray crystal structure determination.

The solid state structure of the Simmons-Smith reagent, $\mathrm{ICH}_{2} \mathrm{ZnI}$, encapsulated in 18-crown-6 has been established by X-ray crystallography ${ }^{198}$. This complex (120) has a rotaxane structure in which, in addition to the $\mathrm{Zn}-\mathrm{C}(1)$ bond [1.995(9) $\AA]$ and the $\mathrm{Zn}-\mathrm{I}(2)$ bond $[2.513(2) \AA]$, three oxygen atoms of the 18-crown- 6 moiety are involved in coordination to zinc $[\mathrm{Zn}-\mathrm{O}(1) 2.34(1), \mathrm{Zn}-\mathrm{O}(2) 2.56(1)$ and $\mathrm{Zn}-\mathrm{O}(3) 2.60(1) \AA]$. 


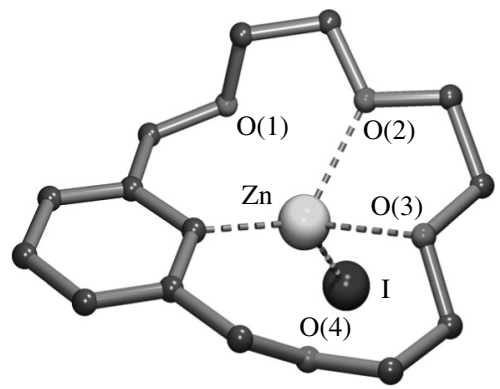

FIGURE 59. Structure of arylzinc iodide $\mathbf{1 1 9}$ in the solid state

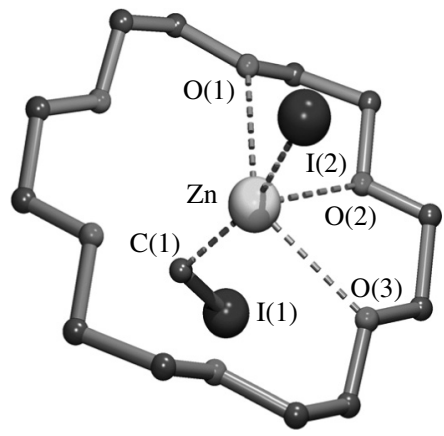

FIGURE 60. The rotaxane structure of $\mathbf{1 2 0}$ in the solid state

This results in a highly distorted trigonal bipyramidal coordination geometry at zinc (Figure 60). The solid state structure of the dibenzo-18-crown-6 analog of $\mathbf{1 2 0}$ has also been established by an X-ray crystal structure determination. Its structural features are closely related to those of $\mathbf{1 2 0}$.

Reaction of the intramolecular chelating copper alkoxides 121 or 122 with $\left(\mathrm{Me}_{3} \mathrm{Si}\right)_{3}$ $\mathrm{CZnCl}$ afforded complexes $\mathbf{1 2 3}$ and $\mathbf{1 2 4}$ (equation 22) ${ }^{199}$. In these complexes the copper bis(alkoxide) moiety acts as an $O, O$-chelating ligand coordinated to zinc.

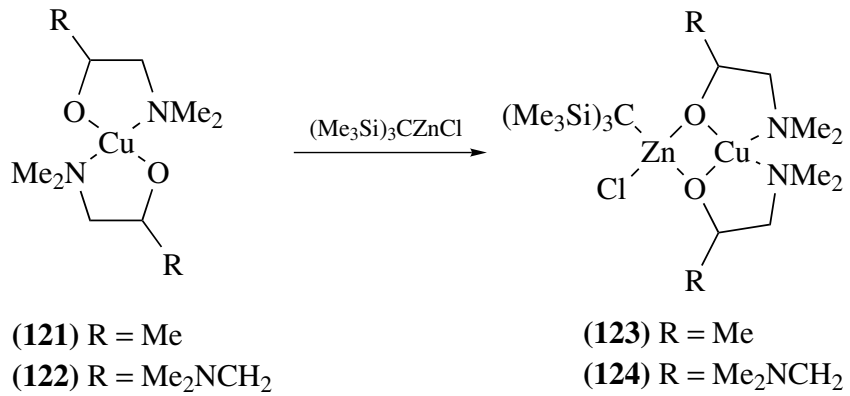

The structures of both $\mathbf{1 2 3}$ and $\mathbf{1 2 4}$ were established by X-ray crystal structure determinations. With respect to the zinc environment the structural features of these complexes are 


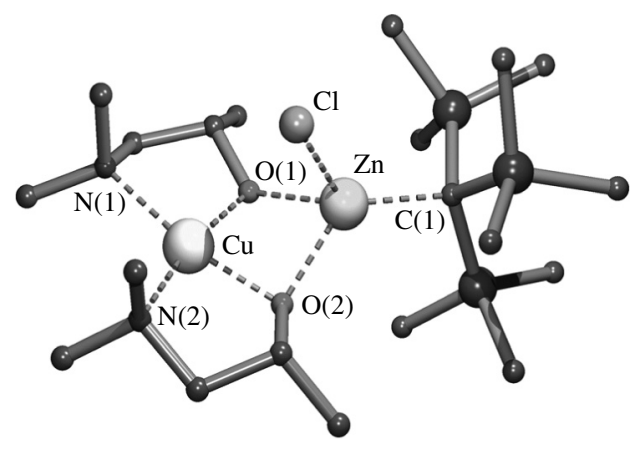

FIGURE 61. Solid state structure of $\mathbf{1 2 3}$

closely related and, as a representative example, the structure of $\mathbf{1 2 3}$ is shown (Figure 61). The geometry at zinc is distorted tetrahedral; the $\mathrm{C}(1)-\mathrm{Zn}-\mathrm{Cl}$ angle of $120.5(3)^{\circ}$ is comparable to the values observed in $\mathrm{RZnCl}$ (TMEDA) complexes ${ }^{128,157,192}$. The $\mathrm{C}(1)-\mathrm{Zn}-\mathrm{O}$ angles $\left[130.7(3)^{\circ}\right.$ and $\left.129.8(3)^{\circ}\right]$ are larger and the $\mathrm{O}-\mathrm{Zn}-\mathrm{Cl}$ angles $\left[93.2(2)^{\circ}\right.$ and $\left.93.7(2)^{\circ}\right]$ are smaller than the ideal tetrahedral value. The $\mathrm{O}-\mathrm{Zn}-\mathrm{O}$ angle $\left[76.0(3)^{\circ}\right]$ is extremely small and is a consequence of the bite angle of the $O, O$-chelating ligand. Furthermore, it is interesting to note that in both $\mathbf{1 2 3}$ and $\mathbf{1 2 4}$ two chiral carbon centres are present in the alkoxide ligand, but only the achiral meso-isomers, with approximately $C_{S}$ symmetry, crystallize from solutions.

With the exception of EtZnI, which in the solid state forms an aggregated structure (vide supra), the structures of the organozinc halide complexes discussed so far are of discrete mononuclear molecules. The presence of the halogen atom bonded to zinc in monoorganozinc halogenides opens the possibility to form dimers via halogen bridges. The formation of such dimers in solid state structures was first reported for $\left[\mathrm{CF}_{3} \mathrm{CCl}_{2} \mathrm{ZnCl}\right.$ $\left.\left(\mathrm{OEt}_{2}\right)\right]_{2}$. Here, a central $\mathrm{Zn}-\mathrm{Cl}-\mathrm{Zn}-\mathrm{Cl}$ square is present and to each of the zinc atoms a $\mathrm{CF}_{3} \mathrm{CCl}_{2}$ group is bonded and a coordinating diethyl ether molecule ${ }^{151}$. The central four-membered $\mathrm{Zn}-\mathrm{Cl}-\mathrm{Zn}-\mathrm{Cl}$ ring is flat and, as a consequence, the zinc atoms have a highly distorted tetrahedral coordination geometry. Although dimerization via halogen bridges was unambiguously established by an X-ray crystal structure determination, further structural details could not be obtained due to crystallographic disorder of the coordinating diethyl ether molecules.

In the solid state $\left[\left(\mathrm{PhMe}_{2} \mathrm{Si}\right)_{3} \mathrm{C}\right] \mathrm{ZnCl}(\mathbf{1 2 5})$ forms chloride-bridged dimers, as was established by an X-ray crystal structure determination ${ }^{200}$. In $\mathbf{1 2 5}$ the two chlorine atoms bridge the two zinc atoms (Figure 62) in a symmetrical manner [ $\mathrm{Zn}(1)-\mathrm{Cl}(1) 2.303(3)$ and $\mathrm{Zn}(2)-\mathrm{Cl}(1) 2.365(3) \AA ̊ \Omega$. The two zinc atoms have a trigonal planar coordination geometry $\left[\mathrm{C}(1)-\mathrm{Zn}(1)-\mathrm{Cl}(1) 137.9(2)^{\circ}, \mathrm{C}(1)-\mathrm{Zn}(1)-\mathrm{Cl}(2) 133.9(2)^{\circ}\right.$ and $\mathrm{Cl}(1)-\mathrm{Zn}(1)-\mathrm{Cl}(2)$ $88.2(1)^{\circ}$ ]. In the presence of THF, 125 forms an adduct in which, according to its ${ }^{1} \mathrm{H}$ NMR spectrum, one THF molecule per zinc atom is present, most likely having a structure comparable to that of the $\left[\mathrm{CF}_{3} \mathrm{CCl}_{2} \mathrm{ZnCl}\left(\mathrm{OEt}_{2}\right)\right]_{2}$ dimer described above.

The organozinc bromide $\mathrm{RZnBr}(\mathbf{1 2 6})$, in which $\mathrm{R}$ is the monoanionic, potentially bidentate coordinating $\left[\mathrm{NC}_{5} \mathrm{H}_{4} \mathrm{C}\left(\mathrm{SiMe}_{3}\right)_{2}-2\right]^{-}$ligand, also forms bromine-bridged dimers in the solid state (Figure 63$)^{201}$. In the centrosymmetric dimer, the $\left[\mathrm{NC}_{5} \mathrm{H}_{4} \mathrm{C}\left(\mathrm{SiMe}_{3}\right)_{2}-2\right]^{-}$ ligand is $\sigma$-bonded via its $\alpha$-carbon atom [Zn-C 2.037(4) $\AA$ ] and an additional coordinate bond is formed with the pyridyl nitrogen atom [Zn-N 2.077(4) $\AA$ ]. The bromine atoms bridge rather symmetrically between the two zinc atoms in the dimer $[\mathrm{Zn}-\mathrm{Br}(1) 2.5398(7)$ and $\mathrm{Zn}-\mathrm{Br}(2)$ 2.4601(6) Å]. 


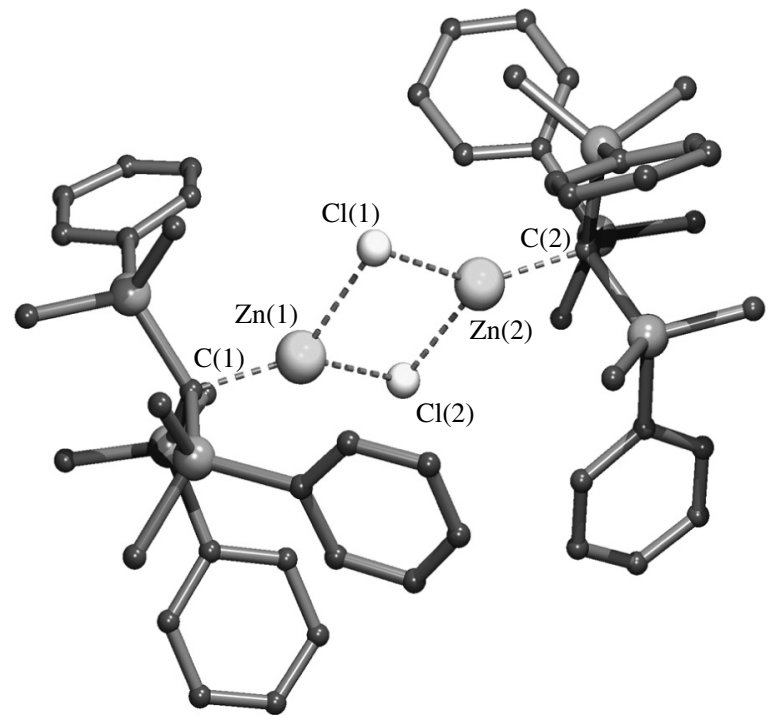

FIGURE 62. Solid state structure of dimeric $\mathbf{1 2 5}$

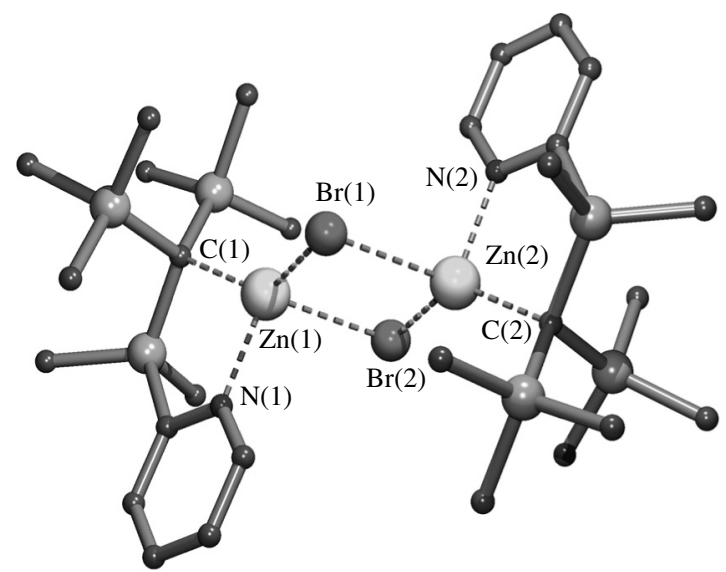

FIGURE 63. Solid state structure of dimeric $\mathbf{1 2 6}$

A similar structure, in which a heteroatom-containing substituent is intramolecularly coordinated to zinc, was observed for $\left[\left\{\left(\mathrm{Me}_{3} \mathrm{Si}_{2}\right)_{2}\left(\mathrm{Me}_{2} \mathrm{NSiMe}_{2}\right) \mathrm{C}\right\} \mathrm{ZnBr}\right]_{2} \quad$ (127) (Figure 64$)^{202}$. Also in this dimer the bromine atoms bridge symmetrically between the two zinc atoms $[\mathrm{Zn}(1)-\operatorname{Br}(1) 2.4614(4)$ and $\mathrm{Zn}(2)-\operatorname{Br}(1) 2.4963(4) \AA]$, while two $\left[\left(\mathrm{Me}_{3} \mathrm{Si}\right)_{2}\left(\mathrm{Me}_{2} \mathrm{NSiMe}_{2}\right) \mathrm{C}\right]^{-}$ligands are $C, N$-chelate-bonded [Zn(1)-C(1) 2.045(3) and $\mathrm{Zn}(1)-\mathrm{N}(1) 2.152(2) \AA]$ to the zinc atoms.

Also, other metal halides can aggregate with monoorganozinc halogenides, as was shown by the X-ray crystal structure determination of $\left[\left(\mathrm{Me}_{3} \mathrm{Si}\right)_{2}\left(\mathrm{MePhNSiMe}_{2}\right) \mathrm{C}\right] \mathrm{ZnBr}_{2} \mathrm{Li}$ 


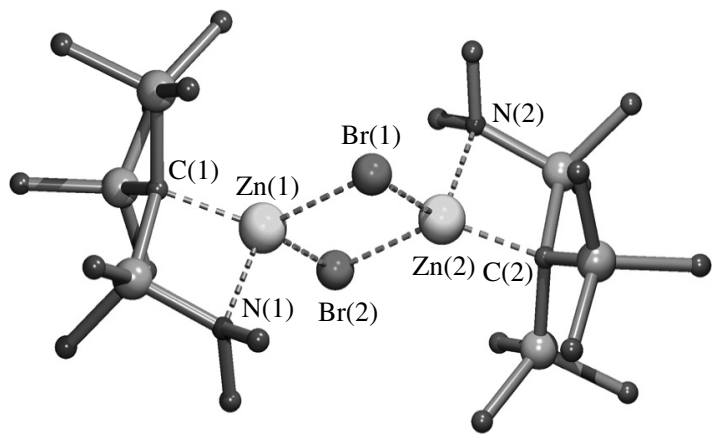

FIGURE 64. Structure of dimeric $\mathbf{1 2 7}$ in the solid state

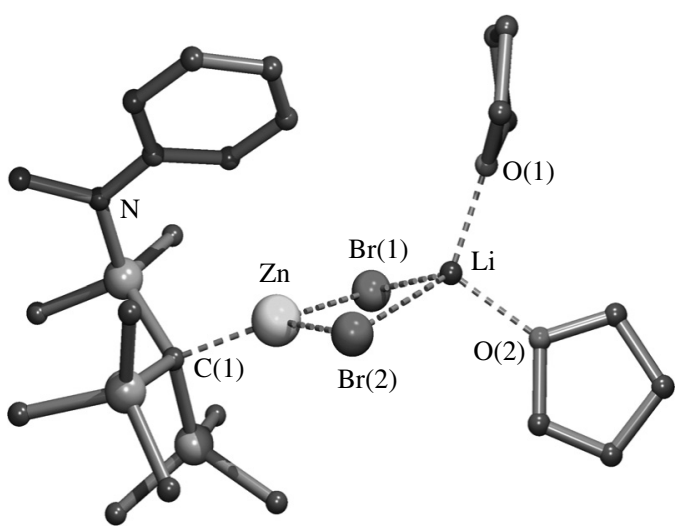

FIGURE 65. Solid state structure of the $\mathrm{RZnBr} 2 \mathrm{Li}(\mathrm{THF})_{2}$ aggregate $\mathbf{1 2 8}$

$(\mathrm{THF})_{2}(\mathbf{1 2 8})$ (Figure 65) ${ }^{202}$. In this compound two bromine atoms are bridging between zinc and lithium. The $\mathrm{Zn}-\mathrm{Br}(1)-\mathrm{Li}-\mathrm{Br}(2)$ ring is folded with an angle of $17^{\circ}$ along the $\mathrm{Br} \cdots \mathrm{Br}$ vector. Surprisingly, the nitrogen atom of the organosilicon fragment is not coordinated to the zinc atom, thus leaving this zinc atom three-coordinate. Most probably, the $N$-methylaniline group is too weakly basic to coordinate to the zinc centre. A tetrahedral coordination geometry at the lithium atom is reached by the coordination of two additional THF molecules.

Dimeric [2-( $\left.\left.\mathrm{Me}_{2} \mathrm{NCH}_{2} \mathrm{CH}_{2}\right)-1,3,4-(i-\mathrm{Pr})_{3} \mathrm{C}_{5} \mathrm{HZnCl}\right]_{2}(\mathbf{1 2 9})$ is the only example of a cyclopentadienylzinc halogenide of which the structure has been established by an X-ray crystal structure determination ${ }^{203}$. The centrosymmetric dimer is formed via two bridging chlorine atoms $[\mathrm{Zn}(1)-\mathrm{Cl}(1) 2.3332(10)$ and $\mathrm{Zn}(2)-\mathrm{Cl}(1) 2.3850(10) \AA]$ between the two zinc atoms (Figure 66). The substituted cyclopentadienyl group is $\eta^{1}$-bonded via $\mathrm{C}(1)$ to zinc $[\mathrm{Zn}(1)-\mathrm{C}(1) 2.063(3) \AA]$, while the $\mathrm{NMe}_{2}$ functionality is coordinated intramolecularly to zinc, affording a six-membered chelate ring [Zn(1)-N(1) 2.124(3) Å]. Each of the zinc atoms has a slightly distorted tetrahedral coordination geometry.

The synthesis of $\beta$-hydroxy acids via their esters from ketones and the Reformatsky reagent ${ }^{172}$ is still one of the best approaches for this class of compounds. This reagent, 


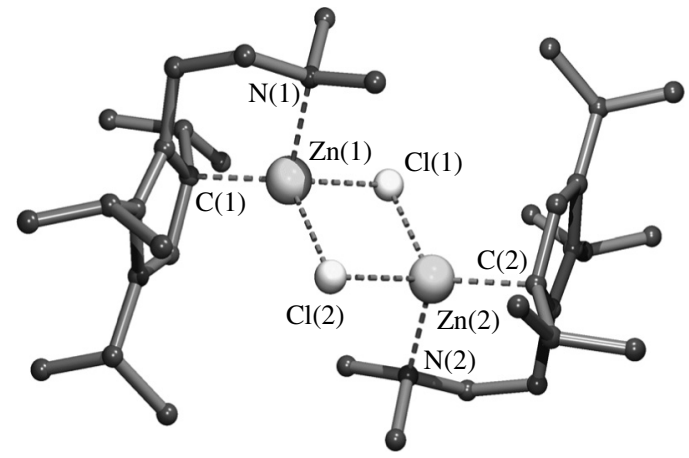

FIGURE 66. Solid state structure of the dimeric cyclopentadienylzinc chloride (129)

simply formulated as ( $\mathrm{RO}) \mathrm{OCCH}_{2} \mathrm{ZnBr}$, is generated in situ from the corresponding bromo ester and zinc powder in the presence of a ketone. It was thought that this reagent would act as a monoorganozinc halide, i.e. a $C$-metallated species, that adds to a carbonyl group like a Grignard reagent. However, there is ample evidence that the Reformatsky reagent also has properties in accordance with an enolate type structure, i.e. an $O$-metallated species $^{204,205}$. A complicating factor in the study of the nature of the Reformatsky reagent in solution is the dependence of its spectroscopic properties on the polarity of the solvent. The changes in both the IR and NMR spectra with solvent polarity have been explained in terms of an equilibrium between a $C$-metallated and an $O$-metallated species. Aggregation-state studies by ebulliometry and cryoscopy have shown that in polar solvents like THF, pyridine and dioxane the Reformatsky reagent exists as a dimer, and that only in extremely polar solvents like DMSO is a monomeric species present ${ }^{206}$.

The debate about its structural constitution (at least in the solid state) came to an end by the structural elucidation in the solid state of the THF adduct of $(t-\mathrm{BuO}) \mathrm{OCCH}_{2} \mathrm{ZnBr}$ by $\mathrm{X}$-ray crystallography ${ }^{206}$. It appeared that this compound $\left[(t-\mathrm{BuO}) \mathrm{OCCH}_{2} \mathrm{ZnBr}(\mathrm{THF})\right]_{2}$ (130) exists as a centrosymmetric dimer (Figure 67). This dimer itself consists of a nonplanar eight-membered $(\mathrm{ZnCCO})_{2}$ ring, each zinc atom being surrounded by a $\sigma$-bonded carbon atom $[\mathrm{Zn}-\mathrm{C} 1.98(2) \AA]$, a bromine atom $[\mathrm{Zn}-\mathrm{Br} 2.346(3) \AA]$, a coordinating carbonyl oxygen atom $[\mathrm{Zn}-\mathrm{O} 2.02(1) \AA]$ and a coordinating THF molecule $[\mathrm{Zn}-\mathrm{O}$ 2.05(1) $\AA$ ]. The bond angles around zinc point to a slightly distorted tetrahedral geometry. The $\mathrm{Zn}-\mathrm{C}$ bond distance of 1.98 (2) $\AA$ has the value expected for a normal $\mathrm{Zn}-\mathrm{C}$ single bond. The $\mathrm{C}-\mathrm{O}$ carbonyl bond of 1.31(2) $\AA$ is elongated compared to an isolated carbonyl $\mathrm{C}-\mathrm{O}$ bond, but that is not unexpected, since the oxygen atom is coordinated to zinc. This also explains the shift of $\mathrm{C}-\mathrm{O}$ carbonyl IR frequency to a lower wave number.

Compound $\mathbf{1 3 1}$ is a rather exotic one and may be described as consisting of one molecule of $\left[\left(\mathrm{Me}_{3} \mathrm{Si}\right)_{3} \mathrm{C}\right] \mathrm{ZnCl}$ and one molecule of $\left[\left(\mathrm{Me}_{3} \mathrm{Si}\right)_{3} \mathrm{C}\right] \mathrm{Zn}(2,5$-(di-tert-butyl)pyrrolidinyl) aggregated in one structure (Figure 68) ${ }^{207}$. In 131, two $\left[\left(\mathrm{Me}_{3} \mathrm{Si}\right)_{3} \mathrm{C}\right] \mathrm{Zn}$ units are linked together via a bridging chlorine atom between the two zinc atoms with equal $\mathrm{Zn}-\mathrm{Cl}$ distances of 2.410(1) $\AA$. Also, the 2,5-di(tert-butyl)pyrrolidinyl ligand bridges between the two zinc atoms, and is $\sigma$-bonded with its nitrogen atom $[\mathrm{Zn}(1)-\mathrm{N} 2.151(6) \AA]$ to one of the zinc atoms and $\eta^{2}$-bonded with C(3) [2.190(7) $\AA$ ] and C(4) [2.194(7) $\AA$ ] to the other zinc atom. As a consequence of the bonding mode of the 2,5-di(tert-butyl)pyrrolidinyl ligand, $\mathrm{Zn}(1)$ is three-coordinate and $\mathrm{Zn}(2)$ is four-coordinate.

The structural elucidation of the THF adduct of thiazolylzinc bromide (132) showed it to be a centrosymmetric dimer (Figure 69) ${ }^{208}$. The two thiazolyl anions are each 


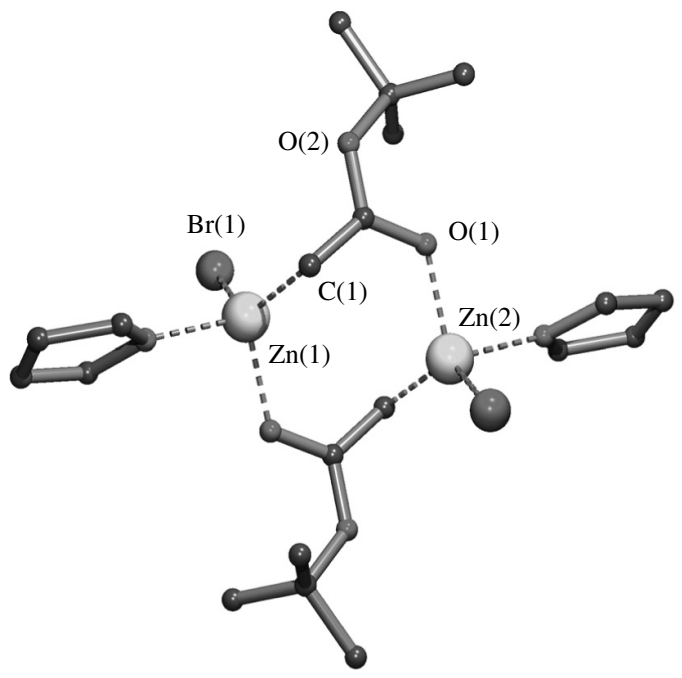

FIGURE 67. Solid state structure of the Reformatsky reagent $\left[(t-\mathrm{BuO}) \mathrm{OCCH}_{2} \mathrm{ZnBr}(\mathrm{THF})\right]_{2}(\mathbf{1 3 0})$

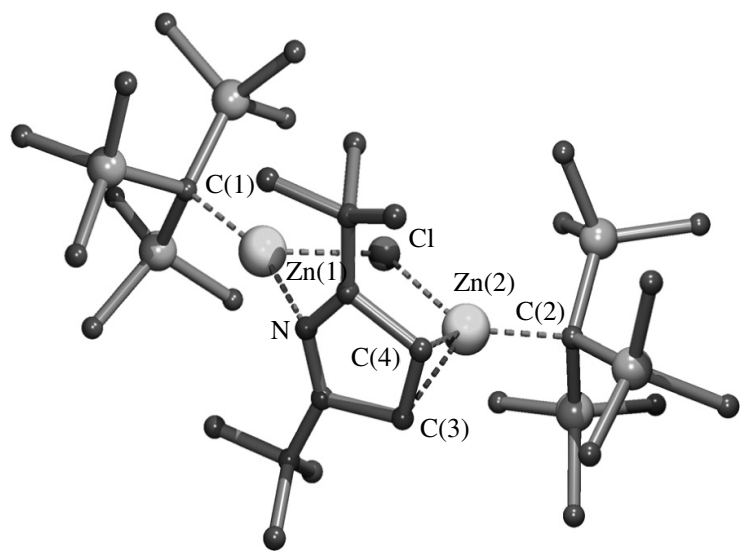

FIGURE 68. Solid state structure of $\mathbf{1 3 1}$

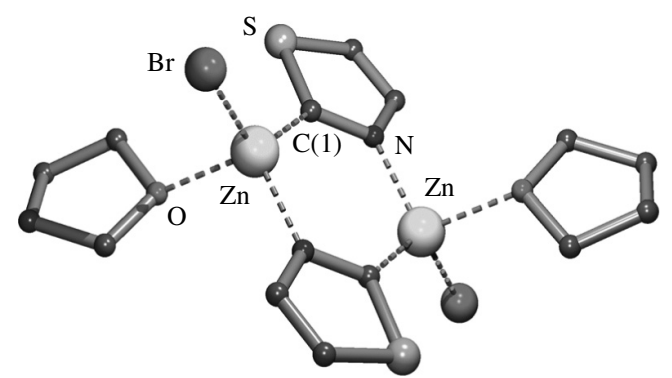

FIGURE 69. Solid state structure of carbenoid compound $\mathbf{1 3 2}$ 
bridge-bonded between the two zinc atoms, with $\mathrm{C}(1)$ to one of the zinc atoms $[\mathrm{Zn}-\mathrm{C}(1)$ $2.000 \AA]$ and with the nitrogen atom $[\mathrm{Zn}-\mathrm{N} 2.021 \AA]$ to the other zinc atom. The bromine atom and a coordinating THF molecule complete the four-coordination at zinc. That the carbon atom bound to zinc has carbene character was concluded from the various bonding distances in the thiazolyl anion, and was corroborated by computational studies.

The compound containing a benzoxazole anion and a $\mathrm{ZnCl}$ cation forms an adduct with THF, the structural features of which are very closely related to those of $\mathbf{1 3 2}^{209}$.

The only example of an organozinc fluoride of which the structure in the solid state has been established by an X-ray crystal structure determination is MeZnF aggregated with $\mathrm{Cp}^{*} \mathrm{TiF}_{3}{ }^{210}$. In this aggregate two $\left(\mathrm{Cp}^{*} \mathrm{TiF}\right)_{2}(\mu-\mathrm{F})_{4}\left(\mu_{3}-\mathrm{F}\right)(\mathrm{ZnMe})$ units are connected by two $\mathrm{Ti}(\mu-\mathrm{F})-\mathrm{Zn}$ bridges.

\section{Monoorganozinc Compounds RZnY with $\mathrm{Y}=\mathrm{OR}$}

A large number of monoorganozinc compounds, in which in addition to the covalently bonded carbon atom an oxygen atom is covalently bound, have been structurally elucidated. These compounds include alkoxides, aryloxides, enolates, $\beta$-diketonates, carboxylates, phosphates and siloxanes. As a consequence of the tendency of zinc to attain tetrahedral coordination geometry, in combination with the presence of a potentially multielectron-donating anionic $\mathrm{RO}^{-}$group, these compounds usually are aggregated via oxygen bridges between zinc atoms. Only a very few compounds are known that exist (in the solid state) as discrete monomers. These compounds contain either very bulky substituents in close proximity to the zinc atom which prevent aggregation, or contain suitably orientated heteroatom-functionalized substituents capable of coordinating to the zinc atom.

Methylzinc 2,6-di-tert-butyl(phenoxide) forms a neutral complex (133) with the guanidine ligand $i-\operatorname{PrN}=\mathrm{C}\left(\mathrm{NMe}_{2}\right)(\mathrm{NHPr}-i)$, of which the structure in the solid state was established by an X-ray crystal structure determination (Figure 70) (11 $^{21}$. In 133, the methyl group and the 2,6-di-tert-butylphenoxide group are both $\eta^{1}$-bonded to zinc [Zn-O 1.9511(15) $\AA$ ] while the guanidine ligand forms one coordinate bond $[\mathrm{Zn}-\mathrm{N}(1)$ 1.9952(18) $\AA$ ] with its imine nitrogen atom to zinc. As a result the zinc atom has planar trigonal coordination geometry (sum of the bond angles around zinc $359.6^{\circ}$ ). It is notable that the guanidine amine-hydrogen atom forms an intramolecular hydrogen bridge with the phenolate oxygen atom. This might be an additional stabilizing factor for this structure.

Compounds $\mathbf{1 3 4}^{212}, \mathbf{1 3 5}^{213}$ and $\mathbf{1 3 6}^{214}$ (Figure 71 ) are alkylzinc alkoxides and aryloxides that exist as discrete monomeric molecules in the solid state. These compounds have in common that in addition to the covalently bonded alkoxy or aryloxy group, two

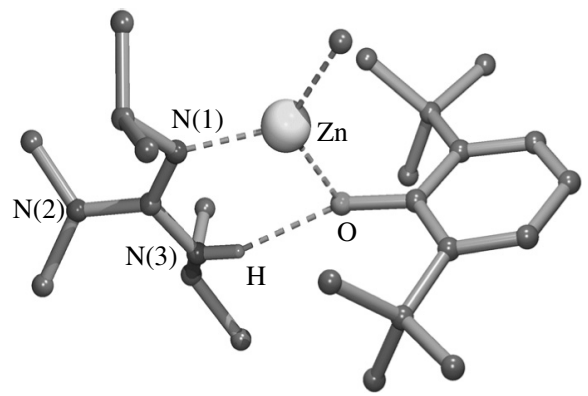

FIGURE 70. Solid state structure of monomeric guanidine complex $\mathbf{1 3 3}$ 


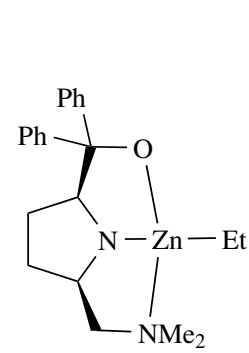

(134)

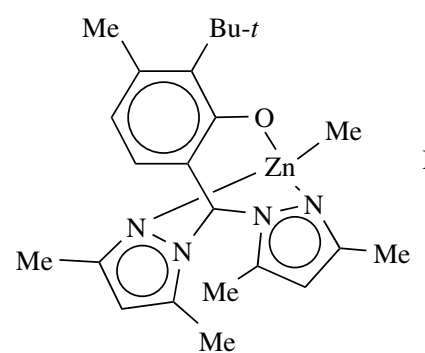

(135)<smiles>CC[Ge]1(CC)Oc2c(Br)cc(CC(C)C)cc2CN1CCN</smiles>

(136)<smiles></smiles>

(137)<smiles>C[C@]1(OC(F)(F)F)N(Cc2ccccc2)C=CN1[13CH2]Cc1ccccc1</smiles>

(138)

FIGURE 71. Monomeric alkylzinc-oxygen compounds

nitrogen atoms are intramolecularly coordinated to the zinc atom. As a result the zinc atoms in these compounds have a distorted tetrahedral coordination geometry.

Compound $137^{215}$ is an example of a monomeric methylzinc carboxylate (Figure 71). In this compound the carboxylate group is $\eta^{1}$-bonded to zinc via one of its oxygen atoms, while tetrahedral coordination geometry at zinc is reached via intramolecular coordination of the nitrogen atoms of the two pyrazolyl moieties. The solid state structure of an analog of 137 containing one 3,5-di-tert-butylpyrazolyl group and one 3,5-dimethylpyrazolyl group has also been established ${ }^{216}$. This compound is isostructural with 137.

An X-ray crystal structure determination of methylzinc triflate DAB complex 138 (Figure 71) (DAB =1,4-di-tert-butyl-1,4-diaza-1,3-butadiene) showed it to be a monomeric compound in which the triflate group is $\eta^{1}$-bonded to zinc with one of its oxygen atoms while the DAB ligand is $N, N$-chelate-bonded to zinc ${ }^{161}$. Thus compound 138 is a neutral compound in which the zinc atom has a distorted tetrahedral coordination geometry instead of the anticipated ionic structure comprising a trigonal monoorganozinc cation and a triflate anion.

Of the RZnY compounds in which the Y group is an organic group bound via oxygen, the organozinc alkoxy or aryloxy compounds are the largest group of which the solid state structures have been determined. For this type of compounds three basic structural motifs have been observed. The first one involves the formation of dimers A (Figure 72) in which two alkoxy or aryloxy groups bridge between two zinc atoms. The zinc atoms are trigonal planar coordinate. Either the organic group bound to zinc $\left(\mathrm{R}^{1}\right)$ or the organic group bound to oxygen $\left(\mathrm{R}^{2}\right)$ contains bulky substituents that prevent the formation of higher aggregates. The second motif $\mathbf{B}$ (Figure 72) is an extension of the first one. The organic group bound to zinc contains a heteroatom-functionalized substituent capable of forming a coordination bond to zinc, affording oxygen-bridged dimers in which the zinc atoms have a tetrahedral coordination geometry. The third motif $\mathbf{C}$ (Figure 72 ) involves 
<smiles>[R][R1]1ON([R])[R1]1[R]</smiles>

(A)

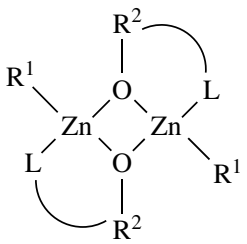

(B)

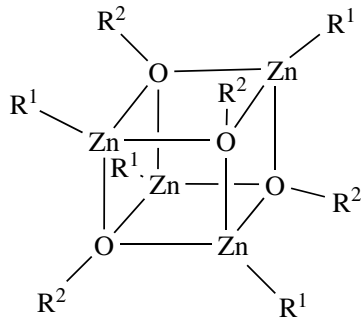

(C)

FIGURE 72. The three basic structural motifs observed for $\mathrm{R}^{1} \mathrm{ZnOR}^{2}$ compounds

the formation of a hetero-cubane structure in which each of the alkoxy or aryloxy groups is $\mu^{3}$-bonded to three zinc atoms. A similar structure has been proposed for $[\mathrm{EtZnCl}]_{4}$ and $[\mathrm{EtZnBr}]_{4}{ }^{189}$.

The solid state structure of tris(dimethylphenylsilyl)methylzinc hydroxide $(\mathbf{1 3 9})^{217}$ (Figure 73) is an example of structural motif $\mathbf{A}$. Two hydroxy groups are symmetrically bridge-bonded [ $\mathrm{Zn}(1)-\mathrm{O}(1)$ 1.908(7) and $\mathrm{Zn}(2)-\mathrm{O}(1)$ 1.891(6) $\AA$ ] between the two zinc atoms affording a flat central $\mathrm{Zn}-\mathrm{O}-\mathrm{Zn}-\mathrm{O}$ square. The two halves of the dimer are symmetry-related via a crystallographic centre of symmetry. Each of the zinc atoms has planar trigonal geometry (the sum of the bond angles around zinc is $360^{\circ}$ within experimental error). The substituent at the oxygen atom (in this case hydrogen) is the smallest one possible, but the bulky tris(dimethylphenylsilyl)methyl groups, one at each zinc atom, prevent the formation of higher aggregates.

In dimeric ethylzinc 2,6-di-tert-butylphenoxide $(\mathbf{1 4 0})^{218}$ the bulk of the groups at zinc and oxygen is reversed. Also here, the centrosymmetric dimer consists of a central flat $\mathrm{Zn}-\mathrm{O}-\mathrm{Zn}-\mathrm{O}$ square $[\mathrm{Zn}(1)-\mathrm{O}(1) 1.970(1)$ and $\mathrm{Zn}(2)-\mathrm{O}(1)$ 1.990(1) $\AA$ ], but now to each zinc atom a relatively small ethyl group is bonded while the bulky 2,6-di-tertbutylphenoxy groups prevent the formation of higher aggregates (Figure 73).

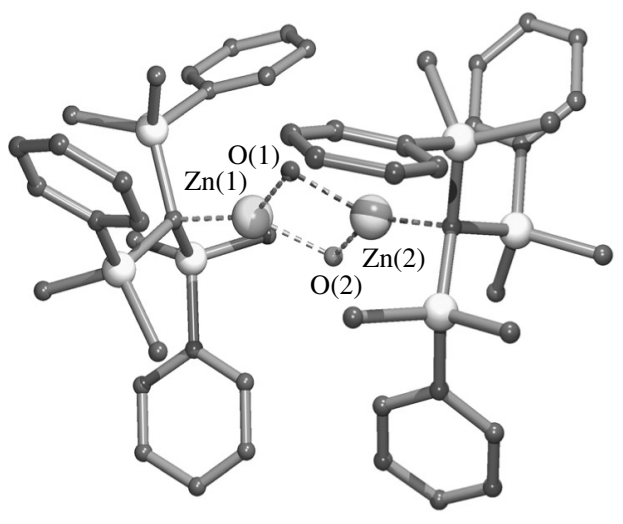

(139)

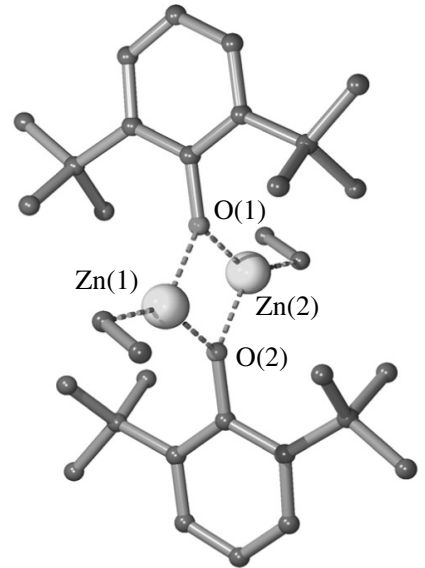

(140)

FIGURE 73. Solid state structures of dimeric $\mathbf{1 3 9}$ and $\mathbf{1 4 0}$ 


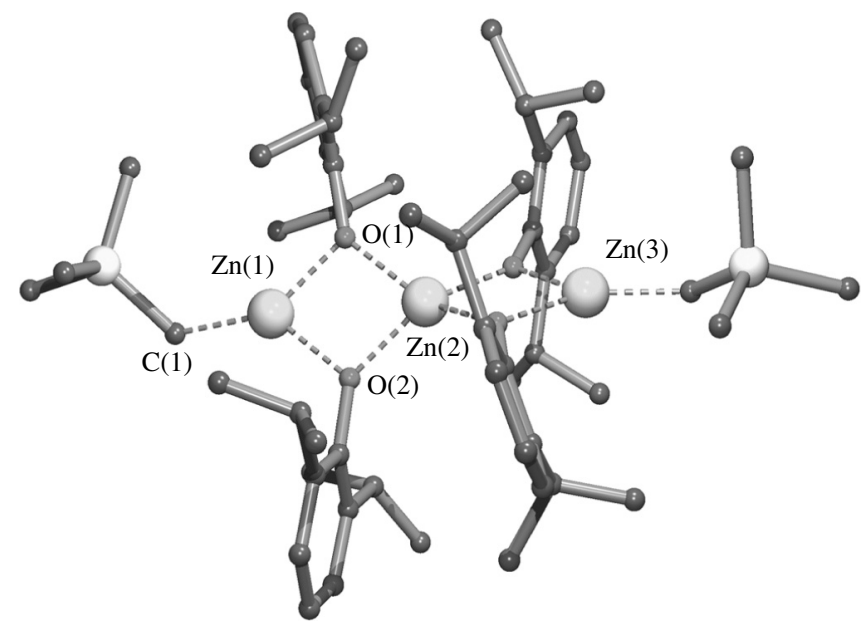

FIGURE 74. Solid state structure of metalla-spirocyclic compound 141

$\mathrm{X}$-ray crystal structure determinations of $\left[\mathrm{EtZnOB}(\mathrm{Mes})_{2}\right]_{2}{ }^{219},\left[\mathrm{Me}_{3} \mathrm{SiCH}_{2} \mathrm{ZnOC}_{6} \mathrm{H}_{3}\right.$ $\left.(\mathrm{Pr}-i)_{2}-2,6\right]_{2}{ }^{220}$ and $\left[\mathrm{Me}_{3} \mathrm{SiCH}_{2} \mathrm{ZnOC}_{6} \mathrm{H}_{3}(\mathrm{Bu}-t)_{3}-2,4,6\right]_{2}{ }^{220}$ revealed structures for these compounds which are identical to those observed for 139 and $\mathbf{1 4 0 .}$

That the stoichiometry of the reactants during the synthesis of such compounds, which are usually prepared by selective alcoholysis of one of the alkyl groups of the corresponding dialkylzinc compound, has to be exactly $1: 1$ became evident from the isolation and structural characterization of $\mathbf{1 4 1}^{220}$ (Figure 74). Formally, this compound may be regarded as consisting of two molecules of $\mathrm{Me}_{3} \mathrm{SiCH}_{2} \mathrm{ZnOC}_{6} \mathrm{H}_{3}(\mathrm{Pr}-i)_{2}-2,6$ and one molecule of $\left[2,6-(i-\mathrm{Pr})_{2} \mathrm{C}_{6} \mathrm{H}_{3} \mathrm{O}_{2} \mathrm{Zn}\right.$ which are aggregated to one structure. The structure of this compound comprises an almost linear array of three zinc atoms that are bridged by the oxygen atoms of four diisopropylphenoxy groups $[\mathrm{Zn}(1)-\mathrm{O}(1) 1.950(2)$ and $\mathrm{Zn}(2)-\mathrm{O}(1) 1.985(2) \AA]$. To each of the terminal zinc atoms one $\mathrm{Me}_{3} \mathrm{SiCH}_{2}$ group is bonded. Consequently, the terminal zinc atoms each have a planar trigonal geometry and the central zinc atom is distorted tetrahedral. This compound is an example of a metallaspirocyclic compound. Identical structural motifs have been observed in the solid state structures of the compounds obtained from the reaction of dimethylzinc with either triphenylsilanol or tris(isopropyl)silanol, i.e. $\mathrm{Me}_{2} \mathrm{Zn}_{3}\left(\mathrm{OSiPh}_{3}\right)_{4}^{221}$ and $\mathrm{Me}_{2} \mathrm{Zn}_{3}\left[\mathrm{OSi}(\mathrm{Pr}-i)_{3}\right]_{4}{ }^{222}$, respectively. It should be noted that a similar reaction of $\mathrm{Me}_{2} \mathrm{Zn}$ or $\mathrm{Et}_{2} \mathrm{Zn}$ with diorganosilane diols ${ }^{221}$ or monoorganosilane triols ${ }^{223}$ affords structurally much more complicated polyhedral organozinc siloxanes.

The second structural motif, B (Figure 72), involves also a dimeric structure in which two alkoxy oxygen atoms bridge between two zinc atoms, but now an additional intramolecular coordinating substituent is present, resulting in the formation of fourcoordinate zinc atoms. Most of these structural investigations are aimed at the elucidation of the mechanism of the enantioselective addition of organozinc compounds to aldehydes ${ }^{224}$, a topic that will be discussed in Chapter 13.

It has been shown that the $\beta$-amino alcohol (-)-3-exo-(dimethylamino)isoborneol (DAIB) serves as an excellent chiral auxiliary in the enantioselective addition of $\mathrm{Et}_{2} \mathrm{Zn}$ to aldehydes ${ }^{225}$. As a model compound for the anticipated intermediate, the structure of $\mathrm{MeZn}(\mathrm{DAIB})(\mathbf{1 4 2})$ in the solid state was determined by X-ray crystallography ${ }^{226}$. In the 


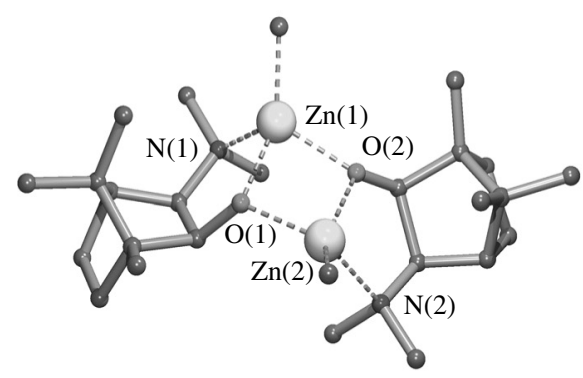

(142)

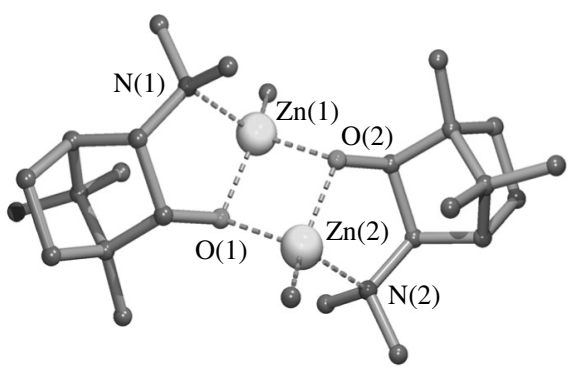

(143)

FIGURE 75. Enantiopure $[\mathrm{MeZn}(\mathrm{DAIB})]_{2}(\mathbf{1 4 2})$ and $m e s o-[\mathrm{MeZn}(\mathrm{DAIB})]_{2}(\mathbf{1 4 3})$

solid state 142 exists as a dimer (Figure 75) via bridging of two alcoholate oxygen atoms between two zinc atoms $[\mathrm{Zn}(1)-\mathrm{O}(1)$ 1.98(1) and $\mathrm{Zn}(2)-\mathrm{O}(1) 2.05(1) \AA]$. To each of the zinc atoms one dimethylamino substituent is intramolecularly coordinated $[\mathrm{Zn}(1)-\mathrm{N}(1)$ 2.25(2) $\AA$ ] and as a consequence the zinc centra are tetrahedrally coordinated. It is notable that both nitrogen atoms approach the zinc atoms from the same side of the central $\mathrm{Zn}-\mathrm{O}-\mathrm{Zn}-\mathrm{O}$ plane affording an overall syn-geometry. The crystallized material, obtained from the reaction of racemic DAIB and $\mathrm{Me}_{2} \mathrm{Zn}$, appeared to consist of a mesodimer (143) of MeZn(DAIB). In this dimer the coordinating nitrogen atoms approach the $\mathrm{Zn}-\mathrm{O}-\mathrm{Zn}-\mathrm{O}$ plane from opposite sides, thus giving an overall anti-geometry.

During these studies also the solid state structures of an oxygen-bridged dimeric compound containing two different alcoholate moieties, i.e. a chiral DAIB anion and achiral $\mathrm{Me}_{2} \mathrm{NCH}_{2} \mathrm{CMe}_{2} \mathrm{O}$, have been established as well as the symmetric dimer containing two $\mathrm{Me}_{2} \mathrm{NCH}_{2} \mathrm{CMe}_{2} \mathrm{O}$ moieties ${ }^{227}$. Both structures have structural properties that are closely related to that of 143; in both structures the intramolecular-coordinating nitrogen atoms approach the $\mathrm{Zn}-\mathrm{O}-\mathrm{Zn}-\mathrm{O}$ plane from opposite sides.

During studies of its application as a catalyst in the enantioselective addition of dialkylzinc compounds to aldehydes and its stereochemical tuning, a series of methylzinc derivatives of exo-(2-aryl-substituted) fenchyl alcohols (Figure 76) have been prepared and structurally characterized in the solid state ${ }^{228-230}$.

Like the isoborneol derivatives the methylzinc fenchyl alcoholates are dimers via alcoholate-oxygen bridges in a central $\mathrm{Zn}-\mathrm{O}-\mathrm{Zn}-\mathrm{O}$ plane, while the two methoxy substituents each coordinate intramolecularly to a zinc atom. In the homo-chiral dimers with $\mathrm{R}=\mathrm{H}$ or Me the methyl groups bound to the zinc atoms and the two coordinating oxygen atoms are in syn-position with respect to the $\mathrm{Zn}-\mathrm{O}-\mathrm{Zn}-\mathrm{O}$ plane ${ }^{228}$. As expected, in the heterochiral derivatives with $\mathrm{R}=t$-Bu or $\mathrm{Me}_{3} \mathrm{Si}$ (144) (Figure 77), obtained from the corresponding racemic fenchyl alcohols, both the methyl groups and the coordinating

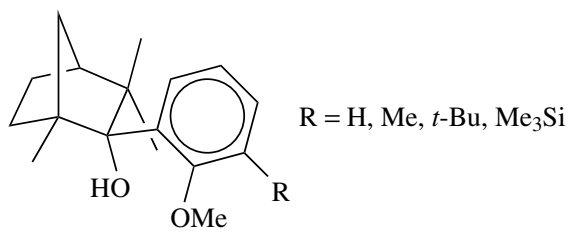

FIGURE 76. Exo-(2-aryl-substituted) fenchyl alcohols 


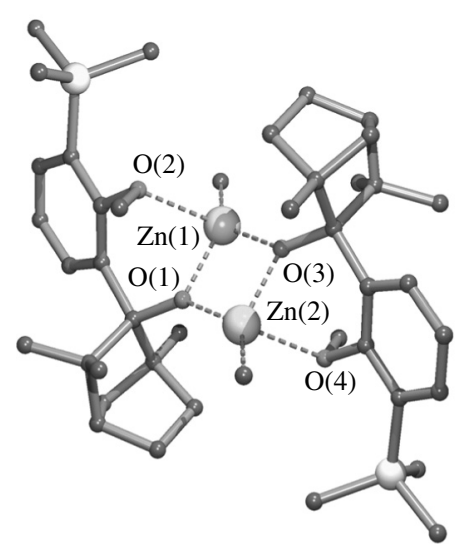

(144)

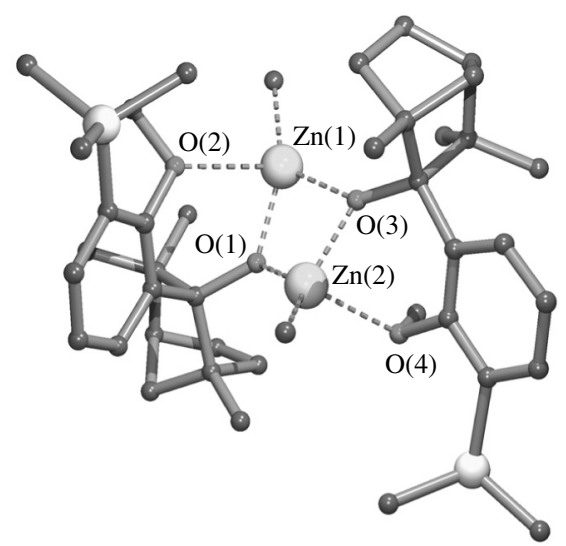

(145)

FIGURE 77. Dimeric heterochiral (144) and homochiral (145) MeZn fenchyl acoholates
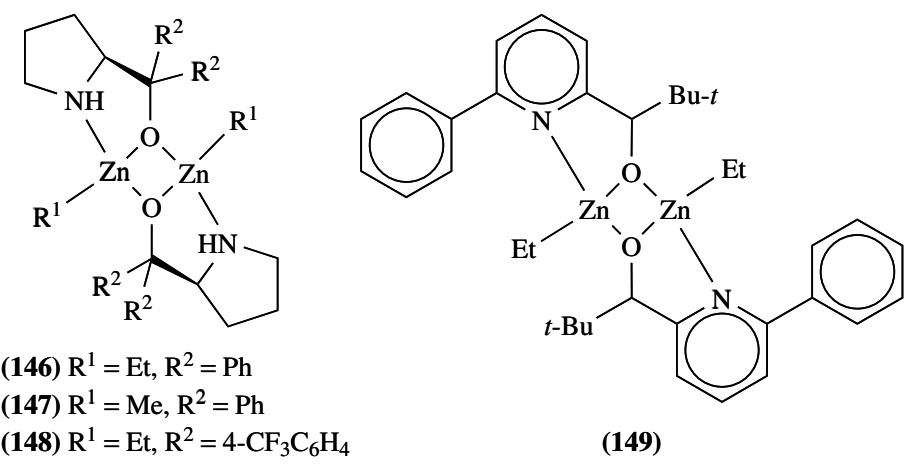

(149)

FIGURE 78. Alkylzinc alkoxides derived from functionalized pyrrolidinyl-2-methanol 146-148 and 2-pyridylmethanol 149

oxygen atoms are in anti-position ${ }^{229,230}$. In contrast, in the homochiral derivatives with $\mathrm{R}=t-\mathrm{Bu}$ or $\mathrm{Me}_{3} \mathrm{Si}(\mathbf{1 4 5})$ (Figure 77) the methyl groups bonded to zinc are syn-orientated but the coordinating methoxy groups are in anti-position.

Chiral $(S)$ - $\alpha, \alpha$-diphenylpyrrolidinyl-2-methanol reacts with $\mathrm{Et}_{2} \mathrm{Zn}$ or $\mathrm{Me}_{2} \mathrm{Zn}$ to give the corresponding homochiral dimeric EtZn-alcoholate (146) ${ }^{231}$ and MeZn-alcoholate (147) ${ }^{232}$ (Figure 78). The dimeric nature of these compounds was established by X-ray crystal structure determinations. Also in these structures the basic structural motif is a central $\mathrm{Zn}-\mathrm{O}-\mathrm{Zn}-\mathrm{O}$ square (bridging oxygen atoms of the alcoholate moieties). In both structures the two pyrrolidinyl nitrogen atoms coordinate each to a zinc atom in such a way that these nitrogen atoms are in anti-position with respect to the $\mathrm{Zn}-\mathrm{O}-\mathrm{Zn}-\mathrm{O}$ plane. Accordingly, the organic groups bound to zinc (Et in 146 and Me in 147) are also in anti-position. Introduction of a $\mathrm{CF}_{3}$ group in the para-position of the phenyl groups does not only influence the reactivity and selectivity of these compounds, when used as catalysts for the asymmetric copolymerization of cyclohexene oxide and $\mathrm{CO}_{2}{ }^{231}$, but also has a large influence on their actual structures in the solid state. The tetra $4-\mathrm{CF}_{3}$ 
derivative of 146, namely 148 (Figure 78), is also a dimer, but now both the ethyl groups bound to zinc and the coordinated nitrogen atoms are anti-orientated with respect to the $\mathrm{Zn}-\mathrm{O}-\mathrm{Zn}-\mathrm{O}$ plane.

The ethylzinc alcoholate (149) prepared from racemic $\alpha$-tert-butyl-6-phenyl-2-pyridylmethanol and $\mathrm{Et}_{2} \mathrm{Zn}$ exists in the solid state as a hetero chiral dimer (Figure 78 ) ${ }^{233}$. Also in this case the alcoholate oxygen atoms bridge between two zinc atoms, affording a central $\mathrm{Zn}-\mathrm{O}-\mathrm{Zn}-\mathrm{O}$ plane. The pyridyl nitrogen atoms are coordinated in such a way to the zinc atoms $[\mathrm{Zn}-\mathrm{N} 2.185(2) \AA]$ that they are in anti-position with respect to this plane.

The reaction of $\mathrm{Me}_{2} \mathrm{Zn}$ with rac-1-phenyl-2-( $N$-methylamino)ethanol or $(S)-N$-methyl2-pyrrolidinemethanol affords the corresponding methylzinc alcoholates ${ }^{232}$. In the solid state, these compounds, $\mathbf{1 5 0}$ and $\mathbf{1 5 1}$ respectively, are trimeric aggregates (Figure 79). In both 150 and 151 three zinc atoms and three bridging oxygen atoms are arranged in a sixmembered ring. In 150 this ring adopts a half-boat conformation and in 151 a half-chair conformation. The nitrogen atom of each ligand coordinates to a zinc atom, resulting in five-membered chelate rings and four-coordinate zinc atoms.

The formation of tetrameric aggregates with a hetero-cubane structure is a structural motif that is observed for several alkylzinc alkoxides in the solid state (Figure 80). In these structures the alkoxy group is $\mu^{3}$-bonded with its oxygen atom to three zinc atoms. The structural elucidation of $[\mathrm{MeZnOMe}]_{4}(\mathbf{1 5 2})$ represented the first example of such a structural motif in organozinc alkoxide chemistry ${ }^{234,235}$. Later, similar structures were observed for alkylzinc alkoxides containing other alkoxy groups $\left(\mathbf{1 5 3}, \mathrm{R}^{2}=t\right.$ $\mathrm{BuO})^{236,237}$ and/or other organic groups $\left(\mathbf{1 5 4}, \mathrm{R}^{1}=\mathrm{Me}_{3} \mathrm{SiCH}_{2}, \mathrm{R}^{2}=1-\mathrm{Ad}^{220}, 155\right.$ and 156, $\mathrm{R}^{1}=$ halomethyl, $\mathrm{R}^{2}=$ benzyloxy ${ }^{238}$ ) bound to zinc. Also, compounds containing a diorganoboryl oxide $(\mathbf{1 5 7})^{239}$ or a triorganosiloxy group $(\mathbf{1 5 8})^{222}$ form tetrameric aggregates with a hetero-cubane structure.

More complicated structures of alkylzinc alkoxides have been observed in the solid state with the stoichiometry $\mathrm{R}_{6}^{1} \mathrm{Zn}_{7}\left(\mathrm{OR}^{2}\right)_{8}$. These compounds have a hetero-di-cubane structure (two hetero-cubanes sharing a corner), and have been observed for $\mathrm{Me}_{6} \mathrm{Zn}_{7}(\mathrm{OMe})_{8}$ $(\mathbf{1 5 9})^{240,241}, \mathrm{Et}_{6} \mathrm{Zn}_{7}(\mathrm{OMe})_{8}(\mathbf{1 6 0})^{242}$ and $\left(\mathrm{ICH}_{2}\right)_{6} \mathrm{Zn}_{7}(\mathrm{OMe})_{8}(\mathbf{1 6 1})^{243}$ (Figure 80).

As a representative example the solid state structure of $[\mathrm{MeZnOMe}]_{4}(\mathbf{1 5 2})$ is shown (Figure 81). The four zinc atoms and the four oxygen atoms of the four $\mu^{3}$-bridging methoxy groups are arranged in such a way that a slightly distorted cube is formed.

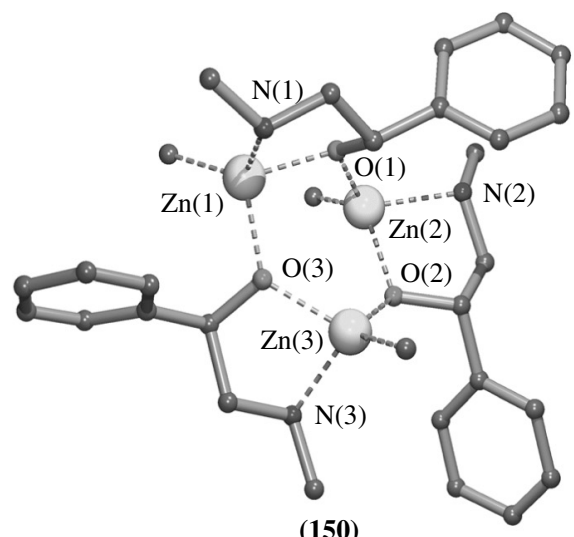

(150)

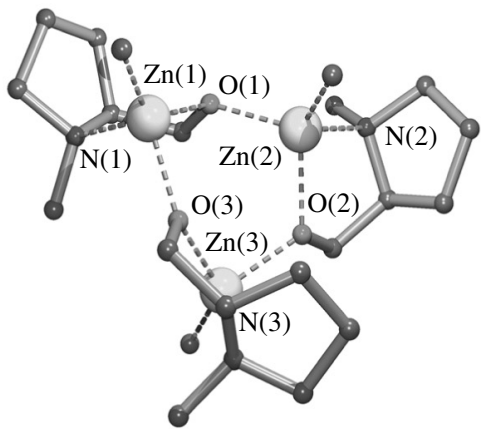

(151)

FIGURE 79. Solid state structures of trimeric aggregates $\mathbf{1 5 0}$ and $\mathbf{1 5 1}$ 


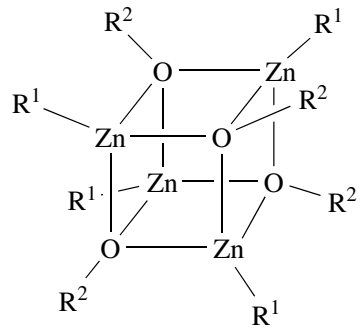

(152) $R^{1}=R^{2}=M e$

(153) $\mathrm{R}^{1}=\mathrm{Me}, \mathrm{R}^{2}=t$-Bu

(154) $\mathrm{R}^{1}=\mathrm{Me}_{3} \mathrm{SiCH}_{2}, \mathrm{R}^{2}=1$-Ad

(155) $\mathrm{R}^{1}=\mathrm{ICH}_{2}, \mathrm{R}^{2}=4-\mathrm{MeOC}_{6} \mathrm{H}_{4} \mathrm{CH}_{2}$

(156) $\mathrm{R}^{1}=\mathrm{ClCH}_{2}, \mathrm{R}^{2}=4-\mathrm{MeOC}_{6} \mathrm{H}_{4} \mathrm{CH}_{2}$

(157) $\mathrm{R}^{1}=\mathrm{Et}, \mathrm{R}^{2}=9$-BBN

(158) $\mathrm{R}^{1}=\mathrm{Me}, \mathrm{R}^{2}=\mathrm{Et}_{3} \mathrm{Si}$

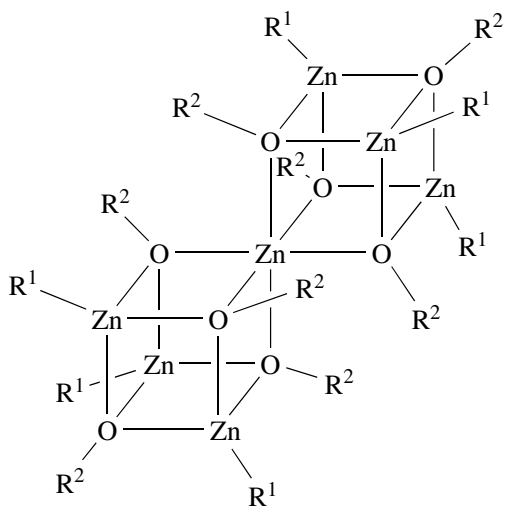

(159) $R^{1}=R^{2}=M e$

(160) $\mathrm{R}^{1}=\mathrm{Et}, \mathrm{R}^{2}=\mathrm{Me}$

(161) $\mathrm{R}^{1}=\mathrm{ICH}_{2}, \mathrm{R}^{2}=\mathrm{Me}$

FIGURE 80. Alkylzinc alkoxides having a hetero-cubane structure

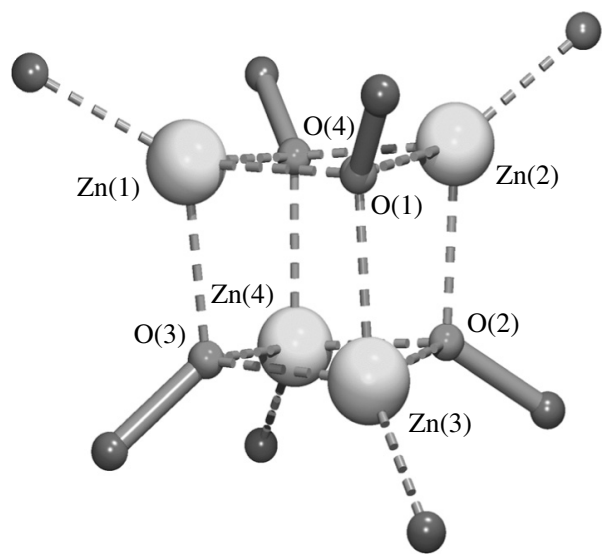

FIGURE 81. Solid state structure of tetrameric methylzinc methoxide

The $\mathrm{Zn}-\mathrm{O}$ distances in one $\mu^{3}$-bridging unit are almost equal $[\mathrm{O}(1)-\mathrm{Zn}(1) 2.114(15)$, $\mathrm{O}(1)-\mathrm{Zn}(2) 2.052(17)$ and $\mathrm{O}(1)-\mathrm{Zn}(3) 2.069(13) \AA]$. The slight distortion of the cube is indicated by the observation that all $\mathrm{Zn}-\mathrm{O}-\mathrm{Zn}$ angles are slightly larger (average $96^{\circ}$ ) than $90^{\circ}$ and the $\mathrm{O}-\mathrm{Zn}-\mathrm{O}$ angles are slightly smaller (average $84^{\circ}$ ) than $90^{\circ}$.

Also, mixed methylzinc alkoxide-alkali metal alkoxide compounds exhibit a heterocubane structure in the solid state. In $\mathrm{Me}_{2} \mathrm{Zn}_{2} \mathrm{Li}_{2}(\mathrm{OBu}-t)_{4}(\mathrm{THF})_{2}(\mathbf{1 6 2})^{244}$ and $\mathrm{Me}_{2} \mathrm{Zn}_{2} \mathrm{~K}_{2}$ $\left(\mathrm{OSiMe}_{3}\right)_{4}(\mathrm{THF})_{4}(\mathbf{1 6 3})^{245}$, two of the alkoxy groups are $\mu^{3}$-bridge-bonded between two zinc atoms and one alkali metal atom and consequently the other two alkoxy groups are $\mu^{3}$-bridge bonded between one zinc atom and two alkali metal atoms (Figure 82). In 162, tetrahedral coordination geometry at the lithium atoms is reached by the coordination of 


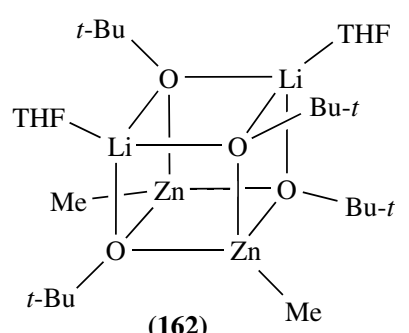

(162)

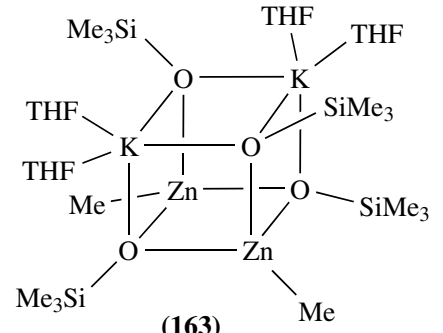

(163)

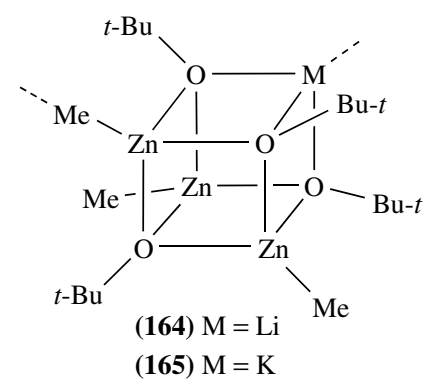

FIGURE 82. Structures of the hetero-cubanes 162-165

a THF molecule, while in $\mathbf{1 6 3}$ the potassium atoms are penta-coordinate via coordination of two THF molecules.

The mixed methylzinc alkoxide-alkali metal alkoxide compounds $\mathrm{Me}_{3} \mathrm{ZnM}(\mathrm{OBu}-t)_{4}$ $\left[\mathrm{M}=\mathrm{Li}(\mathbf{1 6 4})^{246}\right.$ and $\left.\mathrm{M}=\mathrm{K}(\mathbf{1 6 5})^{245}\right]$ form infinite polymeric chains of hetero-cubane units by bridging of one of the methyl groups between zinc and the lithium atom in an adjacent hetero-cubane unit (Figure 82). Unfortunately, in $\mathbf{1 6 4}$ crystallographic site disorder is present for the top two metals in the cube (Figure 82); both positions refine for a site occupancy of $50 \% \mathrm{Zn}$ and $50 \% \mathrm{Li}$. Moreover, the bridging methyl group is located at a crystallographic inversion centre in between $\mathrm{Zn} / \mathrm{Li}$ and its symmetry equivalent. It is therefore impossible to distinguish unambiguously between $\mathrm{Zn}-\mathrm{Me} \cdots \mathrm{Li}$ and $\mathrm{Li}-\mathrm{Me} \cdots \mathrm{Zn}$ bonding modes. In 165, this disorder is not present and the bonding of the bridging methyl group is rather asymmetric [ $\mathrm{Zn}-\mathrm{C} 2.00(1)$ and $\mathrm{K}-\mathrm{C} 3.20(1) \AA]$.

A series of alkylzinc alkoxides in which the alkoxide is an $\alpha$-substituted 2-pyridinemethanol group has been prepared ${ }^{247}$. Based on aggregation-state studies by cryoscopy in benzene, it appeared that depending on the particular $\alpha$-substituent these compounds exist in solution either as dimers or as trimers. An X-ray crystal structure determination of one of these compounds, i.e. $\mathrm{Me}_{3} \mathrm{SiCH}_{2} \mathrm{ZnOCH}_{2}-2-\mathrm{Pyr}$, showed that this compound exists in the solid state as a cyclic tetramer ${ }^{247}$. The four alkylzinc alkoxide units are linked via $\mu^{2}$-bridging alcoholate groups to give a central puckered eight-membered $\mathrm{Zn}_{4} \mathrm{O}_{4}$ ring, in which the $\mathrm{Zn}-\mathrm{O}$ distances are almost equal [average value $1.985(1) \AA$ ]. The pyridyl nitrogen atoms each coordinate to a zinc atom, resulting in slightly distorted tetrahedrally coordinated zinc atoms.

A rather unexpected product was obtained from the reaction of 2-(methylthio)ethanol and $\mathrm{Me}_{2} \mathrm{Zn}$ in dichloromethane as a solvent. Instead of the anticipated methylzinc alkoxy compound, a product was obtained with the constitution $\mathrm{Me}_{4} \mathrm{Zn}_{4}\left(\mathrm{OCH}_{2} \mathrm{CH}_{2} \mathrm{SMe}\right)_{2} \mathrm{Cl}_{2}$ $(\mathbf{1 6 6})^{248}$. The only possible explanation for the formation of this product is that the chloride present originates from the solvent dichloromethane. An X-ray crystal structure 


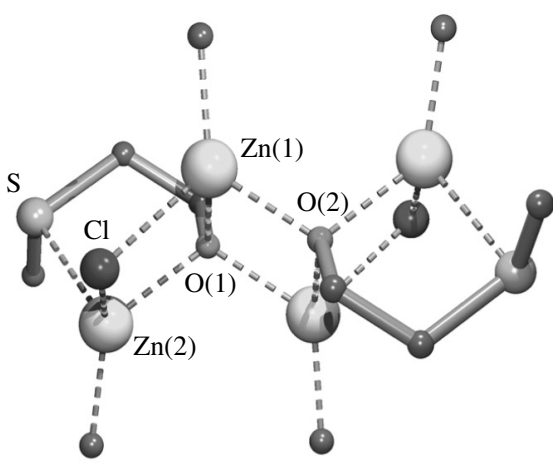

(166)

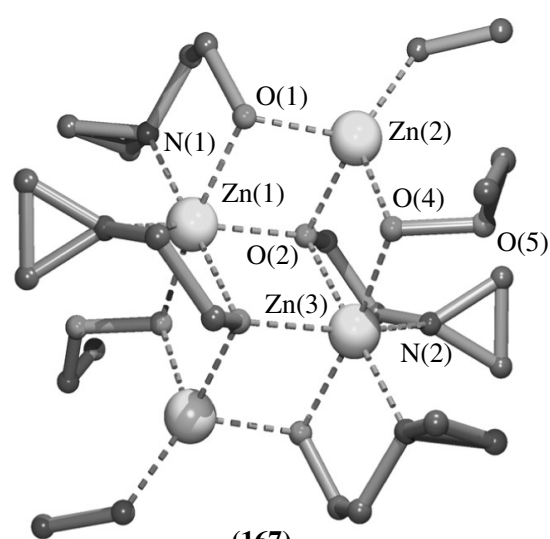

(167)

FIGURE 83. Solid state structures of compounds 166 and 167

determination revealed that 166 can be regarded as consisting of two molecules of $\mathrm{MeZnOCH}_{2} \mathrm{CH}_{2} \mathrm{SMe}$ and two molecules of $\mathrm{MeZnCl}$, aggregated in one structure via two $\mu^{3}$-bridging alkoxides and two $\mu^{2}$-bridging chlorides (Figure 83). The four zinc atoms, the two oxygen atoms and the two chlorine atoms are aggregated in a ladder-type arrangement. The two central zinc atoms are four-coordinate as a result of the $\sigma$-bonded methyl group, two $\mathrm{Zn}-\mathrm{O}$ bonds $[\mathrm{Zn}(1)-\mathrm{O}(1) 2.101(2)$ and $\mathrm{Zn}(1)-\mathrm{O}(2) 2.043(2) \AA]$ and one $\mathrm{Zn}-\mathrm{Cl}$ bond $[2.370(1) \AA]$. To the peripheral MeZn unit one oxygen $[\mathrm{Zn}(2)-\mathrm{O}(1)(2.072(2) \AA]$ and one chlorine atom are bonded $[2.365(1) \AA]$, while tetrahedral coordination is reached by intramolecular coordination of the sulfur atom $[\mathrm{Zn}-\mathrm{S} 2.475(2) \AA]$.

Reaction of $\mathrm{Et}_{2} \mathrm{Zn}$ with 1-aziridine-ethanol affords the corresponding ethylzinc alcoholate in quantitative yield, which, according to molecular weight determinations, exists in benzene solution as a trimeric aggregate. Treatment of this solution with dry oxygen affords a crystalline material (167), which according to its X-ray crystal structure determination consists of four zinc atoms, two ethyl groups, four ethoxyaziridine groups and two ethylperoxo groups. The basic skeletal arrangement of 167 can be best described as an inversion-related, corner-removed face-shared cube (the four zinc atoms are located at the four corners of a defective double hetero-cubane) (Figure 83) ${ }^{241}$. The central zinc atoms $[\mathrm{Zn}(1)$ and $\mathrm{Zn}(3)]$ are octahedrally coordinated as a result of four $\mathrm{Zn}-\mathrm{O}$ bonds and two intramolecular $\mathrm{Zn}-\mathrm{N}$ coordinate bonds. The two other zinc atoms are four-coordinated via one $\sigma-\mathrm{C}-\mathrm{Zn}$ bond and three $\mathrm{Zn}-\mathrm{O}$ bonds. The most interesting feature of $\mathbf{1 6 7}$ is the presence of $\mu^{2}$-bridging ethylperoxo groups, which is unprecedented for organozinc compounds.

Treatment of the linked phenol tris(3,5-di-tert-butyl-2-hydroxyphenyl)methane, abbreviated as $\left[\mathrm{HOC}_{6} \mathrm{H}_{2}(\mathrm{Bu}-t)_{2}\right]_{3} \mathrm{CH}$, with $\mathrm{Et}_{2} \mathrm{Zn}$ affords a variety of complex aggregated compounds of which the structures have been determined by X-ray crystallography ${ }^{249}$. The stoichiometries of these compounds are $\mathrm{Et}_{6} \mathrm{Zn}_{6}\left\{\left[\mathrm{OC}_{6} \mathrm{H}_{2}(\mathrm{Bu}-t)_{2}\right]_{3} \mathrm{CH}\right\}_{2}, \mathrm{Et}_{4} \mathrm{Zn}_{5}\left\{\left[\mathrm{OC}_{6} \mathrm{H}_{2}\right.\right.$ $\left.\left.(\mathrm{Bu}-t)_{2}\right]_{3} \mathrm{CH}\right\}_{2}, \mathrm{Et}_{2} \mathrm{Zn}_{4}\left\{\left[\mathrm{OC}_{6} \mathrm{H}_{2}(\mathrm{Bu}-t)_{2}\right]_{3} \mathrm{CH}\right\}_{2}$ and $\mathrm{Et}_{3} \mathrm{Zn}_{3}\left\{\left[\mathrm{OC}_{6} \mathrm{H}_{2}(\mathrm{Bu}-t)_{2}\right]_{3} \mathrm{CH}\right\}_{2}(\mathrm{THF})_{3}$.

A special class of linked phenols are the so-called calixarenes. Reaction of $p$ - $t$-Bucalix[4]arene, abbreviated $\left(\mathrm{H}_{4} \mathrm{~L}\right)$, with excess $\mathrm{Et}_{2} \mathrm{Zn}$ in the presence of TMEDA affords the fully deprotonated calixarene complex $\mathrm{Et}_{2} \mathrm{Zn}_{5}(\mathrm{~L})_{2}(\mathrm{TMEDA})_{2}(\mathbf{1 6 8})$, the structure of which was determined in the solid state (Figure 84$)^{250}$. The two calixarenes are fused by three zinc atoms. One of these is coordinated by two oxygen atoms from each calixarene unit. The other two zinc atoms, connecting the calixarenes, are five-coordinate, bound by 


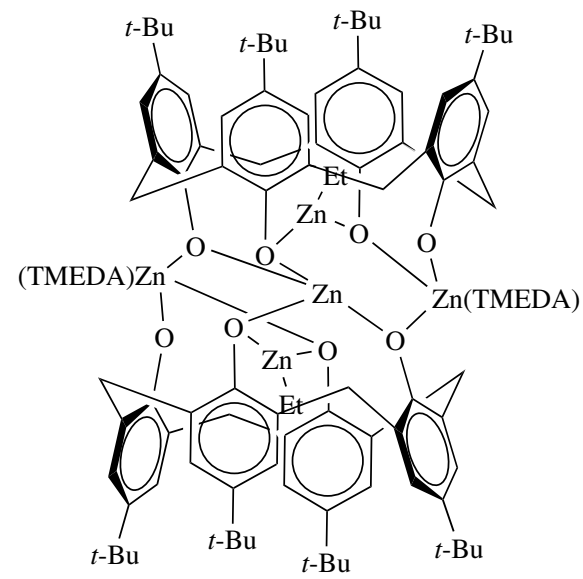

(168)

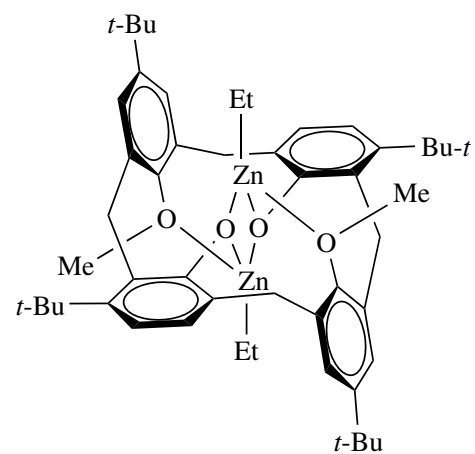

(169)

FIGURE 84. Schematic structures of $\mathbf{1 6 8}$ and $\mathbf{1 6 9}$

one oxygen on one calixarene, two adjacent oxygen atoms on the other calixarene unit and two nitrogen atoms of one TMEDA molecule. The ethyl groups are located endo relative to the cone of the calixarenes with an associated trigonal-planar zinc atom also bound by two oxygen atoms from opposite aromatic rings in the same calixarene.

A similar reaction of 1,3-dimethyl ether $p$ - $t$-Bu-calix[4]arene, abbreviated as $\left(\mathrm{H}_{2} \mathrm{~L}\right)$, with $\mathrm{Et}_{2} \mathrm{Zn}$ affords a monomeric compound $(\mathrm{EtZn})_{2}(\mathrm{~L})(\mathbf{1 6 9})$ with a less complex structure (Figure 84$)^{250}$. The zinc atoms in this compound form a flat $\mathrm{Zn}-\mathrm{O}-\mathrm{Zn}-\mathrm{O}$ arrangement together with the phenolate oxygen atoms. To each zinc atom one ethyl group is bonded, and tetrahedral coordination is reached by the additional coordination of one methoxy group.

The corresponding, sterically more demanding, 1,3-dibenzyl ether analog also forms a monomeric $(\mathrm{EtZn})_{2}$-calixarene complex, but with a somewhat different structure ${ }^{251}$. Here, the calixarene unit is in the pinched-cone conformation with one EtZn group capped by all four oxygen atoms rendering this zinc atom five-coordinate, while the other EtZn group is fully immersed in the calixarene cavity and is three-coordinate via bonding to two oxygen atoms.

Because zinc enolates are intrinsically reactive species, especially towards carbonyl compounds, the attempted synthesis of such species often results in the formation of selfcondensation products which are often polymeric materials ${ }^{252}$. Only in a few cases could pure organozinc enolates be isolated and structurally characterized.

Three ethylzinc enolates containing a tertiary nitrogen atom in $\beta$-position to the enolate oxygen atom have been prepared and were structurally characterized by X-ray crystallography. The structures of these compounds are shown schematically in Figure 85 .

In the solid state, compound $\mathbf{1 7 0}^{253}$ exists as a dimer (Figure 85). Two enolate moieties bridge with their oxygen atoms between two zinc atoms [ $\mathrm{Zn}-\mathrm{O} 2.02(1)$ and 2.12(1) $\AA$ ] affording a central flat $\mathrm{Zn}-\mathrm{O}-\mathrm{Zn}-\mathrm{O}$ ring. The nitrogen substituents each coordinate to a zinc atom [Zn-N 2.21(2) $\AA$ ]. Both the ethyl groups bound to zinc and the two coordinating nitrogen atoms are in syn-position with respect to the central $\mathrm{Zn}-\mathrm{O}-\mathrm{Zn}-\mathrm{O}$ plane. Ethylzinc enolate (171) (Figure 85) has an overall structural motif identical to that of 170. This compound was obtained as an unexpected product from the reaction of CpZnEt and ethyl $N, N$-diethylglycinate ${ }^{254}$. 
<smiles></smiles>

(170)<smiles></smiles>

(171)

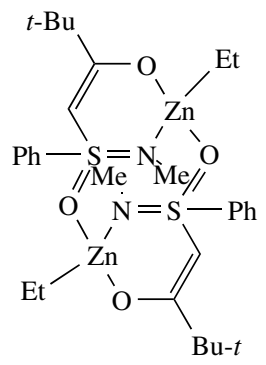

(172)

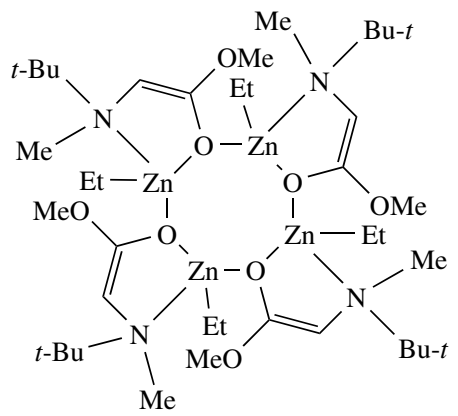

(173)

FIGURE 85 . Schematic structures of zinc enolates stabilized by intramolecular nitrogen coordination

Compound 172 (Figure 85) is an ethylzinc enolate derived from a $\beta$-ketosulfoximine ${ }^{255}$. Also, this compound exists in the solid state as a dimer, but surprisingly dimer formation does not occur via $\mu^{2}$-bridging of the enolate-oxygen atoms, but by coordination of the oxygen atom bound to sulfur to the zinc atom in the other half of the dimer.

Ethylzinc enolate (173) is an alkylzinc enolate derived from an $\alpha$-amino acid ester. Such derivatives have proven to be valuable intermediates in their zinc-mediated condensation with imines to $\beta$-lactams ${ }^{256}$. In the solid state $\mathbf{1 7 3}$ is a tetrameric aggregate (Figure 85$)^{257}$ via four $\mu^{2}$-bridging enolate-oxygen atoms [ $\mathrm{Zn}-\mathrm{O}$ distances range from 2.028(5) to $2.076(6) \AA]$ in a central puckered $(\mathrm{ZnO})_{4}$ eight-membered ring. Each of the zinc atoms in the ethylzinc moieties is tetrahedrally coordinated via intramolecular coordination, in a five-membered chelate ring, to the nitrogen atom of the amino substituent.

Organozinc $\beta$-diketonato compounds also belong formally to the class of organozinc enolates. EtZn(acac) exists in the solid state as a dimer, but due to the poor quality of the crystal data only the basic structural motif, i.e. dimer formation via $\mu^{2}$-oxygen bridges of two acac anions between two zinc atoms, could be established ${ }^{258}$. It appeared that $\mathrm{PhZn}(\mathrm{acac})$ is an unstable compound in solution and spontaneously disproportionates into $\mathrm{Ph}_{2} \mathrm{Zn}$ and a compound having the stoichiometry $\mathrm{Ph}_{2} \mathrm{Zn}_{3}(\text { acac })_{4}(\mathbf{1 7 4})^{259}$. An X-ray crystal structure determination ${ }^{260}$ of $\mathbf{1 7 4}$ (Figure 86) revealed an arrangement of the three zinc atoms that considerably deviates from linear $\left[<\operatorname{Zn}(1)-Z n(2)-Z n(3) 142.5^{\circ}\right]$. Two of the acac anions are $\mu^{2}$-bridge-bonded between the central zinc atom and each one to a different peripheral zinc atom. The other oxygen atom is also bound to the central zinc atom. Only a slight variation in $\mathrm{Zn}-\mathrm{O}$ distances $(2.006$ to $2.051 \AA)$ is observed. The 


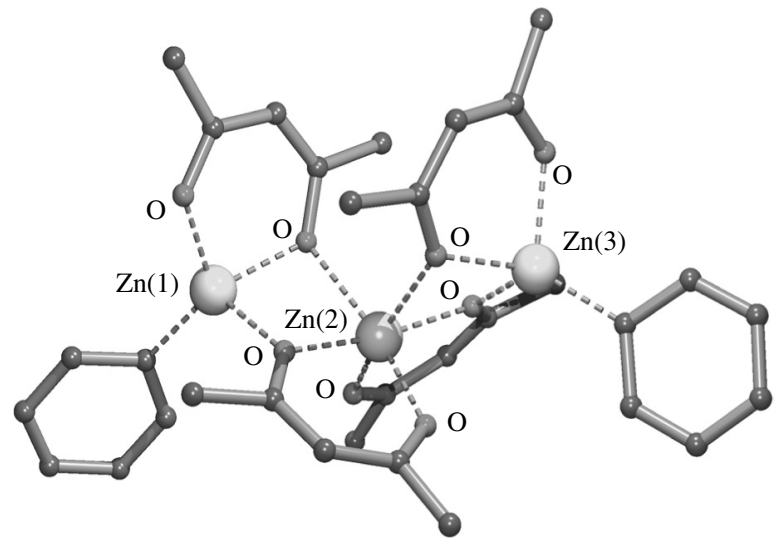

FIGURE 86 . Solid state structure of $\mathbf{1 7 4}$

other two acac anions are also $\mu^{2}$-bridge-bonded between the central zinc atom and the two peripheral zinc atoms, but in a less symmetric way. The $\mathrm{Zn}-\mathrm{O}$ bond lengths to the central zinc atom are considerably longer (average $2.278 \AA$ ) than those to the peripheral zinc atoms (average $2.017 \AA$ ). The other oxygen atoms of those two acac ligands are each bonded to a peripheral zinc atom. These bonding modes render the central zinc atom octahedrally coordinated and the peripheral zinc atoms four-coordinated.

Also, the structures of two organozinc pivaloylacetone derivatives associated with methylzinc methoxide or phenylzinc phenoxide were determined by X-ray crystallography. The complex structures of these compounds, $\mathrm{Et}_{2} \mathrm{Zn}_{4}(\mathrm{Pac})_{4}(\mathrm{OMe})_{2}(\mathbf{1 7 5})^{252}$ and $\mathrm{Ph}_{2} \mathrm{Zn}_{4}(\mathrm{Pac})_{4}(\mathrm{OPh})_{2}(\mathbf{1 7 6})^{261}(\mathrm{Pac}=$ pivaloylacetone anion $)$, are shown schematically in Figure 87.

The structures of only very few organozinc carboxylates (or containing related anionic ligands like carbamates) are known. The structure of $\mathrm{Me}_{4} \mathrm{Zn}_{4}\left(\mathrm{O}_{2} \mathrm{CNEt}_{2}\right)_{4}{ }^{262}$ has been determined. It is a cage-like structure of two puckered $\mathrm{Zn}_{2} \mathrm{O}_{3} \mathrm{C}$ rings, which are linked by bridging oxygen atoms.

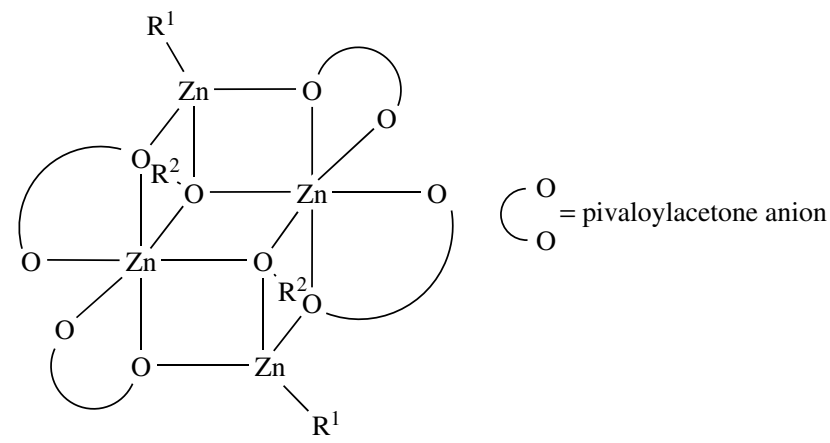

$$
\begin{aligned}
& \text { (175) } R^{1}=E t, R^{2}=M e \\
& \text { (176) } R^{1}=R^{2}=P h
\end{aligned}
$$

FIGURE 87. Schematic structures of $\mathbf{1 7 5}$ and $\mathbf{1 7 6}$ 


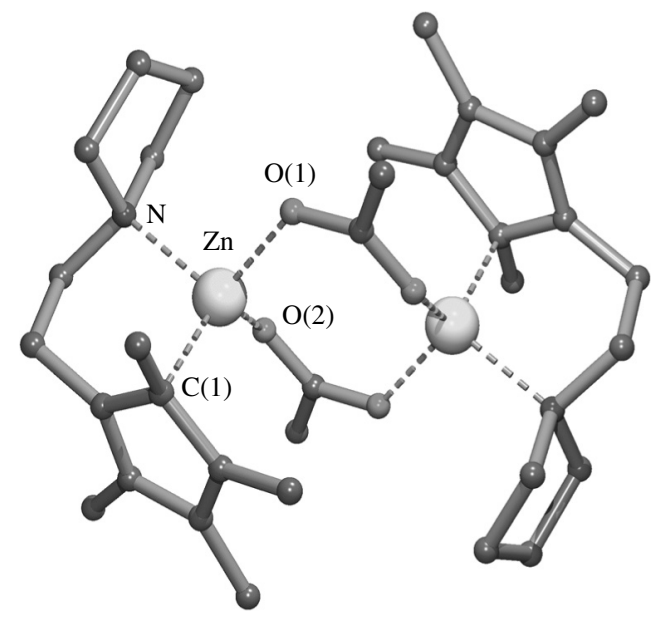

FIGURE 88. Solid state structure of acetate bridged organozinc dimer $\mathbf{1 7 7}$

The penta-substituted-cyclopentadienylzinc acetate derivative $\left[\left(\mathrm{CH}_{2}\right)_{4} \mathrm{~N}\left(\mathrm{CH}_{2}\right)_{2} \mathrm{C}_{5} \mathrm{Me}_{4}\right.$ $\mathrm{ZnO}_{2} \mathrm{CMe}_{2}$ (177) (Figure 88) exists in the solid state as a centro-symmetric dimer via acetate bridges $[\mathrm{Zn}-\mathrm{O}(1) 1.9635(16) \text { and } \mathrm{Zn}-\mathrm{O}(2) 1.9779(15) \AA]^{203}$. The cyclopentadienyl group is $\eta^{1}$-bonded to zinc [ $\mathrm{Zn}-\mathrm{C}(1) 2.110$ (2) $\AA$ ]. Intramolecular coordination of the nitrogen atom of the substituent to zinc $[\mathrm{Zn}-\mathrm{N} 2.124(3) \AA]$ makes this zinc atom tetrahedrally coordinated. A similar compound, in which one of the bridging acetate groups is replaced by a $\mu^{2}$-bridging OEt group, which has closely related structural features, has been reported by the same authors ${ }^{263}$.

A few organozinc compounds containing the $t-\mathrm{BuPO}_{3}$ bis-anion have been reported $^{263,264}$. They form complex aggregated structures containing up to ten zinc atoms, but are of less interest for organozinc chemists.

\section{E. Monoorganozinc Compounds $\mathrm{RZnY}$ with $\mathrm{Y}=\mathrm{NR}_{\mathbf{2}}$}

Monoorganozinc compounds in which the second group is oxygen-bonded to zinc usually exist as aggregated species and discrete monomolecular structures are exceptions. However, for the monoorganozinc compounds in which the second group is bound via nitrogen to zinc, many more structures of discrete mononuclear species are known.

Tris(trimethylsilyl)methylzinc bis(trimethylsilyl)amide (178) is the only example of an organozinc amide in which the zinc atom is two-coordinate, of which the structure has been determined in the solid state (Figure 89) ${ }^{157}$. The $\mathrm{Zn}-\mathrm{C}$ bond distance [1.944(2) $\AA$ ] is as expected for a $\sigma$-bonded zinc atom. The $\mathrm{C}-\mathrm{Zn}-\mathrm{N}$ bond angle $\left[177.8(1)^{\circ}\right]$ is close to linear. The $\mathrm{Zn}-\mathrm{N}$ distance is extremely short [1.846(2) $\AA$ ], but this is a logical consequence of the sp-hybridization of the zinc atom and the $\mathrm{sp}^{2}$-hybridization of the amide-nitrogen atom. The latter is indicated by the fact that the sum of the bond angles around this nitrogen atom is $359.7^{\circ}$.

In the ethylzinc diphenylamide derivative (179) ${ }^{265}$ (Figure 89), the zinc atom has a trigonal planar coordination geometry (sum of the bond angles around zinc is $359.8^{\circ}$ ). Three-coordination at zinc is reached by intramolecular coordination of the phosphorus atom [ $\mathrm{Zn}-\mathrm{P} 2.4450(14) \AA]$. In this compound the amide-nitrogen atom is also $\mathrm{sp}^{2}$-hybridized. This bonding mode (both the zinc atom and the nitrogen atoms are 
$\left(\mathrm{Me}_{3} \mathrm{Si}\right)_{3} \mathrm{C}-\mathrm{Zn}-\mathrm{N}\left(\mathrm{SiMe}_{3}\right)_{2}$

(178)

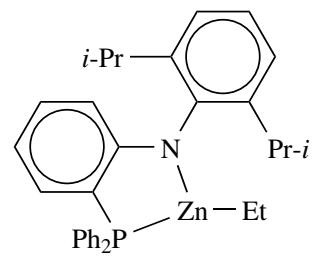

(179)

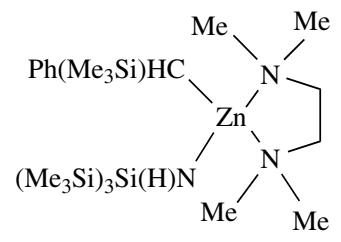

(180)

FIGURE 89. Schematic structures of $\mathbf{1 7 8}, \mathbf{1 7 9}$ and $\mathbf{1 8 0}$

$\mathrm{sp}^{2}$-hybridized) results in a somewhat longer $\mathrm{Zn}-\mathrm{N}$ bond distance in $\mathbf{1 7 9}$ [1.911(4) $\AA$ ] compared to the value observed in $\mathbf{1 7 8}$.

In the organozinc amide complex $(\mathbf{1 8 0})^{156}$ (Figure 89), the zinc atom has a distorted tetrahedral coordination geometry as the result of the coordination by the nitrogen atoms of a TMEDA molecule. The $\mathrm{Zn}-\mathrm{N}$ bond distances [2.182(3) and 2.252(3) $\AA$ ] of the coordinating TMEDA molecule are considerably longer than the $\mathrm{Zn}-\mathrm{N}$ amide $\sigma$-bond [1.904(3) ̊] .

Organozinc $\beta$-diketoiminates form a class of compounds of which the structures have been extensively studied, especially those with sterically demanding 2,6-diisopropylphenyl groups present on the nitrogen atoms. A series of compounds with various organic groups bound to zinc, i.e. $\mathbf{1 8 1}^{266}, \mathbf{1 8 2}^{267}, \mathbf{1 8 3}^{266}, \mathbf{1 8 4}^{266}$ and $\mathbf{1 8 5}^{268}$ (Figure 90), have been prepared and were structurally characterized in the solid state. All compounds have comparable structural features. The bidentate monoanionic diketoiminate ligand is chelatebonded to the zinc atom with almost equal $\mathrm{Zn}-\mathrm{N}$ bond distances (average $1.96 \AA$ ), resulting in a central six-membered $\mathrm{Zn}-\mathrm{N}-\mathrm{C}-\mathrm{C}-\mathrm{C}-\mathrm{N}$ ring. In 181, 182 and 185 this ring is flat, but in $\mathbf{1 8 3}$ and $\mathbf{1 8 4}$ this ring is puckered in a boat conformation with the zinc atom at the bow and the opposite $\mathrm{C}$ atom at the stern. In all compounds the zinc atom has a trigonal planar coordination geometry. In compound $\mathbf{1 8 6}^{\mathbf{2 6 9}}$ (Figure 90), a potentially intramolecularly coordinating substituent was introduced by replacing one of the 2,6-diisopropylphenyl groups by a 2-methoxyphenyl group, to enforce four-coordination at zinc. However, an X-ray crystal structure determination revealed a structure identical to that of 181-185.

The solid state structure of $\mathbf{1 8 7}^{\mathbf{2 7 0}}$ (Figure 90), in which a cyanide group is present on the central carbon atom of the diketoiminate fragment, is different. This compound forms

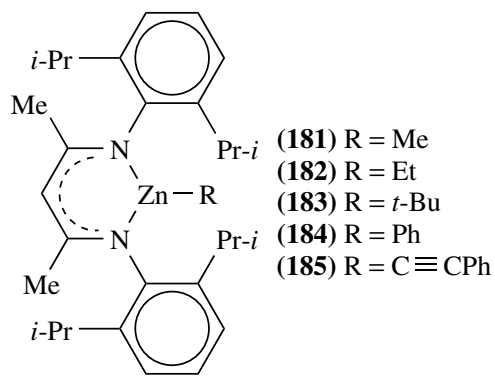

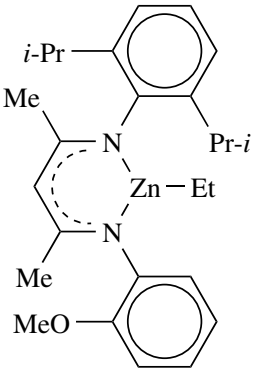

(186)

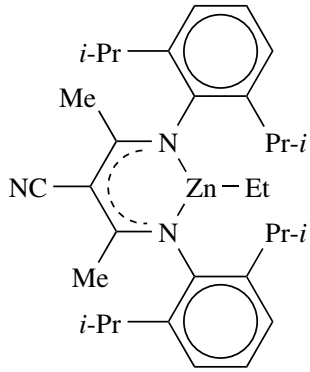

(187)

FIGURE 90. Schematic structures of the organozinc diketoiminates 181-187 


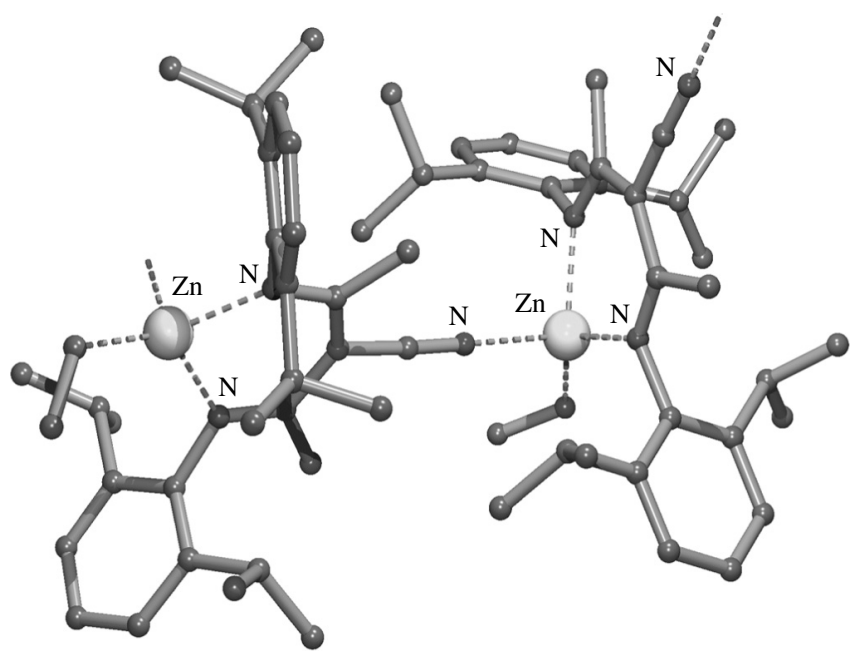

FIGURE 91. Part of the polymeric structure of $\mathbf{1 8 7}$

linear polymeric chains in the solid state (Figure 91) via coordination of the nitrogen atom of the cyanide group to the zinc atom in a neighbouring molecule [ $\mathrm{Zn}-\mathrm{N} 2.136(5) \AA]$, resulting in distorted tetrahedral zinc centres. The pentafluorophenyl analogon of 184, when recrystallized from THF, forms an adduct in which the THF molecule is coordinated to the zinc atom in a distorted tetrahedral geometry ${ }^{271}$.

The solid state structures of the methylzinc iminophosphorane compounds $\mathbf{1 8 8}^{272}$ and $\mathbf{1 8 9}^{273}$ (Figure 92) show large similarities with those of the organozinc diketoiminates described above. The monoanionic bis(iminophosphorane) ligand is $N, N$-chelate-bonded to zinc, resulting in a central $\mathrm{Zn}-\mathrm{N}-\mathrm{P}-\mathrm{C}-\mathrm{P}-\mathrm{N}$ six-membered ring. In both structures the six-membered ring adopts a distorted boat conformation. Trigonal planar coordination

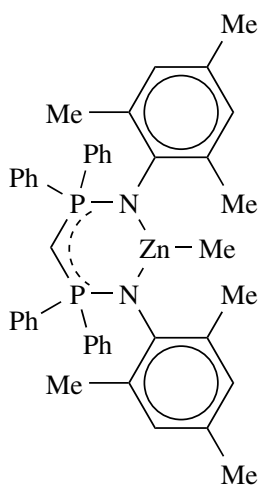

(188)<smiles>C[As]1N([As])[14C](c2ccccc2)P(c2ccccc2)(c2ccccc2)=C=P1(c1ccccc1)c1ccccc1</smiles>

(189)

FIGURE 92. Schematic structures of the methylzinc bis(iminophosphorane) compounds $\mathbf{1 8 8}$ and $\mathbf{1 8 9}$ 


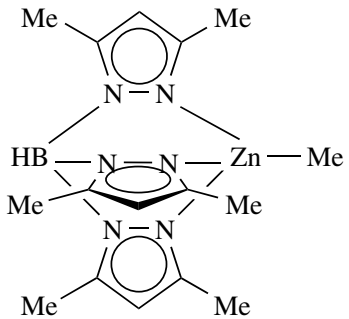

(190)

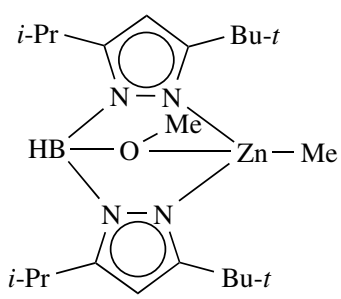

(192)<smiles></smiles>

(191)

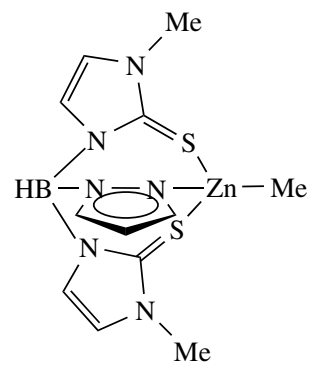

(193)

FIGURE 93. Schematic structures of organozinc pyrazolylhydroborato compounds

of the zinc atoms is indicated by the sum of the bond angles around zinc of $360^{\circ}$ in both compounds.

Another class of organozinc-nitrogen compounds that have been studied intensively by X-ray crystallography are the tris(pyrazolyl)hydroborato-based systems. The structural details of the 2,4-dimethyl derivative $\mathbf{1 9 0}^{274}$ (Figure 93) are given below. It should be noted that the structures of a number of compounds that only differ from $\mathbf{1 9 0}$ in the nature of the substituents present on the pyrazolyl fragment have been determined ${ }^{275-278}$. The structural features of all these compounds are identical. They are monomeric compounds in which the tripodal tris(pyrazolyl)hydroborato fragment caps the zinc atom with its three nitrogen atoms to give a distorted tetrahedral coordination at zinc. In 190 (Figure 94), the three $\mathrm{Zn}-\mathrm{N}$ distances are almost equal [2.048(6), 2.056(4) and 2.056(4) $\AA$ ]. Due to the particular architecture of the ligand system all $\mathrm{N}-\mathrm{Zn}-\mathrm{C}$ angles (average $125.0^{\circ}$ ) are larger than the ideal tetrahedral value and consequently the $\mathrm{N}-\mathrm{Zn}-\mathrm{N}$ angles (average $90.1^{\circ}$ ) are smaller. Another way to describe these complexes is in terms of an organozinc cation which is capped by the three nitrogen atoms of the tris(pyrazolyl)hydroborato anion.

In compound $191^{279}$ one of the pyrazolyl groups is lacking and thus only two nitrogen atoms can coordinate to zinc $[\mathrm{Zn}-\mathrm{N} 2.018(5)$ and 2.021(5) $\AA$ ]. This leads to a trigonal planar geometry at zinc (the sum of the bond angles around zinc is $360^{\circ}$ within experimental error). It has been suggested that an additional weak interaction exists between one of the hydrides and zinc.

Compound 192 (Figure 93) was designed to mimic the binding of zinc to the peptide backbone in thermolysin ${ }^{280}$. The overall structure of $\mathbf{1 9 2}$ shows large similarities with that of 190, but now two nitrogen atoms [ $\mathrm{Zn}-\mathrm{N} 2.101(6)$ and 2.036(6) $\AA$ ] and the oxygen atom of the methoxy group $[\mathrm{Zn}-\mathrm{O} 2.182(5) \AA]$ are involved in bonding to zinc. 


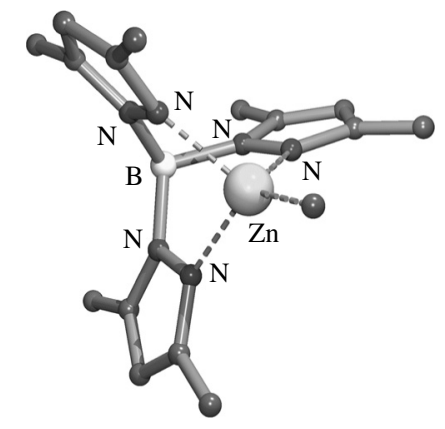

FIGURE 94. Solid state structure of methylzinc tris(pyrazolyl)borato compound 190

The bis(mercaptoimidazolyl)(pyrazolyl)hydroborato unit present in $\mathbf{1 9 3}^{\mathbf{2 8 1}}$ (Figure 93) coordinates via both sulfur atoms $[\mathrm{Zn}-\mathrm{S} 2.404(1)$ and $2.410(1) \AA]$ of the two mercaptoimidazolyl moieties and the nitrogen atom $[\mathrm{Zn}-\mathrm{N} 2.043(4) \AA]$ of the pyrazolyl group to zinc. Because this ligand system is more flexible than the tris(pyrazolyl)hydroborate, the bond angles around zinc are closer to the tetrahedral value than in $\mathbf{1 9 0 .}$

X-ray crystal structure determinations of compounds 194, 195 and 196 (Figure 95) revealed that these compounds exist in the solid state as discrete monomers ${ }^{282}$. In 194, the zinc atom is trigonal planar coordinated as a result of the $N, N$-chelate-bonding [ $\mathrm{Zn}-\mathrm{N}$ 2.007(1) and 1.995(1) $\AA]$. The $\mathrm{N}-\mathrm{Zn}-\mathrm{N}$ bond angle is rather acute $\left[73.83(6)^{\circ}\right]$, but that is a logical consequence of the small bite angle of the ligand.

In 195, the zinc atom is four-coordinate as a result of the $N, S$-chelating ligand [ $\mathrm{Zn}-\mathrm{N}$ 2.009 (3) and $\mathrm{Zn}-\mathrm{S} 2.449$ (1) $\AA$ ] and the additional coordination of a THF molecule [Zn-O 2.241(3) A]. The selenium analog 196 is isostructural with 195.

It has been known for a long time that organozinc amides derived from secondary or primary amines usually exist as dimers in solution ${ }^{176}$. However, depending on the particular groups bound to zinc and/or nitrogen, examples of higher aggregates are also known.

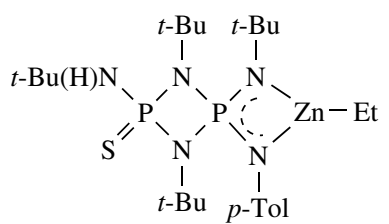

(194)

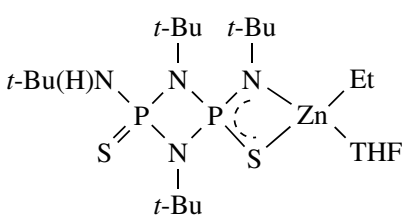

(195)

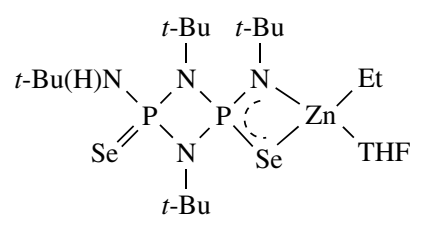

(196)

FIGURE 95. Schematic structures of 194, 195 and 196 in the solid state 


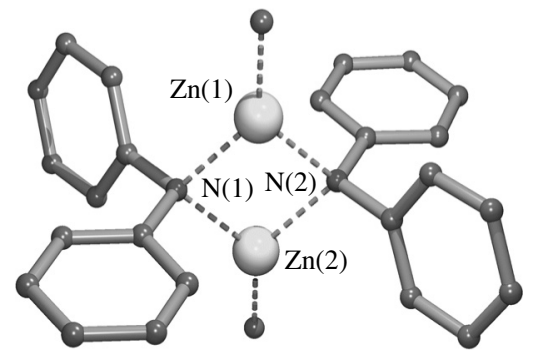

FIGURE 96. Solid state structure of $\mathbf{1 9 7}$

The first organozinc amide of which the dimeric structure in the solid state was unambiguously established is $\left[\mathrm{MeZnNPh}_{2}\right]_{2}$ (197) (Figure 96) ${ }^{283}$. In 197, two diphenylamide groups are $\mu^{2}$-bridge bonded via their nitrogen atoms between two methylzinc units, resulting in a central flat $\mathrm{Zn}-\mathrm{N}-\mathrm{Zn}-\mathrm{N}$ square. All $\mathrm{Zn}-\mathrm{N}$ distances are equal within experimental error [average value 2.072(8) $\AA$ ]. The zinc atoms have a planar trigonal geometry. Because the $\mathrm{N}-\mathrm{Zn}-\mathrm{N}$ bond angle is $90^{\circ}$, consequently the $\mathrm{N}-\mathrm{Zn}-\mathrm{C}$ bond angles (134.4 and $134.6^{\circ}$ ) deviate considerably from the ideal trigonal value of $120^{\circ}$.

The solid state structures of the organozinc amides $\mathbf{1 9 8}^{284}, \mathbf{1 9 9}^{284}$ and $\mathbf{2 0 0}^{285}$ (Figure 97), derived from the corresponding primary amines, are isostructural with that of 197. In principle, two isomers exist of each of these structures, i.e. one with the groups at the nitrogen atoms located at the same side of the plane defined by the two nitrogen atoms and the two zinc atoms, and one with these groups at opposite sides. It appeared that all these compounds exist as the centrosymmetric dimer, i.e. the one with the two groups at opposite sides.

The ethylzinc amide of mesitylamine crystallizes as a dimeric THF adduct (201) (Figure 97) ${ }^{285}$. Also, in this compound the amide nitrogen atom is $\mu^{2}$-bonded [ $\mathrm{Zn}-\mathrm{N}$ $2.070(5)$ and 2.076(5) $\AA$ ] between two zinc atoms. The zinc atoms are distorted tetrahedrally coordinated by additional coordination of a THF molecule [ $\mathrm{Zn}-\mathrm{O} 2.240(5) \AA]$.

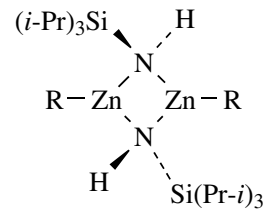

(198) $\mathrm{R}=\mathrm{Me}$

(199) $\mathrm{R}=\mathrm{Et}$

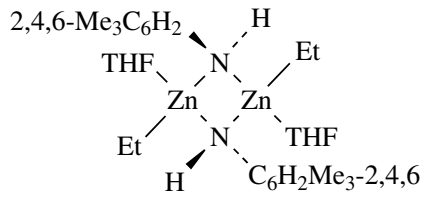

(201)

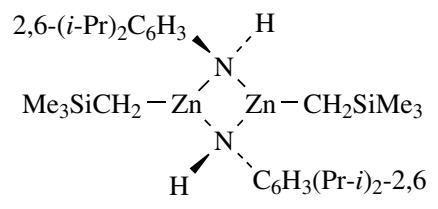

(200)

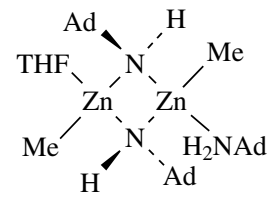

(202)

FIGURE 97. Schematic representation of the structures of 198-202 
The central $\mathrm{Zn}-\mathrm{N}-\mathrm{Zn}-\mathrm{N}$ ring is not flat, but folded $30^{\circ}$ along the $\mathrm{Zn}-\mathrm{Zn}$ axis. The two ethyl groups and the two THF molecules are in a syn configuration, as are the mesitylamine groups.

The dimeric zinc amide derived from adamantylamine was isolated and structurally characterized as an adduct containing one molecule of coordinated THF and one molecule of coordinated adamantylamine (202) (Figure 97) ${ }^{284}$. Its structure shows large similarities with the structure of 201, but the central $\mathrm{Zn}-\mathrm{N}-\mathrm{Zn}-\mathrm{N}$ ring is flat. The two adamantyl groups and the two methyl groups are in syn-position and located at the same side of the $\mathrm{Zn}-\mathrm{N}-\mathrm{Zn}-\mathrm{N}$ plane. The coordinated THF and adamantylamine are also in syn-position but located at the other side of that plane.

The structures of the organozinc amides derived from various diamines, i.e. $N, N, N^{\prime}$ trimethylethylenediamine ${ }^{286}, N, N, N^{\prime}$-trimethylpropylenediamine ${ }^{286}, N, N^{\prime}$-dibenzylethylenediamine ${ }^{287}$ and trans-1,2-bis(trimethylsilylamino)cyclohexane ${ }^{288}$, have also been established. All structures have in common that they are dimers via $\mu^{2}$-bridging amido nitrogens between the two zinc atoms, forming a central four-membered $\mathrm{Zn}-\mathrm{N}-\mathrm{Zn}-\mathrm{N}$ ring, while the second nitrogen atom of each diamine ligand is intramolecularly coordinated to a zinc atom (Figure 98). They only differ in orientation of the various groups present at the central four-membered ring. The two halves of each of the dimers 203, 204, 207 and 208 are symmetry-related via an inversion centre. Consequently, the coordinating nitrogen atoms and the Zn-bonded alkyl groups are pairwise located in anti-position with respect to the $\mathrm{Zn}-\mathrm{N}-\mathrm{Zn}-\mathrm{N}$ plane. In contrast, in $\mathbf{2 0 5}$ and 206 such an inversion centre is not present, but the two halves of the dimer are symmetry-related via a two-fold crystallographic axis. As a result, the two Zn-bonded alkyl groups and the methyl groups at the amide nitrogen are in syn-position at one side of the $\mathrm{Zn}-\mathrm{N}-\mathrm{Zn}-\mathrm{N}$ ring while the coordinating nitrogen atoms are in syn-position at the opposite side.

It appeared to be possible to deprotonate the remaining acidic hydrogen atoms at the coordinating nitrogens in 208 with two additional equivalents of $\mathrm{Et}_{2} \mathrm{Zn}$. The basic structure of the compound obtained $\left[(\mathrm{EtZn})_{2}\left(\mathrm{NSiMe}_{3}\right)_{2}-c-\mathrm{C}_{6} \mathrm{H}_{10}-1,2\right]_{2}$ (209) consists of two trans1,2-bis(trimethylsilylamido)cyclohexane units containing an ethylzinc fragment bonded

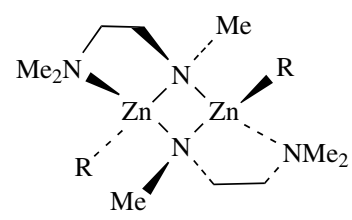

(203) $\mathrm{R}=\mathrm{Me}$

(204) $\mathrm{R}=\mathrm{Et}$

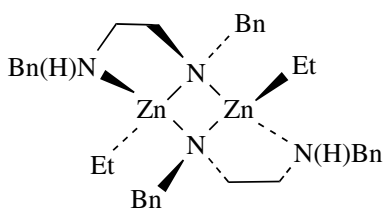

(207)<smiles>[R][Z17]1([R])N(C)[C@@]2([R])N(C)CC[N+]2(C)N1C</smiles>

(205) $\mathrm{R}=\mathrm{Me}$

(206) $\mathrm{R}=\mathrm{Et}$

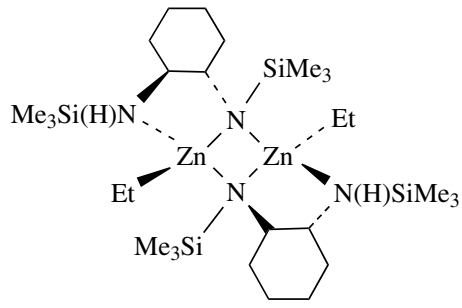

(208)

FIGURE 98. Schematic structures of organozinc amides 203-208 


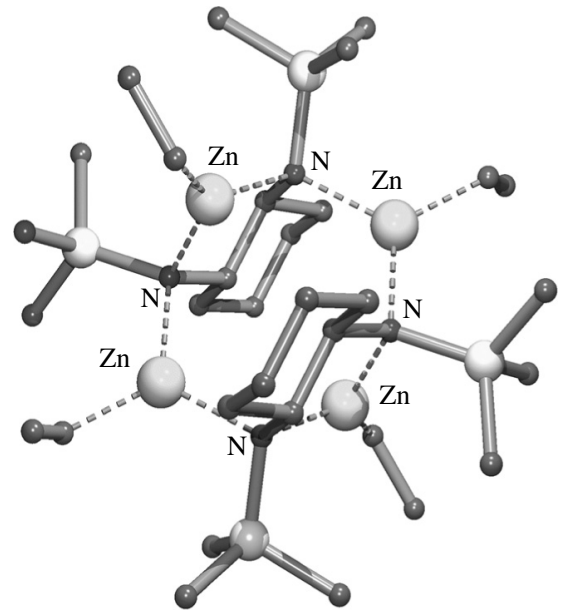

FIGURE 99. Solid state structure of $\mathbf{2 0 9}$

between the two amido nitrogen atoms, which are linked together by two more ethylzinc moieties, via $\mathrm{Zn}-\mathrm{N}$ bonds, into a puckered eight-membered ring of alternating nitrogen and zinc atoms (Figure 99) ${ }^{288}$. One of the cyclohexyl fragments is located below that ring and the other one above it.

The alkylzinc amide compounds $\mathbf{2 1 0}^{289}, \mathbf{2 1 1}^{290}$ and $\mathbf{2 1 2}^{291}$, derived from the corresponding 2-(aminomethyl)pyridines, have structural features identical to those of 203-208 (Figure 100). They form dimers in which the amide nitrogen atom is $\mu^{2}$-bridged between

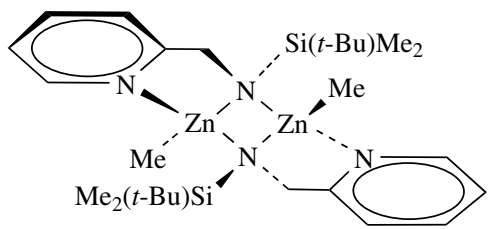

(210)
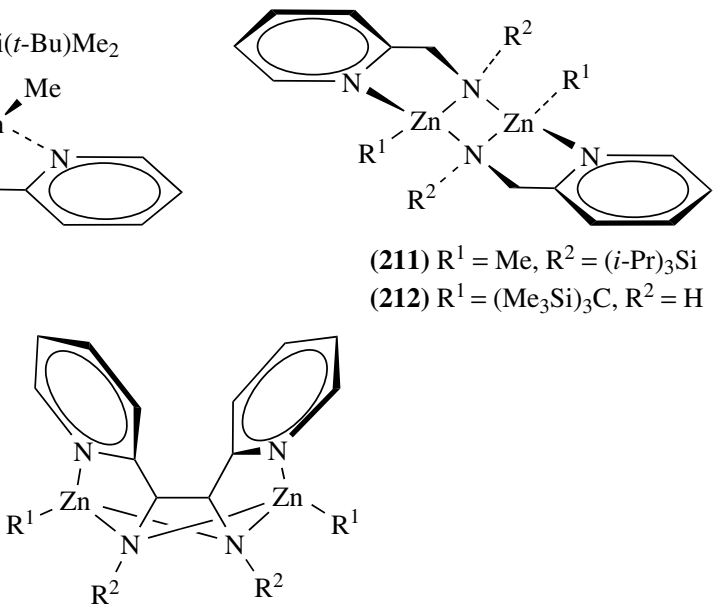

(213) $\mathrm{R}^{1}=\mathrm{Me}, \mathrm{R}^{2}=(i \text {-Pr })_{3} \mathrm{Si}$

(214) $\mathrm{R}^{1}=\mathrm{Me}, \mathrm{R}^{2}=\mathrm{Me}_{2}(t-\mathrm{Bu}) \mathrm{Si}$

(113) $\mathrm{R}^{1}=\mathrm{Et}, \mathrm{R}^{2}=t$-Bu

FIGURE 100. Schematic structures of compounds 210-214 
two zinc atoms to give the central $\mathrm{Zn}-\mathrm{N}-\mathrm{Zn}-\mathrm{N}$ ring, while the pyridyl nitrogen atoms each coordinate to a zinc atom. These compounds can also exist as two different geometrical isomers. Dimer 210 is centrosymmetric and consequently the central $\mathrm{Zn}-\mathrm{N}-\mathrm{Zn}-\mathrm{N}$ ring is flat and the various groups at this ring are pairwise in anti-position with respect to this plane. In both 211 and $\mathbf{2 1 2}$ such an inversion centre is not present. The fourmembered $\mathrm{Zn}-\mathrm{N}-\mathrm{Zn}-\mathrm{N}$ ring in $\mathbf{2 1 1}$ is slightly folded, but essentially flat in $\mathbf{2 1 2}$. In both 211 and 212 the coordinating pyridyl nitrogen atoms approach the zinc atoms from the same side of the plane (syn-position), while the two methyl groups bound to zinc and the amide-nitrogen substituents are in syn-position at the other side of the plane. One of the factors that determines the aggregation state of this type of compounds is the bulk of the respective groups present at zinc and nitrogen. This became evident by the structure determination of the methylzinc analog of 212, which appeared to be a trimeric aggregate in the solid state (vide infra).

Thermolysis of the alkylzinc 2-(amidomethyl)pyridines induces an oxidative $\mathrm{C}-\mathrm{C}$ coupling reaction at the methanide carbon atom. The products $\mathbf{2 1 3}^{290}$ and $\mathbf{2 1 4}{ }^{289}$ (Figure 100) were structurally characterized by X-ray crystallography. These dimers are isostructural with 113, which was obtained from the thermal conversion of the diethylzinc complex of $N$-tert-butyl-2-pyridylcarbaldimine. Details (Figure 52) are given above (Section III.D).

The structure of the ethylzinc amide derived from 2-(trimethylsilylamino)pyridine (215) also consists of a central $\mathrm{Zn}-\mathrm{N}-\mathrm{Zn}-\mathrm{N}$ ring via $\mu^{2}-\mathrm{N}$ bridging amido groups while the pyridine nitrogen atoms coordinate to the zinc atoms [Zn-N 2.125(5) $\AA$ ] (Figure 101) ${ }^{292}$. The $\mu^{2}$-bridging of the amido nitrogen atoms is rather asymmetric [ $\mathrm{Zn}-\mathrm{N} 2.061(5) \AA$ within the four-membered chelate ring and 2.245(5) $\AA$ to the other zinc atom]. The pyridyl groups are syn-orientated with respect to the central $\mathrm{Zn}-\mathrm{N}-\mathrm{Zn}-\mathrm{N}$ ring, as are the ethyl groups bound to zinc and the trimethylsilyl groups at the other side of this ring.

The methylzinc guanidinate complex $\mathbf{2 1 6}$ has a similar structure (Figure 101) ${ }^{211}$. In this compound the $\mu^{2}$-bridging between the zinc atoms is also asymmetric [ $\mathrm{Zn}-\mathrm{N} 2.101(3)$ and 2.201(3) $\AA$ ]. The orientation of the various groups with respect to the central $\mathrm{Zn}-\mathrm{N}-\mathrm{Zn}-\mathrm{N}$ ring is identical to that in $\mathbf{2 1 5}$. The two guanidinate ligands lie in syn-position at one side

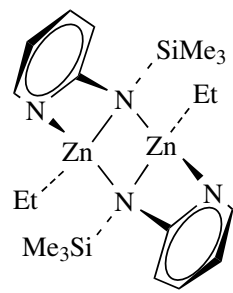

(215)

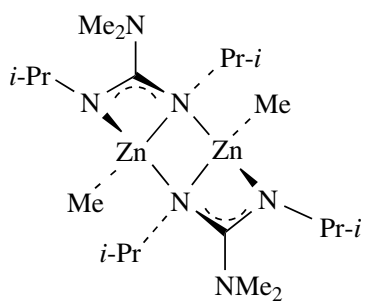

(216)

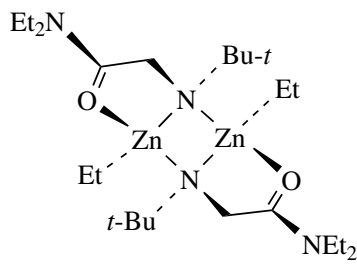

(217)

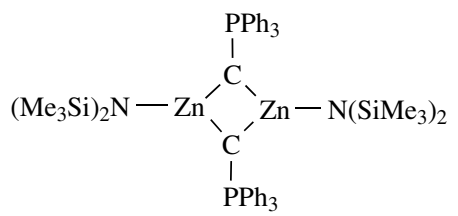

(218)

FIGURE 101. Schematic structures of organozinc amides 215-218 
of the ring and the methyl groups and the isopropyl substituents at the bridging nitrogen atom lie pairwise in syn-position at the other side of the ring.

Compound 217 is formed, among other products, from the reaction of the 1-aza-4-oxa1,3-butadiene, $t$ - $\mathrm{BuN}=\mathrm{C}(\mathrm{H}) \mathrm{C}(=\mathrm{O}) \mathrm{NEt}_{2}$, with $\mathrm{Et}_{2} \mathrm{Zn}^{293}$. The overall structural features are closely related to the organozinc amides discussed before (Figure 101). The central $\mathrm{Zn}-\mathrm{N}-\mathrm{Zn}-\mathrm{N}$ ring formed via $\mu^{2}$-bridging amido nitrogen atoms [ $\mathrm{Zn}-\mathrm{N} 2.069(5)$ and $2.093(5) \AA]$ is flat. The oxygen atoms of the diethylamido group coordinate each to a zinc atom [ $\mathrm{Zn}-\mathrm{O} 2.123(4) \AA]$ and are in syn-position with respect to the central plane. Likewise, the two zinc-bonded ethyl groups and the two $t$-butyl groups are in syn-position at the other side of that plane.

The structure of dimer 218 is remarkable (Figure 101) ${ }^{78}$. In this compound two carbon atoms are $\mu^{2}$-bridge-bonded between two zinc atoms [Zn-C 2.066(4) and 2.070(5) $\AA$ ] and not the amide nitrogen atoms, which are each $\sigma$-bonded to a zinc atom [ $\mathrm{Zn}-\mathrm{N}$ 1.930(4) $\AA$ ]. This 'reversed' bonding mode is most likely a consequence of the ylide character of the bridging carbon atoms. The zinc atoms have trigonal planar coordination geometry. The amide nitrogen atoms are $\mathrm{sp}^{2}$-hybridized, which is indicated by the sum of the bond angles $\left(360^{\circ}\right)$.

When $\mathrm{Cp}_{2} \mathrm{Zn}$ and $\left[\left(\mathrm{Me}_{3} \mathrm{Si}\right)_{2} \mathrm{~N}\right]_{2} \mathrm{Zn}$ are mixed in a 2:1 molar ratio, a new compound with stoichiometry $\mathrm{Cp}_{3} \mathrm{Zn}_{2} \mathrm{~N}\left(\mathrm{SiMe}_{3}\right)_{2}$ (219) is obtained ${ }^{294}$. The solid state structure of this compound comprises two CpZn units linked to a dimer via one $\mu^{2}-\mathrm{N}$-bridging $\left[\mathrm{Me}_{3} \mathrm{Si}\right]_{2} \mathrm{~N}$ group [ $\mathrm{Zn}-\mathrm{N} 2.005(3)$ and 2.024(3) $\AA$ ] and one bridging Cp group (Figure 102). The bonding of the peripheral $\mathrm{Cp}$ group to zinc is not pure $\eta^{1}$, as is indicated by one relatively short $[2.059(6) \AA]$ and one relatively long [2.473(7) $\AA] \mathrm{Zn}-\mathrm{C}$ bond. This points to a bonding mode which is intermediate between $\eta^{1}$ and $\eta^{2}$. A similar type of bonding is observed for the bridging $\mathrm{Cp}$ group. Each of the zinc atoms has one relatively short [average $2.143 \AA$ ] and one relatively long [average $2.553 \AA$ ] interaction with this Cp group.

The alkylzinc amides derived from the primary amines, 2-(aminomethyl)pyridine $(\mathbf{2 2 0})^{291}$, aniline $(\mathbf{2 2 1})^{285}$, 1-naphthylamine $(\mathbf{2 2 2})^{295}$ and tert-butylamine $(\mathbf{2 2 3})^{285}$, have in common that they form trimeric aggregates in the solid state (Figure 103). The three zinc atoms are linked via three $\mu^{2}$-bridging amide nitrogen atoms, with $\mathrm{Zn}-\mathrm{N}$ distances in the expected range, to a cyclohexane-like six-membered ring. In 220, a tetrahedral coordination geometry at zinc is reached by the coordination of a pyridyl nitrogen atom to each zinc atom [average $\mathrm{Zn}-\mathrm{N} 2.160 \AA$ ] . In $\mathbf{2 2 1}$ and 222, the zinc atoms are fourcoordinate as the result of coordination of a THF molecule to each zinc atom with $\mathrm{Zn}-\mathrm{O}$ bond distances ranging from 2.17 to $2.27 \AA ̊$. In 223, no additional coordinating ligands

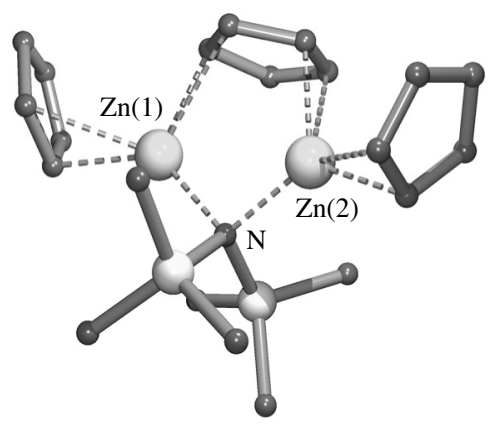

FIGURE 102. Solid state structure of $\mathbf{2 1 9}$ 


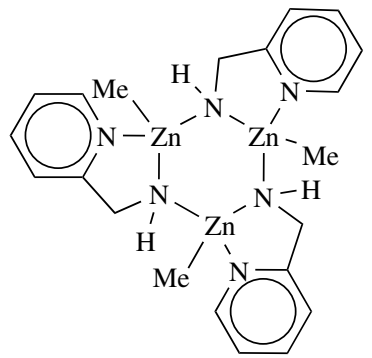

(220)

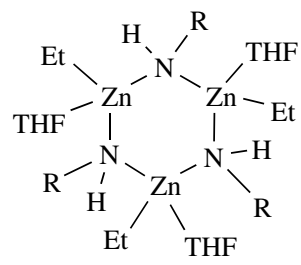

(221) $\mathrm{R}=\mathrm{Ph}$

(222) $\mathrm{R}=1$-naphthyl

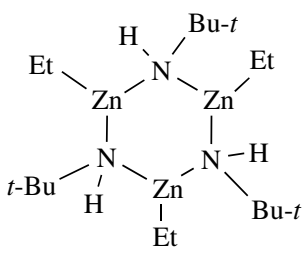

(223)

FIGURE 103. Schematic structures of the trimeric organozinc amides 220-223

are present and the zinc atoms have trigonal planar coordination geometry. The central six-membered metallacycle in $\mathbf{2 2 0}$ adopts a boat conformation while in 221-223 a chair conformation is present.

The hetero-cubane structural motif, which is often found in organozinc alkoxides (Section IV.D), has also been observed in the solid state structures of a few organozinc phosphaneiminato compounds (Figure 104) 296,297 . The central core of compounds (224-226) consists of a cube of alternating zinc and nitrogen atoms, in which each nitrogen atom is $\mu^{3}$-bonded to three zinc atoms. These compounds are isostructural and only differ in the nature of the group bound to zinc. Within experimental error the $\mathrm{Zn}-\mathrm{N}$ distances are equal in each compound [2.088 $\AA$ for $\mathbf{2 2 4}$ and $2.088 \AA$ for $\mathbf{2 2 5}$ and $2.069 \AA$ for 226]. Also, the $\mathrm{Zn}-\mathrm{N}-\mathrm{Zn}$ and $\mathrm{N}-\mathrm{Zn}-\mathrm{N}$ bond angles differ only marginally $\left(<0.5^{\circ}\right)$ from $90^{\circ}$. These values indicate that the central core in these compounds has an almost perfect cubic geometry. Compound 227 is an analog of 225 in which one of the trimethylphospaneiminato groups is replaced by an iodide. As a consequence of the longer $\mathrm{Zn}-\mathrm{I}$ distances [2.986(3), 2.971(3) and 2.939(3) $\AA$ ] compared to the $\mathrm{Zn}-\mathrm{N}$ distances [average $2.055 \AA$ ], the geometry of the central cube is less perfect.

Reaction of secondary benzamides with $\mathrm{Me}_{2} \mathrm{Zn}$ affords the corresponding methylzinc benzamides (equation 23) ${ }^{137}$. X-ray crystal structure determinations of these compounds revealed complex irregular aggregates in which all nitrogen and oxygen atoms are involved in bonding to zinc.

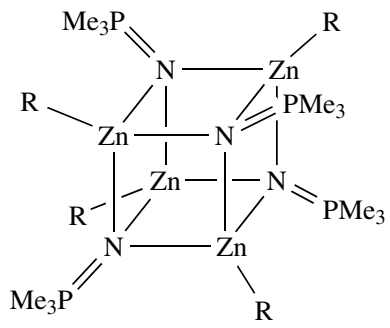

(224) $\mathrm{R}=\mathrm{Me}$

(225) $\mathrm{R}=n$-Bu

(226) $\mathrm{R}=\mathrm{C} \equiv \mathrm{CSiMe}_{3}$

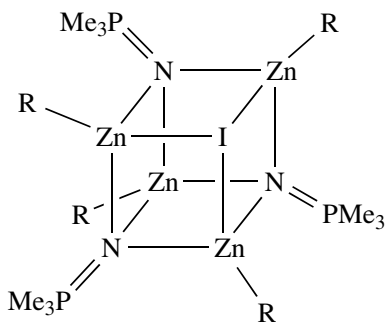

(227) $\mathrm{R}=n-\mathrm{Bu}$

FIGURE 104. Schematic structures of tetrameric organozinc phosphaneiminates 224-227 
An X-ray crystal structure determination of the product obtained from the reaction of methyl $N$-phenylcarbamate with $\mathrm{Et}_{2} \mathrm{Zn}$ (equation 24) shows the formation of a complex aggregate containing two zinc-bonded ethyl groups, four zinc atoms and six deprotonated carbamate molecules, instead of the anticipated ethylzinc carbamate ${ }^{298}$.

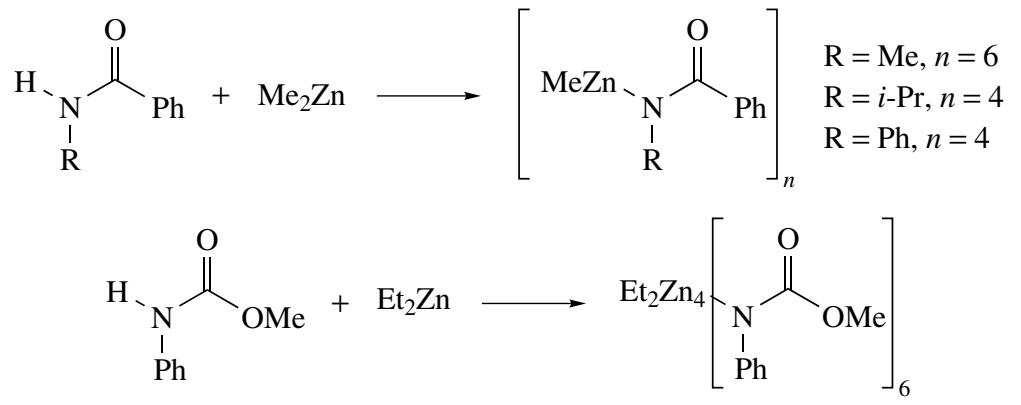

\section{F. Monoorganozinc Compounds RZnY with $\mathrm{Y}=$ Other Heteroatom Bonded Group}

Only for a few organozinc compounds, in which in addition to the zinc-carbon bond a zinc-heteroatom bond other than oxygen or nitrogen is present, have structures in the solid state been determined. These structures include those of organozinc compounds in which, in addition to the zinc-carbon bond, a zinc-sulfur, zinc-selenium, zinc-phosphorus or zinc-arsenic bond is present.

Methylzinc thiolate $\mathrm{MeZnSCMe}{ }_{2} \mathrm{CH}_{2} \mathrm{NMe}\left(\mathrm{CH}_{2}\right)_{2} \mathrm{Pyr}-2$ (228) is the only example of a monomeric organozinc thiolate that has been structurally characterized in the solid state (Figure 105) 299 . This compound was used as a precursor for the synthesis of the corresponding formate complex to mimic peptide deformylase. In addition to the zinc-carbon bond [ $\mathrm{Zn}-\mathrm{C} 1.986(3) \AA]$ and the $\mathrm{Zn}-\mathrm{S}$ bond $[\mathrm{Zn}-\mathrm{S}$ 2.2971(7) $\AA$ ], the two nitrogen atoms of the ligand system are intramolecularly coordinated to zinc $[\mathrm{Zn}-\mathrm{N}(1)$ $2.120(2)$ and $\mathrm{Zn}-\mathrm{N}(2) 2.161(2) \AA]$, rendering the zinc atom distorted tetrahedrally coordinated.

The dimeric structure as present in organozinc-oxygen and -nitrogen aggregates is also observed in the solid state structures of various organozinc thio compounds (Figure 106). The centrosymmetric (trimethylsilyl)methylzinc triphenyl sulfide dimer (229) 220 comprises a flat central four-membered ring of alternating zinc and sulfur atoms. The $\mathrm{Zn}-\mathrm{S}-\mathrm{Zn}$ bridge is slightly asymmetric [Zn-S 2.381(1) and 2.416(1) Å]. The zinc atoms are trigonal

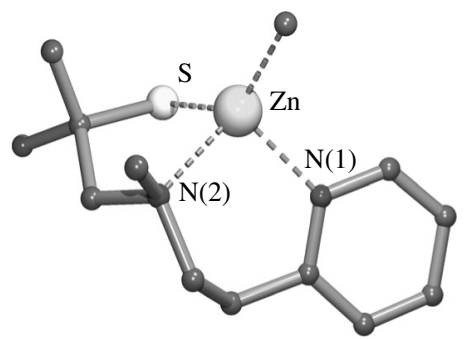

FIGURE 105. Solid state structure of the monomeric organozinc thiolate $\mathbf{2 2 8}$ 
<smiles>CCCCCC[Ga]1S[As](CC)N1C</smiles>

(229)

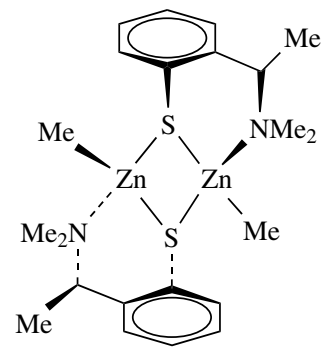

(231)

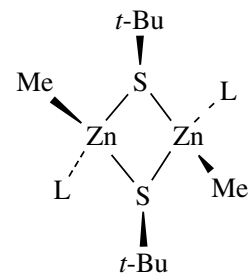

(230a) $\mathrm{L}=\mathrm{Pyr}$

(230b) $\mathrm{L}=$ TMTA

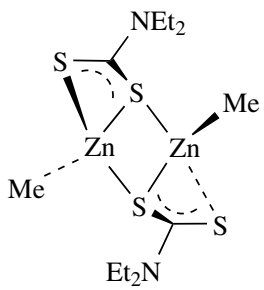

(232)

FIGURE 106. Schematic structures of dimeric organozinc thiolates 229-232

planar coordinated and the two $\mathrm{Ph}_{3} \mathrm{C}$ substituents are in anti-position with respect to the central plane.

Methylzinc tert-butyl sulfide forms with pyridine or 1,3,5-trimethyl-1,3,5-triazine (TMTA) the dimeric complexes $\mathbf{2 3 0 a}$ and $\mathbf{2 3 0 b ^ { 3 0 0 }}{ }^{3}$. In both compounds the central fourmembered $\mathrm{Zn}-\mathrm{S}-\mathrm{Zn}-\mathrm{S}$ ring is folded, to $13^{\circ}$ in $230 \mathrm{a}$ and $40^{\circ}$ in $230 \mathbf{b}$. The two coordinating pyridine ligands in 230a approach the zinc atoms from the same side of the ring (syn-position) [Zn-N 2.141(5) and 2.156(5) $\AA$ ] as the two coordinating TMTA ligands do in 230b [ $\mathrm{Zn}-\mathrm{N} 2.205(5)$ and 2.216(5) $\AA$ ]. Both in 230a and in 230b the two methyl groups at zinc and the two coordinating ligands are in syn-position at the other side of ring.

The enantiopure methylzinc thiolate containing the 2-[(R)-1-(dimethylamino)ethyl] thiophenolate ligand (231) has proven to be an excellent catalyst for the enantioselective addition of diorganozinc compounds to aldehydes ${ }^{301}$. An X-ray crystal structure determination (Figure 107) showed that this compound in the solid state also exists as a dimer ${ }^{302}$. Its structure comprises a central, almost flat, $\mathrm{Zn}-\mathrm{S}-\mathrm{Zn}-\mathrm{S}$ four-membered ring as the result of two $\mu^{2}$-bridging arylthiolate groups with almost equal $\mathrm{Zn}-\mathrm{S}$ bond lengths [average $2.414 \AA$ ]. Both nitrogen atoms of the substituent are intramolecularly coordinated to a zinc atom [Zn-N 2.101(4) and 2.107(4) $\AA$ ], forming a six-membered chelate ring. Remarkably, in one of the chelate rings the methyl substituent is orientated perpendicular to the plane of the aryl ring, while in the other chelate ring this substituent is in the energetically less favourable in-plane position.

Methylzinc $N, N$-diethyldithiocarbamate (232) (Figure 106) exists as a centrosymmetric dimer in the solid state ${ }^{303}$. One sulfur atom of each of the dithiocarbamate groups bridges symmetrically [ $\mathrm{Zn}-\mathrm{S} 2.512(4)$ and 2.501(4) $\AA$ ] between the two zinc atoms to form a flat four-membered ring. The other two sulfur atoms each coordinate to a zinc atom with a considerably shorter bond distance $[\mathrm{Zn}-\mathrm{S} 2.370(3) \AA]$. As a consequence of 


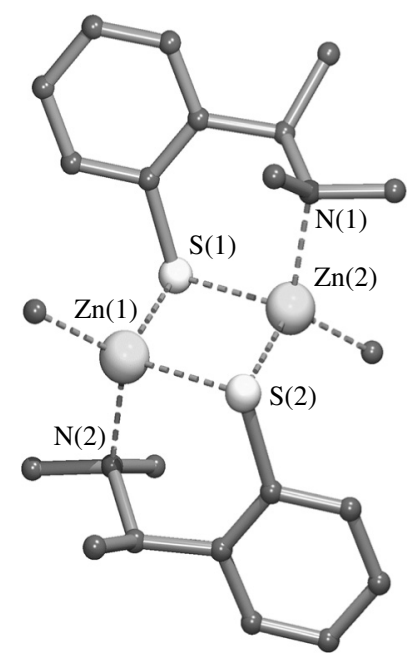

FIGURE 107. Solid state structure of $\mathbf{2 3 1}$

the small bite angle of the dithiocarbamate chelate, the geometry at the zinc atoms is rather distorted tetrahedral. The solid state structures of the corresponding ethylzinc $N, N$ diethyldithiocarbamate ${ }^{304}$ and the selenium analogs methylzinc, ethylzinc and (trimethylsilyl)methylzinc $N, N$-diethyldiselenocarbamate ${ }^{305,306}$ have been determined, and all are isostructural with 232.

The solid state structures of methylzinc tert-butyl sulfide ${ }^{307}$, methylzinc isopropyl sulfide $^{308}$ and ethylzinc ethyl sulfide ${ }^{309}$ have been determined. All are aggregated clusters. Methylzinc tert-butyl sulfide is a pentamer $(\mathrm{MeZnSBu}-t)_{5}$ in which four of the sulfide groups are $\mu^{3}$-bonded to four zinc atoms and one sulfide is $\mu^{2}$-bonded between two zinc atoms (Figure 108). Consequently, four of the zinc atoms have a distorted tetrahedral geometry while the remaining zinc atom is trigonal planar.

Methylzinc isopropyl sulfide is an octamer (MeZnSPr- $i)_{8}$ in which all the sulfide groups are $\mu^{3}$-bridge-bonded to three zinc atoms, rendering them all distorted tetrahedral. No further details are given for this structure.

Ethylzinc ethyl sulfide is a decamer $(E t Z n S E t)_{10}$. In this cluster all sulfide groups are $\mu^{3}$-bonded to three zinc atoms (Figure 108). It is striking that the overall structure of this cluster shows a close resemblance to that of wurtzite.
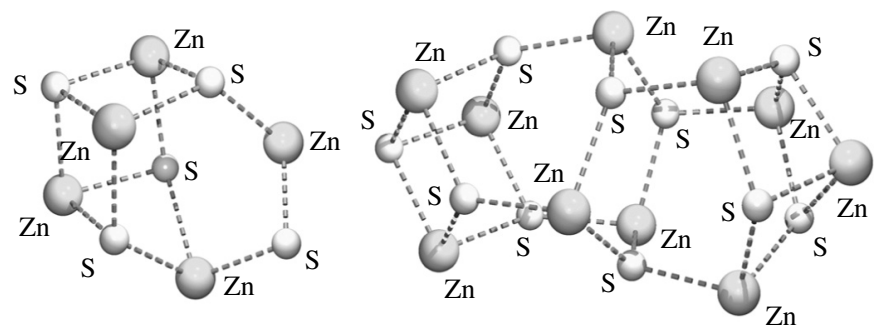

FIGURE 108. Basic arrangement of zinc and sulfur atoms in $(\mathrm{MeZnSBu}-t)_{5}(\mathrm{left})$ and $(\mathrm{EtZnSEt})_{10}$ (right) 


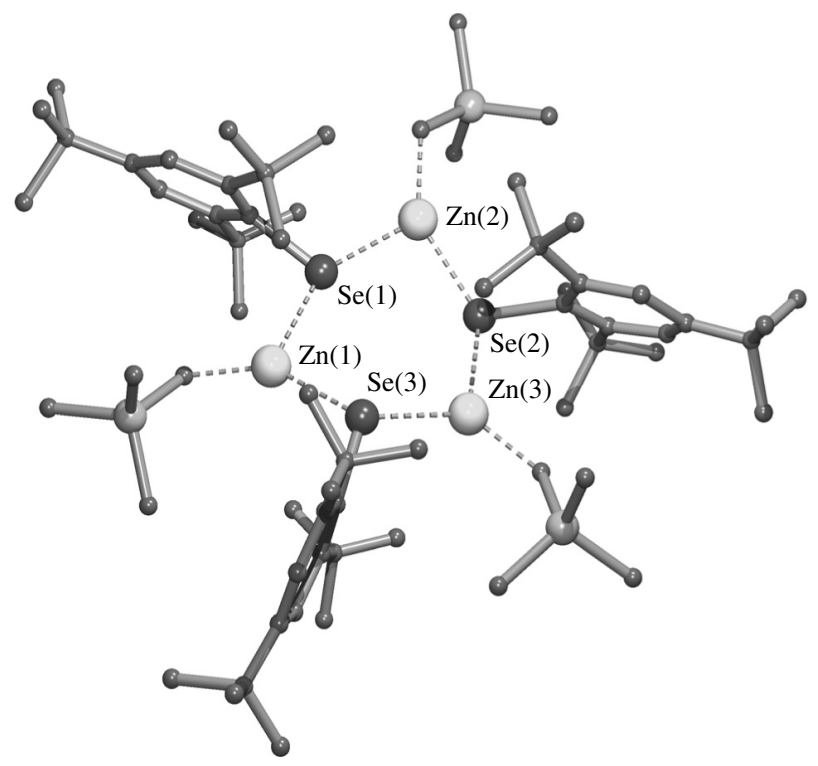

FIGURE 109. Solid state structure of organozinc selenide $\mathbf{2 3 3}$

Apart from the few organozinc diselenocarbamates (vide supra), (trimethylsilyl)methylzinc 2,4,6-tris(tert-butyl)phenyl selenide (233) is the only compound with direct zinc to selenium bonds of which the structure in the solid state has been established ${ }^{310}$. It is a trimeric aggregate (Figure 109) of which the central core comprises a slightly puckered six-membered ring of alternating zinc and selenium atoms as the result of $\mu^{2}$-bridging selenide groups with almost equal $\mathrm{Zn}-\mathrm{Se}$ distances [average $2.445 \AA$ ].

In compound 234 (Figure 110), two organozinc moieties directly bound to phosphorus are present ${ }^{311}$. The $\mathrm{Zn}-\mathrm{P}$ bond lengths are 2.2273(9) and 2.2365(10) $\AA$, while the $\mathrm{Zn}-\mathrm{C}$ bond lengths [both $1.965(3) \AA]$ are slightly shorter than in homoleptic $\left[\left(\mathrm{Me}_{3} \mathrm{Si}\right)_{3} \mathrm{C}_{2} \mathrm{Zn}^{87}\right.$. Due to the steric congestion of the bulky $\left(\mathrm{Me}_{3} \mathrm{Si}\right)_{3} \mathrm{C}$ groups at the zinc atoms and the $i-\mathrm{Pr}_{3} \mathrm{Si}$ groups at phosphorus, the $\mathrm{C}-\mathrm{Zn}-\mathrm{P}$ bond angles $\left[166.5(1)^{\circ}\right.$ and $\left.167.0(1)^{\circ}\right]$ deviate from the ideal value of $180^{\circ}$ for an sp-hybridized zinc atom. The sum of the bond angles around phosphorus is $319^{\circ}$, indicating a pyramidal geometry. Also, the structure of the corresponding arsenic analog 235 has been reported ${ }^{312}$. Apart from the slightly longer $\mathrm{Zn}-\mathrm{As}$ bonds [2.3256(7) and 2.3207(7) $\AA$ ], this compound is isostructural with 234 .

The alkylzinc bis(trimethylsilyl)phosphides $(\mathbf{2 3 6}-\mathbf{2 3 8})^{313}$ and the arsenic analog of 236 (239) $)^{314}$ crystallize as trimeric aggregates (Figure 110). The central part in the organozinc phosphides is a six-membered ring of alternating zinc and phosphorus atoms as a result of $\mu^{2}$-bridging phosphides between zinc atoms. All zinc-phosphorus distances are in the range of 2.38 to $2.41 \AA$. In all compounds, the zinc atoms have a trigonal planar geometry. In 238, the six-membered ring is twisted, but in $\mathbf{2 3 6}$ and $\mathbf{2 3 7}$ this ring has a twist-boat conformation. The arsenic analog $\mathbf{2 3 9}$ is isostructural with $\mathbf{2 3 6}$. It should be noted that the crystallographic asymmetric unit of isopropylzinc bis(trimethylsilyl)phosphide contains both the trimeric aggregate $\mathbf{2 3 8}$ and a dimer (240). This dimer comprises a flat fourmembered $\mathrm{Zn}-\mathrm{P}-\mathrm{Zn}-\mathrm{P}$ ring as a result of $\mu^{2}$-bridging phosphido groups with $\mathrm{Zn}-\mathrm{P}$ distances in the same range as those in the trimeric aggregate. As in the trimer, the 


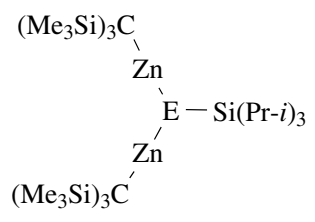

$$
\text { (234) } \mathrm{E}=\mathrm{P}
$$$$
\text { (235) } \mathrm{E}=\mathrm{As}
$$

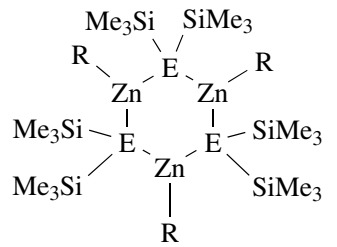

(236) $\mathrm{E}=\mathrm{P}, \mathrm{R}=\mathrm{Me}$

(237) $\mathrm{E}=\mathrm{P}, \mathrm{R}=n-\mathrm{Bu}$

(238) $\mathrm{E}=\mathrm{P}, \mathrm{R}=i$ - $\mathrm{Pr}$

(239) $\mathrm{E}=\mathrm{As}, \mathrm{R}=\mathrm{Me}$

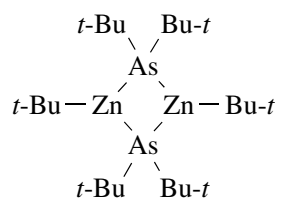

(242)

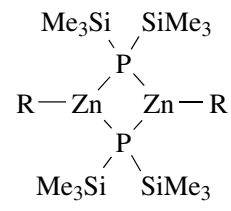

(240) $\mathrm{R}=i$-Pr

(241) $\mathrm{R}=\mathrm{Me}_{3} \mathrm{SiCH}_{2}$

FIGURE 110. Schematic structures of organozinc-phosphides and -arsenides 234-242

zinc atoms have a trigonal planar geometry. The solid state structure of the (trimethylsilyl)methyl analog (241) of $\mathbf{2 4 0}$ shows a large resemblance to that of $\mathbf{2 4 1}^{313}$.

The X-ray crystal structure determination of tert-butylzinc bis(tert-butyl) arsenide (242) revealed a similar structural feature as observed in $\mathbf{2 4 0}$ and $\mathbf{2 4 1}$, i.e. a flat $\mathrm{Zn}-\mathrm{As}-\mathrm{Zn}-\mathrm{As}$ central four-membered ring as a result of $\mu^{2}$-bridging arsenide groups and trigonal planar zinc atoms ${ }^{315}$.

Reaction of dicyclohexylphosphine with $\mathrm{Et}_{2} \mathrm{Zn}$ in a 1:1 molar ratio in THF as a solvent affords, after cooling to $-30{ }^{\circ} \mathrm{C}$, a crystalline material. An X-ray crystal structure determination showed that this product is the trimeric ethylzinc dicyclohexylphosphide (243) (Figure 111$)^{316}$. The structure consists of a central six-membered ring like in the trimeric organozinc phosphides described above. To one of the zinc atoms a molecule of THF is coordinated $[\mathrm{Zn}-\mathrm{O} 2.275(4) \AA]$, rendering this zinc centre tetrahedrally coordinated. The other two zinc atoms have a trigonal planar geometry. The six-membered metallacycle is in the chair conformation.

Similarly, ethylzinc diphenylphosphide (244) was prepared from diphenylphosphine and $\mathrm{Et}_{2} \mathrm{Zn}$ (Figure 111). An X-ray crystal structure determination revealed a central six-membered metallacycle ${ }^{317}$. To two of the zinc atoms additional diphenylphosphine

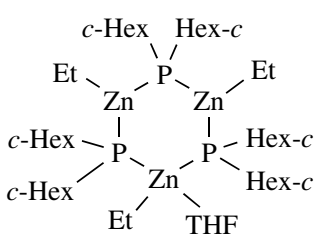

(243)

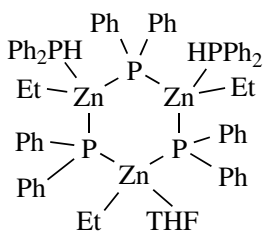

(244)

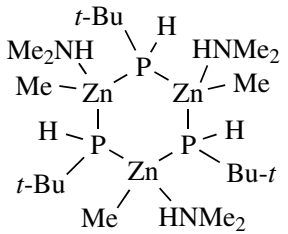

(245)

FIGURE 111. Schematic structures of the organozinc phosphides 243-245 
molecules are coordinated, and the remaining zinc atom is coordinated by a THF molecule, leading to a tetrahedral geometry for all zinc atoms. The $\mathrm{Zn}-\mathrm{P}$ distances of the coordinated phosphines are slightly longer (average $2.55 \AA$ ) than the $\mu^{2}$-bridge-bonding $\mathrm{Zn}-\mathrm{P}$ distances (average $2.44 \AA$ ). Because the zinc atom and its bonded groups (the ethyl group and the coordinating THF molecule) are crystallographically disordered over two positions, no conclusions can be drawn concerning the actual conformation of the six-membered ring.

The primary phosphine $t-\mathrm{BuPH}_{2}$ reacts with $\mathrm{Me}_{2} \mathrm{Zn}$ to give a complex $[\mathrm{MeZn}(\mathrm{P}(\mathrm{H}) \mathrm{Bu}-$ $\left.t\left(t-\mathrm{BuPH}_{2}\right)\right]$. After an exchange reaction with $\left(\mathrm{Me}_{2} \mathrm{~N}\right)_{3} \mathrm{Sb}$, compound 245 was obtained as a crystalline material ${ }^{318}$. The structure of $\mathbf{2 4 5}$ comprises again a six-membered metallacycle in a 'half-boat' conformation with $\mu^{2}$-bonded primary phosphide groups between two zinc atoms. Each of the zinc atoms has a tetrahedral geometry as a result of a coordinating dimethylamine molecule.

\section{ORGANOZINC COMPOUNDS CONTAINING A ZINC-TRANSITION METAL BOND}

Zinc-transition metal compounds in which a direct zinc to transition metal bond is present $\left(\mathrm{Zn}\left[\mathrm{Co}(\mathrm{CO})_{4}\right]_{2} \text { was the first one }\right)^{319}$ have already been known for a long time. However, it was not until 1982 that a compound was isolated and structurally characterized that contained both a zinc-to-carbon and a zinc-to-transition metal bond.

Reaction of $\mathrm{HCo}\left(\mathrm{N}_{2}\right)\left(\mathrm{PPh}_{3}\right)_{3}$ with $\mathrm{Cp}_{2} \mathrm{Zn}$ affords $(\mathrm{CpZn})_{2} \mathrm{Co}(\mathrm{Cp})\left(\mathrm{PPh}_{3}\right)($ 246), which was structurally characterized in the solid state by X-ray crystallography (Figure 112) ${ }^{320}$. The structure of $\mathbf{2 4 6}$ consists of a central cobalt atom, which is surrounded in roughly tetrahedral fashion by two zinc atoms, a phosphorus atom and an $\eta^{5}$-bonded cyclopentadienyl group. In the two CpZn units the cyclopentadienyl groups are $\eta^{5}$-bonded to zinc with an average $\mathrm{Zn}-\mathrm{C}$ distance of $2.34 \AA$. The angles $\mathrm{Co}-\mathrm{Zn}$ to the centre of the $\mathrm{Cp}$ groups are not linear, but slightly bent, $160.6^{\circ}$ and $162.9^{\circ}$, respectively. The $\mathrm{Zn}-\mathrm{Co}$ distances are slightly shorter $[2.2893(5)$ and $2.2882(5) \AA]$ than these distances in $\mathrm{Zn}\left[\mathrm{Co}(\mathrm{CO})_{4}\right]_{2}$ [2.305(2) ̊̊].

Likewise, $\mathrm{CpZnNbH} \mathrm{Cp}_{2}$ (247) was obtained from the reaction of $\mathrm{Cp}_{2} \mathrm{Zn}$ with $\mathrm{Cp}_{2} \mathrm{NbH}_{3}$ and was structurally characterized (Figure 112$)^{321}$. The structural geometry of 247 resembles that of $\mathrm{Cp}_{2} \mathrm{NbH}_{3}{ }^{322}$, with the central hydrogen atom replaced by a $\mathrm{CpZn}$ group. The $\mathrm{Cp}$ ring is bound in a nearly symmetrical $\eta^{5}$-fashion to zinc, with its centre displaced slightly off the $\mathrm{Nb}-\mathrm{Zn}$ axis $(0.15 \AA)$. The $\mathrm{Zn}-\mathrm{Nb}$ distance of $2.5407(7) \AA$ indicates the presence of a normal $\mathrm{Zn}-\mathrm{Nb}$ single bond. The $\mathrm{Nb}-\mathrm{H}$ distance [1.69(4) $\AA$ ] is typical for a terminal $\mathrm{Nb}-\mathrm{H}$ bond, but the slight bridging character of these hydrides to zinc is indicated by $\mathrm{Zn}-\mathrm{H}$ distances of 1.97(4) $\AA$ and relatively small $\mathrm{H}-\mathrm{Zn}-\mathrm{Nb}$ angles of $51.1^{\circ}$.

$\left(\mathrm{Cp}_{2} \mathrm{Zn}\right)_{2} \mathrm{Ta}(\mathrm{H})(\mathrm{MeCp})_{2}(\mathbf{2 4 8})$ was prepared in a similar way to the niobium compound 247. Its structural characterization ${ }^{323}$ in the solid state revealed a structure (Figure 112)

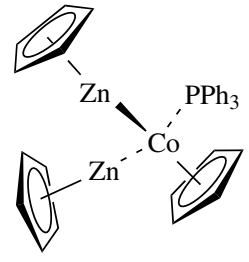

(246)

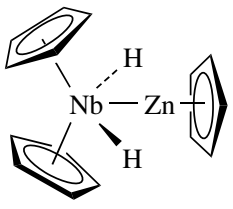

(247)

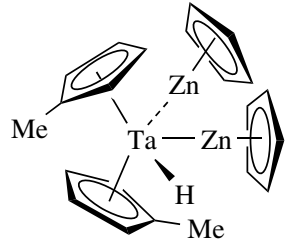

(248)

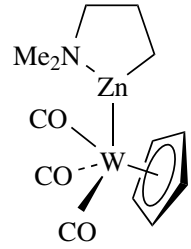

(249)

FIGURE 112. Schematic structures of organozinc-transition metal compounds 246-249 
close to that of $\mathrm{Cp}_{2} \mathrm{TaH}_{3}$ in which two of the hydrogen atoms are replaced by zinc atoms. In the CpZn units the $\mathrm{Cp}$ groups are $\eta^{5}$-bonded to zinc with an average $\mathrm{C}-\mathrm{Zn}$ distance of $2.37 \AA$. The two $\mathrm{Zn}-$ Ta bonds $(2.59 \AA)$ are equal within experimental error and are typical for normal $\mathrm{Zn}-\mathrm{Ta}$ single bonds. The acute $\mathrm{Zn}-\mathrm{Ta}-\mathrm{Zn}$ bond angle [62.8(1) $\left.{ }^{\circ}\right]$ results in a very close approach of the two non-bonded zinc atoms $(2.699 \AA)$.

The organozinc tungsten compound 249 (Figure 112) was prepared by a redistribution reaction of the symmetric diorganozinc compound $\left[\mathrm{Me}_{2} \mathrm{~N}\left(\mathrm{CH}_{2}\right)_{3}\right]_{2} \mathrm{Zn}$ with $\left[\mathrm{CpW}(\mathrm{CO})_{3}\right]_{2}$. Its structural characterization in the solid state revealed an organozinc part in which the dimethylaminopropyl group is $\sigma$-bonded to zinc and the nitrogen atom is intramolecularly coordinated to zinc $[2.19(3) \AA]^{324}$. This organozinc part is connected to a $\mathrm{CpW}(\mathrm{CO})_{3}$ unit via a direct $\mathrm{Zn}-\mathrm{W}$ bond [2.685(3) $\AA$ ]. The overall structural geometry of $\mathbf{2 4 9}$ can be described as consisting of a central tungsten atom, surrounded in a tetragonal pyramidal fashion by a cyclopentadienyl group in the apical position and three $\mathrm{CO}$ molecules and a zinc atom in the basal positions.

Rather unexpected products have been obtained from the reaction of $\mathrm{Cp}_{2} \mathrm{Zn}$ with zero-valent nickel compounds. The reaction of $\mathrm{Cp}_{2} \mathrm{Zn}$ with $\mathrm{Ni}(\mathrm{COD})_{2}(\mathrm{COD}=1,5$-cyclooctadiene) in the presence of $\mathrm{PPh}_{3}$ afforded a product (250) of which the X-ray crystal structure determination revealed a structure consisting of a $\mathrm{CpNi}$ unit in which the $\mathrm{Cp}$ group is $\eta^{5}$-bonded to nickel and a $\mathrm{PPh}_{3}$ molecule which is coordinated to nickel (Figure 113) ${ }^{325}$. Two zinc atoms are bonded via direct $\mathrm{Zn}-\mathrm{Ni}$ bonds $[\mathrm{Zn}-\mathrm{Ni} 2.379(5)$ and 2.383(5) $\AA$ ] to nickel. To each of the zinc atoms, one Cp group is bonded via an $\eta^{1}$-interaction [Zn-C 2.01(4) and 2.09(4) $\AA$ ]. Finally, one Cp group bridges via two $\eta^{2}$ interactions between the two zinc atoms. It is notable that these $\eta^{2}$-interactions have one short (average $2.20 \AA$ ) and one longer (average $2.44 \AA$ ) $\mathrm{Zn}-\mathrm{C}$ contact.

When the same reaction of $\mathrm{Cp}_{2} \mathrm{Zn}$ with $\mathrm{Ni}(\mathrm{COD})_{2}$ was carried out in the absence of $\mathrm{PPh}_{3}$, an entirely different product having the stoichiometry $\mathrm{Cp}_{6} \mathrm{Zn}_{4} \mathrm{Ni}_{2}$ (251) was obtained $^{326}$. An X-ray crystal structure determination revealed the formation of a cluster compound, consisting of an octahedral arrangement of two apical nickel atoms and four equatorial zinc atoms. The octahedron is compressed along the $\mathrm{Ni}-\mathrm{Ni}$ axis giving eight $\mathrm{Ni}-\mathrm{Zn}$ bonds of 2.398(2) $\AA$ and one long $\mathrm{Ni}-\mathrm{Ni}$ bond of 2.571(1) $\AA$. To each of the nickel and zinc atoms one $\mathrm{Cp}$ group is $\eta^{5}$-bonded. Overall, the structure has a spherical shape (Figure 113). Due to the crystallographic symmetry in the tetragonal space-group $\mathrm{P} 4_{2} / \mathrm{mnm}$, the $\mathrm{Cp}$ groups bound to nickel are two- and those to zinc four-fold disordered.

To overcome this disorder, the same synthetic procedure was used with the substituted cyclopentadienyl compounds bis(tert-butylcyclopentadienyl)zinc and bis[(trimethylsilyl) cyclopentadienyl]zinc ${ }^{327}$. Indeed, the corresponding $\mathrm{Zn}_{4} \mathrm{Ni}_{2}$ clusters were formed, in which the geometry of the central cluster core and the bonding of the cyclopentadienyl groups

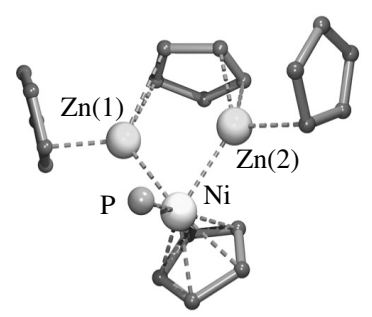

(250)

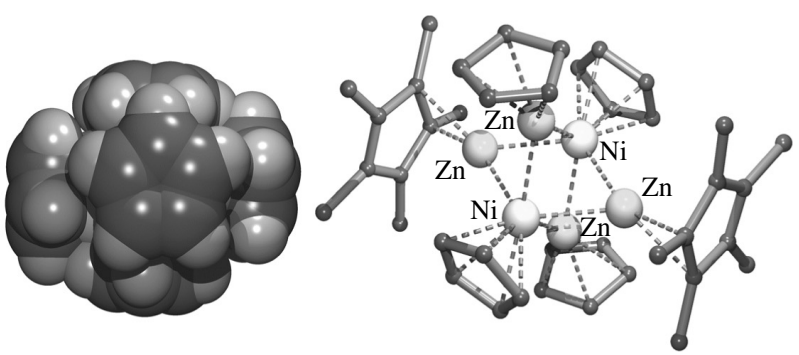

(251)
(252)

FIGURE 113. Solid state structure of 250. Space filling model of 251. Solid state structure of $\mathbf{2 5 2}$ 
to nickel is identical to that in $\mathbf{2 5 1}$. The only difference is the hapticity of the bonding of the cyclopentadienyl groups to zinc. In the tert-butyl-substituted analog, two of the cyclopentadienyl groups are $\eta^{5}$-bonded to two zinc atoms that are in trans-position and the other two cyclopentadienyl groups are $\eta^{1}$-bonded to the other two zinc atoms. Likewise, in the trimethylsilyl derivative two of the cyclopentadienyl groups are $\eta^{3}$-bonded and the other two $\eta^{1}$-bonded.

Reaction of $\mathrm{Cp}_{2} \mathrm{Zn}, \mathrm{Cp}^{*}{ }_{2} \mathrm{Zn}$ and $\mathrm{Ni}(\mathrm{COD})_{2}$ in 1:1:1 ratio afforded a similar $\mathrm{Zn}_{4} \mathrm{Ni}_{2}$ cluster compound $\mathbf{2 5 2}^{328}$. In 252 (Figure 113), two $\mathrm{Cp}$ groups are $\eta^{5}$-bonded to the nickel atoms, while a $\mathrm{Cp}^{*}$ group is bonded to each of two trans-positioned zinc atoms in a $\eta^{2}$-fashion [Zn-C 2.18(1) and 2.24(1) $\AA$ ]. To the other two zinc atoms Cp groups are bonded. Due to relatively large thermal motions of these $\mathrm{Cp}$ groups, their exact bonding mode to zinc could not be determined, but most likely they are intermediate between the $\eta^{2}$ - and $\eta^{3}$-bonding modes.

It has been shown that one of the $\mu^{3}$-bridging hydrogen atoms in the $\mathrm{Cp}^{*}{ }_{3} \mathrm{Ru}_{3} \mathrm{H}_{5}$ cluster can be easily replaced by a main group organometallic fragment like $\mathrm{MeGa}$, EtAl, $i-\mathrm{PrMg}$ or $\mathrm{EtZn}^{329}$. The X-ray crystal structure determination of the product $\mathrm{Cp}^{*}{ }_{3} \mathrm{RuZnEtH}_{4}(\mathbf{2 5 3})$ obtained from the reaction of $\mathrm{Cp}^{*}{ }_{3} \mathrm{Ru}_{3} \mathrm{H}_{5}$ with $\mathrm{Et}_{2} \mathrm{Zn}$ shows that the main structural features of the originating $\mathrm{Cp}^{*}{ }_{3} \mathrm{Ru}_{3} \mathrm{H}_{5}$ cluster are retained, but one of the $\mu^{3}$-bridging hydrogen atoms is replaced by a $\mu^{3}$-bridging EtZn group (Figure 114), with almost equal $\mathrm{Zn}-\mathrm{Ru}$ distances of 2.6747(10), 2.6561(8) and 2.6561(8) ̊.

The organozinc rhodium compounds $\left[(i-\mathrm{Pr})_{2} \mathrm{P}\left(\mathrm{CH}_{2}\right)_{3} \mathrm{P}(\mathrm{Pr}-i)_{2} \mathrm{RhZnCH}_{2} \mathrm{C}_{6} \mathrm{H}_{5}\right]_{2}(\mu-\mathrm{H})_{2}$ (254) and $\left[(i-\mathrm{Pr})_{2} \mathrm{P}\left(\mathrm{CH}_{2}\right)_{3} \mathrm{P}(\mathrm{Pr}-i)_{2} \mathrm{RhZnCp}\right]_{2}(\mu-\mathrm{H})_{2}$ (255) (Figure 114) were obtained from the reaction of $\left[(i-\mathrm{Pr})_{2} \mathrm{P}\left(\mathrm{CH}_{2}\right)_{3} \mathrm{P}(\mathrm{Pr}-i)_{2} \mathrm{Rh}\right]_{2}(\mu-\mathrm{H})_{2}$ with $\left(\mathrm{PhCH}_{2}\right)_{2} \mathrm{Zn}$ and with $\mathrm{Cp}_{2} \mathrm{Zn}$, respectively ${ }^{330,331}$. The solid state structure of 254 consists of two $(i-\mathrm{Pr})_{2} \mathrm{P}\left(\mathrm{CH}_{2}\right)_{3} \mathrm{P}(\mathrm{Pr}-$ $i)_{2} \mathrm{Rh}$ fragments that are linked into a dimer via two $\mu^{2}$-bridging hydrogen atoms and two symmetrically $\mu^{2}$-bridging benzylzinc fragments [Zn-Rh 2.513(1) and 2.558(1) $\AA$ ] between the rhodium atoms.

Compound 255 also contains two $\mu^{2}$-bridging zinc atoms between the rhodium atoms, but in a less symmetrical manner than in $\mathbf{2 5 4}$. This asymmetry is reflected by the difference in bonding distances between rhodium and zinc in one of the bridges [ $\mathrm{Zn}-\mathrm{Rh} 2.6115$ and $2.4812 \AA$ ]. Only one $\mu^{2}$-bridging hydrogen is present between the rhodium atoms. It is remarkable that the other hydrogen atom occupies a $\mu^{2}$-bridging position between one of the rhodium atoms and one of the zinc atoms [ $\mathrm{Rh}-\mathrm{H} 1.57$ and $\mathrm{Zn}-\mathrm{H} 1.66 \AA$ ]. It is notable that the $\mathrm{Cp}$ groups in the organozinc moieties are $\eta^{3}$-bonded to zinc.

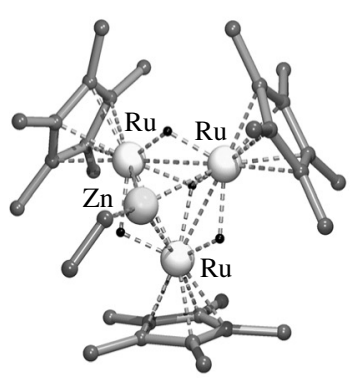

(253)

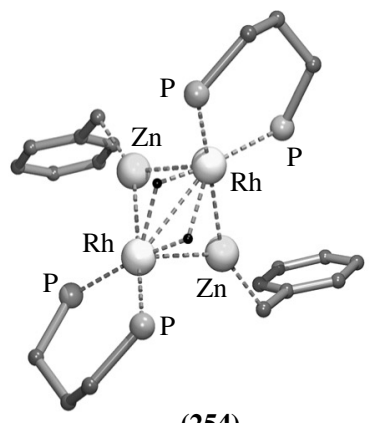

(254)

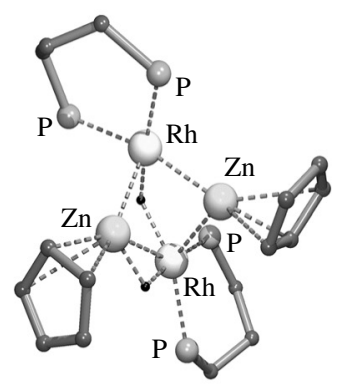

(255)

FIGURE 114. Solid state structures of the organozinc-transition metal compounds 253-255. Note that in $\mathbf{2 5 4}$ and 255 the $i$-Pr groups at phosphorus are omitted for clarity 


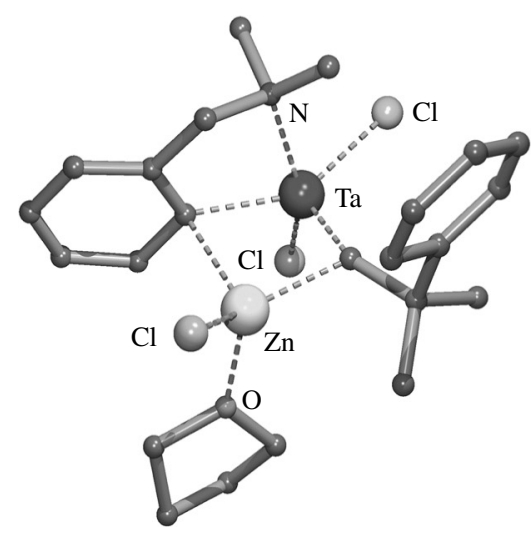

(256)

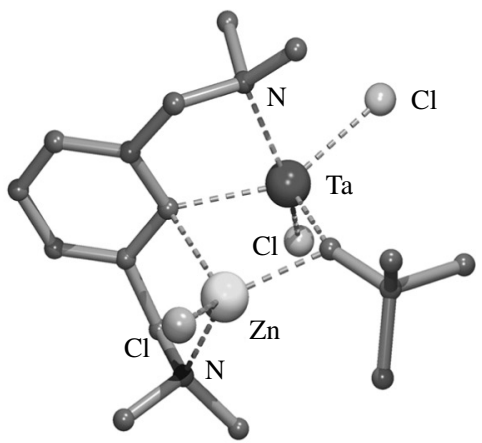

(257)

FIGURE 115. Solid state structures of the organozinc-tantalum compounds 256 and 257

Formally, compounds 2- $\mathrm{Me}_{2} \mathrm{NCH}_{2} \mathrm{C}_{6} \mathrm{H}_{4} \mathrm{TaZn}\left(\mathrm{CH}_{2} \mathrm{CMe}_{2} \mathrm{Ph}\right) \mathrm{Cl}_{3}(\mathrm{THF})$ (256) and 2,6$\left(\mathrm{Me}_{2} \mathrm{NCH}_{2}\right)_{2} \mathrm{C}_{6} \mathrm{H}_{3} \mathrm{TaZn}\left(\mathrm{CH}_{2} \mathrm{CMe}_{3}\right) \mathrm{Cl}_{3}$ (257) (Figure 115) do not belong to the class of organozinc compounds containing a zinc-transition metal bond. However, they are interesting compounds in that they contain both a bridging aryl group and a bridging alkylidyne fragment between a zinc atom and a tantalum atom. X-ray crystal structure determinations confirmed the molecular geometries of both compounds ${ }^{332,333}$.

The overall structures of $\mathbf{2 5 6}$ and $\mathbf{2 5 7}$ show large similarities. The aryl groups bridge in a rather symmetrical manner between zinc and tantalum [in 256, $\mathrm{Zn}-\mathrm{C} 2.27(2)$ and $\mathrm{Ta}-\mathrm{C} 2.23(2) \AA ;$ in 257, $\mathrm{Zn}-\mathrm{C} 2.25(1)$ and Ta-C 2.32(1) $\AA$ ]. The bridge bonding of the alkylidyne carbon between zinc and tantalum is less symmetric [in $\mathbf{2 5 6}, \mathrm{Zn}-\mathrm{C} 2.14(2)$ and $\mathrm{Ta}-\mathrm{C}$ 1.84(2) $\AA$; in 257, $\mathrm{Zn}-\mathrm{C} 2.114(6)$ and $\mathrm{Ta}-\mathrm{C} 1.862(6) \AA]$. In 256, the tantalum atom has a geometry intermediate between a trigonal bipyramidal and a square pyramidal one. Also, an additional THF molecule is coordinated to the zinc centre [Zn-O 1.99(2) A] , resulting in a distorted tetrahedral geometry. In 257, the tantalum atom likewise has a geometry intermediate between that of a trigonal bipyramid and a square pyramid. However, here the second (dimethylamino)methyl substituent is coordinated intramolecularly to the zinc centre $[\mathrm{Zn}-\mathrm{N} 2.101(5) \AA]$ rendering this zinc atom distorted tetrahedrally surrounded. The Ta-Zn non-bonding distances in $\mathbf{2 5 6}$ and 257 are almost equal, 2.740(5) $\AA$ and 2.729(1) ̊, respectively.

\section{CONCLUSIONS}

In this chapter it has become clear that knowledge about the actual solution structures of organozinc reagents is often a pre-requisite to better understand the reaction pathways which operate during reactions in which these organozincs are involved. This is of particular importance for the design of novel synthetic strategies towards (new) organic products which are formed when organozinc reagents are used.

In general, simple dialkylzinc and diarylzinc compounds are monomers in which the zinc atom, as a consequence of its ground-state electronic configuration, is sp hybridized. Thus, such molecules contain a linear $\mathrm{C}-\mathrm{Zn}-\mathrm{C}$ arrangement. The only known exception to this rule is diphenylzinc, which in the solid state is a dimer formed via electron-deficient $\mu^{2}$-bridging phenyl groups. 
In the presence of Lewis bases, diorganozinc compounds form complexes with one or two donor molecules. In the 1:2 complexes, the zinc atom typically has a (distorted) tetrahedral coordination geometry. In contrast, 1:1 complexes contain a zinc atom with a rare trigonal planar geometry. This is only observed when either the coordinating ligand and/or the diorganozinc molecule contain sterically demanding groups.

A variety of structural motifs are observed in the solid state for the heteroleptic monoorganozinc compounds RZnY. In this case, $\mathrm{Y}$ is either a halide or a heteroatom bonded group. Such a group Y might be $\sigma$-bonded to zinc (affording monomers) or $\mu^{2}$ or $\mu^{3}$-bridge-bonded between two and three zinc atoms, respectively. In the latter two cases, aggregated structures (dimers, trimers, tetramers or higher aggregates) are invariably formed. For solutions containing RZnY species, the existence of a Schlenk equilibrium between $\mathrm{RZnY}$ and both $\mathrm{R}_{2} \mathrm{Zn}$ and $\mathrm{ZnY}_{2}$ should always be considered. Moreover, equilibria between two or more higher aggregates cannot be excluded. Such equilibria are naturally driven by thermodynamics. It should be noted that the formation of solid (crystalline) material from such solutions may be influenced by additional factors such as differences in the solubilities of the respective aggregates and packing effects in the crystal lattice. Consequently, caution should be taken when one is drawing conclusions about the structure of aggregates present in solution based on data obtained from solid state (X-ray) crystal structures. It is perhaps more prudent to regard these solid state structures as resting states, and hence they may represent only one of the many structural forms that can be present in solution.

\section{REFERENCES}

1. E. Frankland, Liebigs Ann. Chem., 71, 171 (1849).

2. J. A. Wanklyn, Liebigs Ann. Chem., 107, 125 (1858).

3. K. H. Thiele, Z. Anorg. Allg. Chem., 319, 183 (1962).

4. R. Garth Kidd and R. J. Goodfellow, in NMR and the Periodic Table (Eds. R. K. Harris and B. E. Mann), Chap. 8, Academic Press, London, 1978, pp. 260-261.

5. Cambridge Structural Database, release 5.26, February 2005.

6. W. Strohmeier and K. Nützel, Z. Elektrochem., 59, 538 (1959).

7. J. T. B. H. Jastrzebski and G. van Koten, in Modern Organocopper Chemistry (Ed. N. Krause), Chap. 1, Wiley-VCH, Weinheim, 2002, pp. 1-44.

8. T. Stey and D. Stalke, in The Chemistry of Organolithium Compounds, Part 1 (Eds. Z. Rappoport and I. Marek), Chap. 2, Wiley, Chichester, 2004, pp. 47-120.

9. P. R. Markies, G. Schat, O. S. Akkerman, F. Bickelhaupt, W. J. J. Smeets and A. L. Spek, Organometallics, 9, 2243 (1990).

10. E. Rijnberg, J. T. B. H. Jastrzebski, J. Boersma, H. Kooijman, N. Veldman, A. L. Spek and G. van Koten, Organometallics, 16, 2239 (1997).

11. P. W. J. de Graaf, J. Boersma and G. J. M. van der Kerk, J. Organometal. Chem., 78, C19 (1974).

12. J. Soulati, K. L. Henold and J. P. Oliver, J. Am. Chem. Soc., 93, 5694 (1971).

13. K. L. Henold, J. Soulati and J. P. Oliver, J. Am. Chem. Soc., 91, 3171 (1969).

14. E. Wissing, J. T. B. H. Jastrzebski, J. Boersma and G. van Koten, J. Organometal. Chem., 459, 11 (1993).

15. J. A. Wanklyn, Liebigs Ann. Chem., 108, 67 (1858).

16. J. A. Wanklyn, Liebigs Ann. Chem., 140, 211 (1866).

17. G. Wittig, F. J. Meyer and G. Lange, Liebigs Ann. Chem., 571, 167 (1951).

18. G. Wittig and G. Hornberger, Liebigs Ann. Chem., 577, 11 (1952).

19. H. Gilman and L. A. Woods, J. Am. Chem. Soc., 67, 520 (1945).

20. D. T. Hurd, J. Org. Chem., 13, 711 (1948).

21. R. Nast and R. Müller, Chem. Ber., 91, 2861 (1958).

22. K. Issleib and H. O. Fröhlich, Chem. Ber., 95, 375 (1962).

23. Fr. Hein and H. Schramm, Z. Anorg. Allg. Chem., 158, 153 (1926).

24. Fr. Hein and Fr. A. Segitz, Z. Phys. Chem., 151, 234 (1930). 
25. D. Seyferth, Organometallics, 20, 2940 (2001).

26. W. Tochtermann, Angew. Chem., Int. Ed. Engl., 5, 351 (1966).

27. G. Wittig, Quart. Rev., 191 (1966).

28. N. Krause (Ed.), Modern Organocopper Chemistry, Wiley-VCH, Weinheim, 2002.

29. A. E. H. Wheatley, New J. Chem., 28, 435 (2004).

30. D. J. Linton, P. Schooler and A. E. H. Wheatley, Coord. Chem. Rev., 223, 53 (2001).

31. E. C. Ashby, L-C. Chao and J. Laemmle, J. Org. Chem., 39, 3258 (1974).

32. Y. Okuda, K. Wakamatsu, W. Tückmantel, K. Oshima and H. Nozaki, Tetrahedron Lett., 26, 4629 (1985).

33. M. Uchiyama, M. Koike, M. Kameda, Y. Kondo and T. Sakamoto, J. Am. Chem. Soc., 118, 8733 (1996).

34. T. Takada, H. Sakurai and T. Hirao, J. Org. Chem, 66, 300 (2001).

35. M. Uchiyama, M. Kameda, O. Mishima, N. Yokoyama, M. Koike, Y. Kondo and T. Sakamoto, J. Am. Chem. Soc., 120, 4934 (1998).

36. S. Mori, A. Hirai, M. Nakamura and E. Nakamura, Tetrahedron, 56, 2805 (2000).

37. M. Uchiyama, S. Nakamura, T. Ohwada, M. Nakamura and E. Nakamura, J. Am. Chem. Soc., 126, 10897 (2004).

38. F. Kaufmann, A. Geraudelle, B. Kaempf, F. Schué, A. Deluzarche and A. Maillard, $J$. Organomet. Chem., 24, 13 (1970).

39. M. Uchiyama, Y. Kondo and T. Sakamoto, J. Synth. Org. Chem. Jpn., 57, 1051 (1999).

40. M. Uchiyama, Y. Kondo, T. Miura and T. Sakamoto, J. Am. Chem. Soc., 119, 12372 (1997).

41. E. Weiss and R. Wolfrum, Chem. Ber., 101, 35 (1968).

42. A. Almenningen, T. U. Helgaker, A. Haaland and S. Samdal, Acta Chem. Scand., Ser. A, 36, 159 (1982).

43. E. Weiss and E. A. C. Lucker, J. Organomet. Chem., 2, 197 (1964).

44. H. Dietrich, Acta Crystallogr., 16, 681 (1963).

45. E. Weiss and H. Plass, J. Organomet. Chem., 14, 21 (1968).

46. D. Stalke, Chem. Soc. Rev., 27, 171 (1998).

47. U. Cremer, I. Pantenburg and U. Ruschewitz, Inorg. Chem., 42, 7716 (2003).

48. A. J. Edwards, A. Fallaize, P. R. Raithby, M.-A. Rennie, A. Steiner, K. L. Verhorevoort and D. S. Wright, J. Chem. Soc., Dalton Trans., 133 (1996).

49. H.-O. Fröhlich, B. Kosan, B. Müller and W. Hiller, J. Organomet. Chem., 441, 177 (1992).

50. H.-O. Fröhlich, B. Kosan, B. Undeutsch and H. Görls, J. Organomet. Chem., 472, 1 (1994).

51. R. Wyrwa, H.-O. Fröhlich and H. Görls, Organometallics, 15, 2833 (1996).

52. J. T. B. H. Jastrzebski, G. van Koten, M. Konijn and C. H. Stam, J. Am. Chem. Soc., 104, 5490 (1982).

53. A. Osman, R. G. Steevensz, D. G. Tuck, H. A. Meinema and J. G. Noltes, Can. J. Chem., 62, 1698 (1984).

54. G. van Koten, J. T. B. H. Jastrzebski, F. Muller and C. H. Stam, J. Am. Chem. Soc., 107, 697 (1985).

55. G. van Koten, J. T. B. H. Jastrzebski, C. H. Stam and N. C. Niemann, J. Am. Chem. Soc., 106, 1880 (1984).

56. A. P. Purdy and C. F. George, Organometallics, 11, 1955 (1992).

57. M. Westerhausen, C. Gückel, T. Habereder, M. Vogt, M. Warchhold and H. Nöth, Organometallics, 20, 893 (2001).

58. M. Westerhausen, C. Gückel, H. Piotrowski and M. Vogt, Z. Anorg. Allg. Chem., 628, 735 (2002).

59. M. Westerhausen, B. Rademacher, W. Schwarz, J. Weidlein and S. Henkel, J. Organomet. Chem., 469, 135 (1994).

60. M. Westerhausen, B. Rademacher and W. Schwarz, Z. Anorg. Allg. Chem., 619, 675 (1993).

61. E. Rijnberg, J. T. B. H. Jastrzebski, J. Boersma, H. Kooijman, A. L. Spek and G. van Koten, J. Organomet. Chem., 541, 181 (1997).

62. S. R. Boss, M. P. Coles, R. Haigh, P. B. Hitchcock, R. Snaith and A. E. H. Wheatley, Angew. Chem., Int. Ed., 42, 5593 (2003).

63. M. A. Putzner, B. Neumüller and K. Dehnicke, Z. Anorg. Allg. Chem., 623, 539 (1997).

64. M. Krieger, G. Geiseler, K. Harms, J. Merle, W. Massa and K. Dehnicke, Z. Anorg. Allg. Chem., 624, 1387 (1998).

65. K. H. Thiele, H. Görls and W. Seidel, Z. Anorg. Allg. Chem., 624, 555 (1998). 
66. M. Westerhausen, M. Wieneke, W. Ponikwar, H. Nöth and W. Schwarz, Organometallics, 17, 1438 (1998).

67. M. Westerhausen, B. Rademacher, W. Schwarz and S. Henkel, Z. Naturforsch., B: Chem. Sci., 49, 199 (1994).

68. A. L. Arduengo III, H. V. R. Dias, F. Davidson and R. L. Harlow, J. Organomet. Chem., 462, 13 (1993).

69. E. P. Squiller, R. R. Whittle and H. G. Richey Jr., J. Am. Chem. Soc., 107, 432 (1985).

70. D. M. Kushlan, J. Am. Chem. Soc., 109, 2510 (1987).

71. A. D. Pajerski, M. Parvez and H. G. Richey Jr., J. Am. Chem. Soc., 110, 2660 (1988).

72. R. M. Fabicon, A. D. Pajerski and H. G. Richey Jr., J. Am. Chem. Soc., 113, 6680 (1991).

73. R. M. Fabicon and H. G. Richey Jr., Organometallics, 20, 4018 (2001).

74. P. P. Power, K. Ruhlandt-Senge and S. C. Shoner, Inorg. Chem., 30, 5013 (1991).

75. R. D. Rogers, J. L. Atwood and R. Grüning, J. Organomet. Chem., 157, 229 (1978).

76. R. M. Fabicon, M. Parvez and H. G. Richey Jr., J. Am. Chem. Soc., 113, 1412 (1991).

77. R. M. Fabicon and H. G. Richey Jr., J. Chem. Soc., Dalton Trans., 783 (2001).

78. M. Steiner, H. Grützmacher, H. Prtizkow and L. Zsolnai, Chem. Commun., 285 (1998).

79. Y. Kondo, M. Shilai, M. Uchiyama and T. Sakamoto, J. Am. Chem. Soc., 121, 3539 (1999).

80. M. Uchiyama, S. Furumoto, M. Saito, Y. Kondo and T. Sakamoto, J. Am. Chem. Soc., 119, 11425 (1997).

81. K. Nützel, in Houben-Weyl: Methoden der Organischen Chemie (Ed. E. Müller), Vol. 13/2a, Thieme, Stuttgart, 1973, p. 554.

82. J. Boersma, in Comprehensive Organometallic Chemistry (Eds. G. Wilkinson, F. G. A. Stone and E. W. Abel), Vol. 2, Pergamon, Oxford, 1982, p. 823.

83. H. S. Gutowsky, J. Chem. Phys., 17, 128 (1949).

84. S. Venkateswaran, Indian J. Phys., 5, 145 (1930).

85. A. Haaland, J. C. Green, G. C. McGready, A. J. Downs, E. Gullo, M. J. Lyall, J. Timberlake, A. V. Tutukin, H. V. Volden and K.-A. Østby, Dalton Trans., 4356 (2003).

86. S. Moorehouse and G. Wilkinson, J. Chem. Soc., Dalton Trans., 2187 (1974).

87. M. Westerhausen, B. Rademacher and W. Poll, J. Organomet. Chem., 421, 175 (1991).

88. C. Eaborn, N. Retta and J. D. Smith, J. Organomet. Chem., 190, 101 (1980).

89. S. S. Al-Juaid, C. Eaborn, A. Hebtemariam, P. B. Hitchcock and J. D. Smith, J. Organomet. Chem., 437, 41 (1992).

90. F. I. Aigbirhio, S. S. Al-Juaid, C. Eaborn, A. Habtemariam, P. B. Hitchcock and J. D. Smith, J. Organomet. Chem., 405, 149 (1991).

91. M. Westerhausen and B. Rademacher, J. Organomet. Chem., 443, 25 (1993).

92. R. D. Ernst, J. W. Freeman, P. N. Swepston and D. R. Wilson, J. Organomet. Chem., 402, 17 (1991).

93. C. Eaborn, M. S. Hill, P. B. Hitchcock, J. D. Smith, S. Zhang and T. Ganicz, Organometallics, 18, 2342 (1999).

94. T. Bollwein, M. Westerhausen and A. Pfitzner, Z. Naturforsch., B: Chem. Sci., 58, 493 (2003).

95. W. Strohmeier, K. Hümpfner, K. Miltenberger and F. Seifert, Z. Elektrochem., 63, 537 (1959).

96. S. C. Cole, M. P. Coles and P. B. Hitchcock, Dalton Trans., 3663 (2003).

97. S. Brooker, N. Bertel, D. Stalke, M. Noltemeyer, H. W. Roesky, G. M. Sheldrick and F. T. Edelmann, Organometallics, 11, 192 (1992).

98. Y. Sun, W. E. Piers and M. Parvez, Can. J. Chem., 76, 513 (1998).

99. T. J. Kealy and P. L. Pauson, Nature, 168, 1039 (1951).

100. S. A. Miller, J. A. Tebboth and J. F. Tremaine, J. Chem. Soc., 632 (1952).

101. P. Laszlo and R. Hoffman, Angew. Chem., Int. Ed., 39, 123 (2000).

102. W. Bünder and E. Weiss, J. Organomet. Chem., 92, 1 (1975).

103. W. Bünder and E. Weiss, Z. Naturforsch., B: Chem. Sci., 33, 1235 (1978).

104. E. O. Fischer, H. P. Hoffmann and A. Treiber, Z. Naturforsch., B: Chem. Sci., 14, 599 (1969).

105. J. Lorberth, J. Organomet. Chem., 19, 189 (1969).

106. B. Fischer, G. P. M. van Mier, J. Boersma, G. van Koten, W. J. J. Smeets and A. L. Spek, Recl. Trav. Chim. Pays-Bas, 107, 259 (1988).

107. T. Aoyagi, H. M. M. Shearer, K. Wade and G. Whitehead, J. Organomet. Chem., 146, C29 (1978).

108. P. H. M. Budzelaar, J. Boersma, G. J. M. van der Kerk, A. L. Spek and A. J. M. Duisenberg, J. Organomet. Chem., 281, 123 (1985). 
109. A. Haaland, S. Samdal, N. V. Tverdova, G. V. Girichev, N. I. Giricheva, S. A. Shlykov, O. G. Garkusha and B. V. Lokshin, J. Organomet. Chem., 684, 351 (2003).

110. R. Blom, J. Boersma, P. H. M. Budzelaar, B. Fischer, A. Haaland, H. V. Volden and J. Weidlein, Acta Chem. Scand., Ser. A, 40, 113 (1986).

111. B. Fischer, P. Wijkens, J. Boersma, G. van Koten, W. J. J. Smeets, A. L. Spek and P. H. M. Budzelaar, J. Organomet. Chem., 376, 223 (1989).

112. R. Rernández, I. Resa, D. del Río, E. Carmona, E. Gutiérrez-Puebla and Á. Monge, Organometallics, 22, 381 (2003).

113. D. J. Burkey and T. P. Hanusa, J. Organomet. Chem., 512, 165 (1996).

114. I. Resa, E. Carmona, E. Gutiérrez-Puebla and A. Monge, Science, 305, 1136 (2004).

115. J. A. J. Jarvis, B. T. Kilbourn, R. Pearce and M. F. Lappert, J. Chem. Soc., Chem. Commun., 475 (1973).

116. J. M. Guss, R. Mason, I. Søtofte, G. van Koten and J. G. Noltes, J. Chem. Soc., Chem. Commun., 446 (1972).

117. A. Osman, R. G. Steevensz, D. G. Tuck, H. A. Meinema and J. G. Noltes, Can. J. Chem., 62, 1698 (1984).

118. J. Dekker, J. Boersma, L. Fernholt, A. Haaland and A. L. Spek, Organometallics, 6, 1202 (1987).

119. H. Schumann, S. Freitag, F. Girsdies, H. Hemling and G. Kociok-Köhn, Eur. J. Inorg. Chem., 245 (1998).

120. J. Boersma, L. Fernholt and A. Haaland, Acta Chem. Scand., Ser. A, 38, 523 (1984).

121. J. Dekker, J. W. Münninghoff, J. Boersma and A. L. Spek, Organometallics, 6, 1236 (1987).

122. N. Seidl, K. Jacob, P. Zanello and M. Fontani, J. Organomet. Chem., 620, 243 (2001).

123. S. Wingerter, H. Gornitzka, G. Bertrand and D. Stalke, Eur. J. Inorg. Chem., 173 (1999).

124. A. Steiner and D. Stalke, Angew. Chem., Int. Ed. Engl., 34, 1752 (1995).

125. M. J. Henderson, R. I. Papasergio, C. L. Raston, A. H. White and M. F. Lappert, J. Chem. Soc., Chem. Commun., 672 (1986).

126. A. B. Charette, A. Beauchemin and S. Francoeur, J. Am. Chem. Soc., 123, 8139 (2001).

127. H. Gornitzka, C. Hemmert, G. Bertrand, M. Pfeiffer and D. Stalke, Organometallics, 19, 112 (2000).

128. P. C. Andrews, C. L. Raston, B. W. Skelton and A. H. White, Organometallics, 17, 779 (1998).

129. K. H. Thiele, Z. Anorg. Allg. Chem., 322, 71 (1963).

130. J. G. Noltes and J. W. G. van den Hurk, J. Organomet. Chem., 1, 377 (1963).

131. K. H. Thiele, Z. Anorg. Allg. Chem., 319, 183 (1962).

132. K. H. Thiele, Z. Anorg. Allg. Chem., 325, 156 (1963).

133. H.-J. Gais and G. Bülow, Tetrahedron Lett., 33, 461 (1992).

134. H.-J. Gais, G. Bülow and G. Raabe, J. Am. Chem. Soc., 115, 7215 (1993).

135. B. Walfort, A. P. Leedham, C. A. Russell and D. Stalke, Inorg. Chem., 40, 5668 (2001).

136. J. G. Noltes and J. Boersma, J. Organomet. Chem., 16, 345 (1969).

137. S. R. Boss, R. Haigh, D. J. Linton, P. Schooler, G. P. Shields and A. E. H. Wheatley, Dalton Trans., 1001 (2003).

138. M. Weidenbruch, M. Herrndorf, A. Schäfer, S. Pohl and W. Saak, J. Organomet. Chem., 361, 139 (1989).

139. B. Fischer, J. Boersma, G. van Koten, W. J. J. Smeets and A. L. Spek, Organometallics, 8, 667 (1989).

140. M. Schreuder Goedheijt, T. Nijbacker, O. S. Akkerman, F. Bickelhaupt, N. Veldman and A. L. Spek, Angew. Chem., Int. Ed. Engl., 35, 1550 (1996).

141. P. R. Markies, G. Schat, O. S. Akkerman, F. Bickelhaupt and A. L. Spek, J. Organomet. Chem., 430, 1 (1992).

142. S. E. Denmark, J. P. Edwards and S. L. Wilson, J. Am. Chem. Soc., 114, 2592 (1992).

143. S. J. Dzugan and V. L. Goedken, J. Organomet. Chem., 356, 249 (1988).

144. P. R. Markies, G. Schat, O. S. Akkerman, F. Bickelhaupt, W. J. J. Smeets and A. L. Spek, Organometallics, 10, 3538 (1991).

145. P. R. Markies, T. Nomoto, O. S. Akkerman, F. Bickelhaupt, W. J. J. Smeets and A. L. Spek, J. Am. Chem. Soc., 110, 4845 (1988).

146. A. D. Pajerski, G. L. BergStresser, M. Parvez and H. G. Richey, Jr., J. Am. Chem. Soc., 110, 4844 (1988). 
147. R. M. Fabicon, M. Parvez and H. G. Richey, Jr., Organometallics, 18, 5163 (1999).

148. J. E. Chubb and H. G. Richey, Jr., Organometallics, 17, 3204 (1998).

149. E. Hecht, Z. Anorg. Allg. Chem., 627, 2351 (2001).

150. M. B. Hursthouse, M. Motevalli, P. O'Brien, J. R. Walsh and A. C. Jones, Organometallics, 10, 3196 (1991).

151. J. Behm, S. Lotz and W. A. Herrmann, Z. Anorg. Allg. Chem., 619, 849 (1993).

152. X. Huang, H. Sun, X. Wang, Y. J. Liu, X. You and X. Sun, Main Group Met. Chem., 19, 161 (1996).

153. E. Wissing, R. W. A. Havenith, J. Boersma and G. van Koten, Tetrahedron Lett., 33, 7933 (1992).

154. E. Wissing, R. W. A. Havenith, J. Boersma, W. J. J. Smeets, A. L. Spek and G. van Koten, J. Org. Chem., 58, 4228 (1993).

155. P. O’Brien, M. B. Hursthouse, M. Motevalli, J. R. Walsh and A. C. Jones, J. Organomet. Chem., 449, 1 (1993).

156. M. Westerhausen, M. Wieneke, B. Rademacher and W. Schwarz, Chem. Ber./Recueil, 130, 1499 (1997).

157. M. Westerhausen, M. Wieneke and W. Schwarz, J. Organomet. Chem., 522, 137 (1996).

158. M. Motevalli, P. O'Brien, A. J. Robinson, J. R. Walsh and P. B. Wyatt, J. Organomet. Chem., 461, 5 (1993).

159. C. M. Coward, A. C. Jones, A. Steiner, J. F. Bickley, L. M. Smith and M. E. Pemble, J. Chem. Soc., Dalton Trans., 3480 (2000).

160. H. Mimoun, J. Y. de Saint Laumer, L. Giannini, R. Scopelliti and C. Floriani, J. Am. Chem. Soc., 121, 6158 (1999).

161. E. Wissing, M. Kaupp, J. Boersma, A. L. Spek and G. van Koten, Organometallics, 13, 2349 (1994).

162. M. Westerhausen, B. Rademacher and W. Schwarz, J. Organomet. Chem., 427, 275 (1992).

163. A. B. Charette, J.-F. Marcoux, C. Molinaro, A. Beauchemin, C. Brochu and É. Isabel, J. Am. Chem. Soc., 122, 4508 (2000).

164. M. Kaupp, H. Stoll, H. Preuss, W. Kaim, T. Stahl, G. van Koten, E. Wissing, W. J. J. Smeets and A. L. Spek, J. Am. Chem. Soc., 113, 5606 (1991).

165. H. E. Simmons, T. L. Cairns, S. A. Vladuchick and C. M. Hoiness, Org. React., 20, 1 (1973).

166. E. Wissing, E. Rijnberg, P. A. van der Schaaf, K. van Gorp, J. Boersma and G. van Koten, Organometallics, 13, 2609 (1994).

167. J. M. Klerks, J. T. B. H. Jastrzebski, G. van Koten and K. Vrieze, J. Organomet. Chem., 224, 107 (1982).

168. G. van Koten, J. T. B. H. Jastrzebski and K. Vrieze, J. Organomet. Chem., 250, 49 (1983).

169. E. Wissing, S. van der Linden, E. Rijnberg, J. Boersma, W. J. J. Smeets, A. L. Spek and G. van Koten, Organometallics, 13, 2602 (1994).

170. J. Boersma, A. Mackor and J. G. Noltes, J. Organomet. Chem., 99, 337 (1975).

171. A. L. Spek, J. T. B. H. Jastrzebski and G. van Koten, Acta Crystallogr., C43, 2006 (1987).

172. S. N. Reformatsky, Ber. Dtsch. Chem. Ges., 20, 1210 (1887).

173. M. Gaudemar, Organomet. Rev. A., 8, 183 (1972).

174. H. E. Simmons and R. D. Smith, J. Am. Chem. Soc., 81, 4256 (1959).

175. P. Knochel and R. D. Singer, Chem. Rev., 93, 2117 (1993).

176. G. E. Coates and D. Ridley, J. Chem. Soc., 1870 (1965).

177. J. M. Bruce, B. C. Cutsforth, D. W. Farren, F. G. Hutchinson, F. M. Rabagliati and D. R. Reed, J. Chem. Soc. (B), 1020 (1966).

178. M. H. Abraham and J. A. Hill, J. Organomet. Chem., 7, 23 (1967).

179. J. G. Noltes, Recl. Trav. Chim. Pays-Bas, 84, 126 (1965).

180. J. Boersma and J. G. Noltes, Tetrahedron Lett., 1521 (1966).

181. P. O'Brien, in Comprehensive Organometallic Chemistry II (Eds. E. W. Abel, F. G. A. Stone and G. Wilkinson), Vol. 3, Pergamon, Oxford, 1995, p. 175.

182. D. A. Walker, T. J. Woodman, D. L. Hughes and M. Bochmann, Organometallics, 20, 3772 (2001).

183. M. Haufe, R. D. Köhn, R. Weimann, G. Seifert and D. Zeigan, J. Organomet. Chem., 520, 121 (1996).

184. M. Haufe, R. D. Köhn, G. Kociok-Köhn and A. C. Filippou, Inorg. Chem. Commun., 1, 263 (1998). 
185. H. Tang, M. Parvez and H. G. Richey Jr., Organometallics, 19, 4810 (2000).

186. M. D. Hannant, M. Schormann and M. Bochmann, J. Chem. Soc., Dalton Trans., 4071 (2002).

187. A. Job and R. Reich, Bull. Soc. Chim. Fr., 33, 1414 (1923).

188. M. H. Abraham and P. H. Rolfe, J. Organomet. Chem., 7, 35 (1967).

189. J. Boersma and J. G. Noltes, Tetrahedron Lett., 1521 (1966).

190. J. Boersma and J. G. Noltes, J. Organomet. Chem., 8, 551 (1967).

191. P. T. Moseley and H. M. M. Shearer, J. Chem. Soc., Dalton Trans., 65 (1973).

192. B. Rademacher, W. Schwarz and M. Westerhausen, Z. Anorg. Allg. Chem., 621, 1395 (1995).

193. H. Yasuda, Y. Ohnuma, A. Nakamura, Y. Kai, N. Yasuoka and N. Kasai, Bull. Chem. Soc. Jpn., 53, 1101 (1980).

194. R. W. Lang, Helv. Chim. Acta, 69, 881 (1986).

195. D. Belluš, B. Klingert, R. W. Lang and G. Rihs, J. Organomet. Chem., 339, 17 (1988).

196. T. N. Majid, M. Chang, P. Yeh and P. Knochel, Tetrahedron Lett., 30, 5069 (1989).

197. G.-J. Gruter, O. S. Akkerman, F. Bickelhaupt, W. J. J. Smeets and A. L. Spek, Recl. Trav. Chim. Pays-Bas, 112, 425 (1993).

198. A. B. Charette, J.-F. Marcoux and F. Bélanger-Gariépy, J. Am. Chem. Soc., 118, 6792 (1996).

199. R. Becker, J. Weiss, M. Winter, K. Merz and R. Fischer, J. Organomet. Chem., 630, 253 (2001).

200. S. S. Al-Juaid, C. Eaborn, A. Habtemariam, P. B. Hitchcock, J. D. Smith, K. Tavakkoli and A. D. Webb, J. Organomet. Chem., 462, 45 (1993).

201. C. Eaborn, M. S. Hill, P. B. Hitchcock and J. D. Smith, J. Chem. Soc., Dalton Trans., 2467 (2002).

202. D. Azarifar, M. P. Coles, S. M. El-Hamruni, C. Eaborn, P. B. Hitchcock and J. D. Smith, J. Organomet. Chem., 689, 1718 (2004).

203. D. J. Darensbourg, J. R. Wildeson and J. C. Yarbrough, Organometallics, 20, 4413 (2001).

204. W. R. Vaughan, S. C. Bernstein and M. E. Lorber, J. Org. Chem., 30, 1790 (1965).

205. W. R. Vaughan and H. P. Knoes, J. Org. Chem., 35, 2394 (1970).

206. J. Dekker, P. H. M. Budzelaar, J. Boersma, G. J. M. van der Kerk and A. L. Spek, Organometallics, 3, 1403 (1984).

207. M. Westerhausen, M. Wieneke, H. Nöth, T. Seifert, A. Pfitzner, W. Schwarz, O. Schwarz and J. Weidlein, Eur. J. Inorg. Chem., 1175 (1998).

208. C. Hilf, F. Bosold, K. Harms, J. C. W. Lorenz, M. Marsch, M. Schmeczek and G. Boche, Chem. Ber., 130, 1201 (1997).

209. G. Boche, F. Bosold, H. Hermann, M. Marsch, K. Harms and J. C. W. Lorenz, Chem. Eur. J., 4, 814 (1998).

210. P. Yu, P. Müller, H. W. Roesky, M. Noltemeyer, A. Demsar and I. Usón, Angew. Chem., Int. Ed. Engl., 38, 3319 (1999).

211. M. P. Coles and P. B. Hitchcock, Eur. J. Inorg. Chem., 2662 (2004).

212. E. J. Corey, P.-W. Yuen, F. J. Hannon and D. A. Wierda, J. Org. Chem., 55, 784 (1990).

213. B. S. Hammes and C. J. Carano, Inorg. Chem., 38, 4593 (1999).

214. C. K. Williams, L. E. Breyfogle, S. K. Choi, W. Nam, V. G. Young Jr., M. A. Hillmyer and W. B. Tolman, J. Am. Chem. Soc., 125, 11350 (2003).

215. B. S. Hammes, M. T. Kieber-Emmons, J. A. Letizia, Z. Shirin, C. J. Carrano, L. N. Zakharov and A. L. Rheingold, Inorg. Chim. Acta, 346, 227 (2003).

216. I. Hegelmann, A. Beck, C. Eichhorn, B. Weibert and N. Burzlaff, Eur. J. Inorg. Chem., 339 (2003).

217. S. S. Al-Juaid, N. H. Buttrus, C. Eaborn, P. B. Hitchcock, A. T. L. Roberts, J. D. Smith and A. C. Sullivan, J. Chem. Soc., Chem. Commun., 908 (1986).

218. M. Parvez, G. L. Bergstresser and H. G. Richey Jr., Acta Crystallogr., C48, 641 (1992).

219. R. Anulewicz-Ostrowska, S. Lulinski, E. Pindelska and J. Serwatowski, Inorg. Chem., 41, 2525 (2002).

220. M. M. Olmstead, P. P. Power and S. C. Shoner, J. Am. Chem. Soc., 113, 3379 (1991).

221. K. Merz, H.-M. Hu, S. Rell and M. Driess, Eur. J. Inorg. Chem., 51 (2003).

222. M. Driess, K. Merz and S. Rell, Eur. J. Inorg. Chem., 2517 (2000).

223. G. Anantharaman, V. Chandrasekhar, U. N. Nehete, H. W. Roesky, D. Vidovic and J. Magull, Organometallics, 23, 2251 (2004).

224. K. Soai and S. Niwa, Chem. Rev., 92, 833 (1992).

225. M. Kitamura, S. Suga, K. Kawai and R. Noyori, J. Am. Chem. Soc., 108, 6071 (1986). 
226. M. Kitamura, S. Okada, S. Suga and R. Noyori, J. Am. Chem. Soc., 111, 4028 (1989).

227. M. Kitamura, S. Suga, M. Niwa and R. Noyori, J. Am. Chem. Soc., 117, 4832 (1995).

228. B. Goldfuss, S. I. Khan and K. N. Houk, Organometallics, 18, 2927 (1999).

229. B. Goldfuss, M. Steigelmann and F. Rominger, Eur. J. Org. Chem., 1785 (2000).

230. M. Steigelmann, Y. Nisar, F. Rominger and B. Goldfuss, Chem. Eur. J., 8, 5211 (2002).

231. K. Nakano, K. Nozaki and T. Hiyama, J. Am. Chem. Soc., 125, 5501 (2003).

232. E. Hecht, Z. Anorg. Allg. Chem., 626, 2223 (2000).

233. C. Bolm, G. Schlingloff and K. Harms, Chem. Ber., 125, 1191 (1992).

234. H. M. M. Shearer and C. B. Spencer, J. Chem. Soc., Chem. Commun., 194 (1966).

235. H. M. M. Shearer and C. B. Spencer, Acta Crystallogr., B36, 2046 (1980).

236. W. A. Herrmann, S. Bogdanović, J. Behm and M. Denk, J. Organomet. Chem., 430, C33 (1992).

237. A. D. Bond, D. J. Linton and A. E. H. Wheatley, Acta Crystallogr., E57, m298 (2001).

238. A. B. Charette, C. Molinaro and C. Brochu, J. Am. Chem. Soc., 123, 12160 (2001).

239. S. Luliński, I. Madura, J. Serwatowski and J. Zachara, Inorg. Chem., 38, 4937 (1999).

240. M. L. Ziegler and J. Weiss, Angew. Chem., 82, 931 (1970).

241. J. Lewiński, W. Marciniak, J. Lipkowski and I. Justyniak, J. Am. Chem. Soc., 125, 12698 (2003).

242. M. Ishimori, T. Hagiwara, T. Tsuruta, Y. Kai, N. Yasuoka and N. Kasai, Bull. Chem. Soc. Jpn., 49, 1165 (1976).

243. A. Charette, A. Beauchemin, S. Francoeur, F. Bélanger-Gariépy and G. D. Enright, Chem. Commun., 466 (2002).

244. R. P. Davies, D. J. Linton, P. Schooler, R. Snaith and A. E. H. Wheatley, Chem. Eur. J., 7, 3696 (2001).

245. K. Merz, S. Block, R. Schoenen and M. Driess, Dalton Trans., 3365 (2003).

246. A. D. Bond, D. J. Linton, P. Schooler and A. E. H. Wheatley, J. Chem. Soc., Dalton Trans., 3173 (2001).

247. P. A. van der Schaaf, E. Wissing, J. Boersma, W. J. J. Smeets, A. L. Spek and G. van Koten, Organometallics, 12, 3624 (1993).

248. J. Lewiński, W. Marciniak, Z. Ochal, J. Lipkowski and I. Justyniak, Eur. J. Inorg. Chem., 2753 (2003).

249. M. B. Dinger and M. J. Scott, Inorg. Chem., 40, 1029 (2001).

250. M. G. Gardiner, S. M. Lawrence, C. L. Raston, B. W. Skelton and A. H. White, Chem. Commun., 2491 (1996).

251. E. Bukhaltsev, I. Goldberg and A. Vigalok, Organometallics, 23, 4540 (2004).

252. J. Dekker, A. Schouten, P. H. M. Budzelaar, J. Boersma, A. L. Spek and A. J. M. Duisenberg, J. Organomet. Chem., 320, 1 (1987).

253. M. R. P. van Vliet, G. van Koten, P. Buysingh, J. T. B. H. Jastrzebski and A. L. Spek, Organometallics, 6, 537 (1987).

254. J. T. B. H. Jastrzebski, J. Boersma, G. van Koten, W. J. J. Smeets and A. L. Spek, Recl. Trav. Chim. Pays-Bas, 107, 263 (1988).

255. C. Bolm, J. Müller, M. Zehnder and M. Neuburger, Chem. Eur. J., 1, 312 (1995).

256. J. T. B. H. Jastrzebski and G. van Koten, Bioorg. Med. Chem. Lett., 3, 2351 (1993).

257. F. H. van der Steen, J. Boersma, A. L. Spek and G. van Koten, Organometallics, 10, 2467 (1991).

258. D. Walther, T. Döhler, N. Theyssen and H. Görls, Eur. J. Inorg. Chem., 2049 (2001).

259. J. Boersma, F. Verbeek and J. G. Noltes, J. Organomet. Chem., 33, C53 (1971).

260. A. L. Spek, Cryst. Struct. Commun., 2, 535 (1973).

261. J. Boersma, A. L. Spek and J. G. Noltes, J. Organomet. Chem., 81, 7 (1974).

262. I. Abrahams, M. A. Malik, M. Motevalli and P. O’Brien, J. Chem. Soc., Dalton Trans., 1043 (1995)

263. Y. Yang, J. Pinkas, M. Noltemeyer, H.-G. Schmidt and H. W. Roesky, Angew. Chem., Int. Ed., 38, 664 (1999).

264. G. Anantharaman, V. Chandrasekhar, M. G. Walawalkar, H. W. Roesky, D. Vidovic, J. Magull and M. Noltemeyer, Dalton Trans., 1271 (2004).

265. L.-C. Liang, W.-Y. Lee and C.-H. Hung, Inorg. Chem., 42, 5471 (2003).

266. J. Prust, A. Stasch, W. Zheng, H. W. Roesky, E. Alexopoulos, I. Usón, D. Böhler and T. Schuchardt, Organometallics, 20, 3825 (2001). 
267. M. Cheng, D. R. Moore, J. J. Reczek, B. M. Chamberlain, E. B. Lobkovsky and G. W. Coates, J. Am. Chem. Soc., 123, 8738 (2001).

268. J. Prust, H. Hohmeister, A. Stasch, H. W. Roesky, J. Magull, E. Alexopoulos, I. Usón, H.G. Schmidt and M. Noltemeyer, Eur. J. Inorg. Chem., 2156 (2002).

269. A. P. Dove, V. C. Gibson, E. L. Marshall, A. J. P. White and D. J. Williams, Dalton Trans., 570 (2004).

270. S. D. Allen, D. R. Moore, E. B. Lobkovsky and G. W. Coates, J. Organomet. Chem., 683, 137 (2003).

271. S. Aboulkacem, W. Tyrra and I. Pantenburg, Z. Anorg. Allg. Chem., 629, 1569 (2003).

272. M. S. Hill and P. B. Hitchcock, J. Chem. Soc., Dalton Trans., 4694 (2002).

273. A. Kasani, R. McDonald and R. G. Cavell, Organometallics, 18, 3775 (1999).

274. A. Looney, R. Han, I. B. Gorrell, M. Cornebise, K. Yoon, G. Parkin and A. L. Rheingold, Organometallics, 14, 274 (1995).

275. R. Alsfasser, A. K. Powell, S. Trofimenko and H. Vahrenkamp, Chem. Ber., 126, 685 (1993).

276. J. L. Kisko, T. Fillebeen, T. Hascall and G. Parkin, J. Organomet. Chem., 596, 22 (2000).

277. M. H. Chisholm, N. W. Eilerts, J. C. Huffman, S. S. Iyer, M. Pacold and K. Phomphrai, J. Am. Chem. Soc., 122, 11845 (2000).

278. H. V. R. Dias and W. Jin, Inorg. Chem., 42, 5034 (2003).

279. C. M. Dowling and G. Parkin, Polyhedron, 20, 285 (2001).

280. C. M. Dowling and G. Parkin, Polyhedron, 15, 2463 (1996).

281. C. Kimblin, B. M. Bridgewater, T. Hascall and G. Parkin, J. Chem. Soc., Dalton Trans., 1267 (2000).

282. G. R. Lief, D. F. Moser, L. Stahl and R. J. Staples, J. Organomet. Chem., 689, 1110 (2004).

283. N. A. Bell, H. M. M. Shearer and C. B. Spencer, Acta Crystallogr., C39, 1182 (1983).

284. M. Westerhausen, T. Bollwein, A. Pfitzner, T. Nilges and H.-J. Deiseroth, Inorg. Chim. Acta, 312, 239 (2001).

285. M. M. Olmstead, W. J. Grigsby, D. R. Chacon, T. Hascall and P. P. Power, Inorg. Chim. Acta, 251, 273 (1996).

286. M. A. Malik, P. O'Brien, M. Motevalli and A. C. Jones, Inorg. Chem., 36, 5076 (1997).

287. V. Bette, A. Mortreux, C. W. Lehmann and J.-F. Carpentier, Chem. Commun., 332 (2003).

288. D. Chakraborty and E. Y.-X. Chen, Organometallics, 22, 769 (2003).

289. M. Westerhausen, T. Bollwein, N. Makropoulos, T. M. Rotter, T. Habereder, M. Suter and H. Nöth, Eur. J. Inorg. Chem., 851 (2001).

290. M. Westerhausen, T. Bollwein, N. Makropoulos, S. Schneiderbauer, M. Suter, H. Nöth, P. Mayer, H. Poitrowski, K. Polborn and A. Pfitzner, Eur. J. Inorg. Chem., 389 (2002).

291. M. Westerhausen, T. Bollwein, P. Mayer and H. Poitrowski, Z. Anorg. Allg. Chem., 628, 1425 (2002).

292. L. M. Engelhardt, G. E. Jacobsen, W. C. Patalinghug, B. W. Skelton, C. L. Raston and A. H. White, J. Chem. Soc., Dalton Trans., 2859 (1991).

293. M. R. P. van Vliet, G. van Koten, J. F. Modder, J. A. M. van Beek, W. J. Klaver, K. Goubitz and C. H. Stam, J. Organomet. Chem., 319, 285 (1987).

294. P. H. M. Budzelaar, J. Boersma, G. J. M. van der Kerk and A. L. Spek, Organometallics, 3, 1187 (1984).

295. M. G. Davidson, D. Elilio, S. L. Less, A. Martín, P. R. Raithby, R. D. Snaith and D. S. Wright, Organometallics, 12, 1 (1993).

296. M. Krieger, R. O. Gould, K. Harms, S. Parsons and K. Dehnicke, Chem. Ber., 129, 1621 (1996).

297. M. Krieger, R. O. Gould, B. Neumüller, K. Harms and K. Dehnicke, Z. Anorg. Allg. Chem., 624, 1434 (1998).

298. F. A. J. J. van Santvoort, H. Krabbendam, A. L. Spek and J. Boersma, Inorg. Chem., 17, 388 (1978).

299. S. Chang, R. D. Sommer, A. L. Rheingold and D. P. Goldberg, Chem. Commun., 2396 (2001).

300. M. A. Malik, M. Motevalli, J. R. Walsh, P. O'Brien and A. C. Jones, J. Mater. Chem., 5, 731 (1995).

301. E. Rijnberg, N. J. Hovestad, A. W. Kleij, J. T. B. H. Jastrzebski, J. Boersma, M. D. Janssen, A. L. Spek and G. van Koten, Organometallics, 16, 2847 (1997).

302. D. M. Knotter, M. D. Janssen, D. M. Grove, W. J. J. Smeets, E. Horn, A. L. Spek and G. van Koten, Inorg. Chem., 30, 4361 (1991). 
303. M. B. Hursthouse, M. A. Malik, M. Motevalli and P. O'Brien, Organometallics, 10, 730 (1991).

304. M. A. Malik, P. O'Brien and M. Motevalli, Acta Crystallogr., C52, 1931 (1996).

305. J. B. Hursthouse, M. A. Malik, M. Motevalli and P. O'Brien, J. Mater. Chem., 2, 949 (1992).

306. M. A. Malik, M. Motevalli, J. R. Walsh and P. O'Brien, Organometallics, 11, 3136 (1992).

307. G. W. Adamson, N. A. Bell and H. M. M. Shearer, Acta Crystallogr., B38, 462 (1982).

308. G. W. Adamson and H. M. M. Shearer, J. Chem. Soc., (D), 897 (1969).

309. D. Zeng, M. J. Hampden-Smith and E. N. Duesler, Inorg. Chem., 33, 5376 (1994).

310. K. Ruhlandt-Senge and P. P. Power, Inorg. Chem., 32, 4505 (1993).

311. M. Westerhausen, M. Wieneke, K. Doderer and W. Schwarz, Z. Naturforsch., 51b, 1439 (1966).

312. M. Westerhausen, M. Wieneke and W. Schwarz, J. Organomet. Chem., 572, 249 (1999).

313. B. Rademacher, W. Schwarz and M. Westerhausen, Z. Anorg. Allg. Chem., 621, 287 (1995).

314. B. Rademacher, W. Schwarz and M. Westerhausen, Z. Anorg. Allg. Chem., 621, 1439 (1995).

315. T. J. Groshens, K. T. Higa and R. J. Butcher, J. Organomet. Chem., 463, 97 (1993).

316. A. J. Edwards, M. A. Paver, P. R. Raithby, C. A. Russell and D. S. Wright, Organometallics, 12, 4687 (1993).

317. M. G. Davidson, A. J. Edwards, M. A. Paver, P. R. Raithby, C. A. Russell, A. Steiner, K. L. Verhorevoort and D. S. Wright, J. Chem. Soc., Chem. Commun., 1989 (1995).

318. A. Bashall, J. M. Cole, F. García, A. Primo, A. Rothenberger, M. McPartlin and D. S. Wright, Inorg. Chim. Acta., 354, 41 (2003).

319. W. Hieber and U. Teller, Z. Anorg. Allg. Chem., 249, 43 (1942).

320. P. H. M. Budzelaar, J. Boersma, G. J. M. van der Kerk and A. J. M. Duisenberg, Inorg. Chem., 21, 3777 (1982).

321. P. H. M. Budzelaar, K. H. den Haan, J. Boersma, G. J. M. van der Kerk and A. L. Spek, Organometallics, 3, 156 (1984).

322. R. D. Wilson, T. F. Koetzle, D. W. Hart, A. Kvick, T. L. Tripton and R. Bau, J. Am. Chem. Soc., 99, 1775 (1977).

323. P. H. M. Budzelaar, A. A. H. van der Zeijden, J. Boersma, G. J. M. van der Kerk, A. L. Spek and A. J. M. Duisenberg, Organometallics, 3, 159 (1984).

324. P. H. M. Budzelaar, H. J. Alberts-Jansen, K. Mollema, J. Boersma, G. J. M. van der Kerk, A. L. Spek and A. J. M. Duisenberg, J. Organomet. Chem., 243, 137 (1983).

325. P. H. M. Budzelaar, J. Boersma, G. J. M. van der Kerk, A. L. Spek and A. J. M. Duisenberg, J. Organomet. Chem., 287, C13 (1985).

326. P. H. M. Budzelaar, J. Boersma, G. J. M. van der Kerk, A. L. Spek and A. J. M. Duisenberg, Organometallics, 4, 680 (1985).

327. B. Fischer, J. Boersma, G. van Koten and A. L. Spek, New J. Chem., 12, 613 (1988).

328. B. Fischer, H. Kleijn, J. Boersma, G. van Koten and A. L. Spek, Organometallics, 8, 920 (1989).

329. M. Ohashi, K. Matsubara, T. Iizuka and H. Suzuki, Angew. Chem., Int. Ed., 42, 937 (2003).

330. M. D. Fryzuk, D. H. McConville and S. J. Rettig, Organometallics, 9, 1359 (1990).

331. M. D. Fryzuk, D. H. McConville and S. J. Rettig, Organometallics, 12, 2152 (1993).

332. M. H. P. Rietveld, P. Lohner, M. G. Nijkamp, D. M. Grove, N. Veldman, A. L. Spek, M. Pfeffer and G. van Koten, Chem. Eur. J., 3, 817 (1997).

333. H. C. L. Abbenhuis, N. Feiken, H. F. Haarman, D. M. Grove, E. Horn, A. L. Spek, M. Pfeffer and G. van Koten, Organometallics, 12, 2227 (1993). 
